\title{
Habitat Use by Northern Dusky Salamanders in Riparian Corridors of Southwestern Pennsylvania
}

\author{
Robert Joseph Michalow
}

West Virginia University

Follow this and additional works at: https://researchrepository.wvu.edu/etd

\section{Recommended Citation}

Michalow, Robert Joseph, "Habitat Use by Northern Dusky Salamanders in Riparian Corridors of Southwestern Pennsylvania" (2012). Graduate Theses, Dissertations, and Problem Reports. 4895. https://researchrepository.wvu.edu/etd/4895

This Dissertation is protected by copyright and/or related rights. It has been brought to you by the The Research Repository @ WVU with permission from the rights-holder(s). You are free to use this Dissertation in any way that is permitted by the copyright and related rights legislation that applies to your use. For other uses you must obtain permission from the rights-holder(s) directly, unless additional rights are indicated by a Creative Commons license in the record and/ or on the work itself. This Dissertation has been accepted for inclusion in WVU Graduate Theses, Dissertations, and Problem Reports collection by an authorized administrator of The Research Repository @ WVU. For more information, please contact researchrepository@mail.wvu.edu. 


\title{
Habitat Use by Northern Dusky Salamanders in Riparian Corridors of Southwestern Pennsylvania
}

\author{
Robert Joseph Michalow \\ Dissertation submitted to the \\ Davis College of Agriculture, Natural Resources and Design \\ at West Virginia University \\ in partial fulfillment of the requirements for the degree of \\ Doctorate of Philosophy \\ in \\ Forest Resource Science \\ James T. Anderson Ph.D., Committee Chair \\ Kyle J. Hartman, Ph.D., Committee Member \\ J. Todd Petty, Ph. D., Committee Member \\ Petra Bohall Wood, Ph.D., Committee Member \\ Anthony A. Billings, M.S., Committee Member \\ Division of Forestry and Natural Resources \\ Morgantown, West Virginia
}

Keywords: Northern dusky salamander, Desmognathus fuscus fuscus, habitat fragmentation, Pennsylvania, salamanders, visible implant elastomer, visual encounter survey, metapopulation, a priori models 


\begin{abstract}
Habitat Use by Northern Dusky Salamanders in Riparian Corridors of Southwestern

Pennsylvania
\end{abstract}

Robert Joseph Michalow

Amphibian populations have decreased in many parts of the world and the rate of decline has increased over the past 25 years. Much of the population decline can be attributed to habitat fragmentation, thus, possibly forming metapopulations. The semi-aquatic northern dusky salamander belongs to the family Plethodontidae and the genus Desmognathus. Amphibians, such as salamanders, may occupy undisturbed forest floors with biomass equal to, or exceeding, the biomass of other vertebrate groups and they can achieve their highest densities in ancient or undisturbed forests. Salamander densities can be estimated using cover items and this method has become a more common practice because of its relatively nondisruptive impact on the ecosystem, the ability to attract species that are difficult to trap in pitfalls, minimized observer biases and errors and reliability of developing a model estimating population size. The goals of this study were to 1) evaluate short-term changes in seasonal relative abundance of northern dusky salamanders; 2) determine if there was an increase in their relative abundance where cover boards were placed; 3 ) determine which habitat parameters influence relative salamander density; and 4) create a relative abundance model.

Four study areas each with 4 stream reaches were searched by using a 3-4 pass visual encounter survey and wooden cover boards ( $n=50$ boards/stream reach) during 2008 and 2009. A total of 2,287 salamanders from 7 species were captured and the northern dusky salamander comprised $87 \%$ of the total. Eighty-four percent of all the salamanders were captured under rocks while 9\% were captured under cover boards. Salamanders were marked with a color coded visual implant elastomer and no northern dusky that was captured in one stream was then recaptured in a different stream indicating their strong site fidelity and limited dispersal ability. Of the 6 a priori models evaluated to estimate salamander density, the model using tree canopy cover, protective cover, and stream size proved to be the best fit (lowest corrected Akaike's Information Criterion). The best fit model was then slightly modified (post-hoc) to incorporate stream size differences and a constant was added. The post-hoc model was verified at an independent study area and able to estimate (with a percent error of $\leq 75 \%$ of the estimated number of salamanders $/ \mathrm{m}$ ) the salamander density $75 \%$ of the time. Additional habitat parameters (i.e., tree stand age, water quality, substrate embeddedness, and stream flow) may need to be measured to increase the accuracy of the post-hoc model.

The 3 critical habitat parameters, ranked in order, were tree canopy cover, protective cover, and stream size with the first 2 being directly related to salamander density and the latter suggesting that a stream may be too small or too large to support salamanders. Furthermore, we determined that streams with deficiencies in 1 of these 3 factors had 
relatively lower salamander densities and streams that were deficient in 2 or 3 of these factors had the lowest density estimates. Captured juvenile (snout to vent length $[\mathrm{SVL}]=18.17 \mathrm{~mm}$, mass $=6.99 \mathrm{~g})$ and adult $(\mathrm{SVL}=50.68 \mathrm{~mm}$, mass $=14.15 \mathrm{~g})$ northern dusky salamanders in this study were similar in size (length and mass) to northern dusky salamanders captured in other studies. Likewise, our salamander densities were similar $(\overline{\mathrm{X}}=0.15, \mathrm{SE}=0.02$ salamanders/m) to other studies.

Our study supported the idea that salamanders are indicator species sensitive to riparian habitat conditions and that a single poor riparian zone characteristic may significantly impact the salamander population. As the amount of logging and natural gas drilling continues to increase in Pennsylvania and northeastern United States, wildlife managers could use this information to help manage riparian habitat, especially if the habitat is scheduled to be impacted by some type of anthropogenic disturbance (i.e., road). Furthermore, this study provides wildlife managers with a model that can estimate salamander densities pre- and post-disturbance. With this model, wildlife managers can use it to evaluate the quality of the stream with respect to the northern dusky salamander.

Keywords: Northern dusky salamander, Desmognathus fuscus fuscus, habitat fragmentation, Pennsylvania, salamanders, visible implant elastomer, visual encounter survey, metapopulation 


\section{ACKNOWLEDGMENTS}

I thank the Department of Conservation of Natural Resources (DCNR) for allowing me to conduct this research in 2 of their state parks, Raccoon Creek and Linn Run. I also thank Washington County Parks and Recreation for allowing me to conduct this research at their Mingo Creek County Park and I thank the Pennsylvania Game Commission for allowing me to conduct this research on State Game Land 203. I thank the Saint Vincent College Administration who waited patiently for me to finish this degree, for course release time to work on this project and for several financial contributions to this project. I also thank Dr. James Anderson for all his help over the years as my committee chair member, without his guidance I would never have finished it. I thank my Departmental committee members Dr. Kyle J. Hartman, Dr. J. Todd Petty and Dr. Petra Bohall Wood for their comments, guidance and mentoring over the years. I thank Mr. Anthony A. Billings for all his help with the statistical portion of this study. We spent many hours composing programs in SAS to analyze and interpret the data. I thank all those who helped set up the cover boards and all those who helped collect habitat and salamander data over the past several years. I thank my wife, Megan, for her patience and encouragement to help push me along in this doctoral process. Finally, I thank my kids (Kaitlyn and Robbie) who spent many hours patiently exploring the streams as I collected data. 


\section{TABLE OF CONTENTS}

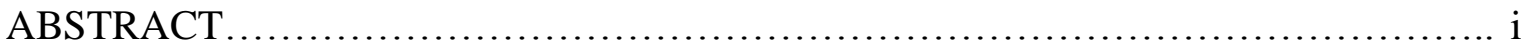

ACKNOWLEDGMENTS .......................................................

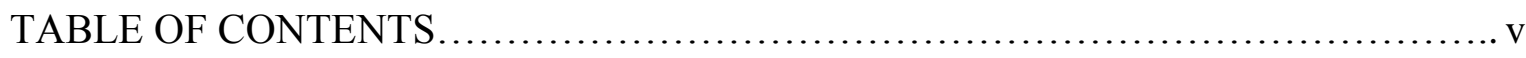

TABLE OF FIGURES AND TABLES .......................................... vii

TABLE OF APPENDICES ..................................................

CHAPTER 1: LITERATURE REVIEW OF HABITAT USE BY NORTHERN DUSKY

SALAMANDERS IN RIPARIAN CORRIDORS OF SOUTHWESTERN

PENNSYLVANIA .................................................................... 1

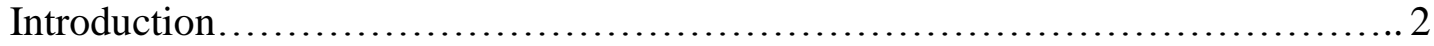

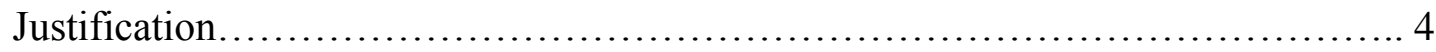

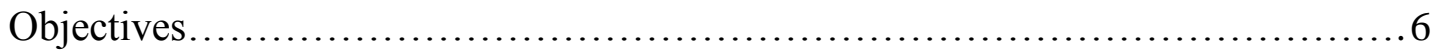

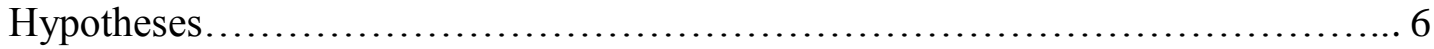

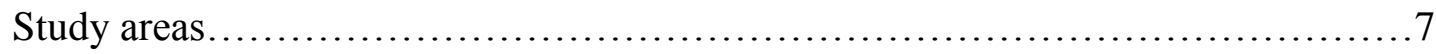

Habitat fragmentation and degradation....................................... 11

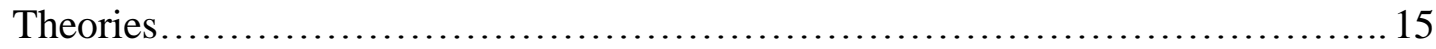

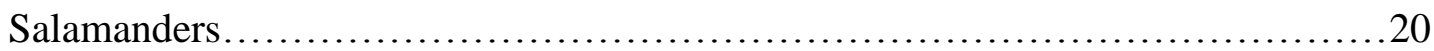

Northern dusky salamanders (Desmognathus fuscus fuscus) ...................... 23

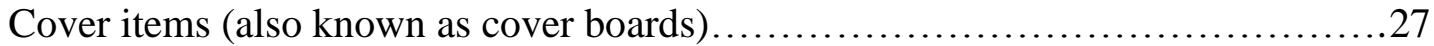

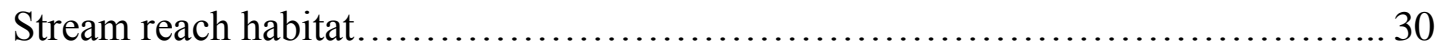

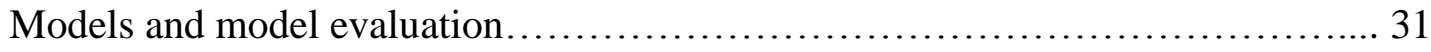

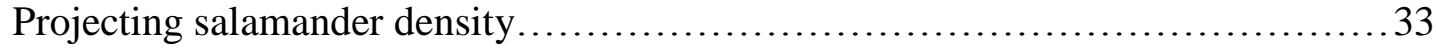

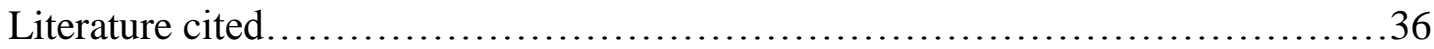

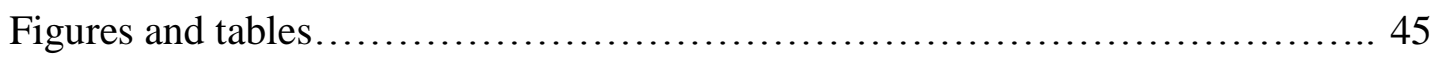

CHAPTER 2: HABITAT USE BY NORTHERN DUSKY SALAMANDERS IN RIPARIAN CORRIDORS OF SOUTHWESTERN

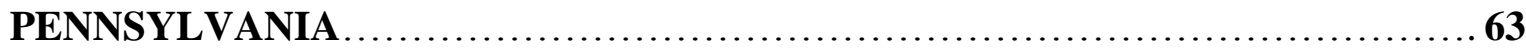

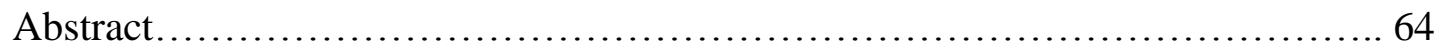

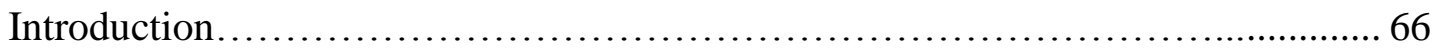

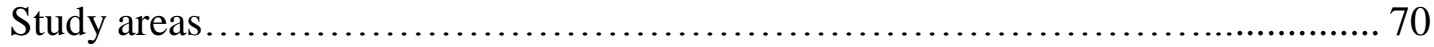

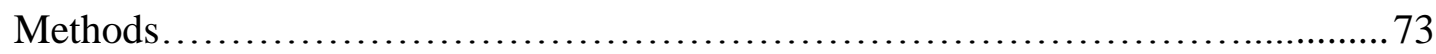

Preliminary site determination...................................... 73 
Cover board placement............................................... 74

Visual encounter survey and visual implant elastomer.....................75

Salamander data...................................................... 76

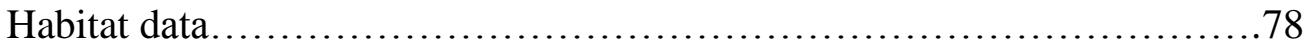

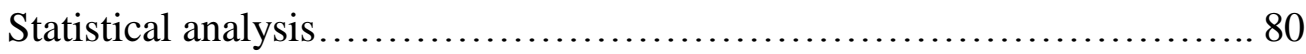

A priori relative abundance modeling ................................... 83

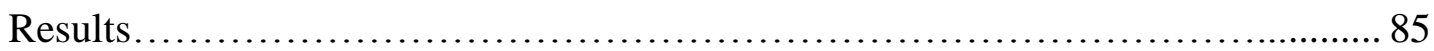

Preliminary salamander data........................................... 85

Descriptive salamander statistics.................................... 85

Temporal and spatial salamander data.................................. 86

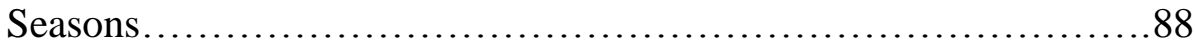

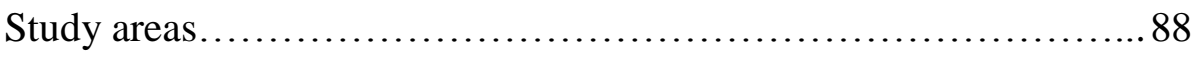

Stream reaches................................................... 89

Cover items................................................... 90

Salamander size ................................................. 91

Temporal and spatial habitat data...................................... 92

Seasons......................................................... 92

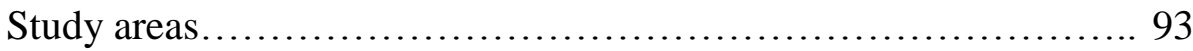

Stream reaches................................................ 94

Habitat interactions.......................................... 94

Good and poor habitat parameters.................................. 95

Mark and recapture estimates versus repeated measures estimates........... 97

A priori relative abundance models................................... 98 
Post-hoc relative abundance model................................. 99

Verification of the post-hoc model............................ 101

Metapopulation analysis........................................ 101

Discussion.............................................................. 102

Critical habitat parameters....................................... 102

Salamander abundance models...................................103

Habitat parameters and density estimates...............................104

Model limitations............................................... 106

Salamander sizes and densities...................................107

Cover board use and numbers................................... 108

Are northern dusky populations metapopulations?.................................. 109

Management implications............................................ 112

Acknowledgments.................................................. 115

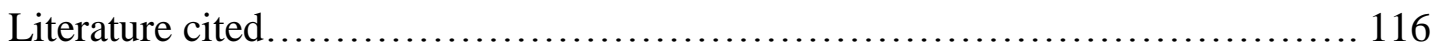

Figures and tables............................................... 123

APPENDICES................................................................. 147 


\section{TABLE OF FIGURES AND TABLES}

\section{CHAPTER 1: LITERATURE REVIEW}

Table 1. Scientific and common name of the 17 recorded salamander species found in Pennsylvania according to Hulse et al. (2001)........................................ 45

Figure 1. Map of southwestern Pennsylvania showing the location of the 4 counties (Allegheny, Beaver, Washington and Westmoreland) and the 5 study areas (4 primary: State Game Land 203, Raccoon Creek State Park, Mingo Creek County Park, and Linn Run State Park; 1 secondary: Cedar Creek County Park) where the study was conducted, 20082009

Figure 2. Aerial photograph of 1 of the 4 primary study areas, Raccoon Creek State Park (RCSP), showing park boundaries (highlighted lime green line) and nearest State Routes 166, 18, and 30, in Beaver County, Pennsylvania. Collection of data occurred in 2008-2009.

Image from Google Earth

Figure 3. Map of 1 of the 4 primary study areas, Raccoon Creek State Park (RCSP), showing park boundaries, elevation, and nearest State Routes 166, 18, and 30, in Beaver County, Pennsylvania. Collection of data occurred in 2008-2009. Image from DCNR ........... 48

Figure 4. Aerial photograph of one of the 4 primary study areas, Linn Run State Park (LRSP), showing park boundaries (highlighted lime green line), nearest State Route 136, and nearest town (Rector, Pennsylvania). Collection of data occurred in 2008-2009....

Figure 5. Map of 1 of the 4 primary study areas, Linn Run State Park (LRSP), showing elevation, proximity to Pennsylvania Toll Road 76, and Forbes State Forest in Westmoreland County, Pennsylvania. Collection of data occurred in 2008-2009. Image from DCNR 50

Figure 6. Aerial photograph of 1 of the 4 primary study areas, Mingo Creek County Park (MCCP), showing park boundaries (highlighted lime green line) and nearest State Routes 136 and 917, in Washington County, Pennsylvania. Collection of data occurred in 2008-2009. Image from Google Earth 51

Figure 7. Map of 1 of the 4 primary study areas, Mingo Creek County Park (MCCP), showing park boundaries, park trails, and State Route 136, in Washington County, Pennsylvania. Collection of data occurred in 2008-2009. Image from Washington County Department of Parks and Recreation. 52

Figure 8. Aerial photograph of 1 of the 4 primary study areas, State Game Land 203 (SGL), showing park boundaries (highlighted lime green line) and nearest State Route 910 and Interstate 79, in Allegheny County, Pennsylvania. Collection of data occurred in 2008-2009. Image from Google Earth 
Figure 9. Map of 1 of the 4 primary study areas, State Game Land 203 (SGL), showing park boundaries, elevation, State Route 910 and Interstate 79, and nearby towns in Allegheny County, Pennsylvania. Collection of data occurred in 2008-2009. Image from Pennsylvania Game Commission....................................................... 54

Figure 10. Aerial photograph of the Cedar Creek County Park (CCCP) (secondary) study area, Westmoreland County, Pennsylvania, that was used to verify the best a priori model and the post-hoc model, showing park boundaries (highlighted lime green line) and nearest State Route 51 and Interstate 70. Verification of models occurred in September 2011. Image from Google Earth................................................................ 55

Figure 11. Map of the Cedar Creek County Park (CCCP) (secondary) study area, showing park boundaries, park trails, and Youghiogheny River, in Westmoreland County, Pennsylvania. Collection of data occurred in September 2011. Image from Westmoreland County Department of Parks and Recreation..................................... 56

Figure 12. The recorded home range of the northern dusky salamander in eastern United

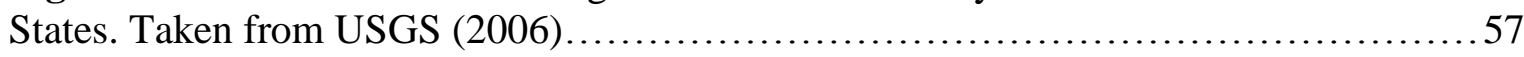

Figure 13. Distribution of northern dusky salamander in the northeastern United States, including confirmed sightings in Pennsylvania indicated by the dots (Hulse et al. 2001).

Figure 14. Fragmentation, as define for the 16 streams (located in the 4 primary study areas: Linn Run State Park, Mingo Creek County Park, Raccoon Creek State Park, and State Game Land 203) in this investigation, is a $20 \mathrm{~m}$ migration range with an additional $35 \mathrm{~m}$ for an edge buffer (not drawn to scale). Collection of data occurred in 2008-2009. .59

Figure 15. An isolated stream, as define for the 16 streams (located in the 4 primary study areas: Linn Run State Park, Mingo Creek County Park, Raccoon Creek State Park, and State Game Land 203) in this investigation, is a $20 \mathrm{~m}$ migration range (not drawn to scale). The collection of data occurred in 2008-2009 60

Figure 16. For the 16 streams (located in 4 primary study areas: Linn Run State Park, Mingo Creek County Park, Raccoon Creek State Park, and State Game Land 203) in this investigation, 2 low order streams at their confluence, showing at some point the streams become too far apart to allow the salamanders to cross from one stream to the next (not drawn to scale). Collection of data occurred in 2008-2009. 
Figure 17. For the 16 streams (located in 4 primary study areas: Linn Run State Park, Mingo Creek County Park, Raccoon Creek State Park, and State Game Land 203) in this investigation, an unfragmented forested habitat with a continuous stream that is transected with a prohibitive barrier (i.e., trail, trail-bridge, dirt road, paved road, culvert, etc.) that isolates salamander populations upstream from downstream populations (not drawn to scale).

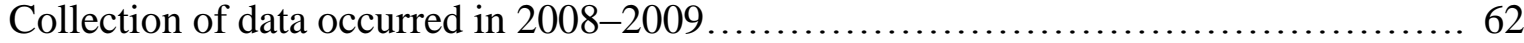




\section{CHAPTER 2: HABITAT USE BY NORTHERN DUSKY SALAMANDERS IN RIPARIAN CORRIDORS OF SOUTHWESTERN}

Table 1. Summary of symbols used in the a priori models that predict northern dusky salamander density and species richness in southwestern Pennsylvania that included 4 primary study areas (Linn Run State Park, Mingo Creek County Park, Raccoon Creek State Park, and State Game Land 203). Spring sampling occurred in April and May (4 visits/year) and fall sampling occurred in September and October (4 visits/year) 2008-2009. Each variable was measured once at the beginning of each stream reach. 123

Table 2. Number of captured individual salamanders by species and stream reach in all 4 primary study areas (Linn Run State Park (LRSP), Mingo Creek County Park (MCCP), Raccoon Creek State Park (RCSP), and State Game Land 203 (SGL)) in southwestern Pennsylvania, 2008-2009

Table 3. Snout-vent length (SVL), total length (ToL) and mass for northern dusky salamanders from 4 primary study areas (Linn Run State Park, Mingo Creek County Park, Raccoon Creek State Park, and State Game Lands 203) by season and year in southwestern Pennsylvania, 2008-2009. 125

Table 4: Spring and fall estimated northern dusky salamander densities from the 4 southwestern Pennsylvania primary study areas: Linn Run State Park (LRSP), Westmoreland County; Mingo Creek County Park (MCCP), Washington County; Raccoon Creek State Park (RCSP), Beaver County, and State Game Lands 203 (SGL), Allegheny County that we used to evaluate 4 (1-4) stream reaches in each primary study area, 20082009 126

Table 5. Estimated northern dusky salamander density by using repeated measure visual encounter survey from the 4 southwestern Pennsylvania primary study areas: Linn Run State Park (LRSP), Westmoreland County; Mingo Creek County Park (MCCP), Washington County; Raccoon Creek State Park (RCSP), Beaver County, and State Game Lands 203 (SGL), Allegheny County that we used to evaluate 4 (1-4) stream reaches in each primary study area, 2008-2009.

Table 6. Northern dusky salamander capture data and total capture data by type of protective cover from all 4 primary study areas (Linn Run State Park, Mingo Creek County Park, Raccoon Creek State Park, and State Game Lands 203) by season and year in southwestern Pennsylvania, 2008-2009. 128

Table 7. Cover board use data from the 4 southwestern Pennsylvania primary study areas: Linn Run State Park (LRSP), Westmoreland County; Mingo Creek County Park (MCCP), Washington County; Raccoon Creek State Park (RCSP), Beaver County, and State Game Lands 203 (SGL), Allegheny County that we used to evaluate 4 (1-4) stream reaches in each primary study area, 2008-2009 129 
Table 8. Estimated Northern Dusky densities from a robust mark and recapture design from the 4 southwestern Pennsylvania primary study areas: Linn Run State Park (LRSP), Westmoreland County; Mingo Creek County Park (MCCP), Washington County; Raccoon Creek State Park (RCSP), Beaver County, and State Game Lands 203 (SGL), Allegheny County that we used to evaluate 4 (1-4) stream reaches in each primary study area, 20082009

Table 9. Ranking of 6 a priori models estimating northern dusky salamander density from 4 primary study areas (each with 4 stream reaches) in southwestern Pennsylvania, 2008-2009. Models were ranked using Akaike's Information Criterion adjusted for small sample size $\left(\mathrm{AIC}_{\mathrm{c}}\right)$ 131

Table 10. Estimated northern dusky salamander density using the best fit $\mathrm{AIC}_{\mathrm{c}}$ a priori model (Model 5) and a post-hoc model (Model 7) with data from the 4 southwestern Pennsylvania primary study areas: Linn Run State Park (LRSP), Westmoreland County; Mingo Creek County Park (MCCP), Washington County; Raccoon Creek State Park (RCSP), Beaver County and State Game Lands 203 (SGL), Allegheny County that we used to evaluate 4 (1-4) stream reaches in each primary study area, 2008-2009. Cedar Creek County Park (CCCP), Westmoreland County, was an independent secondary site where collected data (September 2011) was used in Model 5 and to verify the post-hoc model. 132

Figure 1. Map of southwestern Pennsylvania showing the location of the 4 counties (Allegheny, Beaver, Washington and Westmoreland) and the 5 study areas (4 primary: State Game Land 203, Raccoon Creek State Park, Mingo Creek County Park, and Linn Run State Park; 1 secondary: Cedar Creek County Park) where the study was conducted, 20082009 134

Figure 2. Conceptual diagram of cover boards placement (not drawn to scale) for stream side salamander study in southwestern Pennsylvania, 2008-2009. Sixteen streams in the 4 primary study areas with each stream having 5 groups of 10 boards ( 2 are shown here) with each group $5 \mathrm{~m}$ apart. Each group of cover boards consisted of 5 pairs of $30 \mathrm{~cm} \times 30 \mathrm{~cm} \times 5 \mathrm{~cm}$ cover boards with each pair being $2 \mathrm{~m}$ apart. 135

Figure 3. Scatter plot of the number of salamanders captured under a cover board versus mean protective cover by stream reach for the 16 streams in 4 primary study areas (Linn Run State Park (LRSP), Mingo Creek County Park (MCCP), Raccoon Creek State Park (RCSP), and State Game Land 203 (SGL)) in southwestern Pennsylvania, 2008-2009. 136

Figure 4. Scatter plots of the mean measured non-correlated habitat parameters (stream size, mean temperature, percent herbaceous cover, $\mathrm{pH}$, relative humidity, percent canopy cover, percent deciduous trees, and percent protective cover) versus estimated northern dusky salamander density (No. salamanders/m) from the 16 visit of the 16 stream reaches in the 4 study areas (Linn Run State Park, Mingo Creek County Park, Raccoon Creek State Park, and State Game Land 203) of southwestern Pennsylvania that were studied in 20082009 137 
Figure 5. Bar graphs showing selected non-correlated measured habitat parameter (protective cover, canopy cover, stream size, and herbaceous cover) values sorted by stream reach and classification (Good or Poor) of the 16 streams in the 4 study areas (LRSP: Linn Run State Park, MCCP: Mingo Creek County Park, RCSP: Raccoon Creek State Park, and SGL: State Game Land 203) for this study in southwestern Pennsylvania, 2008-

2009.

Figure 6. Scatter plot of the repeated measures density versus mark and recapture density for the 16 streams in 4 primary study areas (Linn Run State Park (LRSP), Mingo Creek County Park (MCCP), Raccoon Creek State Park (RCSP), and State Game Land 203 (SGL)) in southwestern Pennsylvania, 2008-2009.

Figure 7. Scatter plots of the estimated northern dusky salamander density from the mark and recapture survey for each of the 6 a priori abundance models versus northern dusky salamander density (from repeated measures) from the 16 stream reaches of southwestern

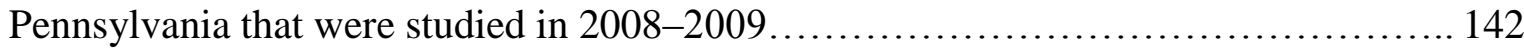

Figure 8. Scatter plots of the estimated northern dusky salamander density for each of the $6 a$ priori abundance models versus northern dusky salamander density (from repeated measures) for the 16 stream reaches of southwestern Pennsylvania that were studied in 20082009

Figure 9. Scatter plots of the estimated northern dusky salamander density versus percent error for Model 5 (a) and the post-hoc model (b) for the 16 stream reaches of southwestern Pennsylvania that were studied in 2008-2009. 144

Figure 10. Scatter plot of the measured non-correlated habitat parameter stream size difference $\left(\mathrm{S}^{\prime}{ }_{\mathrm{wd}}\right)$ versus estimated northern dusky salamander density (from repeated measures) from the 16 stream reaches of southwestern Pennsylvania that were studied in

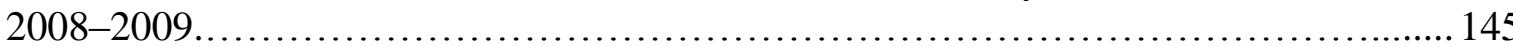

Figure 11. Scatter plot of the estimated northern dusky salamander density for post-hoc model 7 versus northern dusky salamander density (from repeated measures) from the 16 stream reaches of southwestern Pennsylvania that were studied in 2008-2009.......... 146 


\section{TABLE OF APPENDICES}

Appendix 1. Thirty year average of climatic conditions in southwestern Pennsylvania (Region 3609 of NOAA's Climate Divisions), 1971-2000 (NOAA 2005).

Appendix 2. Identifying lateral eye stripe of the dusky salamander as used in this southwestern Pennsylvania study that included 4 primary study areas (Linn Run State Park, Mingo Creek County Park, Raccoon Creek State Park, and State Game Land 203) 2008-2009 (Hulse et al. 2001). 148

Appendix 3. Identifying wide dorsal stripe of the northern dusky salamander as used in this southwestern Pennsylvania study that included 4 primary study areas (Linn Run State Park, Mingo Creek County Park, Raccoon Creek State Park, and State Game Land 203) 2008-2009 (Hulse et al. 2001). 148

Appendix 4. Identifying keeled tail (on right) of the northern dusky salamander shown as used in this southwestern Pennsylvania study that included 4 primary study areas (Linn Run State Park, Mingo Creek County Park, Raccoon Creek State Park, and State Game Land 203) 2008-2009 (Hulse et al. 2001). 149

Appendix 5. Preferred habitat of the Northern dusky salamander of the 4 primary study areas (Linn Run State Park, Mingo Creek County Park, Raccoon Creek State Park, and State Game Land 203) as determined by GIS data from Pennsylvania Spatial Data Access (PASDA) 150

Appendix 6. Mean separated habitat data from the 4 southwestern Pennsylvania primary study areas: Linn Run State Park (LRSP), Westmoreland County; Mingo Creek County Park (MCCP), Washington County; Raccoon Creek State Park (RCSP), Beaver County, and State Game Lands 203 (SGL), Allegheny County, 2008-2009. 154

Appendix 7. Measured mean habitat and salamander data by stream reach from the 4 southwestern Pennsylvania primary study areas: Linn Run State Park (LRSP), Westmoreland County; Mingo Creek County Park (MCCP), Washington County; Raccoon Creek State Park (RCSP), Beaver County, and State Game Lands 203 (SGL), Allegheny County that we used to evaluate 4 (1-4) stream reaches in each primary study area, 20082009 


\title{
CHAPTER 1: Literature Review of
}

\section{Habitat Use by Northern Dusky Salamanders in Riparian Corridors of Southwestern Pennsylvania}

\author{
Robert J. Michalow ${ }^{1}$
}

${ }^{1}$ School of Social Sciences, Communication and Education 300 Fraser Purchase Road

Saint Vincent College

Latrobe, Pennsylvania 15650, USA

724-805-2710; Fax: 724-805-2024; rob.michalow@email.stvincent.edu 


\section{Introduction}

Habitat fragmentation or degradation (from here on forward just referenced as habitat fragmentation) is the process of dissecting large and contiguous areas of similar native vegetative types into smaller units separated by different vegetative types and or areas of intense human activity (Saunders et al. 1991). Although typically applied to forest ecosystems, habitat fragmentation can be applied to any type of landscape. Gradual natural habitat fragmentation has occurred for thousands of years due to natural topography such as mountain ridges and or rivers that have partitioned landscapes (Harris 1984); however, anthropogenic disturbances have exacerbated the problems associated with habitat fragmentation in a broader perspective via resource extraction, agriculture, and urbanization (Roberts et al. 2000). In efforts to limit the negative impacts of habitat fragmentation, ecological corridors have been created which benefit various species because they can enhance plant and animal interactions and increase plant pollination (Graham 2002); yet other studies indicate different species do not benefit or are unaffected by corridors (Belisle and St. Clair 2001).

Habitat fragmentation also can occur within a stream reach via some type of barrier (e.g., road, culvert, dam), thus preventing species such as salamanders from moving up and down the stream (Jackson 2003). Stream barriers also can increase the amount of sediment flowing downstream (Miller et al. 1997) while channelization (usually occurring above and below road crossings) increases destruction of riparian vegetation, increases water temperature because of a lack of canopy cover, decreases pool and riffle habitat, decreases protective cover for aquatic organisms and increases bank erosion (Beschta and Platts 1986). When properly installed, culverts allow continuous stream flow and keep stream water 
separate from the road (Adair et al. 2002); however, culverts may act as stream barriers because of improper installation (Ward et al. 2008). For example, 55\% of the culverts within the Lower Shavers Fork and Dry Fork watersheds of West Virginia were classified as complete barriers for salamanders while an additional $34 \%$ of the culverts were classified as partial barriers (Ward et al. 2008).

Smith and Green (2005) reported that amphibians are frequently characterized as having limited dispersal abilities, strong site fidelity, and spatially disjoint breeding habitat. As such, some species of salamanders are often alleged to form metapopulations while other species do not (Smith and Green 2005). The metapopulation concept (the idea of spatially structured populations with local extinction and recolonization) has been published since the early to mid $20^{\text {th }}$ century. However, to date no attempt has been made to assess the class-wide generalization of amphibian populations as metapopulations (Smith and Green 2005). Strong evidence indicates that amphibian dispersal is not as uniformly limited as often thought (Smith and Green 2005). Finally, caution needs to be exercised in the application of the metapopulation approach to amphibian population conservation because some amphibian populations are structured as metapopulations, but not all. This is important because of the different theoretical philosophies and management techniques used for species that are considered metapopulations and ones that are not.

The general population trend of salamanders is relatively unknown because data are few, scattered, research-oriented rather than monitoring-oriented and largely unpublished; thus, providing little information about the regional stability of salamanders (United States Geological Survey [USGS] 2004). Because of their dependence to the forest floor and a water source, salamanders are more likely to indicate significant environmental changes than any 
other North American amphibian (USGS 2004) and semi-aquatic salamanders (i.e., streamside salamanders) are receiving more attention as ecological indicators (Roth et al. 1999; Ohio EPA 2001) for headwater stream ecosystems (those draining less than 400 ha) because of the salamander's longevity, relatively stable populations, small home ranges, abundance and ubiquity (Welsh and Ollivier 1998, Rocco and Brooks 2000). In western Pennsylvania, salamander populations have been documented to occupy undisturbed forest floors with densities equal to, or exceeding, the biomass of all other vertebrate groups (Burton and Likens 1975a, Hairston and Wiley 1993) and they have achieved their highest densities in ancient or undisturbed forests (Welsh 1990, Meier et al. 1996). However, some studies indicate that stream-side salamander populations have been negatively affected by higher impervious surface area in the basin area, abandoned mine drainage, nearby road construction, and logging (Bury and Corn 1988, Corn and Bury 1989, Welsh and Ollivier 1998, Boward et al. 1999, Middlekoop et al. 1999, Rocco and Brooks 2000, Chambers 2008, Sepulveda and Lowe 2009). Furthermore, northern dusky salamander populations are negatively impacted by urbanization and or pollution with the decrease in populations attributed primarily to the loss of vegetative cover and stream quality degradation (Orser and Shure 1972, Grant et al. 2004, Bank et al. 2006).

\section{Justification}

Amphibian populations have decreased in many parts of the world and the rate of decline has increased over the past 25 years (BeeBee and Rowe 2005). Much of the population decline can be attributed to habitat loss; however, other factors (i.e., environmental contaminants, ultra-violet-B radiation, emerging diseases, alien species, direct exploitation, and climate change) also have contributed to the decline (BeeBee and Rowe 2005). For 
example, in Acadia National Park, Maine, the northern dusky salamander population, once widespread and common, is no longer as robust as before; the population is so low that in a 4year study, only 2 adult northern dusky salamanders and no egg masses were found (Bank et al. 2006). Means and Travis (2007) reported that Plethodon salamander populations have decreased in Georgia, Louisiana, and Florida over the past 25 years and 1 possible factor that may have contributed to the recent decrease is habitat disruption by feral pigs (Sus scrofa). Because of their sensitivity to ecological disturbances, stream salamanders such as the northern dusky have been used as indices for stream classification systems based on flow and ecological health. Moreover, Burton and Likens (1975a) found that the annual energy flow through salamanders in the Hubbard Brook ecosystem to be $11,000 \mathrm{kcal} / \mathrm{ha}$ and this amount was roughly equal to $20 \%$ of the energy flow through bird and mammal populations.

This study is significant because not only will it estimate the salamander density for streams in southwestern Pennsylvania, it also will develop a relative abundance model that will estimate salamander density by measuring habitat parameters. This study also will investigate what riparian zone factors affect the quality of habitat of the northern dusky salamander and thus impact their densities. There have been no studies pertaining to the northern dusky salamander at these study areas, and thus, it would be ecologically important to determine the northern dusky salamander density so the data could then be used at a later date to determine if they are suffering the same losses as mentioned by others (Orser and Shure 1972, Bank et al. 2006). Smith and Green (2005) demonstrated that the applicability of the metapopulation paradigm to amphibian species is largely dependent on the hypothesis of limited dispersal. As there are wide ranges of dispersal abilities within amphibian species, we need to be cautious with the indiscriminant application of the metapopulation approach to 
amphibians, especially where conservation decisions are to be based on the assumptions of isolation and metapopulation structure through limited dispersal (Smith and Green 2005). This study will investigate the characteristics of streams that enhance salamander abundance.

\section{Objectives}

The objectives for this study are to:

1. Estimate the northern dusky salamander density at each of the stream reaches;

2. Assess if there is a statistical difference in salamander density within a stream between areas where cover boards are present (areas of additional protective cover and thus possibly higher densities) and where cover boards are not present;

3. Examine if the selected streams within a study area are geographically isolated from one another for the northern dusky salamander;

4. Determine which measured stream and riparian zone characteristics impact the salamander density and use these to develop a density estimation model for the northern dusky salamander; and

5. Determine the percentage of northern dusky salamanders that are captured under cover boards.

\section{Hypotheses}

The hypotheses for this study include:

1. $\mathrm{H}_{0}$ : The streams, seeps, and runs within each study area do not inhibit the movement of northern dusky salamanders from one stream reach to another. $\mathrm{H}_{\mathrm{a}}$ : The streams, seeps, and runs within each study area are geographically isolated with respect to the populations of northern dusky salamanders. 
2. $\mathrm{H}_{0}$ : The placement of cover boards will have no impact on the northern dusky salamander density estimates.

$\mathrm{H}_{\mathrm{a}}$ : Areas in which cover boards are used will have a higher number of salamander captures than areas without cover boards.

3. $\mathrm{H}_{0}$ : All the streams analyzed in this study will be similar to each other so that the density estimate models will not provide any statistical differences between them. $\mathrm{H}_{\mathrm{a}}$ : Data analysis will indicate different stream habitat values will have different northern dusky salamander densities.

4. $\mathrm{H}_{0}$ : There will be a significant proportion $(>20 \%)$ of the northern dusky salamanders using the cover boards as artificial habitat. $\mathrm{H}_{\mathrm{a}}$ : There will not be a significant proportion $(<20 \%)$ of northern dusky salamanders using the cover boards as artificial habitat.

\section{Study areas}

The study region for this investigation is southwestern Pennsylvania, USA and the 4 specific study areas are Raccoon Creek State Park in Beaver County; Linn Run State Park in Westmoreland County; Mingo Creek County Park in Washington County; and State Game Land 203 in Allegheny County (Figure 1). One additional study area, Cedar Creek County Park in Westmoreland County, was used as an independent site to verify the density estimate model. All 5 study areas are located in southwestern Pennsylvania (Region 3609 of National Oceanic and Atmospheric Administration's NOAA Climate Divisions) and classified as temperate deciduous forests where the average precipitation $(96.1 \mathrm{~cm})$ ranges from a high in June $(10.5 \mathrm{~cm})$ to a low in October $(5.7 \mathrm{~cm})$, the average high temperature $\left(15.8^{\circ} \mathrm{C}\right)$ ranges from a high in July $\left(28.2^{\circ} \mathrm{C}\right)$ to a low in January $\left(1.7^{\circ} \mathrm{C}\right)$, the average low temperature $\left(5.3^{\circ}\right.$ 
C) ranges from a high in July $\left(16.9^{\circ} \mathrm{C}\right)$ to a low in January $\left(-6.7^{\circ} \mathrm{C}\right)$, the annual average number of days with $0.03 \mathrm{~cm}$ of precipitation (152) is highest in the months of January and December (16) and lowest in July, August and September (10), and the average relative humidity is $80 \%$ during the day and $58 \%$ in the afternoon with September having the highest morning and afternoon levels at $87 \%$ and $57 \%$ respectively and April having the lowest values at $74 \%$ and $51 \%$, respectively (NOAA 2005) (Appendix 1).

Raccoon Creek State Park is located 48 km west of Pittsburgh, PA, just north of Frankfort Springs (DCNR 2005) (Figure 2). The park's beginning was a Recreational Demonstration Area operated by the National Park Service in the 1930s and is now one of the largest state parks in Pennsylvania (DCNR 2005). The 3,064 ha park (elevation range: 274$366 \mathrm{~m}$ above sea level) features a 40.8 ha lake (Raccoon Lake) and large tracts of undeveloped land (DCNR 2005). Traverse Creek and Service Run flow $6 \mathrm{~km}$ from west to the east before entering Raccoon Creek Lake and eventually into Raccoon Creek. Additionally, there are many unnamed tributaries that flow into Traverse Creek, Raccoon Lake and Raccoon Creek within the park's boundaries (DCNR 2005) (Figure 3). The land use of Raccoon Creek State Park is over 90\% rural deciduous forest, with numerous small patches of rural mixed forest dominated by oaks (Quercus spp.), maples (Acer spp.) and basswoods (Tilia spp.), rural evergreen forests and rural perennial herbaceous plant cover. There are many different soil types located in Raccoon Creek State Park; however, soil types found within the riparian zones are the Atkins silt loam, Clymer loam, Culleoka silt loam, Ernest silt loam, Ernest very strong silt loam, Gilpin silt loam, Gilpin-Upshure complex, Gilpin-Weikert, Guernsey silt loam, Guernsey-Vandergrift complex, Hazleton channery loam, Monongahela 
loam, Philo silt loam, Pope silt loam, Urban land and Vandergraft-Gilpin complex (USDA 1982a).

Linn Run State Park is located 96 km east of Pittsburgh, PA within the Laurel Mountains (396-853 m above sea level), encompasses 247 ha and borders the > 20,000 ha Forbes State Forest (Figure 4). Pennsylvania acquired this land in 1909 and it was the first major public purchase of denuded forest land in the Ohio River Basin (DCNR 2005b). About 15 years prior to the State's acquisition of the property, the entire old growth forested area was clear-cut. In 1910, the Pennsylvania Game Commission cooperated with the former Department of Forestry to restock white-tailed deer (Odocoileus virginianus) and evidence remains of the Pittsburgh, Westmoreland and Somerset Railroad that serviced the area. The park has a varied topography and is $95 \%$ mixed hardwood (oaks and maples) and evergreen forests. Grove Run and Rock Run join to form Linn Run that flows from southeast to northwest through the park (Figure 5). There are many different soil types located in Linn Run State Park; however, soil types found within the riparian zones are the Atkins silt loam, Clymer loam, Ernest silt loam, Gilpin silt loam, Guernsey-Vandergrift complex, Urban land and Vandergraft-Gilpin complex (USDA 1982b).

Mingo Creek County Park (271-370 m above sea level) is a 1,052 ha park that is $19 \mathrm{~km}$ east of the City of Washington, PA (Figure 6). Aerial photographs reveal that this park has about $70 \%$ rural forests that are dominated by basswood, oaks and maples with the remaining $30 \%$ being cleared fields for recreation. Mingo Creek meanders $6 \mathrm{~km}$ from west to east through the park and 2 historical covered bridges (Ebenezer and Henry) span the creek. Many unnamed tributaries within the park's boundary flow into Mingo Creek (Figure 7). There are many different soil types located in Mingo Creek County Park; however, soil types found 
within the riparian zones are the Atkins silt loam, Clymer silt-loam, Ernest silt loam, Gilpin silt loam, Gilpin-Weikert, Guernsey silt loam, Philo silt loam, Pope silt loam, Urban land, and Wharton silt loam (USDA 1982c).

State Game Land 203 (290-378 m above sea level) was established in 1942 when 2 parcels were donated to the Pennsylvania Game Commission with both parcels located south of Warrendale, PA (Figure 8). The 512 ha game land has the East Branch of the Big Sewickley Creek that flows several kilometers from east to west and transects the southern portion of the land. There are also many unnamed tributaries that feed the East Branch (Figure 9). During the 1920s, the land was clear cut for timber and the forest has been permitted to regenerate and has not been cut since. A current aerial photograph reveals that this game land is over $90 \%$ rural mixed deciduous forest that is dominated by maples, poplars (Lirodendron spp.) and basswoods. The remaining 10\% encompasses cleared areas for a pipeline right-a-way, food plots for deer management and 2 firearm ranges. There are many different soil types located in State Game land 203; however, soil types found within the riparian zones are the Atkins silt loam, Cavode silt loam, Clymer silt loam, Gilpin Weikert Culleoka shaly silt loam, Ernest silt loam, Gilpin silt loam, Guernsey silt loam, Pope silt loam, Urban land and Wharton silt loam (USDA 1982d).

Cedar Creek County Park is a 188 ha park located $43 \mathrm{~km}$ southeast of Pittsburgh, PA, just east of Rostraver, Westmoreland County, PA. Aerial photographs reveal that the park is $30 \%$ urban land and that $70 \%$ is rural deciduous forest dominated by maples, poplars and oaks. The photographs also reveal that the majority of the deciduous forest is located at the park's lower elevations $(229 \mathrm{~m})$ and that the urban land is more common at the higher elevations (344 m) (Figure 10). The Manderino Riverfront accesses the Youghiogheny River 
which comprises the eastern edge of the park and Cedar Creek flows easterly to drain into the Youghiogheny. The Great Allegheny Passage (a trail that connects Pittsburgh, PA and Washington D.C.) passes through Cedar Creek Park along the Youghiogheny River (Figure 11). Soil types found within the riparian zones of Cedar Creek Park and the unnamed tributaries are the Clymer loam, Culleoka silt loam, Ernest silt loam, Gilpin silt loam, GilpinUpshure complex, Guernsey silt loam, Guernsey-Vandergrift complex, Hazleton channery loam, Monongahela loam, Philo silt loam, Pope silt loam, and Urban land (USDA 1982b).

\section{Habitat fragmentation and degradation}

Habitat fragmentation is the process of dissecting large and contiguous areas of similar native vegetative types into smaller units separated by different vegetative types and or areas of intense human activity (Saunders et al. 1991). Typically, habitat fragmentation has been applied to forest ecosystems (Harris and Silva-Lopez 1992); however, the term can be applied to any type of natural native landscape. Habitat fragmentation has occurred naturally for thousands of years due to topography such as mountain ridges or rivers that have partitioned landscapes (Harris 1984). However, these changes in habitat are generally slow, except for geological or climatic processes that undergo chronic abrupt changes (i.e., fires, floods, volcanic eruptions) (Roberts et al. 2000). Human-induced habitat fragmentation has exacerbated the problems associated with habitat fragmentation in a broader sense via resource extraction, agriculture, and urbanization (Roberts et al. 2000).

Studies concerning habitat fragmentation can be broadly grouped into 2 categories: studies that analyze the effects of fragmentation on processes within a fragment or studies that analyze the effects of fragmentation between fragmented patches (Davies et al. 2001). Factors such as patch isolation, patch size and amount of edge all impact species within the 
fragmented habitat; while factors such as dispersal capability and matrix composition impact species between fragments (Davies et al. 2001). Others claim that fragmentation can be studied in 3 ways that include: the absolute amount of fragmented patches, the spatial pattern of those patches and the associated changes (Turner 1990). Isolation of a species within a fragment can increase the chance of extirpation because of factors such as environmental stochasticity, deterministic threats, demographic stochasticity and loss of genetic variation (Davies et al. 2001).

The amount of edge (or shape) a patch has impacts the biodiversity within the patch because edge habitats have different physical and chemical characteristics when compared to the interior portion of the fragment (Davies et al. 2001); thus leading to differences in the plant and animal composition and structure. For example, in temperate deciduous forests of the eastern United States, Weathers et al. (2001) has shown that forest edges have higher levels of nutrients, such as sulfur, inorganic nitrogen, and calcium; thus impacting soilnutrient cycling, microbial activity, seeding dominance, and other ecological processes. In general, the smaller the forest fragment the less interior habitat available for interior forest animals and plants. Additionally, fragments with a larger perimeter-to-area ratio have more edge characteristics and less core area than fragments with a lower perimeter-to-area ratio (Davies et al. 2001). De Maynadier and Hunter (1995) suggest that the impacts of an edge (edge effect) can reach $35 \mathrm{~m}$ into a forest, while Crawford and Semlitsch (2007) report as far as $50 \mathrm{~m}$. This phenomena also can impact stream and riparian zone habitat characteristics, and salamander behavior such as breeding site selection and movement (Crawford and Semlitsch (2007). 
Two factors that affect the processes between fragmented patches include the dispersal of patches and the matrix surrounding the patches because both of these impact species survival. MacArthur and Wilson (1967) in the theory of island biogeography and later Levins (1969) in the metapopulation theory, claim that processes within a patch are influenced by the between-fragment factors mentioned above (Davies et al. 2001). Both theories also claim that as patches become more distant, colonization and re-colonization rates decrease, and the number of species within a patch decrease (Davies et al. 2001). Matrix characteristics can vary significantly such that it can slightly prohibit the movement of a species from one patch to another or the matrix can completely prohibit the movement altogether, or any degree in between as shown by Ward et al. (2008) with culverts and stream in West Virginia. Thus, matrix characteristics have strongly influenced between-patch processes in several ways that include dispersal between fragments, suitable habitat for invasive species (Stouffer and Bierregaard 1995) and how far within the edge effect penetrates the fragmented patch (Davies et al. 2001).

Whether examining processes that occur within the fragmented habitat or processes between fragmented habitats, fragmentation has a wide variety of impacts (both negative and positive) on the ecosystem. Henle et al. (1996) reported that habitat destruction and fragmentation are the likely causes of increased extinction rates for many species over the most recent decades while other studies have shown that habitat fragmentation has increased the population of other species, such as the Argentine ant (Linepithema humile) (Saurez et al. 1998). In essence, fragmentation can reduce the population size of species that require larger patches of forest, hinder the movement of other species, introduce species from one type of ecosystem to another, alter the effects of fire, genetic diversity and even affect seed dispersal 
(Heinz 2002). In efforts to limit the negative impacts of forest fragmentation, ecological corridors have been created (Aalen 1997) that can benefit various species because they enhance plant and animal interactions and increase plant pollination (Graham et al. 2002); yet other studies indicate various species are unaffected by corridors (Belisle and St. Clair 2001). Nauman and Olson (2008) have reported that not only do patches need to be protected, but also that disturbed land (matrixes) need to be mitigated in order to minimize the disruption of Plethodon salamander populations.

One of the challenges in determining the effects of fragmentation is that fragmentation is sensitive to spatial scale such that a habitat may be considered fragmented for one particular species, but not for a different species (Lord 1990). For example, Belisle and St. Clair (2001) state that fragmentation impedes the movement of some birds such as the Red-breasted Nuthatch (Sitta canadensis), while other birds such as the Golden-crowned Kinglet (Regulis satrapa) were indifferent to forest fragmentation. Others suggest that there are even differences among similar species and a more complex interpretation is needed (Belisle and St. Clair 2001). Ultimately, additional studies are needed to determine which parameters (i.e., size, shape, proximity, ecosystem type, etc.) have the greatest impact on increasing the quality of the ecosystem and scientists agree there are still large gaps of species-specific data.

Habitat fragmentation can also occur with respect to aquatic ecosystems, such as a stream being fragmented by a culvert or some other barrier. For salamanders, connectivity of a long stream reach is vital because many adult semi-aquatic species tend to move up and down stream during various stages of their life cycle (Jackson 2003). Some objects, such as roads can serve as barriers for not just salamanders, but a variety of species because roads create breaks in microclimate, create disturbance and increase direct mortality (Mader 1984). 
For example, Fahrig et al. (1995) found that the number of road killed frogs increased with an increase in road usage. Furthermore, Miller et al. (1997) reported a decrease in basal area of overstory trees near roads in Pennsylvania, while Mader (1984) reported that the vegetation in road clearings are often disturbed by mowing, thus preventing ecological succession. Roads have also increased the amount of sediment flowing downstream (Miller et al. 1997) while channelization (usually occurring above and below road crossings) increases destruction of riparian vegetation, increases water temperature because of a lack of canopy cover, decreases pool and riffle habitat, decreases protective cover for aquatic organisms and increases bank erosion (Beschta and Platts 1986).

Culverts, when properly installed, allow streams to flow continuously and keep the stream's water separate from the road (Adair et al. 2002). Most studies on the passage of culverts have concentrated on fish, while few have concentrated on salamanders (Ward et al. 2008). This is significant because culverts increase stream velocity, making it more difficult for salamanders to navigate through the culvert because salamanders have a relatively poor swimming performance when compared to fish (Ward et al. 2008). Finally, Ward et al. (2008) reported that due to overhang, 55\% of the culverts within the Lower Shavers Fork and Dry Fork watersheds of West Virginia were classified as complete barriers for salamanders, while an additional $34 \%$ of the culverts were classified as partial barriers.

\section{Theories}

Although widely accepted that the biodiversity of an ecosystem is dependent on a variety of factors, 2 factors that greatly influence the amount of biodiversity in an ecosystem are size of the particular ecosystem and degree of isolation (Miller 2000). Robert MacArthur and E. O. Wilson first proposed a theory that incorporates these 2 factors and their impact on a 
habitat's biodiversity. This theory, called "The Species Equilibrium Model" and better known as "The Theory of Island Biogeography" (MacArthur and Wilson 1967) states that the equilibrium number of species (biodiversity) in an ecosystem is dependent upon the rates of immigration and emigration, and biodiversity varies with island size and distance to a mainland. Initially, research in forest habitat fragmentation (Wilcox 1980, Harris 1984) incorporated the theory of island biogeography in efforts to understand the function and sustainability of isolated patches of terrestrial habitats (Roberts et al. 2000). However, because of physical and logistic differences (i.e., the matrix for the theory of island biogeography is different from the matrix for fragmented forests), a new theory was needed to explain terrestrial biodiversity. Hence, the metapopulation theory evolved (Hanski and Gilpin 1997).

The metapopulation concept has been published since the early to mid $20^{\text {th }}$ century by evolutionary biologists and or geneticists such as Sewall Wright, A. E. Boycott, Cyril Diver, and M. Lamotte (Hanski and Gilpin 1997); however, it never gained much attention. The idea resurfaced in the works of Richard Levins (Levins 1969, 1970), but once again, the idea remained a minor concept in the scientific community (Hanski and Gilpin 1997). In the late 1980s, as the theory of island biogeography waned, the metapopulation theory finally bloomed as a way of thinking about terrestrial habitat islands, fragmented habitats and heterogeneous terrestrial environments (Hanski and Gilpin 1997).

More recently, the amount of literature on the metapopulation theory has grown exponentially with a doubling time of less than 2 years (Hanski and Gilpin 1997). For instance, there have been a number of metapopulation studies examining various species that include coral trout (Arius thalassinus) (Little et al. 2005), forest plants (Vellend et al. 2005), 
butterflies (Baguette and Schtickzelle 2005) and amphibians (van Buskirk 2005). There also have been studies creating metapopulation models (Gavrilets et al. 2000, Moilanen 2000, Hakoyama and Iwasa 2004). Van Buskirk (2005) reported that amphibian species differed in preference for permanent or temporary ponds, high- or low-predator ponds and landscapes within forested or open areas, thus their occurrence was positively correlated with the densities of other species suggesting that competition was less important than variation in quality among sites. Furthermore, Smith and Green (2005) reported that amphibians are frequently characterized as having limited dispersal abilities, strong site fidelity and spatially disjunctive breeding habitat. As such, some species of salamanders often form metapopulations while others do not (Smith and Green 2005). If the simplification of amphibians occupying metapopulations is accurate, then a regionally based conservation strategy, informed by metapopulation theory, is a powerful tool to estimate the isolation and extinction risk of ponds or populations (Smith and Green 2005). However, Smith and Green (2005) report that no attempt (via reviewing 166 published journal articles) has been made to assess amphibian population trends, as a whole, as metapopulations. This is because Smith and Green (2005) found that $74 \%$ of the time, the assumptions of the metapopulation paradigm were not tested and that breeding patch isolation via limited dispersal and or strong site fidelity was the most frequently implicated or tested metapopulation condition; however, strong evidence supports that amphibian dispersal is not as uniformly limited as is often thought (Smith and Green 2005). Finally, caution should be exercised in the application of the metapopulation approach to amphibian population conservation plans because some amphibian populations are structured as metapopulations, but not all (Smith and Green 2005). Thus different wildlife management plans and or techniques need to be applied. 
In the strictest sense, metapopulations can be defined as populations that are spatially structured into assemblages of discrete local breeding populations regardless of population turnover, while migration among the local populations has some effect on local dynamics including the possibility of population reestablishment following extinction (Hanski and Gilpin 1997). This definition states the 2 key premises behind the metapopulation approach: populations are spatially structured into assemblages of local breeding populations, and migration among the local populations has some effect on local dynamics. Furthermore, because this theory views a population as a conglomerate of individual local populations, it has created new ideas concerning patterns of distribution and population turnover, landscape ecology, community structure, population viability and time to extinction, relation between and within species, ecological consequences of migration, inbreeding and heterozygosity, genetic differentiation, adaptation and co-evolutionary processes (Hanski and Gilpin 1997). Furthermore, single species studies pertaining to the metapopulation theory have tended to emphasize the benefits of migration, leading to the establishment of new populations and thereby compensating for extinctions in small habitat patches (Hanski and Gilpin 1997). Within the metapopulation theory, it is assumed that populations are impacted by 4 components: variation in patch quality, variation in the quality of the surrounding landscape (matrix), boundary effects, and how the landscape influences patch connectivity (Hanski and Gilpin 1997).

Moilanen (2000) reports that when studying a species that displays isolated populations, the important question is not to find out if there are any trends in the data, but rather to determine whether the metapopulation is persistent or not. For example, some metapopulations may be stable, yet are in danger of going extinct because of their small size, 
yet other metapopulations may show strong short-term fluctuations, but these fluctuations may be regular extinction-recolonization stochasticity or regional stochasticity (Moilanen 2000). Others, such as Gavrilets et al. (2000), have taken the idea of metapopulation and looked at how isolated patches can lead to diversification and speciation. From this, Gavrilets et al. (2000) developed a framework that can be used to approach a number of metapopulation questions that include species-area distribution, species range-size distribution, rate of ecological turnover, asymmetries of range distribution between sister species, waiting time until speciation and extinction, the relation between geographic range size and the probability of speciation, the relation of sub-population level parameters and metapopulation parameters and the effects of taxonomic level on these rates, distributions and parameters.

Hanski (1999) suggested 4 conditions that need to be satisfied in order to indicate the existence of a metapopulation. Condition 1: The habitat supports a local breeding population. According to Grant et al. (2004), the presence of larval salamanders indicates that the population is reproducing and resident in the stream on an annual basis. Thus, to provide evidence that a study site supports local breeding populations, juvenile salamanders need to be recorded when observed. Additionally, egg masses, even unguarded, indicate the presence of a local breeding population (Grant et al. 2004).

Condition 2: No single population is large enough to ensure long-term survival. Bank et al. (2006) reported that a historical assessment of northern dusky salamander populations and ranges during a comprehensive survey of stream habitats in the mid-1950s indicate that all age classes were commonly found in streams with cobble substrates and that adults and larvae were widely distributed throughout Acadia National Park, Maine. During 2000-2003, Bank et al. (2006) searched the same habitat that historically supported the northern dusky 
salamander and found only 2 adult salamanders in the lower reaches of one stream.

Furthermore, no eggs or larvae were observed. Thus, indicating that even large populations of northern dusky salamanders can be extirpated. Although the cause for the observed decline of the northern dusky salamander population is unknown, Bank et al. (2006) identified multiple stressors including stocking of predatory fish, fungal pathogens, substrate embeddedness and widespread pollution (i.e., from atmospheric pollutants) as possible causes.

Condition 3: Patches are not too isolated to prevent recolonization. In several studies (Barbour et al. 1969; Houck and Bellis 1972; Ashton 1975), northern dusky salamanders have been reported to migrate distances of $17 \mathrm{~m}, 40 \mathrm{~m}$, and $20 \mathrm{~m}$, respectively. Furthermore, Berven and Grudzien (1990), Sjogren (1991), Vos and Chardon (1998), Newman and Squire (2001), Conroy and Brook (2003) all use $1 \mathrm{~km}$ as the estimated distance beyond which amphibian populations would be isolated from dispersal events. Likewise, Smith and Green (2005) report that $94 \%$ of the maximum dispersal distances for salamanders are less than $1 \mathrm{~km}$ and the frequency distribution of distances was an inverse power function. Thus, indicating that most salamanders may not move far, but some individuals may complete long-distance movements.

Condition 4: Local dynamics are sufficiently asynchronous to make simultaneous extinction of all local populations unlikely. Because of the varied topography in the eastern United States, many small isolated watersheds are present, and thus simultaneous extinction of all populations due to a localized disturbance is highly unlikely.

\section{Salamanders}

According to the USGS (2006), the general population trend of salamanders is relatively unknown because data are few, scattered, research oriented rather than monitoring 
oriented, largely unpublished and provide little information about the regional stability of salamanders. Because of their dependence to the forest floor, a water source and their sensitivity to toxins, semi-aquatic salamanders are more likely to indicate significant environmental changes than any other North American amphibian (USGS 2004). Rationale for monitoring salamanders includes their key role and high densities in many forests, their stability in counts, vulnerability to air and water pollution, sensitivity as a measure of change, and the threatened and endangered status of several species (USGS 2004).

Worldwide there are 10 existing families of salamanders (with approximately 415 described species) belonging to the amphibian order Caudata. In the Americas (North, Central, and South), there are more species of salamanders than the rest of the world combined and within the U.S., there are 9 families with 148 described species (Hulse et al. 2001). Of the 9 U.S. salamander families, 5 are native to the northeastern U.S. (Hulse et al. 2001) including the Cryptobranchidae (Giant salamanders), Proteidae (Mudpuppies and Waterdogs), Ambystomatidae (Mole salamanders), Salamandridae (Newts), and Pletholontidae (Lungless salamanders). Within these 5 northeastern families, 23 species of salamanders exist and their size ranges from approximately $5 \mathrm{~cm}$ to nearly $122 \mathrm{~cm}$ in length (Conant and Collins 1998). Seventeen species are found in Pennsylvania (Table 1).

Salamanders, unlike lizards, have smooth moist skin and are clawless (Conant and Collins 1998). Other characteristics of salamanders include a life span of $\geq 20$ years (Hairston and Wiley 1993), high adult survivorship, low fecundity, parental behavior such as guarding their eggs, sexual maturity reached in 2 years for most species and elimination of the energetic costs of lungs and ventilation by respiring directly through their moist skin (White 1987). Furthermore, salamanders can go for months without eating (Feder 1983), their body 
temperatures fluctuate with the local substrate (Feder 1982) and they store fat in their tails. They may occupy undisturbed forest floors with biomass equal to, or exceeding, the biomass of other vertebrate groups (Burton and Likens 1975a, Hairston and Wiley 1993) and they achieve their highest densities in ancient or undisturbed forests (Welsh 1990, Meier et al. 1996). In Monongahela National Forest, West Virginia, up to 25 species (Green and Pauley 1987) can occur in the oak-dominated stands and densities for some species reaching up to 2,118 individuals/ha (Klein 1960). Finally, most salamanders are more active at night because the environmental conditions (i.e., higher humidity, lower temperatures) are better for surface activity (Hulse et al. 2001).

Physiologically, the salamander's moist skin is highly glandular with 2 types of skin glands: mucous glands that moisten the skin and poison glands to which the degree of toxicity varies greatly (Hulse et al. 2001). Salamanders are so dependent on water that they can dehydrate even when the air is saturated with moisture (Feder 1983). Most species of salamanders have an aquatic larval stage before maturing into terrestrial adults (Hulse et al. 2001) in about 2-3 years. All adult salamanders are carnivorous (Hulse et al. 2001) and can convert $60 \%$ of their ingested food into tissue (Burtons and Likens 1975b). Salamanders have 10 cranial nerves and possess a 3-chambered heart (Hulse et al. 2001).

Courtship and mating between a male and female salamander varies with respect to species, but can occur on land or in water (Hulse et al. 2001). In general, the courtship is initiated when a male approaches a female, and using his chin, touches the female's body or head. If the female is receptive, she will then follow the male to a nesting site (Hulse et al. 2001). The male salamander then deposits a gelatinous packet of sperm on the ground and the female picks up the sperm with her cloacae and usually stores the sperm in a spermatheca 
until the eggs are ready for fertilization (Hulse et al. 2001). The process may occur in the spring, summer, or fall and eggs are laid either on land or in water. No matter where the eggs are laid, they are concealed by vegetation, rocks, leaf litter, or other earthy material (Hulse et al. 2001). When the eggs hatch, gilled larvae emerge (Hulse et al. 2001).

\section{Northern dusky salamanders (Desmognathus fuscus fuscus)}

Northern dusky salamanders belong to the family Plethodontidae and the genus Desmognathus, which contains 12 species. Their habitat ranges along the East Coast as far north as Maine and as far south as South Carolina and as far west as western Kentucky (Figure 12) with many confirmed sites in Pennsylvania (Figure 13). Dusky salamanders (Desmognathus fuscus) can be identified by a lighter colored lateral eye stripe that extends from the eye to the angle of the jaw (Appendix 2). Dusky salamanders are a semi-aquatic species that prefer seeps, runs, and small streams without predatory fish (Hulse et al. 2001). Young northern dusky salamanders are more vividly patterned than adults, but all salamanders of this species can be identified by their yellow to grayish brown bodies that have a wide dorsal stripe (Appendix 3) and a series of 5-8 pairs of yellowish spots connected by a dark wavy band (Hulse et al. 2001). Northern dusky salamanders also have a keeled tail (Appendix 4) and exhibit caudal autonomy (Hulse et al. 2001).

In Pennsylvania, mature northern dusky males have a mean snout to vent length (SVL) of $51.2 \mathrm{~mm}$ and a mean total length (ToL) of $94 \mathrm{~mm}$ with mature females usually being shorter $($ SVL mean $=46.2 \mathrm{~mm}$; ToL mean $=86.3 \mathrm{~mm})$ than mature males $($ Hulse et al. 2001). However, Davic (1983) showed that the mean length values of the salamanders can have large interpopulation variation. Grant et al. (2004) determined that adult northern dusky salamanders in the Shenandoah National Park, Virginia, had a mean SVL of $43+/-1.0 \mathrm{~mm}$ 
and a mean ToL of $76+/-1.9 \mathrm{~mm}$, while juvenile northern dusky salamanders had a mean SVL of $23+/-0.8 \mathrm{~mm}$ and a mean ToL of $41+/-1.6 \mathrm{~mm}$. Furthermore, Grover (2000) reported that the northern dusky salamanders at Mountain Lake, Virginia, ranged from 38.9$65.2 \mathrm{~mm} \mathrm{SVL}$ (mean $51.1 \mathrm{~mm}$ ); 5.7-9.9 mm in width (mean $8.0 \mathrm{~mm}$ ) and a mass of 1.28-6.24 $\mathrm{g}$ (mean $3.19 \mathrm{~g}$ ). Males can be distinguished from females by the presence of mental glands (i.e., subdentary glands, a cluster of glands on the chin of a male salamander most noticeable during the breeding season) and a heavier lower jaw musculature. The presence of yoked follicles in the female abdomen may also be used to determine the sex of the northern dusky salamander (Hulse et al. 2001).

Hulse et al. (2001) reported that a retreat site of northern dusky salamanders averaged less than 1 meter from flowing water and Grover (2000) reported that the northern dusky salamanders found had a mean distance from water of $106.2 \mathrm{~cm}(n=111)$ during the day and $188.2 \mathrm{~cm}(n=90)$ during the night. Northern dusky salamanders are active at night, but can be found undercover during day. More specifically, in Kentucky, Barbour et al. (1969) determined that the most active daily periods (between mid May through mid-July) were 0800 and 2300 while the least active periods were 0300 and 1600. Furthermore, Barbour et al. (1969) determined that the most active animals were adult males and females, while the most quiescent were gravid females. Similarly, Keen and Sharp (1984) found that their most active time occurs shortly after sunset during dry spells, but are continuously active (dusk to dawn) during warm moist periods. Grover (2000) determined that northern dusky salamanders have a tendency to occupy wet retreats in or near the stream but moved upstream to drier microenvironments when actively foraging. Finally, Grover (2000) reports that surface-active northern dusky salamanders were found significantly farther from water during spring and 
summer than when in their winter retreat sites with the peak activity period for northern dusky salamanders occurring in the spring and summer; however, they can be active all year round if an unfrozen water source is present.

Grover (2000) determined that the retreats and substratum occupied by northern dusky salamanders were usually saturated with water and that the mean retreat temperature was $16.5^{\circ} \mathrm{C}$, cooler than 3 other terrestrial salamander species studied. Ashton (1975) investigated the movement and home range for summer and winter months of the northern dusky salamander and found that during the spring to fall season, the salamander's home range varied from $0.11 \mathrm{~m}^{2}$ to $3.6 \mathrm{~m}^{2}$ with an average of $1.44 \mathrm{~m}^{2}$. During cold winters, the salamanders burrow below the frost line where they continue to feed in their subterranean retreats. However, Ashton (1975) documented that the winter movements prior to the final retreat site $30-50 \mathrm{~cm}$ below the surface was considerably within their home ranges. However, these particular home range data varies greatly with the data from Barbour et al. (1969), who determined the average home range to be $48.4 \mathrm{~m}^{2}$ (ranging from $0.81 \mathrm{~m}^{2}$ to $114.54 \mathrm{~m}^{2}$ ). It should be noted, though, that the Barbour et al. (1969) study occurred during a drought season and thus water stress may have contributed to the increase in home range. Additionally, 4 of the 14 salamanders studied by Barbour et al. (1969) had a home range of less than $7 \mathrm{~m}^{2}$. It also should be noted that both Ashton (1975) and Barbour et al. (1969) reported maximum migration distances of $20 \mathrm{~m}$ and $17 \mathrm{~m}$, respectively. Hall (1977) found 1 animal per $0.8 \mathrm{~m}^{2}$ of stream bank in Tioga County, Pennsylvania, while Burton and Likens (1975) found a density of 1 animal per $26.3 \mathrm{~m}^{2}$ in 1970 and 1 animal per $32.3 \mathrm{~m}^{2}$ in 1971. In Gaston County, North Carolina, Spight (1967) found a density range of 0.43-1.42 individuals $/ \mathrm{m}^{2}$, with an estimated biomass of $0.097-0.32 \mathrm{~g} / \mathrm{m}^{2}$. 
Grover (2000) reported that smaller salamanders generally dehydrate more rapidly than larger salamanders and terrestrial salamanders (Plethodon cinereus and Plethodon glutinosus) generally re-hydrate faster than semi-aquatic salamanders (Desmognathus fuscus). More specifically, the dehydration and re-hydration rates of the northern dusky salamander were 44.2 milligrams per gram per hour $(\mathrm{mg} / \mathrm{g} / \mathrm{h})$ and $8.7 \mathrm{mg} / \mathrm{g} / \mathrm{h}$, respectively. Finally, Grover (2000) reported that salamanders that occupied relatively drier habitats were able to withstand greater dehydration and had faster recovery than species that occupied wetter habitats.

The carnivorous northern dusky salamander feeds primarily on small aquatic and terrestrial invertebrates including adult and larval flies (Diptera), ants (Formicidae), centipedes (Chilopoda), mayflies (Ephemeroptera), adult and larval beetles (Coleoptera), amphipods (Amphipoda) and snails (Gastopoda) (Hulse et al. 2001). Raimondo et al. (2003) reported that in the Monongahela National Forest, West Virginia, the northern dusky salamander primarily fed upon flies (Diptera), bur spiders (Araneae), beetles (Coleoptera) and ants (Hymenoptera: Formicidae). Hulse et al. (2001) indicates that northern dusky salamanders are opportunistic and feed on whatever invertebrates are present. For example, in Westmoreland County, Pennsylvania, Krzysik (1979) determined that northern dusky salamanders fed on not only adult and larvae of flies, but also moths.

Mating of the northern dusky salamander involves a spring courtship with the follicles maturing by mid June and oviposition occurring in July. In Pennsylvania, the average clutch size is 28.6 eggs (range 18-51) with most nesting occurring under rocks (Hulse et al. 2001). Eggs are generally protected by the female and in Ohio, Juterbock (1987) showed a 100\% mortality of eggs that were left unattended. Egg incubation generally lasts 40-60 days with 
hatchlings emerging as early as August but as late as the beginning of October (Hulse et al. 2001). When the hatchlings emerge, they are generally $10.5-12 \mathrm{~mm}$ in size and reach adult size during May or June of the following year (Hulse et al. 2001); however, the hatchlings don't reach sexual maturity usually until 1 year later. Females can reproduce annually.

\section{Cover items (also known as cover boards)}

There are many methods used to capture salamanders; however, leaf litter trapping tends to capture larger individuals (>15 mm SVL) while dip netting tends to capture smaller individuals (Nowakowski and Maerz 2009). However, the use of cover items, to estimate a salamander population has become a more common practice because of the cover item's relatively non-disruptive impact on the ecosystem, the ability to attract species that are difficult to trap in pitfalls, minimized observer biases and errors, and the cover boards can be used to develop a reliable index of population size (Heyer et al. 2001). Although there are many different types and sizes of cover items, using them allows for certain advantages such as being able to have a standard number of cover items of standard size, little betweenobserver variability, limited disturbance to natural cover items, modest investment of time and money, limited training required and easy maintenance (Heyer et al. 2001). Other advantages include the observer's ability to control the time of day and season the data are collected, the habitat type in which the cover items are placed and the cover items can be checked several times to accommodate seasonal differences. Furthermore, Marsh and Goicochea (2003) reported that salamanders are able to hide in holes in and under natural objects, but an advantage of using artificial cover board is that they are easier to see under artificial cover boards. Some disadvantages of using cover items include: they provide only an index of population, the use of cover items varies with species and availability of natural cover, counts 
vary with local weather, and they may be difficult to locate in thick brush. The number of cover boards needed for adequate statistical analysis depends on heterogeneity of the habitat, site fidelity of the organisms, the size of the area to be sampled and whether species presence or individual abundance is needed (Heyer et al. 2001).

The number of cover items used per site depends upon the number of salamanders discovered. The USGS (2006) recommends there be an average of $\geq 10$ salamanders discovered per site so the USGS North American Amphibian Monitoring Program (NAAMP) recommends that there be 100 cover items in areas with low salamander density, 50 in areas with moderate densities and 25 in areas with high densities. According to de Maynadier and Hunter (1995), most species of salamanders are impacted by an "edge effect" to a distance of 25-35 m, thus cover items should not be placed in any of these areas. The number of cover boards used in other Plethodon studies have ranged from as few as 15 to more than 300 (Marsh and Goicochea 2003 [ $n=169$ ], Raimondo et al. 2003 [ $n=320]$, Bailey et al. 2004 [ $n$ $=100]$ ). Finally, the NAAMP recommends placing cover boards next to one another to eliminate interspecies and intraspecies territoriality.

Cover items can be made from a variety of substrate (i.e., metal, brick or wood), but wood should be used as the substrate for cover boards as they tend to work best at attracting organisms (Monti 1995). The boards should be replaced if they are cracked because they do not provide the same microhabitat as full sized cover boards. Near Mountain Lake, Virginia, of the 350 northern dusky salamanders captured $51 \%(n=178)$ were found under wood, $38 \%$ $(n=134)$ were found under rock, and $11 \%(n=38)$ under litter (Grover 2000). Although there has been no studies published on the species of wood that is preferred by a particular species of salamander, "green" wood (untreated lumber from a local saw mill) which has been 
recently cut ( $<1$ year) works the better as opposed to kiln dried wood from a local lumber yard (USGS 2004). Furthermore, northern dusky salamanders in Virginia prefer cover objects that were natural (rock) or artificial (wood) averaging $23.7 \mathrm{~cm}$ and $108.8 \mathrm{~cm}$ in length, $16.0 \mathrm{~cm}$ and $10.3 \mathrm{~cm}$ in width, and $4.6 \mathrm{~cm}$ and $7.6 \mathrm{~cm}$ in thickness, respectively (Grover 2000). In Ohio, northern dusky salamanders used wet leaves, logs, and bark for retreat sites $24 \%$ of the time (Ashton 1975).

Variability in cover board thickness has an impact on the cover board's suitability to salamanders. More specifically, Heyer et al. (2001) reports that $0.5 \mathrm{~cm}$ thick cover boards were not as suitable for monitoring salamanders because the boards do not maintain a high enough moisture content and or stable environment. Salamanders appear to be more attracted to smaller cover boards $(18 \mathrm{~cm} \times 107 \mathrm{~cm} \times 1.25 \mathrm{~cm})$ than larger ones $(61 \mathrm{~cm} \times 122 \mathrm{~cm} \times 1$ $\mathrm{cm}$ ) because the larger boards tend to dry out the soil beneath them and the USGS (2004) recommends the use of $30 \mathrm{~cm} \times 30 \mathrm{~cm} \times 2.5 \mathrm{~cm}$ boards (USGS 2004). Hulse et al. (2001) recommends the use of cover boards that are $30 \mathrm{~cm} \times 30 \mathrm{~cm} \times 5 \mathrm{~cm}$. Cover boards should be placed in the spring when there is high air moisture, calm wind conditions, high soil and litter moisture and low but above freezing temperatures (USGS 2004). These physiological conditions are optimal to encourage salamanders to move out of the soil and under the cover boards (Feder 1983). In general, spring sampling should occur after complete thawing of the soil column which occurs when temperatures are around $3-6^{\circ} \mathrm{C}$ (upper $30 \mathrm{~s}-$ lower $40^{\circ} \mathrm{F}$ ) and sampling should stop about 2 months after that date (USGS 2004). Fall sampling should occur one month before the average hard freeze and end with the first hard freeze. 


\section{Stream reach habitat}

The main determinant for a study area for this research is the presence of a water source such as a first or second order stream, seep and run with a secondary requirement being the presence of rural forests. Thus, a particular stream reach can be categorized as either disturbed or undisturbed (i.e., fragmented or unfragmented) by having a forest cover of $55 \mathrm{~m}$ in all directions. This $55 \mathrm{~m}$ value incorporates the $20 \mathrm{~m}$ migration distance determined by Ashton (1975) and the $35 \mathrm{~m}$ buffer zone from the impacts of an edge suggested by de Maynadier and Hunter (1995). Others have determined a $27 \mathrm{~m}$ core habitat distance that encompasses 95\% of 4 Plethodon species (Crawford and Semlitsch 2007). Thus, a single first order stream would need a minimum of $55 \mathrm{~m}$ of forest cover on each side to be considered unfragmented, any forest patch smaller than this value would be considered fragmented (Figure 14). Furthermore, a stream, seep, or run would be considered isolated if there were no other stream, seep, or run within $20 \mathrm{~m}$ (Figure 15). Although the home ranges of the northern dusky are considerably smaller, the maximum distance traveled needs to be incorporated to eliminate migration from one water source to another. If a first order stream drains into a lake, pond, or a larger stream (one that contains predatory fish), then the lake, pond, or larger stream will be considered a habitat barrier.

If 2 low order streams connect in a suitable habitat, there will be at some point, a distance too great between the 2 streams that will prohibit the movement of northern dusky salamanders from one stream to the other (Figure 16). However, there may be migration down one tributary and up the other. Furthermore, unfragmented forested low-order streams crossed by a walking trail, trail bridge, culvert pipe, road (dirt or paved) or any other structure may prohibit the lateral migration of northern dusky salamanders from upstream to 
downstream, and vice versa. Thus, the continuous stream habitat may actually be several fragmented habitats, leading to geographically isolated salamander populations (Figure 17).

As recommended by Southerland et al. (2007), small first and second order streams can be located using USGS topographic maps, aerial photographs, United States Department of Agriculture (USDA) soil conservation maps or other GIS information. In 2000, Wayne L. Myers and Joseph A. Bishop from Pennsylvania State University created the Pennsylvania conservation GAP amphibian habitat model (at the 30-m resolution) for the dusky salamander as part of the Gap Analysis Program (PASDA 2006). This GIS data represents preferred habitat for the dusky salamander in Pennsylvania and the model associates occurrence of preferred habitat with key environmental factors that can be mapped over the entire state (PASDA 2006). Meyers and Bishop (PASDA 2006) used the following key factors to determine potential dusky salamander habitat: vegetative land cover, presence of human activity and disturbance, elevation, slope, aspect, topographic position, wetland characteristics, stream size and location (PASDA 2006). Areas of potential species presence, what Meyers and Bishop call "preferred" habitat, was tabulated based on current and historical information and a series of conditional statements proceeded using layers derived to depict the key factors on a landscape scale (PASDA 2006). In addition to the previously described variables, a minimum area variable was included to help locate areas suitable for species that are sensitive to landscape fragmentation. All this information was reviewed by Art Hulse of Indiana University of Pennsylvania, Indiana Pennsylvania (PASDA 2006).

\section{Models and model evaluation}

Models of data are used in the empirical sciences to make inferences concerning both processes and parameters of interest and modeling is important because the parameters used 
within the model and the relation expressed between and among variables allow us to make statistical inferences to real or conceptual ideas such as populations (Burnham and Anderson 2002). A priori model creation needs careful attention to not over-parameterize and "data dredge" (Burnham and Anderson 2002); however, the first step in an a priori model strategy is to develop a global model that includes all measured parameters and then the development of plausible candidate models that use only some of the measured parameters (Burnham and Anderson 2002). Selection of the best model can be completed by a number of statistical criteria and these criteria may appear to be superior to graphical and parameter variability criteria because they are less subjective; however, all these criteria should be used together in making one's decision about the best model (Bourne 2006).

One such statistical criterion to evaluate the goodness of fit of a set of models is Akaike's Information Criterion (AIC) that can be corrected for small sample sizes $\left(\mathrm{AIC}_{\mathrm{c}}\right)$. The original information criterion was developed by Hirotsugu Akaike in 1971 and proposed in Akaike (1974); AIC is a measure of the "goodness of fit" of an estimated statistical model (Burnham and Anderson 2002). $\mathrm{AIC}_{\mathrm{c}}$ is grounded in the concept of entropy and is an operational way of trading off the complexity of an estimated model against how well the model fits the data (Burnham and Anderson 2002). Anderson et al. (1994), Burnham et al. (1994), Burnham et al. (1995) have all reported that $\mathrm{AIC}_{\mathrm{c}}$ has performed well in simulation studies with mark-recapture or depletion models, while Lebreton et al. (1992), and Burnham and Anderson (2002) have indicated it is the recommended approach to model selection in mark-recapture studies.

Mathematically, $\mathrm{AIC}_{\mathrm{c}}$ can be expressed as:

$$
\mathrm{AIC}_{\mathrm{c}}=\left(2 K-2 L_{m}\right)+\frac{2 K(K+1)}{n-K-1}
$$


where $L_{m}$ is the maximized log-likelihood, $\mathrm{K}$ is the number of parameters in the model and $n$ is the number of observations. The index takes into account both the statistical goodness of fit and the number of parameters that have to be estimated to achieve this particular degree of fit by imposing a penalty for increasing the number of parameters (Everitt 2002). When comparing 2 or more models, the lowest number is best (Bourne 2006).

\section{Projecting salamander density}

When estimating salamander density, one must be sure to indicate whether the study estimates the surface density or the super density (population of salamanders both on and beneath the surface). A variety of methods for estimating the surface density can be used, but the recommended methods for amphibian studies are the mark-recapture method and the depletion method (Heyer et al. 1991). A visual encounter survey (VES) as recommended by Southerland et al. (2007) and Bank et al. (2006) can be used as a removal method within a stream and its channel. A 3-pass or 4-pass method (Southerland et al. 2007) such that after the $3^{\text {rd }}$ pass, a $4^{\text {th }}$ pass needs to be completed if the total number of captures for the $1^{\text {st }}$ and $2^{\text {nd }}$ were less than the number of captures for $3^{\text {rd }}$ pass.

Examples of several 2-sample mark and recapture methods are: the Peterson Index, Bailey's modification of the Peterson index, and Chapman's modification of the Peterson Index, while the Triple Catch model requires 3-samples, and the Weighted mean, Fisher-Ford, Schumacher, Jackson's positive, Jackson's negative, Manly-Parr, and the Jolly-Seber methods require several samples (Gans and Huey 1988, Heyer et al. 2001). Both the mark and recapture method and the depletion method are considered labor intensive and are 
recommended when researchers require detailed knowledge of the target population (Bailey et al. 2004).

Mark-recapture estimators are separated into 3 classes: closed-population, openpopulation, and robust design models (Bailey et al. 2004), with each having several assumptions. Previous salamander studies have used a 2-sample closed population method (Burton and Likens 1975b, Welsh 1990), and other studies have used the more than 2-sample closed population methods: Schabel's (Stewart and Bellis 1970, Howard et al. 1987, Smith and Petranka 2000), and Schumacher-Eschmeyer (Semlitsch 1980, Howard et al. 1987). Some researchers have used an open population method, such as the Jolly-Seber model (Hall 1977, Tilley 1980, Welsh 1990, Marvin 1996) while others have used a depletion method (Petranka and Murray 2001). Bailey et al. (2004) is considered the most extensive terrestrial study that focuses on density estimates and used the robust design and reports that many studies were conducted only on 1 to 4 sites, but resulted in low effective capture probabilities $(P<0.15)$ and imprecise density estimates. Thus, Bailey et al. (2004) recommends the use of Pollock's robust design in mark-recapture studies because of its flexibility to incorporate variation in capture probabilities and to estimate temporal emigration probabilities.

Bailey et al. (2004) indicated that models used for estimating salamander density (both surface and super densities) include parameters incorporating random temporary emigration (most important) and behavioral effects in capture probabilities are better than models that estimate salamander densities using just equal capture probabilities. Bailey et al. (2007) also recommends that there needs to be a balance between spatial replication (no. sample sites/area) and temporal replication (no. of repeated surveys) when designing a sampling regime. Robust design models are a combination of the opened (such as the Jolly-Seber) and 
closed-population (such as the Lincoln Peterson) models. With a robust design, a long-term study of an open population can be viewed as a sequence of short-term studies of a closed population (Williams et al. 2002). Two distinctive advantages of using a robust design include: 1) a more robust estimation of model parameters and 2) an estimation of parameters not otherwise estimable with either an open or a closed model, when conducted separately (Williams et al. 2002). 


\section{LITERATURE CITED}

Aalen, F.H.A. 1997. Management of the landscape. In F.H.A. Aalen, K. Whelan, and M. Stout. (eds.), 1992. Atlas of the Irish rural landscape. Cork University Press, Cork, Ireland.

Adair, S.M., L. Dereske, J. Doyle, A. Edwards, S. Jacobson, R. Jemison, L. Lewis, W. Melgin, C. Napper, T. Ratcliff, and T. Warhol. 2002. Management and techniques for riparian restorations. United States Department of Agriculture, Forest Service, Rocky Mountain Research Center, Research Note: RMRS-CTR-102.

Akaike, H. 1974. Maximum likelihood identification of Gaussian autoregressive moving average models. Biometrica 60:255-265.

Anderson, D.R., K.P. Burnham, and G.C. White. 1994. AIC model selection in over dispersed capture-recapture data. Ecology 75:1780-1793.

Ashton, R.E., Jr. 1975. A study of movement, home range, and winter behavior of Desmognathus fuscus. Journal of Herpetology 9:85-91.

Baguette, M., and N. Schtickzelle. 2005. Negative relationship between dispersal distance and demography in butterfly metapopulations. Ecology 87:648-654.

Bailey, L.L., T. Simmons, and K.H. Pollock. 2004. Temporal and spatial variation in detection probability of Plethodon salamanders using robust capture-recapture design. Journal of Wildlife Management 68:1-13.

Bailey, L.L., J.E. Hines, J.D. Nichols, and D.I MacKenzie. 2007. Sampling design trade-offs in occupancy studies with imperfect detection; examples and software. Ecological Applications 17:281-290.

Bank, M.S., J.B. Crocker, S. Davis, D.K. Brotherton, R. Cook, J. Behler, and B. Connery. 2006. Population decline of northern dusky salamanders at Acadia National Park, Maine, USA. Biological Conservation 130:230-238.

Barbour, R.W., J.W. Hardin, J.P. Schafer, and M.J. Harvey. 1969. Home range, movements, and activity of the dusky salamander, Desmognathus fuscus. Copeia 1969:293-297.

BeeBee, T.J.C., and G. Rowe. 2005. Intraspecific competition disadvantages inbred Natterjack toad (Bufo calamit) genotypes over out bred ones in a shared pond environment. Journal of Animal Ecology 74:71-76.

Belisle, M., and C.C. St. Clair. 2001. Cumulative effects of barriers on the movements of forest birds. Conservation Ecology 5:9. [online] URL: http://www.consecol.org/vol5/iss2/art9. 
Berven, K.A., and T.A. Grudzien. 1990. Dispersal in the wood frog (Rana sylvatica): implications for genetic population structure. Evolution 44:2047-2056.

Beschta, R.L., and W.S. Platts. 1986. Morphological features of small streams: significance and function. Water Resources Bulletin 22:369-379.

Bourne, D.W.A. 2006. MultiForte and Boomer: Non-linear regression programs for the analysis of pharmacokinetic and pharmacodynamic data. Oklahoma University: College of Pharmacy. Boomer Statistical Criteria: http://www.boomer.org/c/p3/c19/c1904.html

Burnham, K.P., and D.R. Anderson. 2002. Model selection and inference: a practical information-theoretic approach. Springer-Verlag, New York, New York, USA.

Burnham, K.P., D.R. Anderson, and G.C. White. 1994. Evaluation of the Killback-Lieber discrepancy for model selection in open population capture-recapture models. Journal of Biometrics 36:299-315.

Burnham, K.P., D.R. Anderson, and G.C. White. 1995. Model selection strategy in the analysis of capture-recapture data. Journal of Biometrics 51:888-898.

Burton, T.M., and G.E. Likens. 1975a. Energy flow and nutrient cycling in salamander populations in the Hubbard Brooks Experimental Forest, New Hampshire. Ecology 56:1068-1080.

. 1975b. Salamander populations and biomass in the Hubbard Brook Experimental Forest, New Hampshire. Copeia 1975:541-546.

Chambers, D.L. 2008. Logging road effects on breeding site selection in Notophthalus viridescens (red-spotted newt) and three Ambystomatid salamanders in south-central Pennsylvania. Northeastern Naturalist 15:123-130.

Conant, R., and J.T. Collins. 1998. Reptiles and amphibians: Eastern and Central North America. Houghton Mifflin Company, New York, New York, USA.

Conroy, S.D., and B.W. Brook. 2003. Demographic sensitivity and persistence of the whiteand orange-bellied frogs of western Australia. Population Ecology 45:105-114.

Crawford, J.A., and R.P. Semlitsch. 2007. Estimation of Core Terrestrial Habitat for stream breeding salamanders and delineation of riparian buffers for protection of biodiversity. Conservation Biology 21:152-158.

Davic, R.D. 1983. Micrographic body size variation in Desmognathus fuscus fuscus salamanders from Western Pennsylvania. Copeia 1983:1101-1114. 
Davies, K.F., C. Gascon, and C.R. Margules. 2001. Habitat fragmentation: consequences, management, and future research priorities. In M.E. Soule and G.H. Orians (eds.). 1997. Conservation Biology, Island Press, Washington D.C., USA.

de Maynadier, P.G., and M.L. Hunter, Jr. 1995. The relationship between forest management and amphibian ecology: a review of the North American literature. Environmental Review 3:230-261.

Department of Conservation of Natural Resources. 2005. Pennsylvania State Parks. http://www.dcnr.state.pa.us/stateparks/parks/raccooncreek.aspx. 2005.

b. Pennsylvania State Parks. 2005. http://www.dcnr.state.pa.us/stateparks/parks/lynnrun.aspx.

Everitt, B.S. 2002. The Cambridge dictionary of statistics. 2nd edition. King's College, London, UK.

Fahrig, L., J.H. Pedlar, S.E. Pope, P.D. Taylor, and J.F. Wegner. 1995. Effects of road traffic on amphibian densities. Biological Conservation 73:177-182.

Feder, M.E. 1983. Integrating the ecology and physiology of plethodontid salamanders. Herpetologica 39:291-310. , 1982. Thermal ecology of neotropical lungless salamanders (Amphibia: Plethodontidae): environmental temperatures and behavioral responses. Ecology 63:16571164.

Gans, C. and R.B. Huey. 1988. Biology of the reptilia: defense and life history. Alan R. Liss, Inc., New York, New York, USA.

Gavrilets, S., R. Acto, and J. Gravner. 2000. Dynamics of speciation and diversification in a metapopulation. Evolution 54:1493-1501.

Graham, C., J.E. Martinez-Levva, and L.C. Paredes. 2002. Use of fruiting trees by birds in continuous forest and riparian forest remnants in Los Tuxtlas, Veracruz, Mexico. Biotropica 34:589-597.

Grant, E., H. Cambell, R.E. Jung, and K.C. Rice. 2004. Stream salamander species richness and abundance in relation to environmental factors in Shenandoah National Park, Virginia. American Midland Naturalist 153:348-356.

Green, N.B., and T.K. Pauley. 1987. Amphibians and reptiles in West Virginia. University of Pittsburgh Press, Pittsburgh, PA. 
Grover, M.C., 2000. Determinants of salamander distributions along moisture gradients. Copeia 2000:156-168.

Hairston, N.G. Sr., and R.H. Wiley. 1993. No decline in salamander (Amphibia: Caudata) populations: a twenty-year study in the southern Appalachians. Brimeyana 1.

Hakoyama, H., and Y. Iwasa. 2004. Extinction risk of a metapopulation: aggregation approach. Journal of Theoretical Biology 232:203-216.

Hall, R.J. 1977. A population analysis of two species of streamside salamanders, genus Desmognathus. Herpetologica 33:109-113.

Hanski, I. 1999. Habitat connectivity, habitat continuity, and metapopulations in dynamic landscapes. Oikos 87:209-218.

Hanski, I., and M. Gilpin. 1997. Metapopulation biology: ecology, genetics, and evolution. Academic Press. New York, New York, USA.

Harris, L.D. and G. Silva-Lopez, 1992. Forest fragmentation and the conservation of biological diversity. Chapman and Hall, New York, New York, USA.

Harris, L.D., 1984. The fragmented forest: Island biogeography theory and the preservation of biotic diversity. University of Chicago Press, Chicago, Illinois, USA.

Heinz, H.J. III, Center for Science, Economics and the Environment. 2002. The state of the nation's ecosystems. Cambridge University Press, New York, New York, USA.

Henle, K., P. Poschlod, C. Margules, and J. Settele. 1996. Species survival in relation to habitat quality, size and isolation: Summary conclusions and future directions. In J. Settele, C. Margules, and P. Poschlod (eds) Species survival in fragmented landscapes. Kluwer Academic Publishers, Norwell, Massachusetts, USA.

Heyer, R., M. Donnelly, R. McDiarmid, L. Hayek, and M. Foster. 2001. Measuring and monitoring biological diversity: standard methods for amphibians. Smithsonian Institution Press, Washington D.C., USA.

Houck, M.A., and E.D. Bellis. 1972. Comparative tolerance to desiccation in Desmognathus f. fuscus and Desmognathus o. ochrophaeus. Journal of Herpetology 6:209-215.

Howard, V.W., K.M. Cheap, R.H. Hier, T.G. Thompson, and J.A. Dimas. 1987. Effects of cabling pinyon-juniper on mule deer and lagomorphs use. Wildlife Society Bulletin $15: 242-247$. 
Hulse, A.C., C.J. McCoy, and E.J. Censky. 2001. Amphibians and reptiles of Pennsylvania and the Northeast. Cornell University Press. Ithaca, New York, USA.

Jackson, S.D. 2003. Ecological considerations in the design of river and stream crossings, In C. L. Irwin, P. Garret, and K. P. McDermott (Eds.), 2003 Proceedings of the International Conference on Ecology and Transportation. Raleigh, North Carolina: Center for Transportation and the Environment, North Carolina State University.

Juterbock, J.E. 1987. The nesting behavior of the dusky salamander, Desmognathus fuscus. II. Nest site tenacity and disturbance. Herpetologica 43:361-368.

Keen, W.H., and S. Sharp. 1984. Responses of a plethodontid salamander to conspecific and congeneric intruders. Animal Behavior 32:58-65.

Klein, H. 1960. Population estimates of the red-backed salamander. Herpetologica 16:52-55.

Krzysik, A.J. 1979. Resource allocation, coexistence, and the niche structure of a stream bank salamander community. Ecological Monographs 49:173-194.

Lebreton, J.D., K.P. Burnham, J. Clobert, and D.R. Anderson. 1992. Modeling survival and testing biological hypotheses using marked animals: a unified approach with case studies. Ecological Monographs 62:67-118.

Levins, R. 1969. Some demographic and genetic consequences of environmental heterogeneity for biological control. Bulletin of the Entomological Society of America 15:237-240.

Levins, R. 1970. Review of: an introduction of mathematical ecology by E. C. Pielou. Evolution 24:482.

Little, L.R., A.D.M. Smith, and A.D. McDonald. 2005. Effects of size and fragmentation of marine reserves and fisher infringement on the catch and biomass of the coral trout, Plectropomus leopardus, on the Great Barrier Reef, Australia. Fisheries Management and Ecology 12:177-188.

Lord, J.M., 1990. Scale and spatial concept of fragmentation. Conservation Biology 4:197202.

MacArthur R.H., and E.O. Wilson. 1967. The theory of island biogeography, Princeton, New Jersey, Princeton University Press.

Mader, H.J. 1984. Animal habitat isolation by roads and agricultural fields. Biological Conservation 29:81-96. 
Marsh, D.M., and M.A. Goicochea. 2003. Monitoring terrestrial salamanders: biases caused by intense sampling and choice of cover objects. Journal of Herpetology 37:460-466.

Marvin, G.A. 1996. Life history and population characteristics of the salamander Plethodon kentucki with a review of Plethodon life histories. American Midland Naturalist 136:385400 .

Means, D.B., and J. Travis. 2007. Declines in ravine-inhabiting Dusky salamanders of the southeastern US coastal plain. Southeastern Naturalist 6:83-96.

Meier, A.J., S.P. Bratton, and D.C. Duff. 1996. Biodiversity in the herbaceous land and salamanders in Appalachian primary forests, In M.B. Davis (ed.) Eastern old-forests. Island Press, Washington D. C., USA.

Miller, Jr. G.T. 2000. Living in the Environment: Principles, connections, and solutions. $11^{\text {th }}$ edition. Brooks/Cole Publishing Company, Pacific Grove, California, USA.

Miller, Jr., R.L., D.R. Dewalle, R.P. Brooks, and J.C. Finley. 1997. Long-term impacts of forest road crossings of wetlands in Pennsylvania. Northern Journal of Applied Forestry 14:109-116.

Moilanen, A. 2000. The equilibrium assumption in estimating the parameters of metapopulation models. Journal of Animal Ecology 69:143-153.

Monti, L. 1995. The red-back salamanders (Plethodon cinereus) population in a Maine oakpine forest. Master's thesis, University of Maine.

National Oceanic and Atmospheric Administration, 2005. Division of Normals and Standard Deviations of Temperature, Precipitation, and Heating and Cooling degree Days. http://hurricane.ncdc.noaa.gov/climatenormals/clim85/CLIM85_PRCP02.pdf

Nauman, R.S., and D.H. Olson. 2008. Distribution and conservation of Plethodon salamanders on Federal lands in Siskiyou County, California. Northwestern Naturalist 89:1-9.

Newman, R.A., and T. Squire. 2001. Microsatelite variation and fine-scale population structure in the wood frog (Rana sylvatica). Molecular Ecology 10:1087-1110.

Nowakowski, A.J., and J.C. Maerz. 2009. Estimation of larval stream salamander densities in three proximate streams in the Georgia piedmont. Journal of Herpetology 43:503-509.

Orser, P.N., and D.J. Shure. 1972. Effect of Urbanization on the salamander Desmognathus fuscus fuscus. Ecology 53:1148-1154.

Ohio EPA. 2001. Field evaluation manual for Ohio’s primary headwater habitat streams. Ohio EPA Division of Surface Water, Columbus, OH. 
Pennsylvania Spatial Data Access. 2006. The Pennsylvania Geospatial Data Clearinghouse. http://www.pasda.psu.edu.

Petranka, J.W., and S.S. Murray. 2001. Effectiveness of removal sampling for determining salamander density and biomass: a case study in an Appalachian streamside community. Journal of Herpetology 35:36-44.

Raimondo, S., T.K. Pauley, and L. Butler. 2003. Potential impacts of Bacillus thuringiensis var. kurstaki on five salamander species in West Virginia. Northeastern Naturalist $10: 25-38$.

Roberts, S.A., G.B. Hall, and P.H. Calamai, 2000. Analyzing forest fragmentation using spatial autocorrelation, graphs and GIS. International Journal of Geographical Information Science 14:185-204.

Roth, N.E., T. Southerland, G. Mercurio, J.C. Challou, D.G. Heimbuch, J.C. Seibel, R. Klauda, P. Kazyak, D. Boward, S. Stranko, M. Hurd, and T. Prochaska. 1999. State of the Streams: Results of the 1995-1997 Maryland Biological Stream Survey. Report to Monitoring and Non-Tidal Assessment Division, Maryland Department of Natural Resources, Annapolis, MD.

Saunders, D.A., R.H. Hobbs, and C.R. Margules, 1991. Biological consequences of ecosystem fragmentation: A review. Conservation Biology 5:18-32.

Saurez, A.V., D.T. Bolger, and T.J. Case. 1998. Effects of fragmentation and invasion on native ant communities in coastal Southern California. Ecology 79:2041-2056.

Semlitsch, R.D. 1980. Geographic and local variation in population parameters of the slimy salamander, Plethodon glutinosus. Herpetologica 36:6-16.

Sepulveda A.J., and W.H. Lowe. 2009. Local and landscape influences on the occupancy and density of Dicamptodon aterrimus, the Idaho giant salamander. Journal of Herpetology 43:469-484.

Sjogren, P. 1991. Extinction and isolation gradients in metapopulations: the case of the pool frog (Rana lessonae). Biological Journal of Linnean Society 42:135-147.

Smith, C.K., and J.W. Petranka. 2000. Monitoring terrestrial salamanders: repeatability and validity of area-constrained cover object searches. Journal of Herpetology 34:547-557.

Smith, M.A., and D.M Green. 2005, Dispersal and the metapopulation paradigm in amphibian ecology and conservation: are all amphibian populations metapopulations? Ecography 28:110-128. 
Southerland, M.T., R.E. Jung, J. Volstad, D. Baxter, G. Mercurio, and I.C. Chellman.

Patuxent Wildlife Research Center. 2007. Streamside salamanders as indicators of stream quality in Maryland. http://www.pwrc.usgs.gov/.

Spight, T.M. 1967. Population structure and biomass production by a stream salamander. American Midland Naturalist 78:437-447.

Stewart, G.D. and E.D. Bellis. 1970. Dispersion patterns of salamanders along a brook. Copeia 1970:86-89.

Stouffer, P.C., and R.O. Bierregaard. 1995. Use of Amazonian forest fragments by understory insectivorous birds. Ecology 76:2429-2445.

Tilley, S.G. 1980. Life histories and comparative demography of two salamander populations. Copeia 1980:806-821.

Turner, M.G. 1990. Spatial and temporal analysis of landscape patterns. Landscape Ecology $4: 21-30$.

United States Department of Agriculture, Soil Conservation Service. 1982a. Pennsylvania State University, College of Agriculture, and the Pennsylvania Department of Environmental Resources, State Conservation Commission. Soil Survey of Beaver and Lawrence Counties, Pennsylvania, USA.

. 1982b. Pennsylvania State University, College of Agriculture, and the Pennsylvania Department of Environmental Resources, State Conservation Commission. Soil Survey of Westmoreland County, Pennsylvania, USA.

. 1982c. Pennsylvania State University, College of Agriculture, and the Pennsylvania Department of Environmental Resources, State Conservation Commission. Soil Survey of Washington and Greene Counties, Pennsylvania, USA.

. 1982d.Pennsylvania State University, College of Agriculture, and the Pennsylvania Department of Environmental Resources, State Conservation Commission. Soil Survey of Allegheny County, Pennsylvania, USA.

United States Geological Survey. Northern Prairie Wildlife Research Center. 2006. http://www.npwrc.usgs.gov/resource/herps/amphibid/species/dfuscus.htm.

. 2004. North American Amphibian Monitoring Program. http://www.mplpwrc.usgs.gov/amphibs.html.

van Buskirk, J. 2005. Local and landscape influence on amphibian occurrence and abundance. Ecology 86:1936-1947. 
Vellend, M., K. Verheyen, H. Jacquemyn, A. Kolb, H. Van Calster, G. Peterkin, and M. Hermy. 2005. Extinction debt of forest plants persists for more than a century following habitat fragmentation. Ecology 87:542-548.

Vos, C.C. and J.P. Chardon. 1998. Effects of habitat fragmentation and road density on the distribution pattern of the moor frog, Rana arvalis. Journal of Applied Ecology 35:44-56.

Ward, R.L., J.T. Anderson, and J.T. Petty. 2008. The effects of roads crossings on stream and stream-side salamanders. Journal of Wildlife Management 72:760-771.

Weathers, K.C., M.L. Cadenasso, and S.T.A. Pickett. 2001. Forest edges as nutrient and pollutant concentrators: Potential synergisms between fragmentation, forest canopies, and the atmosphere. Conservation Biology 15:1506-1514.

Welsh, H.H. 1990. Spatial associations among individuals in a population of slimy salamanders (Plethodon glutinosos). Herpetologica 36:271-275.

Welsh, H.H. and L.M. Ollivier. 1998. Stream amphibians as indicators of ecosystems stress: A case study from California's Redwoods. Ecological Applications 8:1118-1132.

White, F.N. 1987. Comparative aspects of vertebrate cardiorespiratory physiology. Applied Physiology 40:471-499.

Wilcox, B.A. 1980. Insular ecology and conservation. In: Soule, M.E., and B.A. Wilcox (eds), Conservation Biology: An evolutionary-ecological perspective, Sinauer Associates. Sunderland, Massachusetts, USA.

Williams, B.K., J.D. Nichols, and M.J. Conroy. 2002. Analysis and management of animal populations: modeling, estimation, and decision making. Academic Press: An Elsevier Science Imprint. New York, New York, USA. 


\section{FIGURES AND TABLES}

Table 1. Scientific and common name of the 17 recorded salamander species found in Pennsylvania according to Hulse et al. (2001).

\begin{tabular}{rll}
\hline & Scientific Name & Common Name \\
\hline 1 & Ambystoma jeffersonianum & Jefferson salamander \\
2 & Ambystoma maculatum & Spotted salamander \\
3 & Cryptobranchus alleghaniensis alleghaniensis & Eastern hellbender \\
4 & Desmognathus fuscus fuscus & Northern dusky salamander \\
5 & Desmognathus monticola & Seal salamander \\
6 & Desmognathus ochrophaeus & Mountain dusky salamander \\
7 & Eurycea bislineata & Northern two-lined salamander \\
8 & Eurycea longicauda longicauda & Longtail salamander \\
9 & Gyrinophilux porphyriticus porphyriticus & Northern spring salamander \\
10 & Hemidactylium scutatum & Four-toed salamander \\
11 & Necturus maculosus maculosus & Mudpuppy \\
12 & Notophthalmus viridescens viridescens & Red-spotted newt \\
13 & Plethodon cinereus & Red-backed salamander \\
14 & Plethodon glutinosus & Northern slimy salamander \\
15 & Plethodon richmondi & Ravine salamander \\
16 & Plethodon wehlei & Wehrle's salamander \\
17 & Pseudotriton ruber ruber & Northern red salamander \\
\hline
\end{tabular}


Figure 1. Map of southwestern Pennsylvania showing the location of the 4 counties (Allegheny, Beaver, Washington and Westmoreland) and the 5 study areas (4 primary areas: State Game Land 203, Raccoon Creek State Park, Mingo Creek County Park, and Linn Run State Park; 1 secondary: Cedar Creek County Park) where the study was conducted, 20082009.

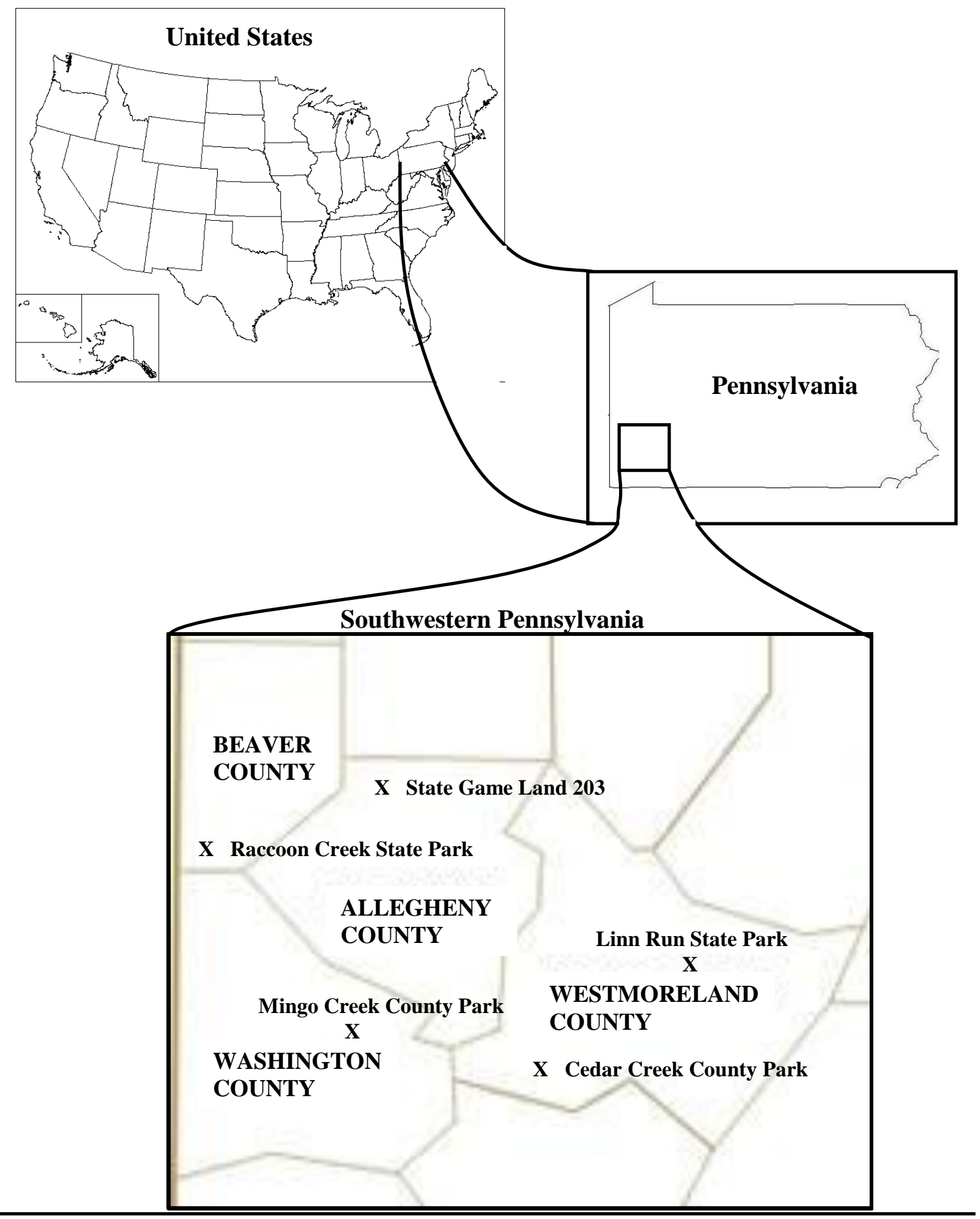


Figure 2. Aerial photograph of 1 of the 4 primary study areas, Raccoon Creek State Park (RCSP), showing park boundaries (highlighted lime green line) and nearest State Routes 166, 18, and 30, in Beaver County, Pennsylvania. Collection of data occurred in 20082009. Image from Google Earth.

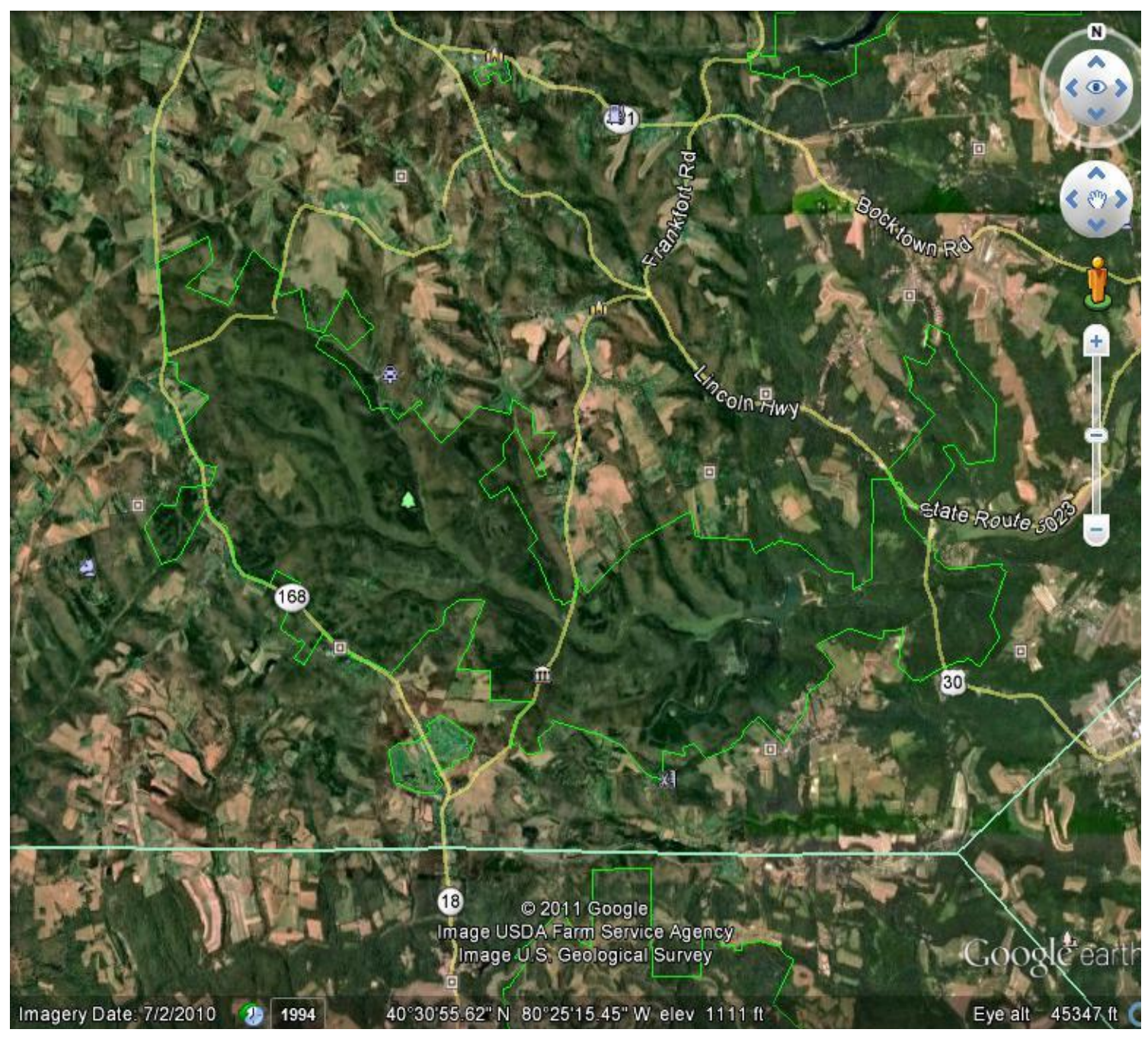


Figure 3. Map of 1 of the 4 primary study areas, Raccoon Creek State Park (RCSP), showing park boundaries, elevation, and nearest State Routes 166, 18, and 30, in Beaver County, Pennsylvania. Collection of data occurred in 2008-2009. Image from DCNR.

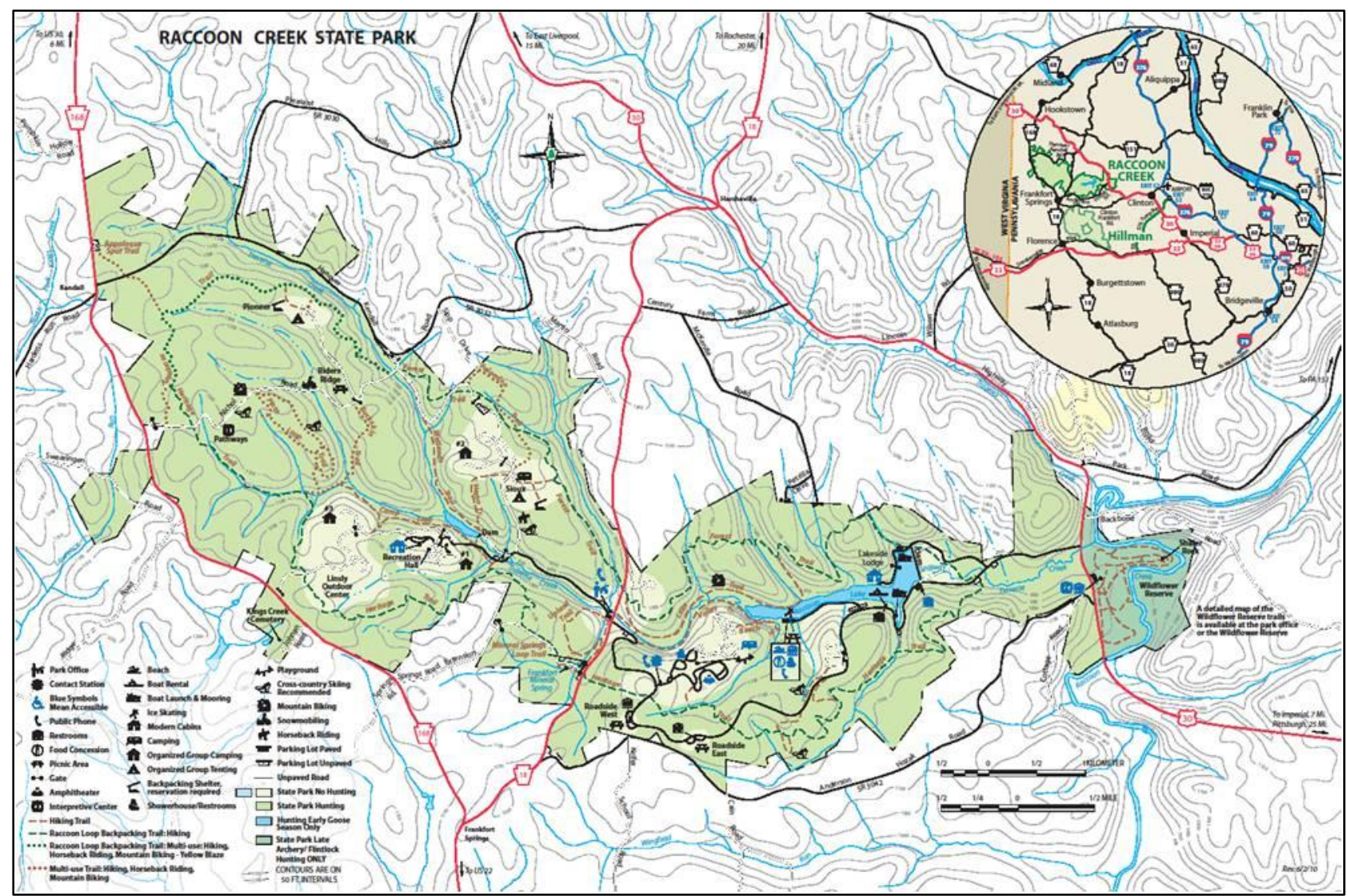


Figure 4. Aerial photograph of 1 of the 4 primary study areas, Linn Run State Park (LRSP), showing park boundaries (highlighted lime green line), nearest State Route 136, and nearest town (Rector) in Westmoreland County, Pennsylvania. Collection of data occurred in 20082009. Image from Google Earth.

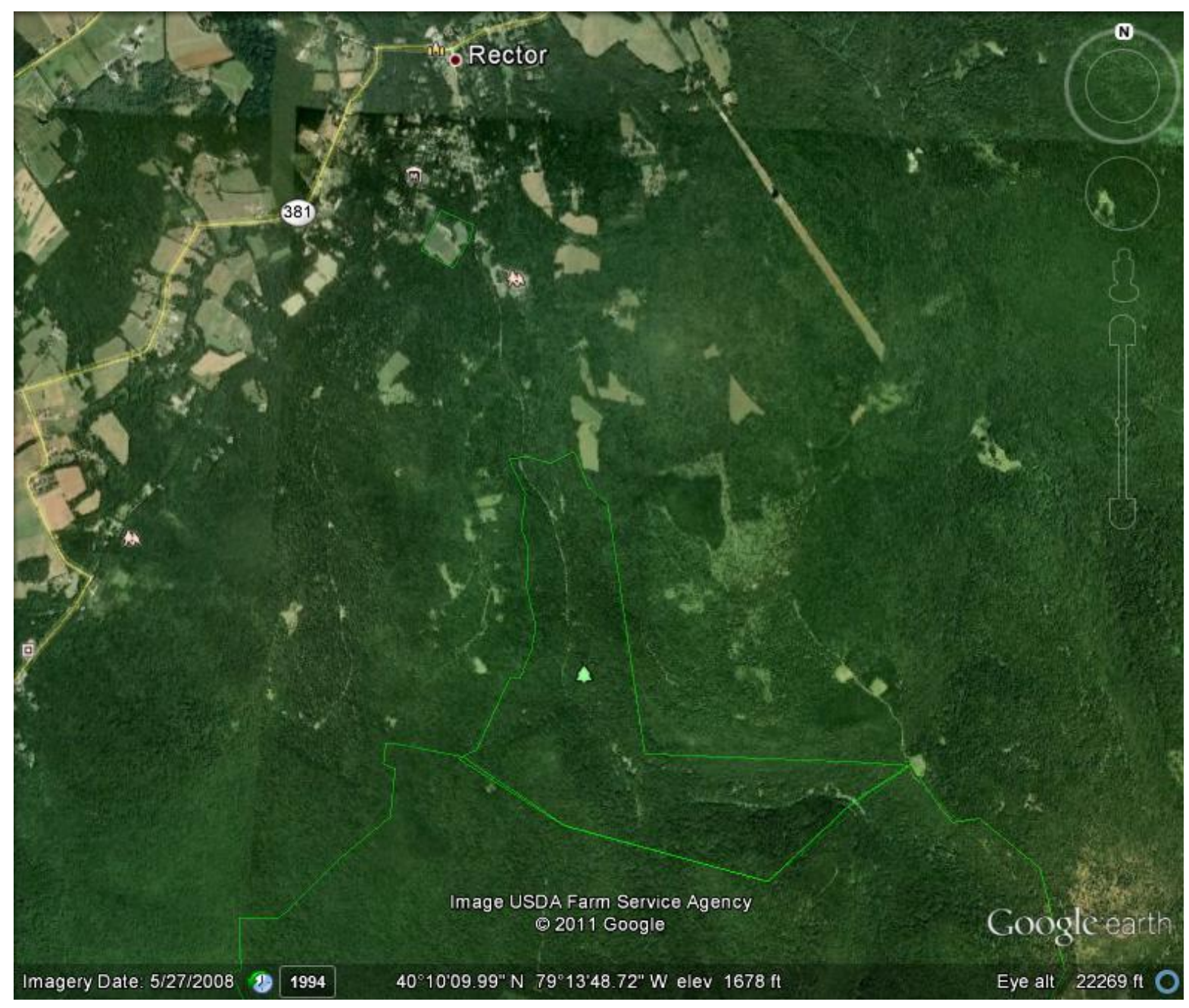


Figure 5. Map of 1 of the 4 primary study areas, Linn Run State Park (LRSP), showing elevation, proximity to Pennsylvania Toll Road 76, and Forbes State Forest in Westmoreland County, Pennsylvania. Collection of data occurred in 2008-2009. Image from DCNR.

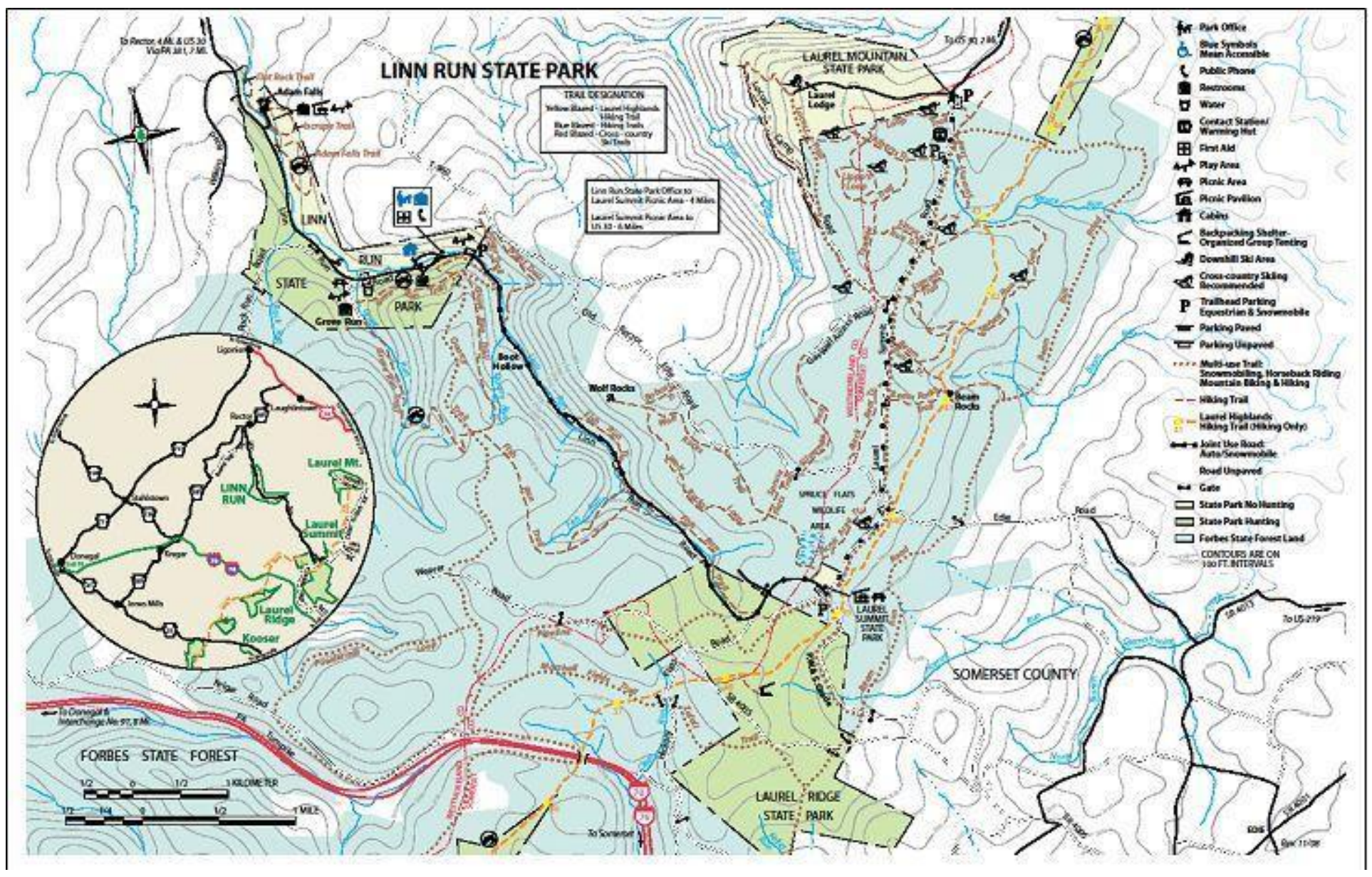


Figure 6. Aerial photograph of 1 of the 4 primary study areas, Mingo Creek County Park (MCCP), showing park boundaries (highlighted lime green line) and nearest State Routes 136 and 917, in Washington County, Pennsylvania. Collection of data occurred in 20082009. Image from Google Earth.

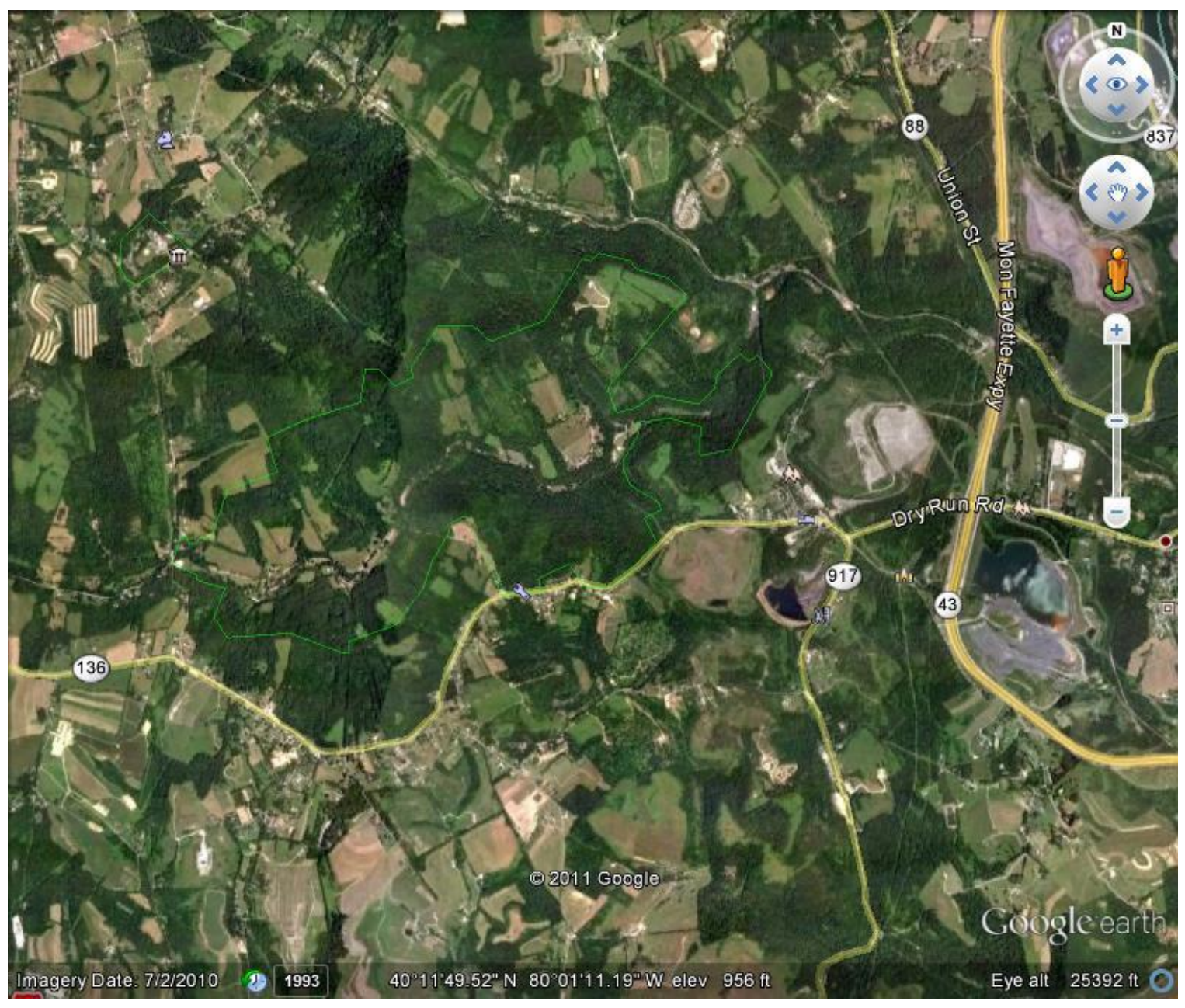


Figure 7. Map of 1 of the 4 primary study areas, Mingo Creek County Park (MCCP), showing park boundaries, park trails, and State Route 136, in Washington County, Pennsylvania. Collection of data occurred in 2008-2009. Image from Washington County Department of Parks and Recreation.

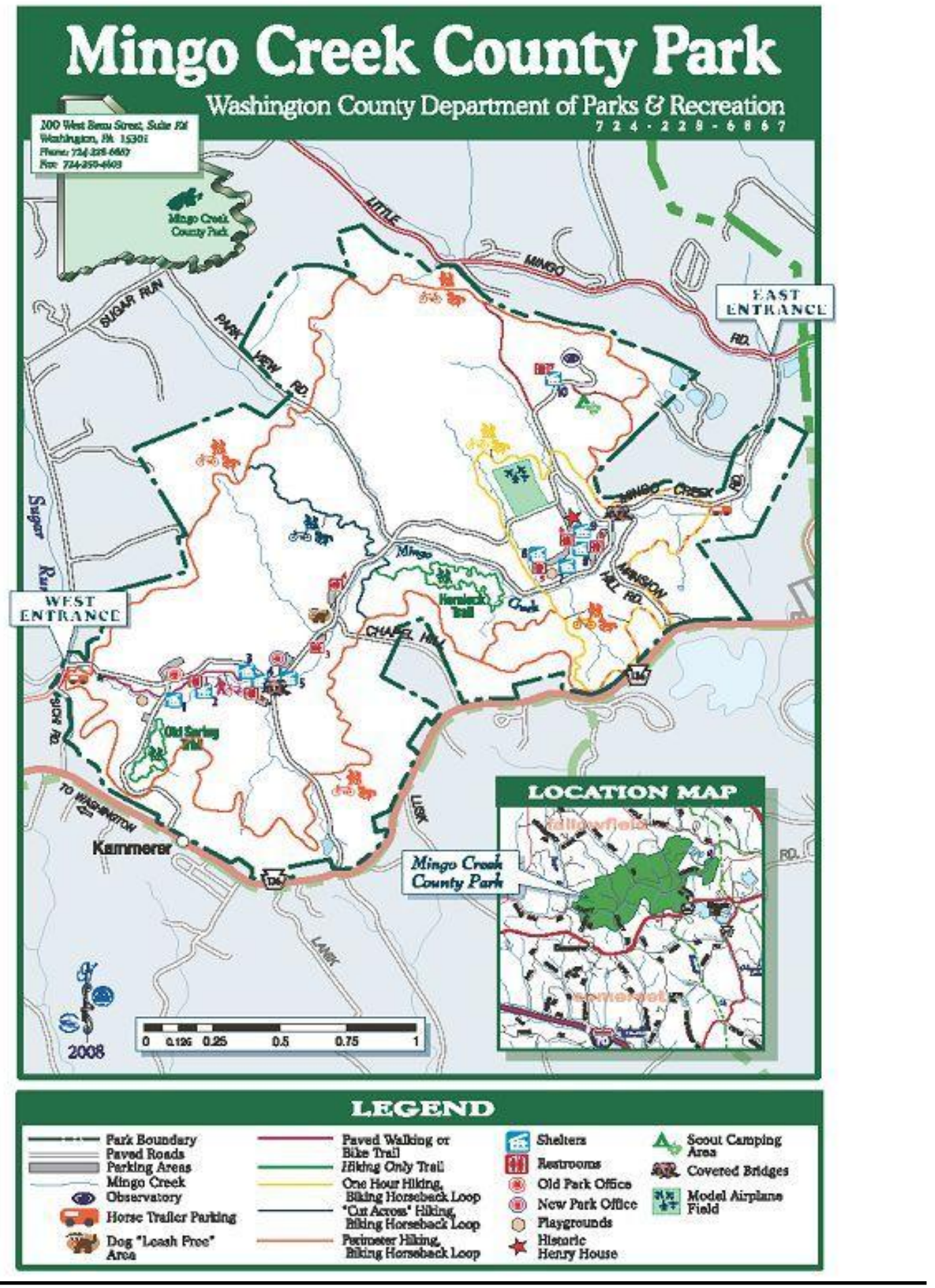


Figure 8. Aerial photograph of 1 of the 4 primary study areas, State Game Land 203 (SGL), showing park boundaries (highlighted lime green line) and nearest State Route 910 and Interstate 79, in Allegheny County, Pennsylvania. Collection of data occurred in 2008-2009. Image from Google Earth.

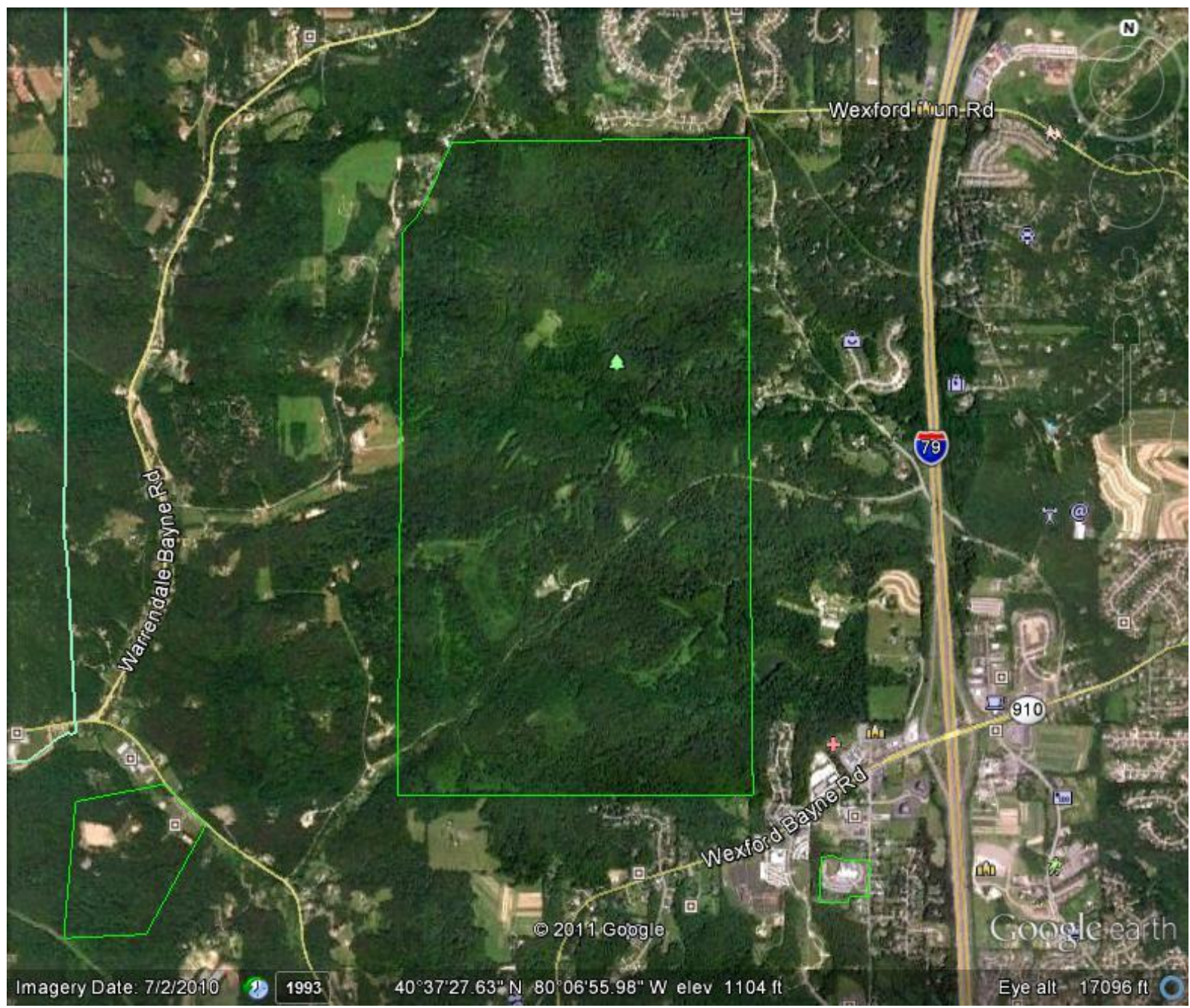


Figure 9. Map of 1 of the 4 primary study areas, State Game Land 203 (SGL), showing park boundaries, elevation, State Route 910 and Interstate 79, and nearby towns in Allegheny County, Pennsylvania. Collection of data occurred in 2008-2009. Image from Pennsylvania Game Commission.

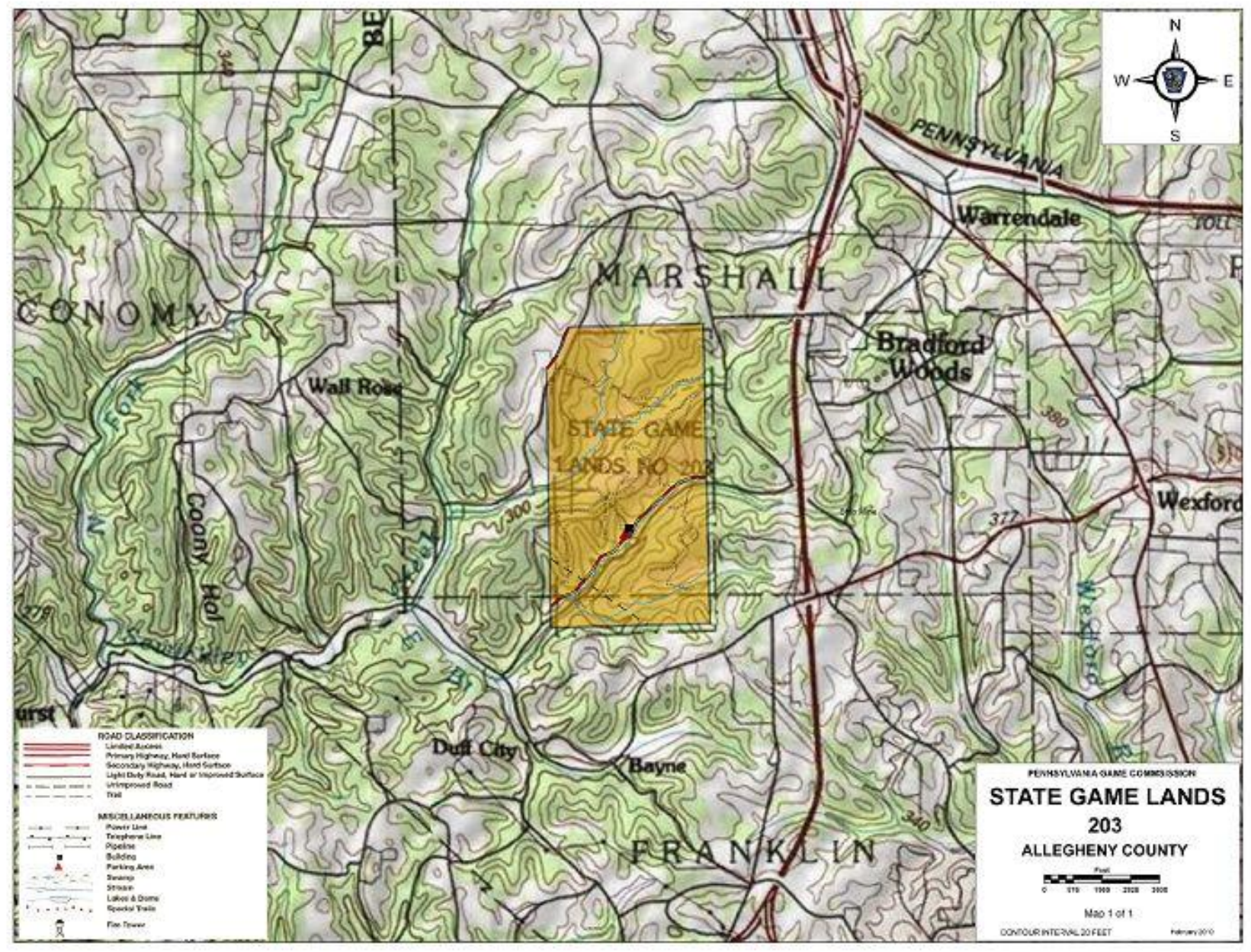


Figure 10. Aerial photograph of the Cedar Creek County Park (CCCP) (secondary) study area, Westmoreland County, Pennsylvania, that was used to verify the best a priori model and the post-hoc model, showing park boundaries (highlighted lime green line) and nearest State Route 51 and Interstate 70. Verification of models occurred in September 2011. Image from Google Earth.

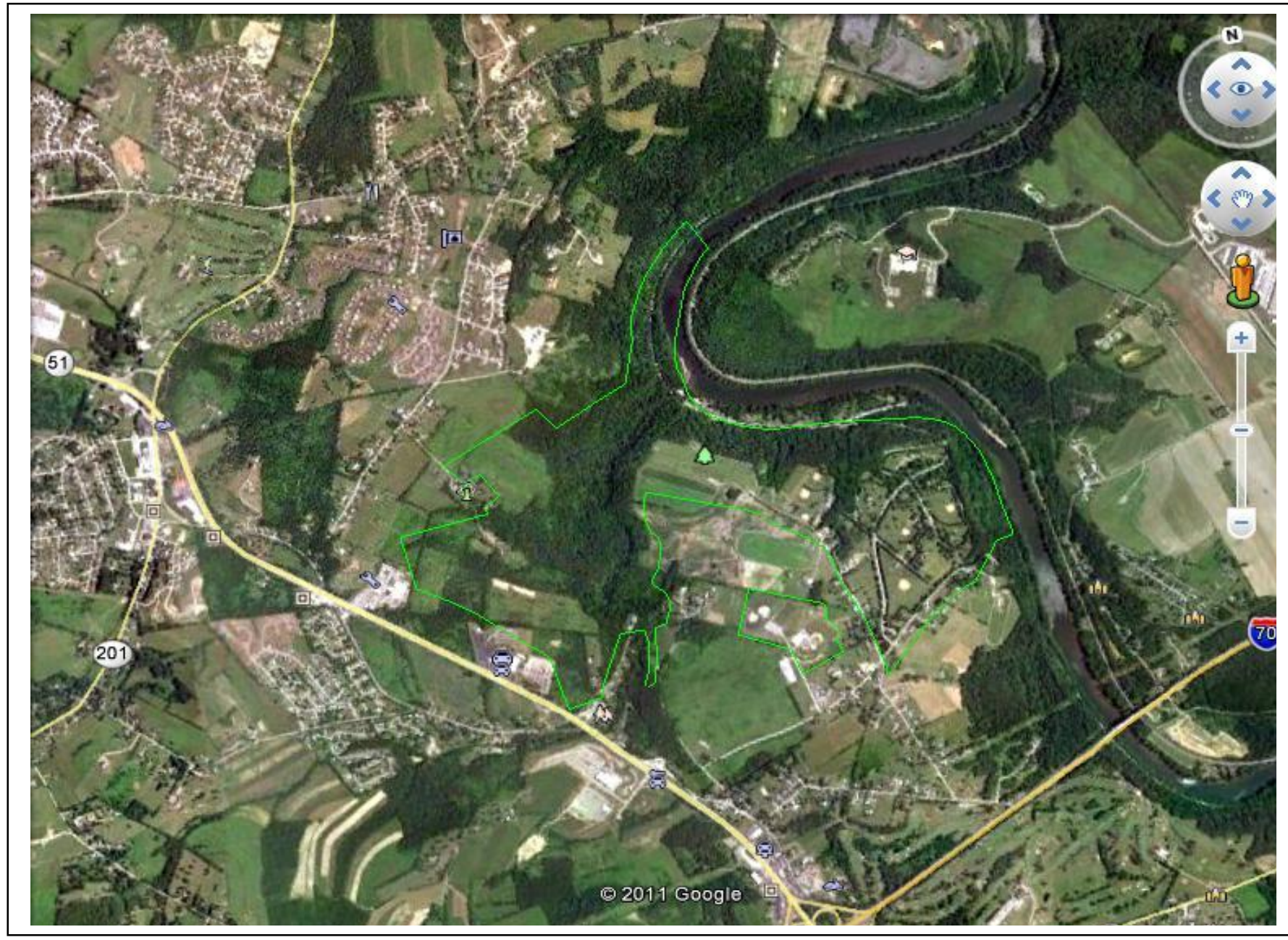


Figure 11. Map of the Cedar Creek County Park (CCCP) (secondary) study area, showing park boundaries, park trails, and Youghiogheny River, in Westmoreland County, Pennsylvania. Collection of data occurred in September 2011. Image from Westmoreland County Department of Parks and Recreation.

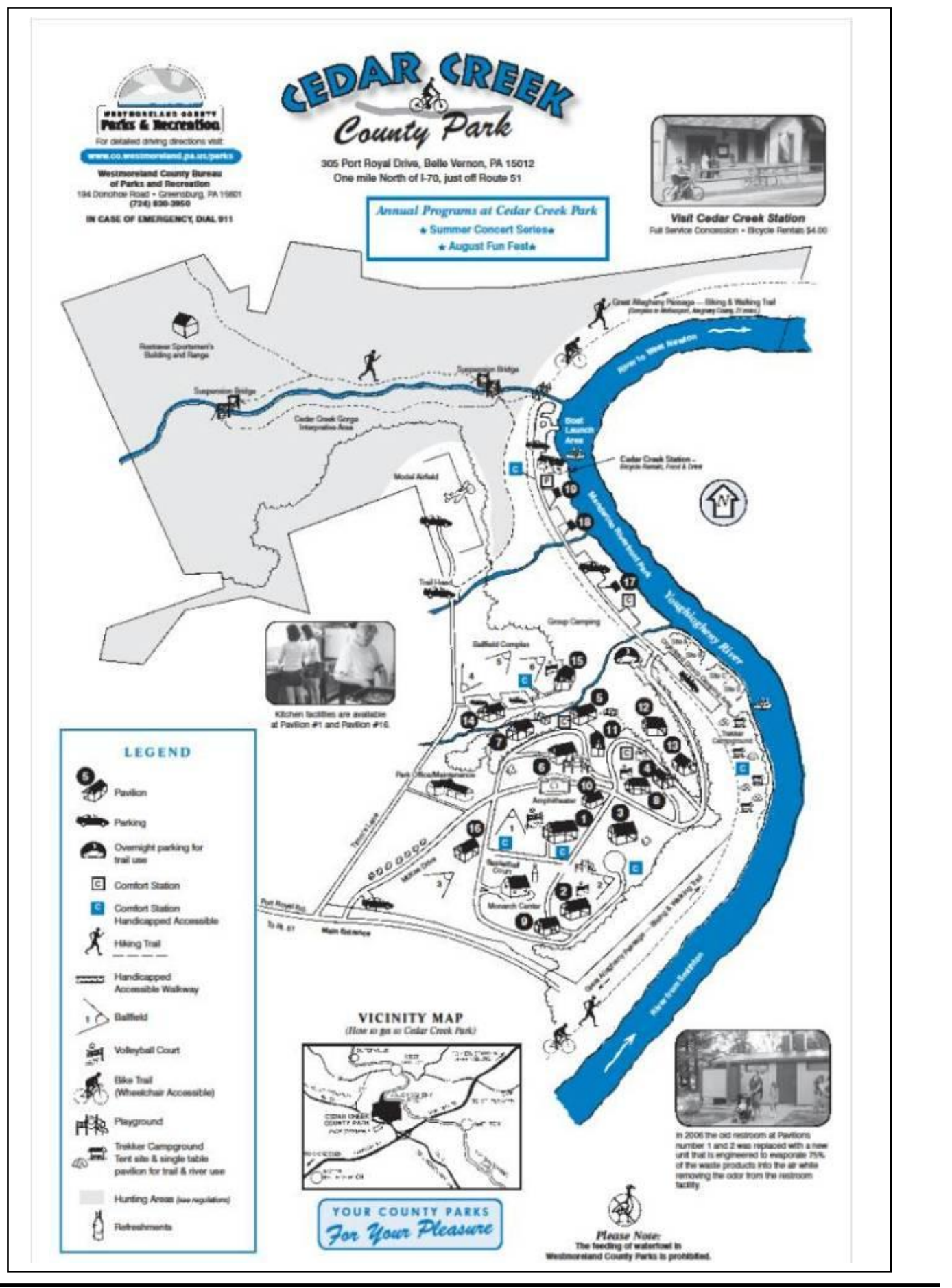


Figure 12. The recorded home range of the northern dusky salamander in eastern United States. Taken from USGS (2006).

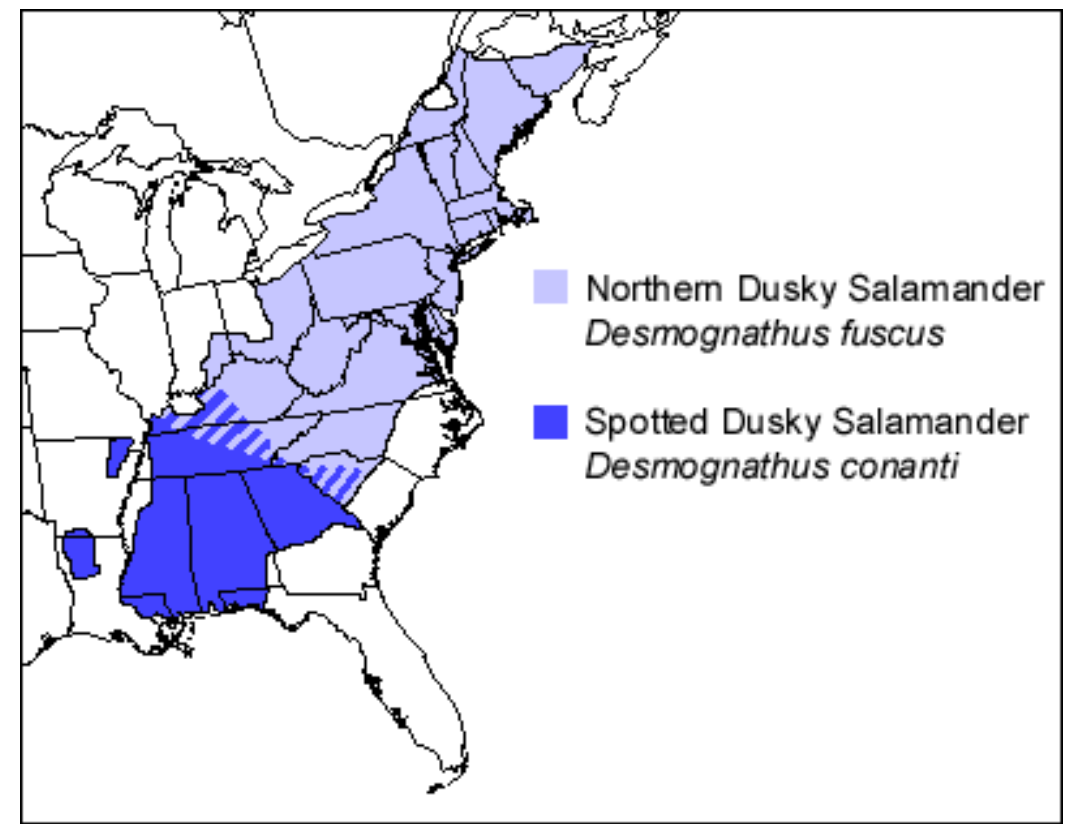


Figure 13. Distribution of northern dusky salamander in the northeastern United States, including confirmed sightings in Pennsylvania indicated by the dots (Hulse et al. 2001).

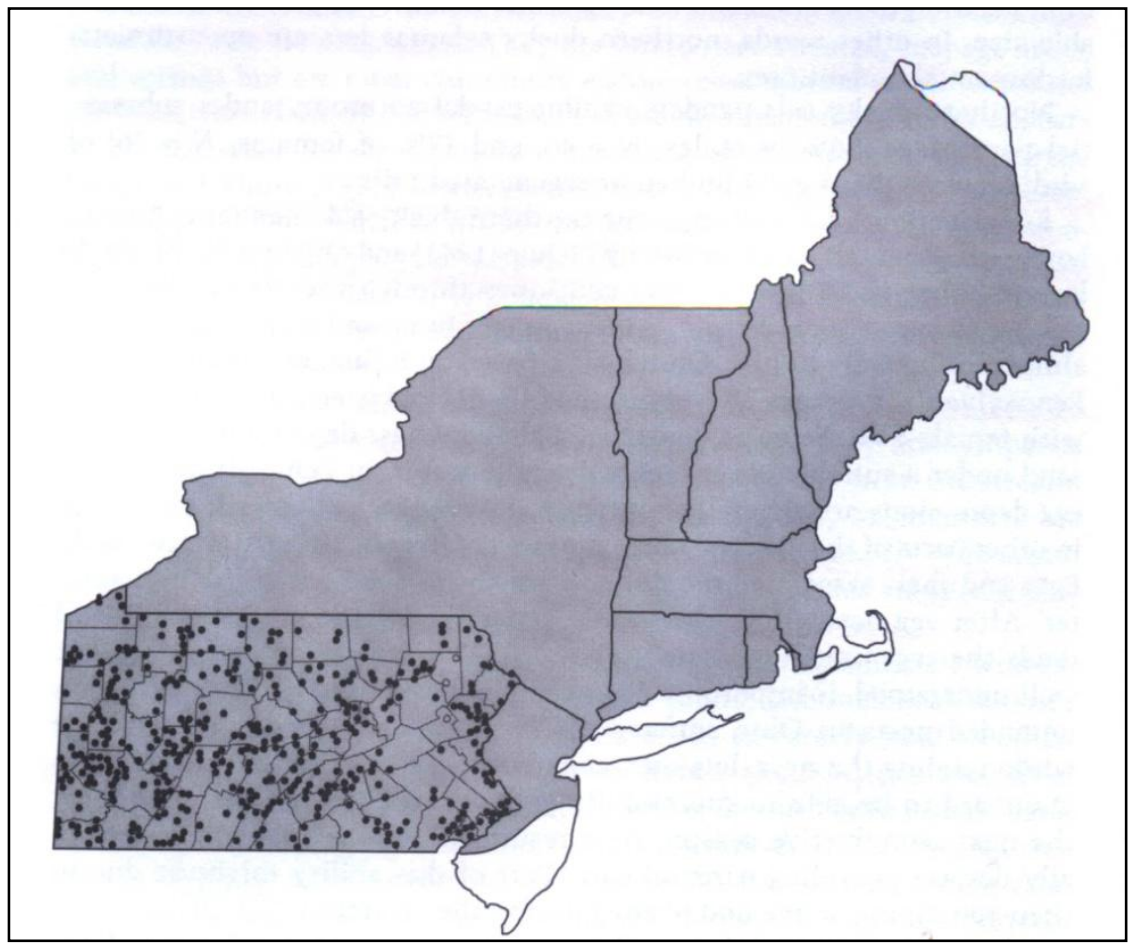


Figure 14. Fragmentation, as defined for the stream reaches located in the 4 primary study areas (Linn Run State Park, Mingo Creek County Park, Raccoon Creek State Park, and State Game Land 203) in this investigation, is a $20 \mathrm{~m}$ migration range with an additional $35 \mathrm{~m}$ for an edge buffer (not drawn to scale). Collection of data occurred in 2008-2009.

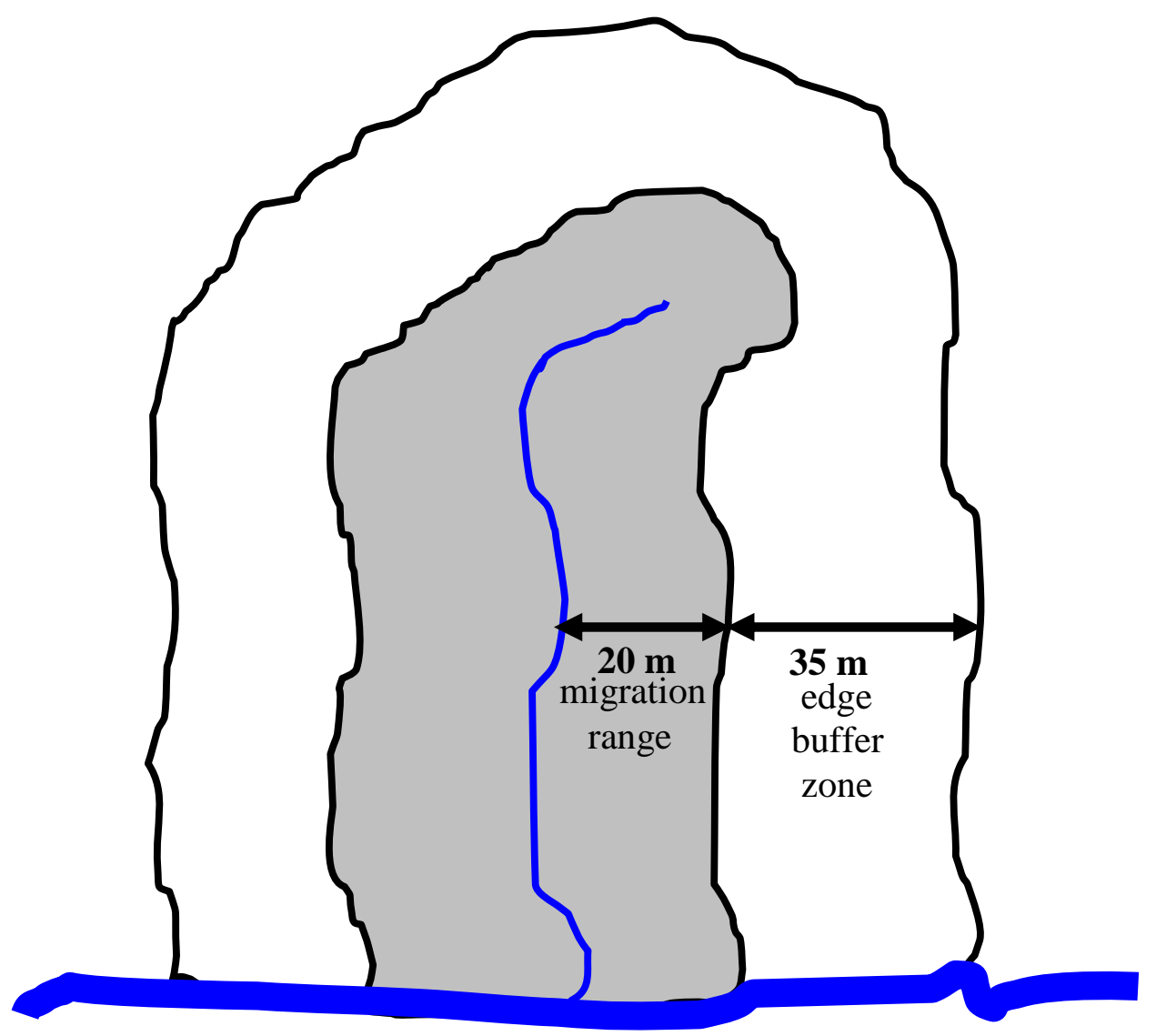


Figure 15. An isolated stream, as defined for the stream reaches located in the 4 primary study areas (Linn Run State Park, Mingo Creek County Park, Raccoon Creek State Park, and State Game Land 203) in this investigation, is a $20 \mathrm{~m}$ migration range (not drawn to scale). The collection of data occurred in 2008-2009.

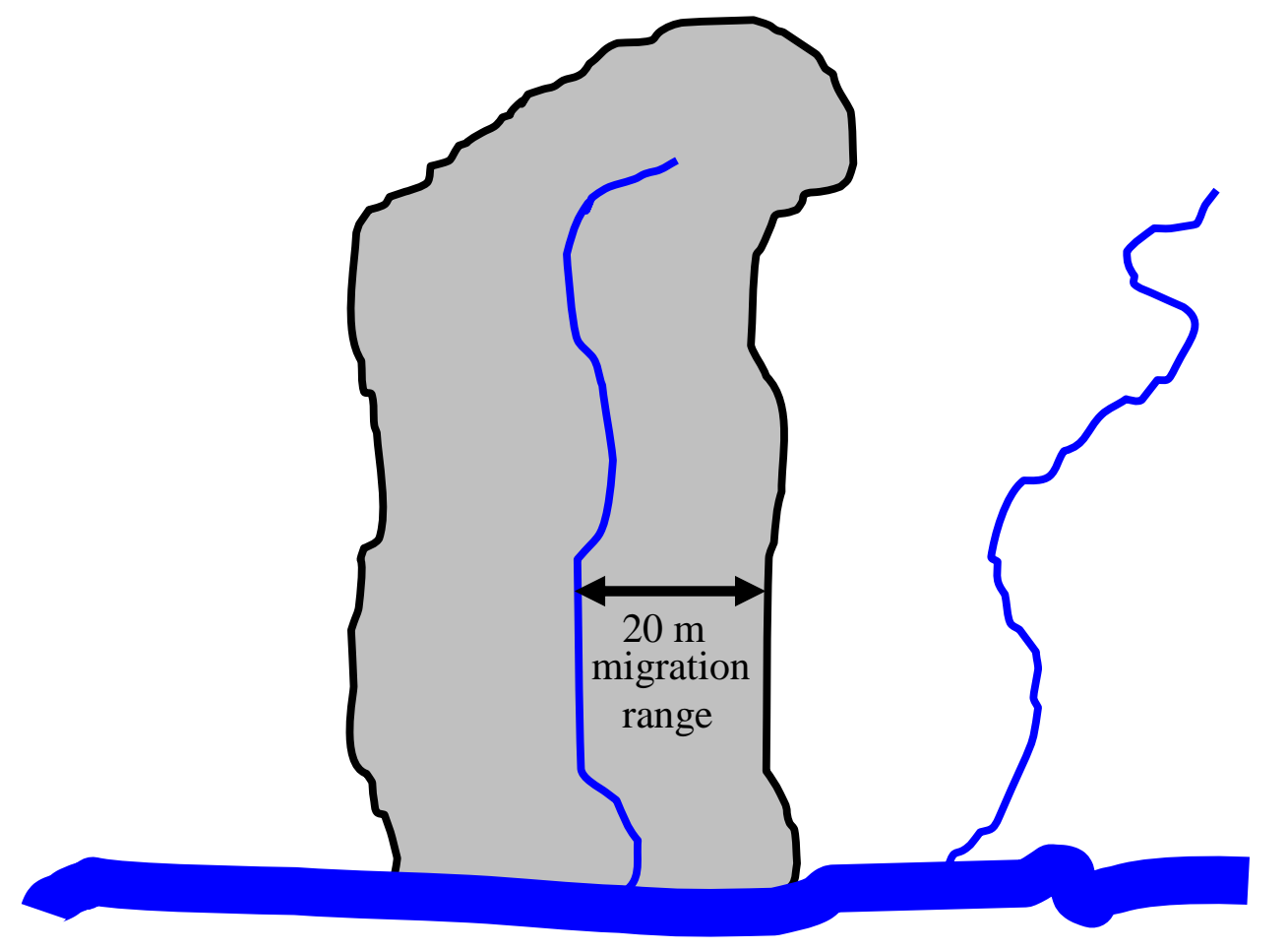


Figure 16. For stream reaches located in the 4 primary study areas (Linn Run State Park, Mingo Creek County Park, Raccoon Creek State Park, and State Game Land 203) in this investigation, 2 low order streams at their confluence, showing at some point the streams become too far apart to allow the salamanders to cross from one stream to the next nor exceed the migration distance along a stream because of site fidelity (not drawn to scale). Collection of data occurred in 2008-2009.

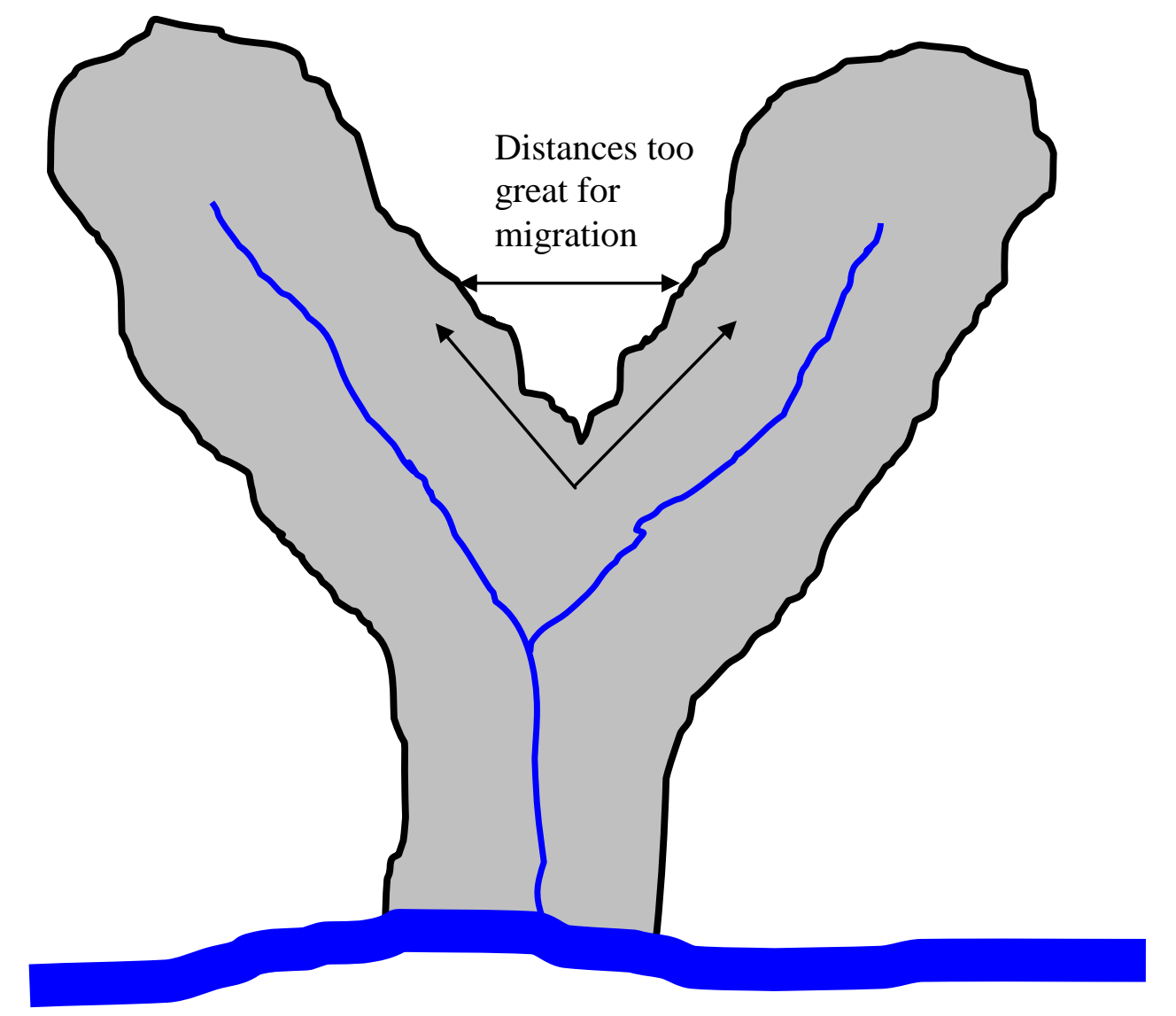


Figure 17. For the streams reaches located in the 4 primary study areas (Linn Run State Park, Mingo Creek County Park, Raccoon Creek State Park, and State Game Land 203) in this investigation, an unfragmented forested habitat with a continuous stream that is transected with a prohibitive barrier (i.e., trail, trail-bridge, dirt road, paved road, culvert, etc.) that isolates salamander populations upstream from downstream populations (not drawn to scale). Collection of data occurred in 2008-2009.

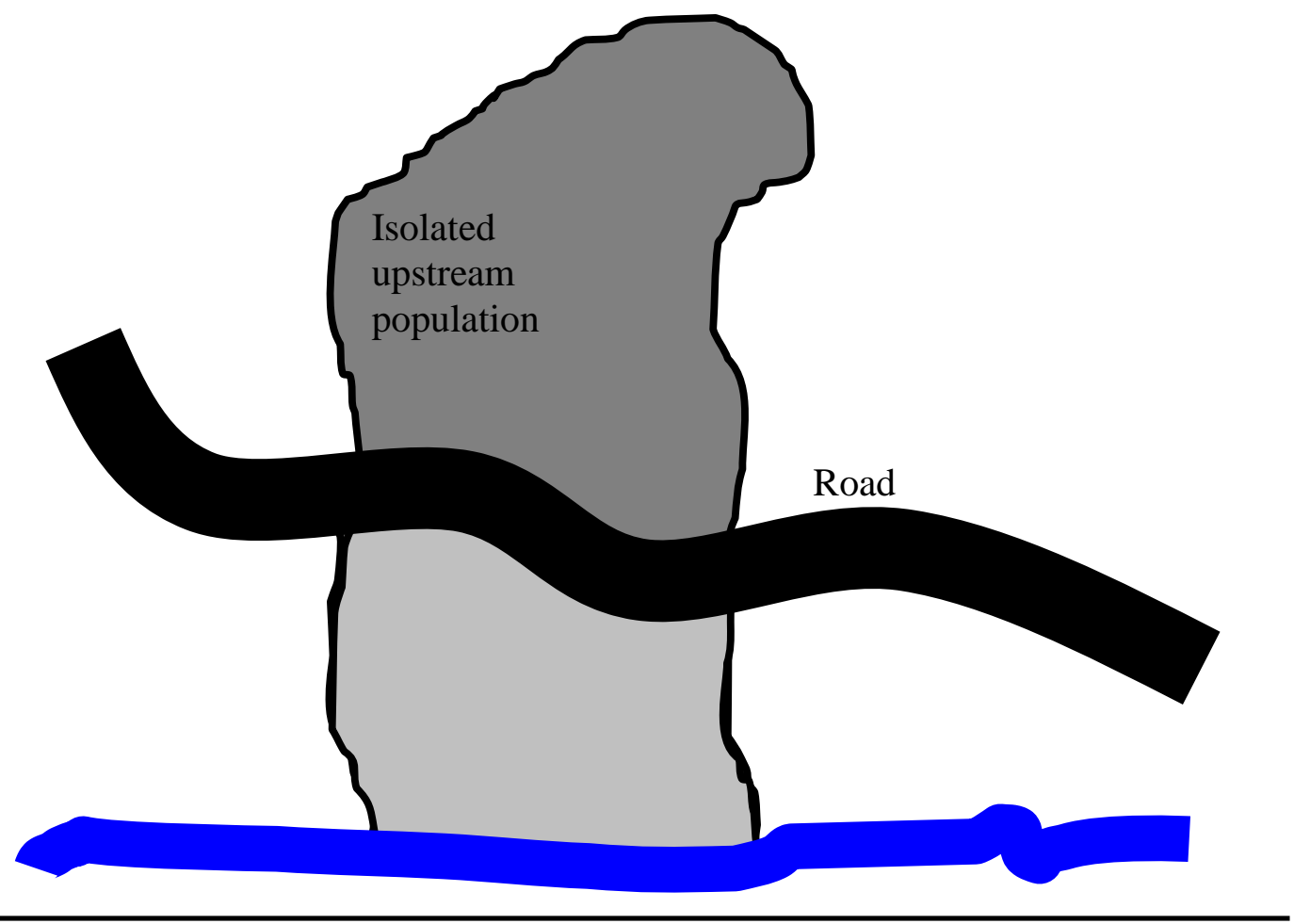




\title{
CHAPTER 2: Habitat Use by Northern Dusky Salamanders in Riparian Corridors of Southwestern Pennsylvania
}

\author{
Mr. Robert J. Michalow ${ }^{1}$, \\ Mr. Anthony A. Billings ${ }^{2}$, \\ and \\ Dr. James T. Anderson ${ }^{3}$
}

This chapter formatted in the style of the Northeastern Naturalist, Eagle Hill Publications, Steuben, Maine, USA.

\footnotetext{
${ }^{1}$ Saint Vincent College

School of Social Sciences, Communication and Education 300 Fraser Purchase Road Latrobe, Pennsylvania 15650, USA

724-805-2710; Fax: 724-805-2024; rob.michalow@ email.stvincent.edu

${ }^{2}$ West Virginia University

Department of Statistics

P.O. Box 6330

Morgantown, West Virginia 26506

${ }^{3}$ West Virginia University

Davis College of Agriculture, Natural Resources and Design

Division of Forestry and Natural Resources

P.O. Box 6125

Morgantown, West Virginia 26506-6125

304-293-3825; wetland@wvu.edu
} 
21 April 2012

Robert Joseph Michalow

Saint Vincent College

School of Social Sciences, Communication and Education

300 Fraser Purchase Road

Latrobe, Pennsylvania 15650, USA

724-805-2710; Fax: 724-805-2024; rob.michalow@email.stvincent.edu

RH: Salamander Habitat Evaluation • Michalow, Billings, and Anderson

\section{HABITAT USE BY NORTHERN DUSKY SALAMANDERS IN RIPARIAN CORRIDORS OF SOUTHWESTERN PENNSYLVANIA}

Robert J. Michalow, School of Social Sciences, Communication and Education, 300 Fraser Purchase Road, Saint Vincent College, Latrobe, PA 15650, USA

Anthony A. Billings, Department of Statistics, West Virginia University, P.O. Box 6330, Morgantown, West Virginia 26506, USA

James T. Anderson, Davis College of Agriculture, Natural Resources and Design, Division of Forestry and Natural Resources, West Virginia University, P.O. Box 6125, Morgantown, West Virginia 26506-6125, USA

\section{Abstract:}

Salamander populations have been on the decline due to habitat loss and fragmentation. We assessed habitat parameters to determine those most critical to estimating northern dusky salamander (Desmognathus fuscus fuscus) densities in southwestern Pennsylvania. Four study 
areas each with 4 stream reaches were searched by using a 3-4 pass visual encounter survey and wooden cover boards for a period of 2 years. A total of 2,287 salamanders from 7 species were captured and the northern dusky salamander comprised $87 \%$ of the total. Of all the salamanders captured, $84 \%$ were under rocks while $9 \%$ were captured under cover boards. The salamander density for the entire study was 0.15 salamanders/m of stream reach. In no case was a northern dusky captured in one stream and later a different stream suggesting low likelihood of captures if they do disperse and limited dispersal ability. Of 6 a priori relative abundance models, the model using percent tree canopy cover, percent protective cover and stream size was the best fit. Streams were categorized into good and poor streams and the good streams had a mean tree canopy cover of $84 \%$, mean protective cover (percentage of 20 $\mathrm{cm}$ diameter rocks within the stream) of $35 \%$, and a cross-sectional area stream size of 2,146 $\mathrm{cm}^{2}$. The best fit model was then slightly modified to incorporate stream size difference and a constant was added. The post-hoc model was verified at an independent study area and was able to estimate (with a percent error of $\leq 75 \%$ salamander/visit) the salamander density $75 \%$ of the time. Thus, from our study, the most critical riparian zone characteristics for northern dusky salamander abundance were tree canopy cover, protective cover, and stream size such that small shallow streams with high percent canopy cover and protective cover contained the highest abundance of northern dusky salamanders.

Keywords: northern dusky salamander, Desmognathus fuscus fuscus, habitat fragmentation, Pennsylvania, salamanders, visible implant elastomer, visual encounter survey, species richness 


\section{INTRODUCTION}

Habitat fragmentation or degradation (from here on just referenced as habitat fragmentation) is the process of dissecting large and contiguous areas of similar native vegetative types into smaller units separated by different vegetative types and or areas of intense human activity (Saunders et al. 1991). Although typically applied to forest ecosystems, habitat fragmentation can be applied to any type of landscape. Gradual natural habitat fragmentation has occurred for thousands of years due to natural topography such as a mountain ridges and or rivers that have partitioned landscapes (Harris 1984); however, anthropogenic disturbances have exacerbated the problems associated with habitat fragmentation in a broader perspective via resource extraction, agriculture, and urbanization (Roberts et al. 2000, Chambers 2008, Sepulveda and Lowe 2009). In efforts to limit the negative impacts of habitat fragmentation, ecological corridors have been created and the latest data indicate that corridors benefit various species because they enhance plant and animal interactions and increase plant pollination (Graham et al. 2002); yet other studies indicate different species are unaffected by corridors (Belisle and St. Clair 2001). Ecological corridors, such as riparian zones for Plethodon salamanders, need to be protected at a species specific distance equal to core habitat $(27 \mathrm{~m})$ plus a buffer zone $(50 \mathrm{~m})$ (Crawford and Semlitsch 2007). Not only do patches need to be protected, but also the disturbed lands (matrices) need to be mitigated in order to minimize the disruption of Plethodon salamander populations (Nauman and Olson 2008). Additionally, there has been an increase in ecosystem fragmentation and there needs to be an increased use of geographic information systems (GIS) software to help devise spatially explicit conservation plans to create lower levels of isolation (Greenwald et al. 2009). 
Habitat fragmentation also can occur within a stream reach via some type of barrier (e.g., road, culvert, dam), thus preventing species such as salamanders from moving up and down the stream (Jackson 2003). Stream barriers also can increase the amount of sediment flowing downstream (Miller et al. 1997) while channelization (usually occurring above and below road crossings) increases destruction of riparian vegetation, increases water temperature because of a lack of canopy cover, decreases pool and riffle habitat, decreases protective cover for aquatic organisms and increases bank erosion (Beschta and Platts 1986). When properly installed, culverts allow streams to flow continuously and keep the stream's water separate from the road (Adair et al. 2002); however, due to culvert overhang, 55\% of the culverts within the Lower Shavers Fork and Dry Fork watersheds of West Virginia were classified as complete barriers for salamanders, while an additional $34 \%$ of the culverts were classified as partial barriers (Ward et al. 2008).

Smith and Green (2005) reported that amphibians are frequently characterized as having limited dispersal abilities, strong site fidelity and spatially disjoint breeding habitat. As such, some species of salamanders are often alleged to form metapopulations (Smith and Green 2005). The metapopulation concept, that is, the idea of spatially structured populations with local extinction and recolonization, has been published since the early to mid $20^{\text {th }}$ century; however, to date no attempt has been made to assess the class-wide generalization of amphibian populations as metapopulations and strong evidence indicates that amphibian dispersal is not as uniformly limited as often thought (Smith and Green 2005). Finally, caution needs to be exercised in the application of the metapopulation approach to amphibian population conservation because some amphibian populations are structured as metapopulations, but not all. This is important because of the different theoretical 
philosophies and management techniques that are used for species that are considered metapopulations and ones that are not.

The general population trend of salamanders is relatively unknown because data are few, scattered, research-oriented rather than monitoring-oriented and largely unpublished; thus, providing little information about the regional stability of salamanders (United States Geological Survey USGS 2004). Furthermore, there needs to be a balance between spatial replication (no. sample sites/area) and temporal replication (no. of repeated surveys) when designing a sampling regime (Bailey et al. 2007). Because of their dependence to the forest floor and a water source, salamanders are more likely to indicate significant environmental changes than any other North American amphibian (USGS 2004) and semi-aquatic salamanders (i.e., stream-side salamanders) are receiving more attention as ecological indicators (Roth et al. 1999, Ohio Environmental Protection Agency EPA 2001) for headwater stream ecosystems (those draining less than 400 ha) because of the salamander's longevity, relatively stable populations, small home ranges, abundance and ubiquity (Welsh and Ollivier 1998, Rocco and Brooks 2000). Snodgrass et al. (2007) reported that northern dusky salamander nest sites typically were found in watersheds that were $<70$ ha in size and these headwaters were important nesting habitat. In western Pennsylvania, salamander populations occupy undisturbed forest floors with densities equal to, or exceeding, the biomass of all other vertebrate groups (Burton and Likens 1975, Hairston and Wiley 1993) and they have achieved their highest densities in ancient or undisturbed forests (Welsh 1990, Meier et al. 1996). However, some studies indicate that stream-side salamander populations have been negatively affected by higher impervious surface area in the basin area, abandoned mine drainage, nearby road construction and logging (Bury and Corn 1988, Corn and Bury 1989, Welsh and Ollivier 
1998, Boward et al. 1999, Middlekoop et al. 1999, Rocco and Brooks 2000) and that there are depressed capture rates, risky reproductive migrations and decreased populations in drier areas (Becker et al. 2010). Others reported that a decrease in Plethodon salamander populations may be due to disturbances caused by feral pigs (Sus scrofa) (Means and Travis 2007) and because of their limited dispersal and hydrologically sensitive habitat, they are sensitive to future climatic changes (Lawler et al. 2010). Whatever the cause of the disturbance, salamanders in the disturbed area are spending $33 \%$ more of their mean caloric intake for daily maintenance (Homyack et al. 2011). Finally, populations of northern dusky salamanders, especially juvenile populations (Price et al. 2011) are negatively impacted by urbanization and or pollution with the decrease in populations attributed primarily to the loss of vegetative cover and stream quality degradation (Orser and Shure 1972, Grant et al. 2004, Bank et al. 2006). The semi-aquatic dusky salamanders are found from southern Quebec and New Brunswick to northern South Carolina, westward to southeastern Indiana and are widely distributed throughout Pennsylvania (Hulse et al. 2001). Northern dusky salamanders (Desmognathus fuscus fuscus) are a member of the Plethodontidae family and the Desmognathus genus and can be identified by a lighter colored lateral eye stripe that extends from the eye to the angle of the jaw (Appendix 2), yellow to grayish brown bodies that have a wide dorsal stripe (Appendix 3) and a series of 5-8 pairs of yellowish spots connected by a dark wavy band (Hulse et al. 2001). Northern dusky salamanders also have a keeled tail (Appendix 4) and exhibit caudal autonomy (Hulse et al. 2001).

The goals of this study were to: 1) evaluate short-term changes in seasonal relative abundance of northern dusky salamanders; 2) determine if the increased amount of protective cover in areas where cover boards were placed has an increase in relative abundance; 3 ) 
determine which habitat parameters influence relative salamander density; and 4) create a model that is able to estimate salamander density. We hypothesized that the placement of cover boards would increase salamander density; and that temperature, canopy cover, herbaceous cover, stream size, protective cover and $\mathrm{pH}$ are habitat parameters that impact semi-aquatic salamander density.

\section{STUDY AREAS}

Our study was conducted in 4 primary areas of southwestern Pennsylvania (PA), USA: Raccoon Creek State Park in Beaver County; Linn Run State Park in Westmoreland County; Mingo Creek County Park in Washington County; and State Game Land 203 in Allegheny County. We applied the model to Cedar Creek County Park in Westmoreland County as a secondary site (Figure 1). This region of southwestern Pennsylvania (Region 3609 of National Oceanic Atmospheric Administration's NOAA Climate Divisions) is a temperate deciduous forested area where the average monthly precipitation ranges from a high in June $(10.5 \mathrm{~cm})$ to a low in October (5.7). The region's average monthly high temperature ranges from a high in July $\left(28.2^{\circ} \mathrm{C}\right)$ to a low in January $\left(1.7^{\circ} \mathrm{C}\right)$ while the average monthly low temperature ranges from a high in July $\left(16.9^{\circ} \mathrm{C}\right)$ to a low in January $\left(-6.7^{\circ} \mathrm{C}\right)$. The average monthly number of days in this region with $\geq 0.03 \mathrm{~cm}$ of precipitation is highest in January and December (16) and lowest in July, August and September (10). The region has an average relative humidity of $80 \%$ during the morning and $58 \%$ in the afternoon with September having the highest morning and afternoon levels at $87 \%$ and $57 \%$ respectively and April having the lowest values at 74\% and 51\%, respectively (NOAA 2005) (Appendix 1).

Raccoon Creek State Park is located 48 km west of Pittsburgh, PA, just north of Frankfort Springs (Department of Conservation and Natural Resources DCNR 2005). The 
park's beginning was a Recreational Demonstration Area operated by the National Park Service in the 1930s and is now one of the largest state parks in Pennsylvania (DCNR 2005). The 3,064 ha park (elevation range: $274-366 \mathrm{~m}$ above sea level) features a 40.8 ha lake (Raccoon Lake) and large tracts of undeveloped land (DCNR 2005). Traverse Creek and Service Run flow $6 \mathrm{~km}$ from west to the east before entering Raccoon Creek Lake and eventually into Raccoon Creek. Additionally, there are many unnamed tributaries that flow into Traverse Creek, Service Run, Raccoon Lake and Raccoon Creek within the park's boundaries (DCNR 2005). The land use of Raccoon Creek State Park is over 90\% rural deciduous forest, with numerous small patches of rural mixed forest dominated by oaks (Quercus spp.), maples (Acer spp.) and basswoods (Tilia spp.), rural evergreen forests and rural perennial herbaceous plant cover. Soil types found within the riparian zones of Raccoon Creek State Park are the Atkins silt loam, Clymer loam, Culleoka silt loam, Ernest silt loam, Ernest very strong silt loam, Gilpin silt loam, Gilpin-Upshure complex, Gilpin-Weikert, Guernsey silt loam, Guernsey-Vandergrift complex, Hazleton channery loam, Monongahela loam, Philo silt loam, Pope silt loam, Urban land and Vandergraft-Gilpin complex (United States Department of Agriculture USDA 1982a).

Linn Run State Park is located 96 km east of Pittsburgh, PA, within the Laurel Mountains (396-853 m above sea level), encompasses 247 ha and borders the > 20,000 ha Forbes State Forest. Pennsylvania acquired this land in 1909 and was the first major public purchase of denuded forest land in the Ohio River Basin (DCNR 2005). About 15 years prior to the State's acquisition of the property, the entire old growth forested area was clear-cut. In 1910, the Pennsylvania Game Commission cooperated with the former Department of Forestry to restock white-tailed deer (Odocoileus virginianus) and traces remain of the 
Pittsburgh, Westmoreland and Somerset Railroad that serviced the area. The park has a varied topography and is $95 \%$ mixed hardwood (oaks and maples) and evergreen forests. Grove Run and Rock Run join to form Linn Run that flows from southeast to northwest through the park. Soil types found within the riparian zones of Linn Run State Park are the Atkins silt loam, Clymer loam, Ernest silt loam, Gilpin silt loam, Guernsey-Vandergrift complex, Urban land and Vandergraft-Gilpin complex (USDA 1982b).

Mingo Creek County Park (271-370 m above sea level) is a 1,052 ha park that is $19 \mathrm{~km}$ east of the City of Washington, PA. Aerial photographs reveal that this park has 70\% rural forests that are dominated by basswood, oaks and maples with the remaining $30 \%$ being fields for recreation. Mingo Creek meanders $6 \mathrm{~km}$ from west to east through the park and 2 historical covered bridges (Ebenezer and Henry) span the creek and many unnamed tributaries within the park's boundary flow into Mingo Creek. Soil types found within the riparian zones of Mingo Creek County Park are the Atkins silt loam, Clymer silt-loam, Ernest silt loam, Gilpin silt loam, Gilpin-Weikert, Guernsey silt loam, Philo silt loam, Pope silt loam, Urban land and Wharton silt loam (USDA 1982c).

State Game Land 203 (290-378 m above sea level) was established in 1942 when 2 parcels were donated to the Pennsylvania Game Commission with both parcels located just south of Warrendale, Allegheny County, PA. The 512 ha game land has the East Branch of the Big Sewickley Creek that flows several kilometers from east to west and transects the southern portion of the land and many unnamed tributaries that feed the East Branch. During the 1920s, the land was clear cut for timber and the forest has been permitted to regenerate and has not been cut since. An aerial photograph reveals that this game land is over $90 \%$ rural mixed deciduous forest that is dominated by maples, poplars and basswoods. The remaining 
$10 \%$ encompasses cleared areas for a pipeline right-a-way, food plots for deer management and 2 firearm ranges. Atkins silt loam, Cavode silt loam, Clymer silt loam, Gilpin Weikert Culleoka shaly silt loam, Ernest silt loam, Gilpin silt loam, Guernsey silt loam, Pope silt loam, Urban land and Wharton silt loam are the primary soil types found in the State Game Land 203 riparian zones (USDA 1982d).

Cedar Creek County Park, a study area used to verify the abundance models, is a 188 ha park located $43 \mathrm{~km}$ southeast of Pittsburgh, PA, just east of Rostraver, Westmoreland County, PA. Aerial photographs reveal that the park is $70 \%$ rural deciduous forest which is predominantly at the lower elevations $(229 \mathrm{~m})$ that is dominated by maples, poplars and oaks. The remaining $30 \%$ of the land is field and urban land which are more common at the higher elevations (344 m). The Manderino Riverfront accesses the Youghiogheny River which comprises the eastern edge of the park and Cedar Creek flows easterly and drains into the Youghiogheny. The Great Allegheny Passage (a trail that connects Pittsburgh, PA and Washington D.C.) passes through Cedar Creek Park along the Youghiogheny River. Soil types found within the riparian zones of Cedar Creek and the unnamed tributaries are the Clymer loam, Culleoka silt loam, Ernest silt loam, Gilpin silt loam, Gilpin-Upshure complex, Guernsey silt loam, Guernsey-Vandergrift complex, Hazleton channery loam, Monongahela loam, Philo silt loam, Pope silt loam, and Urban land (USDA 1982b).

\section{METHODS}

\section{Preliminary site determination}

In 2006 and 2007, we used information from the Pennsylvania State University's Pennsylvania Spatial Data Access (PASDA) and Global Information System (GIS) software from ArcGIS 9.1 to determine the possible "preferred habitat" stream reaches available in all 
4 study areas (PASDA 2005) (Appendix 5). Then, we investigated each low-order stream by finding it on a park map and conducted a preliminary walk-through to determine if the stream had the necessary components (canopy cover, herbaceous cover, stream "size", deciduous trees, presence of protective cover, trail bridges or any type of anthropogenic item that may impede the movement of salamanders and the presence of salamanders via observation within the stream channel) for this investigation (Southerland et al. 2007). If any stream had current major anthropogenic disruption, it was eliminated from a possible stream selection. Of the streams not eliminated by this preliminary walk-through, we randomly selected 4 streams in each study area for a total of 16 stream reaches.

Each stream reach width measured $2 \mathrm{~m}$ on each side of the stream's wetted edge to include the maximum northern dusky salamander retreat distance (Grover 2000, Hulse et al. 2001) and $60 \mathrm{~m}$ long. Also, we noted the presence of any trails, trail bridges or dirt roads that may have transected the stream. The width of a transecting trail, trail bridge or road was not included in the total length of the stream reach.

\section{Cover board placement}

Cover board placement aligned with the protocols of the North American Amphibian Monitoring Program (NAAMP), the North American component of the Declining Amphibian Populations Task Force (DAPTF) that is governed by the USGS (USGS 2004). In July 2007, we placed paired cover boards within $2 \mathrm{~m}$ of the stream channel with each pair being $2 \mathrm{~m}$ from each other at all 16 stream reaches. We placed 25 pairs of cover boards into 5 groups (of 5 pairs for each group) with each group being $5 \mathrm{~m}$ from an adjacent group (Mathis et al. 1995)

(Figure 2). Cover boards were placed as pairs to eliminate any intraspecies competition (Mathis et al. 1995). When we placed cover boards, leaf litter was removed and the soil 
leveled so that the board had maximum contact with the ground because boards that touch the ground are more attractive to Plethodon salamanders (Bonin and Bachand 1997). In the top right hand corner of each $30 \mathrm{~cm} \times 30 \mathrm{~cm} \times 5 \mathrm{~cm}$ cover board, we marked a 3-4 digit code indicating stream reach (1-4), group number (1-5) and cover board number (1-10). When a trail, trail bridge or road crossed the stream, we placed at least 1 group (5 pairs) of cover boards upstream or downstream of the transecting object. We temporarily marked the beginning and end of each stream reach with flagging by pounding a $1 \mathrm{~m} \times 1.25 \mathrm{~cm} \times 2.5 \mathrm{~cm}$ wood stake into the ground. In all, we placed 50 cover boards at each of the 16 stream reaches for a total of 800 cover boards.

\section{Visual encounter survey and visual implant elastomer}

Although the cover boards were placed in July 2007, data from the first year were not recorded because newly placed cover boards have depressed capture rates in relation to ones that have been there for a longer period of time (Grant et al. 1992). Starting in 2008, we checked the cover boards a total of 4 times during the spring sampling period (April and May) and 4 times during the fall sampling period (September and October). Our start date for the spring sampling period occurred after the complete thawing of the soil column, which occurs when temperatures are around $3-6^{\circ} \mathrm{C}$ (upper $30 \mathrm{~s}-$ lower $40^{\circ} \mathrm{F}$ ) and stopped about 2 months after that date (USGS 2005). The sampling method mimicked a robust design such that the first 2 cover board checks (visits 1 and 2) at any particular stream reach occurred within 5 days of each other (closed), likewise with the second set of checks (visits 3 and 4); while visits 3 and 4 occurred $>3$ weeks (open) after visits 1 and 2 .

We used a visual encounter survey (VES) as recommended by Southerland et al. (2007) and Bank et al. (2006) in conjunction with the cover boards to capture salamanders. The VES 
occurred within the stream, its channel and $2 \mathrm{~m}$ from the stream's edge starting at the first cover board (downstream) and ending at the last cover board $60 \mathrm{~m}$ upstream. During the VES, we overturned up to 100 cover items that were $20 \mathrm{~cm}$ in diameter (Grover 2000). We

used a 3-pass or 4-pass method (Southerland et al. 2007) such that after the $3^{\text {rd }}$ pass, a $4^{\text {th }}$ pass was completed if the total number of salamanders captured for the $1^{\text {st }}$ and $2^{\text {nd }}$ were less than the number of salamanders captured for $3^{\text {rd }}$ pass. Whether a salamander was captured under a cover board or during the VES, we measured the same habitat and salamander parameters. The northern dusky surface density was determined by taking the total number of northern dusky captured (both adult and juvenile) and dividing this count by the stream reach length $(60 \mathrm{~m})$.

We marked captured adult target salamanders with less than $0.1 \mathrm{ml}$ of a visible implant elastomer (VIE) with 1 of 4 colors (a particular color for each of the stream reaches within a study area). Markings were only injected at the beginning of every sampling season (spring and fall) and the placement of the VIE mark was on the underside of the salamander near the right front leg. If a salamander did not possess a front right leg, then we placed the VIE mark near the front left leg. If a salamander did not posses either front leg, then we placed the VIE mark near the hind legs. If a marking became undeterminable at a later capture period, we eliminated that individual salamander from any statistical analysis.

\section{Salamander data}

Handling of specimens was approved by the Saint Vincent College's Biology Department's Animal Care and Use Committee and all appropriate state and local permits were obtained to capture the salamanders. When a salamander was captured, it was placed into a plastic sandwich bag containing $5-10 \mathrm{~cm}^{3}$ of stream water and air (Southerland et al. 
2007). Then we placed the bag in a shaded spot and marked the spot with temporary flagging. Once the VES was completed, we measured, identified and recorded the following core data for all northern dusky salamanders captured: location captured, color of VIE mark placed on the salamander, snout to vent length (mm: snout to posterior end of cloacae), total length (mm; snout to end of tail), age (adult or juvenile), mass, (g; via an electronic balance) and anything unusual about an individual (missing tail, malformed, etc.). When a salamander was captured under a cover board, we recorded the same salamander data as if it were captured during the VES with the location being noted by the 3-4 digit cover board number (i.e., 1-3-7 would indicate that a salamander was observed at the $1^{\text {st }}$ stream reach of that particular study area, the $3^{\text {rd }}$ group of cover boards and the $7^{\text {th }}$ cover board of that group. If a salamander was captured during the VES (not under a cover board), then we used a similar 3-4) digit numbering system (i.e., 1-3-0 would indicate that a salamander was observed at the $1^{\text {st }}$ stream reach of that particular study area, the $3^{\text {rd }}$ group of cover boards, but not under any cover board). If a salamander was captured during the VES within the stream reach but between 2 cover board areas, then we used a similar numbering code (i.e., 1-23-0 would indicate that a salamander was observed at the $1^{\text {st }}$ stream reach of that particular study area, between the $2^{\text {nd }}$ and $3^{\text {rd }}$ cover board groups and not under any cover board).

We recorded the type of species using several identification keys and photographs to insure proper identification. While the salamander was in the plastic baggie, we used the edge of a ruler to straighten out the salamander against the baggie's edge and measured to the nearest $1 \mathrm{~mm}$ the salamander snout-to-vent length (SVL). If the vent could not be found, then the snout-to-hind leg distance was recorded in lieu of the SVL (Southerland et al. 2007). We 
measured the salamander's total length (ToL) from snout to the end of its tail using the same process as the SVL measurement.

All target salamanders were categorized as either a juvenile $(\mathrm{J})$ if their total length was $<44 \mathrm{~mm}$ and as an adult (A) if their total length was $\geq 44 \mathrm{~mm}$ (Grant et al. 2004). We

recorded the salamanders mass to the nearest $0.01 \mathrm{~g}$ by using an electronic balance by placing the baggie containing the salamander and water directly on the balance. We then released the salamander without removing any of the water by placing it directly on the ground near where it was captured. We re-weighed the baggie and water to determine the difference in mass with and without the salamander. Finally, if a salamander was captured under a cover board, we recorded any other ancillary data such as the presence of worms, ants, non-target amphibians and reptiles and or any other organisms.

\section{Habitat data}

The following data collection methods were followed at all stream reaches for every visit that occurred. In a shaded area at the beginning of each stream reach, we measured ambient air temperature $\left(\mathrm{T}_{\mathrm{a}}\right)$ to the nearest $0.1^{\circ} \mathrm{C}$ using a digital thermometer that was held 1 $\mathrm{m}$ from the ground (Grover 2000, Southerland et al. 2007). Every time a salamander was captured, we measured salamander retreat soil temperature $\left(T_{s}\right)$ to the nearest $0.1^{\circ} \mathrm{C}$ by placing a digital thermometer directly into the soil (Grover 2000, Raimondo et al. 2003). If for some reason we were unable to place the thermometer directly into the soil, we then measured the salamander retreat air temperature by placing the digital thermometer $2 \mathrm{~cm}$ from the soil surface where the salamander was captured. Water temperature $\left(T_{\mathrm{w}}\right)$ was measured to the nearest $0.1^{\circ} \mathrm{C}$ once at each stream reach using a digital thermometer that was placed in the middle of the stream with the tip of the thermometer $2 \mathrm{~cm}$ below the water surface 
(Southerland et al. 2007). If the stream was $<2 \mathrm{~cm}$ deep, the thermometer's bulb was submerged as much as possible to get an accurate reading.

We measured percent tree canopy cover $\left(\mathrm{C}_{\mathrm{t}}\right)$ once at the beginning of each cover board group with a densiometer by standing in 1 location and 4 readings were taken facing opposite directions (i.e., north, south, east and west). The mean of the 4 readings was recorded. For each group of cover boards, we estimated the average herbaceous cover (non-woody plant material $<2 \mathrm{~m}$ tall $)\left(\mathrm{C}_{\mathrm{h}}\right)$ and availability of protective cover (logs, root mats, moss, leaf litter clumps, rocks that were $20 \mathrm{~cm}$ in diameter, and coverboards) as a percentage of the total area within the stream channel using the ocular estimate guide obtained from Cornell University's Birds in Forested Lands project (Cornell University 2007). We calculated the percent of mature deciduous trees (16 $\mathrm{m}$ or taller) (D) by using a direct count method at the beginning of each stream reach for an area that was the length of the stream reach and $10 \mathrm{~m}$ wide $(5 \mathrm{~m}$ on each side of the stream reach) to incorporate canopy overhang of the stream.

We recorded the type of protective cover $\left(\mathrm{C}_{\mathrm{p}}\right)$ that each salamander was captured under and categorized the type of protective cover as 1 of 5 categories: cover board, rock, log, leaf litter or moss. At the beginning of each stream reach, we measured the $\mathrm{pH}$ of the stream to the nearest 0.1 by placing an electronic $\mathrm{pH}$ meter at least $1 / 3 \mathrm{~m}$ from the stream's edge and 2 $\mathrm{cm}$ below the water surface (Southerland et al. 2007). When 1/3 $\mathrm{m}$ from the stream's edge or $2 \mathrm{~cm}$ below the surface of the water could not be obtained, then the middle of the stream was used and we submerged the bulb as much as possible to get an accurate reading. We determined relative humidity $\left(\mathrm{H}_{\mathrm{r}}\right)$ to the nearest $1 \%$ by using a wet and dry bulb sling psychrometer; 3 measurements were taken and the mean was recorded. 
Using a metered tape, we measured the depth at $1 / 4,1 / 2$, and $3 / 4$ of the stream's wetted width to the nearest $1 \mathrm{~cm}$ and stream's wetted width to the nearest $1 \mathrm{~cm}$. All depth and width measurements were taken once at the beginning of each stream reach. We calculated the stream size $\left(\mathrm{cm}^{2}\right)\left(\mathrm{S}_{\mathrm{wd}}\right)$ by finding the average of the 3 depth measurements and multiplying this average by the stream's wetted width.

At the onset of each spring sampling period per year, we determined the presence of fish (P) by using a 2-pass method with seines (Southerland et al. 2007) throughout the entire length of each stream reach starting at the beginning (downstream) of each stream reach and worked our way upstream to the end of the stream reach. Then, we did the $2^{\text {nd }}$ pass by returning back to the beginning of the stream reach. The results were recorded as either a yes $(\mathrm{Y})$ or a no $(\mathrm{N})$ if any fish were captured.

\section{Statistical analysis}

We used SAS 9.2 to analyze the habitat and salamander data (SAS 2005) in a randomized block design (RBD) with repeated measures where each stream reach was an experimental unit. Over the 2 year study, each stream was visited a total of 16 times. The data were blocked, where applicable, at the study area level to examine any regional effects among the study areas. We examined the main effects (years, seasons, study areas and streams) and interactions between years, seasons, study areas and streams. We tested and measured parameter data for normality with scatter plots and normal probability plots. If any parameter data were not normal, we then normalized the data using log-transformation (Wang et al. 2000). Mean habitat parameter values for each stream reach were determined by taking the mean of the repeated measures (visits). Similarly, mean habitat values for year, season and study area were determined by using the mean values from each stream reach. We 
reviewed the salamander count data for homogeneity of variance using SAS PROC

UNIVARIATE along with normal probability and schematic plots and the data showed homogeneous variance. Mean stream reach salamander density was determined by using the counts from the repeated visits. The mean stream reach salamander density was then used to determine the mean density for year, season, and study area. We used Generalized Linear Models Procedure (PROC GENMOD) to examine the salamander count data and measured habitat parameters for main effects and interactions among years (2008 and 2009), sampling seasons (spring and fall), study areas $(n=4)$, and streams $(n=16)$. We used Poisson regressions to model the salamander counts among the study areas $(n=4)$, between sampling seasons, and among the stream reaches $(n=16)$. We also used Poisson regression to model salamander counts between areas where cover boards were placed and areas between where they were placed. We used ordinary least squares (OLS) and Generalized Linear Models Procedure (PROC GENMOD) to model measured habitat data among the study areas and among stream reaches. Salamander populations were estimated twice a year (spring and fall) using Schnabel Method mark and recapture (Overton 1965, Chapman and Overton 1966) from the repeated visits where salamanders were marked at the beginning of each season and recaptured at the next 3 visits. We estimated the northern dusky salamander density for each of the 16 stream reaches. The mark and recapture densities were then compared to the repeated measures densities to determine how well they correlated to one another.

We used a stepwise variable selection method from the models we developed and removed highly correlated variables. Soil temperature and water temperature correlated $\left(\mathrm{r}^{2}=\right.$ $0.93)$ to each other and to the mean temperature $\left(T_{m}=T_{s}+T_{w}+T_{a} / 3\right)\left(r^{2}=0.76\right)$. Ambient air temperature also correlated to mean temperature $\left(r^{2}=0.82\right)$. So we eliminated the 3 
measured temperatures (soil, water, and ambient air) and used the mean temperature in our models. Stream size correlated with the presence of fish $\left(\mathrm{r}^{2}=0.91\right)$ so we eliminated the latter and used the former. Thus, we used mean temperature, tree canopy cover, herbaceous cover, deciduous trees, relative humidity, protective cover and stream size in Chamberlin's (1965) multiple working hypothesis approach to assess 6 a priori linear regression models to predict the estimated density of the northern dusky salamander at each stream reach. We used Akaike's Corrected Information Criterion $\left(\mathrm{AIC}_{\mathrm{c}}\right)$ to select among the candidate a priori models which one had the best fit, with the best fit model having the smallest $\mathrm{AIC}_{\mathrm{c}}$ value (Burnham and Anderson 2002). We used Aikaike's weights and adjusted coefficients of determination $\left(\mathrm{R}^{2}{ }_{\text {adj }}\right.$ ) as a measure of performance (Gray et al. 1999a, b). We compared the $a$ priori models by using linear regression without any intercepts to evaluate the relation of the measured habitat parameters to salamander density and to insure no negative population estimates. We also compared the models by inspecting the $\mathrm{R}^{2}$ adj values, Akaike's weights and $\mathrm{AIC}_{\mathrm{c}} \Delta_{\mathrm{i}}=\left|\mathrm{AIC}_{\mathrm{c} \text { lowest }}-\mathrm{AIC}_{\mathrm{ci}}\right|$ for the $\mathrm{i}^{\text {th }}$ model. According to Burnham and Anderson (2002), a $\Delta_{\mathrm{i}}<2$ implies substantial support for the models while a $\Delta_{\mathrm{i}}>10$ implies essentially no support for a model when compared to the best model (i.e., lowest $\mathrm{AIC}_{\mathrm{c}}$ ).

After the salamander density and habitat parameters were modeled, we categorized streams as good or poor following the NAAMP recommendations $(\geq 10$ salamander observations $/$ visit $=$ good,$<10$ salamander observations/visit $=$ poor $)$ and used a multivariable logistic regression of the habitat parameters to model their odds ratio to determine which of the measured habitat parameters showed any relation to salamander density. Then we used a multivariable logistic regression to determine which variables and how much each variable impacts the density of northern dusky salamanders. Using the best fit model, we then created 
a post-hoc model with a corrected stream size parameter and added a constant to estimate salamander density. Using the same methods as described previously, habitat parameters were measured and salamanders were captured (but not marked) at 4 randomly chosen stream reaches at an independent study area (Cedar Creek County Park, Westmoreland County, PA) to validate this model in September of 2011. Then, we used the post-hoc model to estimate the northern dusky surface density at this independent study area. Finally, we used RAMAS Metapop 5.0 Viability Analysis for Stage-structured Metapopulations software to analyze the data to see if it fit any metapopulation characteristics as suggested by Hulse et al. (2001).

\section{A priori relative abundance modeling}

Six a priori models were designed to incorporate the measured biotic and abiotic habitat parameters to determine which model best explained the relative abundance of the northern dusky salamander. After removing the highly correlated variables $(|r| \geq 0.75)$, the following parameters were used in the development of the models: mean temperature $\left(\mathrm{T}_{\mathrm{m}}=\right.$ $\left.\left(T_{a}+T_{w}+T_{s}\right) / 3\right)$, tree canopy cover $\left(C_{t}\right)$, herbaceous cover $\left(C_{h}\right)$, percent of deciduous trees (D), $\mathrm{pH}$ of the stream $(\mathrm{pH})$, relative humidity $\left(\mathrm{H}_{\mathrm{r}}\right)$, stream size $\left(\mathrm{S}_{\mathrm{wd}}=\right.$ stream width $\times(($ depth at $1 / 4$ across + depth at $1 / 2$ at across + depth at $3 / 4$ across)/3)), and the availability of protective cover $\left(\mathrm{C}_{\mathrm{p}}\right)$ as a percentage of the total area within the stream reach. As previously described, the mean habitat values were determined (at the stream reach level) and used in the 6 a priori models. The a priori models are designed to be used by a field researcher so he or she can record several measurements and determine if the particular habitat is of high quality that would contain a relatively large density of the northern dusky salamander or not. For each of the a priori models, the higher the model value (MV), the higher the estimated relative salamander density. The symbols used in the models, justification of values used and whether 
the value was measured as a continuous variable or categorical variable are listed in Table 1. We examined the follow models to determine which a priori best predicted the northern dusky salamander density.

1. Global model in which all measured, non-correlated habitat parameters are incorporated. All of these measured parameters were chosen because of their relevance to impacting the relative abundance of northern dusky salamanders.

$$
\mathrm{MV}=\mathrm{S}_{\mathrm{wd}}+\mathrm{T}_{\mathrm{m}}+\mathrm{C}_{\mathrm{h}}+\mathrm{pH}+\mathrm{H}_{\mathrm{r}}+\mathrm{C}_{\mathrm{t}}+\mathrm{D}+\mathrm{C}_{\mathrm{p}}
$$

2. Global model with a larger emphasis (in this case, double) is placed on the following measured, non-correlated parameters: tree canopy cover and stream size. The values for these parameters are doubled because these are more critical to the relative abundance of northern dusky salamanders.

$$
\mathrm{MV}=2 \mathrm{~S}_{\mathrm{wd}}+\mathrm{T}_{\mathrm{m}}+\mathrm{C}_{\mathrm{h}}+\mathrm{pH}+\mathrm{H}_{\mathrm{r}}+2 \mathrm{C}_{\mathrm{t}}+\mathrm{D}+\mathrm{C}_{\mathrm{p}}
$$

3. Three parameter model using only \% tree canopy cover, \% herbaceous cover and $\mathrm{pH}$. This model was devised to include only certain measured, non-correlated parameters that evaluate the amount of plant cover and $\mathrm{pH}$.

$$
\mathrm{MV}=\mathrm{C}_{\mathrm{t}}+\mathrm{C}_{\mathrm{h}}+\mathrm{pH}
$$

4. Four parameter model using only the mean temperature, $\%$ tree canopy cover, $\%$ herbaceous cover and $\mathrm{pH}$. This model was devised to evaluate the impact of temperature may have on determining the relative abundance of northern dusky salamanders when compared to model 3.

$$
\mathrm{MV}=\mathrm{T}_{\mathrm{m}}+\mathrm{C}_{\mathrm{t}}+\mathrm{C}_{\mathrm{h}}+\mathrm{pH}
$$


5. Three parameter model using $\%$ tree canopy cover, stream size and $\%$ protective cover. This model was devised to use the 3 predicted most important characteristics of salamander habitat. Thus limiting the amount of work necessary to determine relative abundance of northern dusky salamanders.

$$
\mathrm{MV}=\mathrm{C}_{\mathrm{t}}+\mathrm{S}_{\mathrm{wd}}+\mathrm{C}_{\mathrm{p}}
$$

6. Three parameter model using $\%$ tree canopy cover, stream size and $\%$ herbaceous cover. This model assumes that stream size (and thus the presence of predatory fish) is important to the relative abundance of northern dusky salamanders.

$$
\mathrm{MV}=\mathrm{C}_{\mathrm{t}}+\mathrm{S}_{\mathrm{wd}}+\mathrm{C}_{\mathrm{h}}
$$

\section{RESULTS}

\section{Preliminary salamander data}

During a pilot study in 2006, we recorded 5 species of salamanders that were captured using a VES at 8 stream reaches within the Raccoon Creek State Park, Beaver County, Pennsylvania, that resulted in the discovery of adult and juvenile salamanders at each stream reach. In 2007, we expanded the pilot study to 3 additional study areas (Linn Run State Park (Westmoreland County), Mingo Creek County Park (Washington County) and State Game Land 203 (Allegheny County)) which provided opportunities to observe both adult and juvenile salamanders representing several species. The salamanders were observed under protective cover such as rocks, leaf litter, moss and woody debris. No data from the pilot study were analyzed because we collected only the presence and species of salamander.

\section{Descriptive salamander statistics}

We captured 2,287 salamanders ( $n=1,094$ in 2008 and $n=1,193$ in 2009) with 87\% $(n=1,998)$ being northern dusky salamanders and 13\% $(n=289)$ being non-target species 
that included mud puppy (Necturus maculosus) (5\%), northern 2-lined (Eurycea bislineata) (3\%), northern spring (Gyrinophilus porphyriticus porphyriticus) (3\%), seal (Desmognathus monticola) (1\%), spotted (Ambystoma maculatum) $(<1 \%)$ and red-backed (Plethodon cinereus) $(<1 \%)$ salamanders (Table 2). All 7 species were found in both 2008 and 2009. Of the 2,287 salamanders captured, 807 were recaptured (LRSP: $n=636$ captured, $n=225$ recaptured; MCCP: $n=218$ captured, $n=60$ recaptured; RCSP: $n=1,168$ captured, $n=439$ recaptured; SGL: $n=265$ captured, $n=83$ recaptured) during successive visits (visits 2-4, 58). The number of salamanders marked from the initial seasonal visit (visit 1 and 5) varied among study areas (LRSP: $n=123$ MCCP: $n=47$ RCSP: $n=274$, SGL: $n=61$ ). Salamanders that were recaptured within a sampling season were not re-marked with any additional VIE so we were unable to accurately determine if an individual salamander was recaptured more than once during successive visits. The total salamander density (no. salamanders $/ \mathrm{m}$ of stream reach surveyed) was similar between the $2008(\bar{x}=0.14$ salamanders $/ \mathrm{m}, \mathrm{SE}=0.05)$ and $2009(\overline{\mathrm{x}}=0.16$ salamanders $/ \mathrm{m}, \mathrm{SE}=0.06)$ study years; likewise, for the northern dusky salamander density $(2008: \overline{\mathrm{x}}=0.16$ salamanders $/ \mathrm{m}, \mathrm{SE}=$ 0.04, 2009: $\overline{\mathrm{x}}=0.17$ salamanders $/ \mathrm{m}, \mathrm{SE}=0.05)$.

\section{Temporal and spatial salamander data}

We constructed a 4-factor full effects model with the main effects of the model being: year, season, study area, and stream reach. We determined there were no statistical differences in the total salamander count main effects for year $\left(\chi^{2}{ }_{1,30}=6.08 ; P=0.658\right)$ and season $\left(\chi_{1,30}^{2}=1.43, P=0.853\right)$; however, salamander counts differed among study areas $\left(\chi_{3,60}^{2}=35.37, P<0.001\right)$ and stream reaches $\left(\chi^{2}{ }_{15,240}=28.57, P<0.001\right)$. Similarly, there were no statistical differences in the number of northern dusky captured between the study 
years $\left(\chi_{1,30}^{2}=5.03 ; P=0.822\right)$ and seasons $\left(\chi_{1,30}^{2}=1.59, P=0.802\right)$; however, northern dusky salamander count differed among study areas $\left(\chi_{3,60}^{2}=36.02, P<0.001\right)$ and stream reaches $\left(\chi^{2}{ }_{15,240}=29.23, P<0.001\right)$. Finally there were no statisical differences in the number of adult northern dusky captures (year: $\chi^{2}{ }_{1,30}=6.23 ; P=0.604$; season: $\chi_{1,30}^{2}=1.65, P=$ 0.789 ) nor juvenile northern dusky captures (year: $\chi^{2}{ }_{1,30}=5.63 ; P=0.704$ ); however, there was a difference in juvenile northern dusky count data between seasons $\left(\chi_{1,30}^{2}=18.08, P=\right.$ $0.031)$ and for both adult $\left(\chi_{1,30}^{2}=38.84, P<0.001\right)$ and juvenile $\left(\chi_{1,30}^{2}=34.25, P<0.001\right)$ northern dusky count data among study areas.

The 4-way interaction in total salamander count data for year $\times$ season $\times$ study area $\times$ stream reach $\left(\chi^{2}{ }_{15,180}=0.78, P=0.543\right)$ was not statistically significant. The 3-way interactions in total count data for year $\times$ season $\times$ study area $\left(\chi^{2}{ }_{7,360}=0.62, P=0.629\right)$, year $\times$ season $\times$ stream reach $\left(\chi^{2}{ }_{19,360}=1.02, P=0.439\right)$, year $\times$ study area $\times$ stream reach $\left(\chi^{2}{ }_{21,360}=\right.$ $0.43, P=0.657)$, and season $\times$ study area $\times$ stream reach $\left(\chi^{2}{ }_{21,360}=0.56, P=0.606\right)$ were also not statistically significant. Finally, the 2-way interactions for year $\times$ season $\left(\chi_{3,59}^{2}=2.98, P\right.$ $=0.638)$, year $\times$ study area $\left(\chi_{5,95}^{2}=1.98, P=0.749\right)$, year $\times$ stream reach $\left(\chi^{2}{ }_{15,239}=1.51, P=\right.$ $0.628)$, season $\times$ study area $\left(\chi^{2}{ }_{5,95}=2.05, P=0.691\right)$, season $\times$ stream reach $\left(\chi^{2}{ }_{15,239}=0.89, P\right.$ $=0.822)$, and study area $\times$ stream reach $\left(\chi^{2}{ }_{19,299}=1.96, P=0.539\right)$ were not statistically significant.

After removal of captured non-target species, the 4-way interaction in northern dusky count data for year $\times$ season $\times$ study area $\times$ stream reach $\left(\chi^{2}{ }_{18,216}=0.70, P=0.596\right)$ was not statisically significant. Similarly, the 3-way interactions in northern dusky count data for year $\times$ season $\times$ study area $\left(\chi_{3,39}^{2}=0.59, P=0.723\right)$, year $\times$ season $\times$ stream reach $\left(\chi^{2}{ }_{17,221}=0.93, P\right.$ $=0.499)$, year $\times$ study area $\times$ stream reach $\left(\chi_{17,221}^{2}=0.40, P=0.669\right)$, and season $\times$ study area 
$\times$ stream reach $\left(\chi^{2}{ }_{17,221}=0.48, P=0.678\right)$ also not statistically significant. Finally, the 2 -way interactions for year $\times$ season $\left(\chi^{2}{ }_{1,14}=3.11, P=0.606\right)$, year $\times$ study area $\left(\chi^{2}{ }_{1,14}=1.77, P=\right.$ $0.702)$, year $\times$ stream reach $\left(\chi^{2}{ }_{15,210}=1.23, P=0.774\right)$, season $\times$ study area $\left(\chi_{1,14}^{2}=1.42, P=\right.$ $0.737)$, season $\times$ stream reach $\left(\chi^{2}{ }_{15,210}=0.80, P=0.868\right)$, and study area $\times$ stream reach $\left(\chi^{2}{ }_{15,210}=1.43, P=0.627\right)$ were not statistically significant.

\section{Seasons}

Of the total number of captured salamanders, 1,251 (55\%) were captured during the spring sampling period (April and May) and 1,036 (45\%) in the fall (September and October). As previously mentioned, since there was no statistical difference in count between season, density between the fall $(\overline{\mathrm{X}}=0.14$ salamanders $/ \mathrm{m}, \mathrm{SE}=0.05)$ and spring $(\overline{\mathrm{X}}=0.16$ salamanders $/ \mathrm{m}, \mathrm{SE}=0.05)$ sampling periods were similar. Count data differed among seasons with 101 juvenile salamanders (36\%) captured during the spring and 181 juvenile salamanders $(64 \%)$ during the fall with the mean number of spring juvenile captures $(\bar{x}=0.08$ salamanders $/ \mathrm{m}, \mathrm{SE}=0.04)$ being $54 \%$ lower than the mean number of fall juvenile captures $(\overline{\mathrm{x}}$ $=0.04$ salamanders $/ \mathrm{m}, \mathrm{SE}=0.05)($ Table 3$)$. Finally, as previously mentioned, there were no seasonal interactions with respect to total salamander count and northern dusky salamander count data.

\section{Study areas}

There was a statistical difference $\left(\chi^{2}{ }_{3,60}=35.37, P<0.001\right)$ in the total number of salamanders captured among all 4 study areas with MCCP $(n=217)$ having the lowest number of captures, SGL $(n=264)$ being $22 \%$ higher, LRSP $(n=636)$ being $193 \%$ higher and RCSP $(n=1,170)$ being the highest (439\% higher than MCCP). Similarly, RCSP had the highest estimated northern dusky density $(\overline{\mathrm{x}}=0.27$ salamanders $/ \mathrm{m}, \mathrm{SE}=0.05)$ and LRSP was 
half as large $(\overline{\mathrm{x}}=0.13$ salamanders $/ \mathrm{m}, \mathrm{SE}=0.03) . \mathrm{SGL}(\overline{\mathrm{x}}=0.06$ salamanders $/ \mathrm{m}, \mathrm{SE}=0.03)$ and MCCP $(\overline{\mathrm{X}}=0.05$ salamanders $/ \mathrm{m}, \mathrm{SE}=0.03)$ had density values that were similar to each other, but both were half as large as LRSP (Table 4). We captured 7 species at RCSP with the northern dusky, northern spring, northern 2-lined and mud puppy captured in all 4 stream reaches. Five species were captured at LRSP, 4 species at SGL and 3 species at MCCP. Only the northern dusky was captured in all the stream reaches for all the study areas (Table 2). Finally, as previously described, there were no study area interactions with respect to total salamander count and northern dusky count data.

\section{Stream reaches}

Statistical differences were detected in the total number of salamanders captured among stream reaches at $\operatorname{LRSP}\left(\chi_{3,60}^{2}=29.23, P<0.001\right)$ with $86 \%$ of this study area's captures occurring at LRSP1 (45\%) and LRSP3 (41\%) and the remaining 14\% at LRSP2 (13\%) and LRSP4 (1\%). Likewise, at MCCP, 95\% of the captures for this study area occurred at MCCP2 (36\%), MCCP3 (24\%) and MCCP4 (35\%), while 5\% at MCCP1 $\left(\chi_{3,60}^{2}=\right.$ 44.70, $P<0.001)$. At RCSP, $87 \%$ of the captures for this study area occurred at RCSP1 (24\%), RCSP2 (37\%), and RCSP3 (26\%), while $13 \%$ at RCSP4 $\left(\chi_{3,60}^{2}=35.62, P<0.001\right)$. Finally, at SGL, $62 \%$ of the captures for this study area occurred at SGL4 and $38 \%$ occurring at SGL1 (7\%), SGL2 (21\%), and SGL3 (11\%) $\left(\chi^{2}{ }_{3,46}=26.37, P<0.001\right)$ (Table 2). All 4 stream reaches at RCSP not only had the highest densities, but they also had the least amount of variability in the densities, ranging from $0.15-0.38$ salamanders $/ \mathrm{m}$. The 4 stream reaches at SGL showed the largest range of densities ranging from as high as 0.16 salamanders $/ \mathrm{m}$ (SGL4) to as low as 0.02 salamanders/m at the SGL1 (Table 4). Finally, as previously 
described, the stream reach interactions with respect to total salamander count and northern dusky count data were not statistically significant.

\section{Cover items}

We captured $84 \%(n=1,924)$ of the total number of salamanders under rocks, $9 \%(n=$ 203) under cover boards, 3\% $(n=65)$ under leaves, $2 \%(n=54)$ under logs and $2 \%(n=41)$ under moss. We captured more salamanders $\left(F_{1,30}=42.38, P<0.001\right)$ under rocks during the spring sampling period (47\%) than during the fall sampling period (37\%), but all other protective cover items had similar capture percentages between the 2 sampling seasons: $5 \%$ under cover boards in the spring and $4 \%$ in the fall, $1 \%$ under leaves in the spring and $2 \%$ in the fall, $1 \%$ under logs for both spring and fall, and $1 \%$ under moss for both spring and fall (Table 6). All 4 of the study areas had a similar percent cover board capture rates (LRSP: $\bar{x}=$ $10.53 \%, \mathrm{SE}=0.75, \mathrm{MCCP}: \overline{\mathrm{x}}=7.54 \%, \mathrm{SE}=0.1 .21, \mathrm{RCSP}: \overline{\mathrm{x}}=8.24 \%, \mathrm{SE}=0.68, \mathrm{SGL}: \overline{\mathrm{x}}=$ $\left.7.00 \%, \mathrm{SE}=0.96, F_{3,60}=3.86 ; P=0.249\right)($ Table 7$)$. There was no statistical difference $\left(\mathrm{F}_{1,30}\right.$ $=9.07, \mathrm{P}=0.839)$ between the densities $(n=675$, density $=0.14$ salamanders $/ \mathrm{m}, \mathrm{SE}=0.05)$ in the area between the groups of cover boards ( $20 \mathrm{~m} / \mathrm{stream}$ reach) and the number captured $(n=1,612$, density $=0.11$ salamanders $/ \mathrm{m}, \mathrm{SE}=0.04)$ in the area where cover boards were placed (40 m/stream reach) (Table 5).

Although only $9 \%$ of the total number of salamanders captured was under cover boards, $25 \%$ of the total cover boards were used. There was a difference $\left(F_{3,48}=23.12 ; P<\right.$ 0.001) between total cover board use among study areas with RCSP having the highest use $(12.88 \%, \mathrm{SE}=2.54), \mathrm{LRSP}$ the next highest $(7.75 \%, \mathrm{SE}=2.63)$, then SGL $(2.88 \%, \mathrm{SE}=$ 1.47) and finally $\mathrm{MCCP}(1.88 \%, \mathrm{SE}=1.32)$. However, there was no difference in total cover board use between seasons (spring: $13.38 \%, \mathrm{SE}=2.14$, fall: $12.00 \%, \mathrm{SE}=1.99 ; F_{1,30}=1.31$; 
$P=0.839)$. There were differences $\left(F_{15,240}=39.48 ; P<0.001\right)$ in total cover board use among stream reaches within 2 of the study areas. In $\operatorname{LRSP}\left(F_{3,48}=44.67 ; P<0.001\right)$, LRSP1 (3.13\%), LRSP2 (2.25\%), and LRSP3, (2.13\%) all had similar total cover board use while LRSP4 $(0.24 \%)$ was lower. At SGL $\left(F_{3,48}=51.11 ; P<0.001\right)$, SGL1, SGL2, and SGL3 all had a total cover board use of $0.25 \%$ while SGL4 was 8 times higher (2.13\%). However, in $\operatorname{MCCP}\left(F_{3,48}=2.89 ; P=0.251\right)$, total cover board use ranged from a low at MCCP1 $(0.25 \%)$ to a high at MCCP4 $(0.88 \%)$ and similarly at $\operatorname{RCSP}\left(F_{3,48}=3.01 ; P=0.229\right)$, total cover board use ranged from a low at RCSP $(2.50 \%)$ to a high at RCSP2 (4.38\%). Furthermore, the mean total cover board use per visit across all study areas and stream reaches was low $(\overline{\mathrm{X}}=1.59 \%$, $\mathrm{SE}=0.42)$ and ranged from a high for the first visit during the first year of sampling $(2.38 \%)$ to a low on the second visit during the first year of sampling (1.00\%). Additionally, there were no juvenile salamanders found under any cover board, which may be indicative to semiaquatic species of salamanders having juvenile salamanders being more aquatic than adults. Finally, the data suggests that there is no relation between the amount of protective cover and cover board use (Figure 3).

\section{Salamander size}

Adult northern dusky salamanders had a mean SVL of $50.68 \mathrm{~mm}(\mathrm{SE}=0.21)$, a mean ToL of $100.67 \mathrm{~mm}(\mathrm{SE}=0.43)$ and a mean mass of $14.15 \mathrm{~g}(\mathrm{SE}=0.05)$ with no statistical difference in SVL $\left(F_{1,1710}=2.20, P=0.138\right)$, ToL $\left(F_{1,1710}=0.21, P=0.645\right)$ and mass $\left(F_{1,1710}\right.$ $=0.69, P=0.400$ ) between study years. Juvenile northern dusky salamanders had a mean SVL of $18.17 \mathrm{~mm}(\mathrm{SE}=0.26)$, a mean $\mathrm{ToL}$ of $36.62 \mathrm{~mm}(\mathrm{SE}=0.40)$ and a mean mass of $6.99 \mathrm{~g}(\mathrm{SE}=0.05)$ with no statistical difference in $\operatorname{SVL}\left(F_{1,279}=1.25, P<0.001\right), \operatorname{ToL}\left(F_{1,279}\right.$ $=0.03, P=0.856)$ and mass $\left(F_{1,279}=3.52, P=0.062\right)$ between study years $($ Table 3$)$. 


\section{Temporal and spatial habitat data}

We constructed a 4-factor full effects model with the main effects of the model being: year, season, study area, and stream reach. We determined there was no statistical difference $\left(\chi^{2}{ }_{1,30}=1.52, P=0.893\right)$ in the main effects for the measured habitat parameters between the 2 study years. More specifically, stream characteristics (stream size: $2008: \bar{X}=1,973.34 \mathrm{~cm}^{2}$, $\mathrm{SE}=45.23,2009: \overline{\mathrm{X}}=1,979.74 \mathrm{~cm}^{2}, \mathrm{SE}=43.50, F_{1,30}=0.01, P=0.978$; protective cover: 2008: $\overline{\mathrm{X}}=32.92 \%, \mathrm{SE}=0.53$ and 2009: $\overline{\mathrm{X}}=34.03 \%, \mathrm{SE}=0.53, F_{1,30}=2.24, P=0.134 ; \mathrm{pH}$ : 2008: $\overline{\mathrm{X}}=6.18, \mathrm{SE}=0.00$ and 2009: $\overline{\mathrm{X}}=6.20, \mathrm{SE} 0.00, F_{1,30}=0.72, P=0.963$ ), vegetative characteristics (canopy cover: $2008: \bar{X}=79.75 \%, S E=0.51$ and $2009: \bar{X}=80.40 \%$ SE $=0.48$, $F_{1,30}=0.51, P=0.474$; percent deciduous trees: $2008: \overline{\mathrm{x}}=98.15 \%, \mathrm{SE}=0.14$ and 2009: $\overline{\mathrm{x}}=$

98.22\%, SE 0.14, $F_{1,30}=0.07, P=0.792$; herbaceous cover: $2008: \overline{\mathrm{X}}=60.50 \%, \mathrm{SE}=0.47$ and 2009: $\overline{\mathrm{X}}=59.16 \%, \mathrm{SE}=0.48, F_{1,30}=2.35, P=0.186$ ), and atmospheric conditions (relative humidity: 2008: $\overline{\mathrm{x}}=66.22 \%, \mathrm{SE}=0.49$ and 2009: $\overline{\mathrm{x}}=67.59 \%, \mathrm{SE}=0.43 F_{1,30}=2.47, P=$ 0.117; mean temperature: $2008: \overline{\mathrm{X}}=14.58^{\circ} \mathrm{C}, \mathrm{SE}=0.07$ and $2009: \overline{\mathrm{X}}=13.78^{\circ} \mathrm{C}, \mathrm{SE}=0.06$, $\left.F_{1,30}=2.95, P=0.226\right)$ were statistically similar.

\section{Seasons}

There were statistical differences in the measured habitat parameters for the season main effect $\left(\chi_{1,30}^{2}=19.43, P<0.001\right)$. More specifically, there were statistical differences in the measured habitat parameters between the sampling seasons with stream size being $8 \%$ $\operatorname{larger}\left(F_{1,30}=35.43, P<0.001\right)$ in the spring $\left(\overline{\mathrm{X}}=2,053.97 \mathrm{~cm}^{2}, \mathrm{SE}=38.59\right)$ than the fall $(\overline{\mathrm{X}}$ $\left.=1,891.24 \mathrm{~cm}^{2}, \mathrm{SE}=47.49\right)$, herbaceous cover was $9 \%$ higher $\left(F_{1,30}=32.43, P<0.001\right)$ in the fall $(\overline{\mathrm{X}}=65.47 \%, \mathrm{SE}=0.42)$ than the spring $(\overline{\mathrm{X}}=56.11 \%, \mathrm{SE}=0.53)$ and relative humidity was $11 \%$ higher $\left(F_{1,30}=31.29, P<0.001\right)$ in the fall $(\overline{\mathrm{X}}=72.78 \%, \mathrm{SE}=0.45)$ than the spring 
$(\overline{\mathrm{X}}=61.80 \%, \mathrm{SE}=0.47)$. All other measured habitat parameters were the statistically similar between sampling seasons (canopy cover: spring: $\bar{x}=80.20 \%$, SE $=0.44$, fall: $\bar{x}=82.55$, SE $=0.40, F_{1,30}=2.46, P=0.854$; percent deciduous trees: spring: $\overline{\mathrm{x}}=97.91 \%, \mathrm{SE}=0.16$, fall: $\overline{\mathrm{x}}$ $=98.27 \%, \mathrm{SE}=0.15, F_{1,30}=1.57, P=0.942 ;$ protective cover: spring: $\overline{\mathrm{x}}=34.15 \%, \mathrm{SE}=0.54$, fall: $\overline{\mathrm{x}}=32.74 \%, \mathrm{SE}=0.58, F_{1,30}=3.90, P=0.601$; mean temperature: spring: $\overline{\mathrm{x}}=14.38^{\circ} \mathrm{C}$, $\mathrm{SE}=0.08$, fall: $\overline{\mathrm{x}}=13.93^{\circ} \mathrm{C}, \mathrm{SE}=0.07, F_{1,30}=3.42, P=0.748 ; \mathrm{pH}:$ spring: $\overline{\mathrm{x}}=6.18, \mathrm{SE}=$ 0.00 , fall: $\overline{\mathrm{X}}=6.20$, SE $0.00, F_{1,30}=0.97, P=0.983$ ).

\section{Study areas}

There were statistical differences in the measured habitat parameters for main effect of study area $\left(\chi_{3,60}^{2}=28.69, P<0.001\right)$. For example, statistical differences $\left(F_{3,60}=65.89, P\right.$ $<0.001)$ were detected in mean stream size among study areas such that the streams at LRSP $\left(\overline{\mathrm{X}}=2,889.56 \mathrm{~cm}^{2}, \mathrm{SE}=73.63\right)$ were at least $60 \%$ larger than the streams in $\operatorname{RCSP}(\overline{\mathrm{X}}=$ $\left.1,803.25 \mathrm{~cm}^{2}, \mathrm{SE}=37.99\right)$ and $\mathrm{SGL}\left(\overline{\mathrm{x}}=1,599.84 \mathrm{~cm}^{2}, \mathrm{SE}=114.66\right)$ and $800 \%$ larger than the streams in MCCP $\left(\overline{\mathrm{x}}=362.59 \mathrm{~cm}^{2}, \mathrm{SE}=22.21\right)$. Similarly, canopy cover in RCSP $(\overline{\mathrm{x}}=$ $84.05 \%, \mathrm{SE}=0.26), \operatorname{LRSP}(\overline{\mathrm{x}}=82.31 \%, \mathrm{SE} 0.49$ and $\operatorname{MCCP}(\overline{\mathrm{x}}=78.89 \%, \mathrm{SE}=1.22)$ was a minimum of $9 \%$ higher $\left(F_{3,60}=12.37, P<0.001\right)$ than in SGL $(\overline{\mathrm{X}}=69.71 \%, \mathrm{SE} 1.74)$. There was a maximum of $20 \%$ difference $\left(F_{3,60}=23.31, P<0.001\right)$ in herbaceous cover among the study areas (LRSP: $\overline{\mathrm{x}}=47.79 \%, \mathrm{SE}=0.66 ; \mathrm{MCCP}: \overline{\mathrm{x}}=67.09 \%, \mathrm{SE}=0.83 ; \mathrm{RCSP}: \overline{\mathrm{x}}=$ $65.41 \%, \mathrm{SE}=0.45$ and SGL: $\overline{\mathrm{X}}=61.69 \%, \mathrm{SE}=0.87)$, and a maximum of $22 \%$ difference $\left(F_{3,60}=26.74, P<0.001\right)$ in protective cover among the study areas $($ LRSP $\bar{x}=46.48 \%, \mathrm{SE}=$ $1.19 ; \mathrm{MCCP} \overline{\mathrm{x}}=35.35 \%, \mathrm{SE}=0.80 ; \operatorname{RCSP} \overline{\mathrm{x}}=28.43 \%, \mathrm{SE}=0.21$ and $\mathrm{SGL} \overline{\mathrm{x}}=24.86 \%, \mathrm{SE}$ $=0.59$ ). The remaining measured habitat parameters were statistically similar among the 
study areas $\left(\mathrm{T}_{\mathrm{m}}: F_{3,60}=2.79, P=0.756, \mathrm{pH}: F_{3,59}=1.31, P=0.874\right.$, percent deciduous trees: $F_{3,60}=1.22, P=0.898$ and relative humidity: $\left.F_{3,60}=3.16, P=0.532\right)$ (Appendix 6).

\section{Stream reaches}

There were statistical differences in the measured habitat parameters for the main effect of stream reach $\left(\chi_{15,240}^{2}=24.21, P<0.001\right)$. For example, statistically significant differences were detected in herbaceous cover $\left(F_{15,240}=17.54, P<0.001\right)$, protective cover $\left(F_{15,240}=84.32, P<0.001\right)$, percent tree canopy $\left(F_{15,240}=77.94, P<0.001\right)$, and stream size $\left(F_{15,240}=64.81, P<0.001\right)$. For example, LRSP1 $\left(\overline{\mathrm{X}}=4,532 \mathrm{~cm}^{2}, \mathrm{SE}=46.55\right)$ was approximately twice as large as both $\operatorname{LRSP} 3\left(\overline{\mathrm{X}}=2,036 \mathrm{~cm}^{2}, \mathrm{SE}=11.13\right)$ and LRSP4 $(\overline{\mathrm{X}}=$ $\left.1,975 \mathrm{~cm}^{2}, \mathrm{SE}=49.08\right)$ and approximately 31 times larger than LRSP2 $\left(\overline{\mathrm{X}}=145 \mathrm{~cm}^{2}, \mathrm{SE}=\right.$ 9.28), $\operatorname{MCCP} 1\left(\overline{\mathrm{X}}=1,920 \mathrm{~cm}^{2}, \mathrm{SE}=102.75\right)$ was about 4 times as large as MCCP4 $(\overline{\mathrm{X}}=515$ $\left.\mathrm{cm}^{2}, \mathrm{SE}=31.28\right)$ and about 9 times larger than $\operatorname{MCCP} 2\left(\overline{\mathrm{X}}=214 \mathrm{~cm}^{2}, \mathrm{SE}=15.64\right)$ and $\operatorname{MCCP} 3\left(\overline{\mathrm{X}}=200 \mathrm{~cm}^{2}, \mathrm{SE}=20.72\right)$; at RCSP all 4 streams varied in size with $\mathrm{RCSP} 1(\overline{\mathrm{X}}=$ $\left.3,023 \mathrm{~cm}^{2}, \mathrm{SE}=22.49\right)$ being the largest and $\operatorname{RCSP} 4\left(\overline{\mathrm{x}}=246 \mathrm{~cm}^{2}, \mathrm{SE}=5.02\right)$ being the smallest; and all 4 streams at SGL varied with SGL1 $\left(\overline{\mathrm{X}}=6,033 \mathrm{~cm}^{2}, \mathrm{SE}=81.41\right)$ being the largest and SGL4 $\left(\overline{\mathrm{X}}=481 \mathrm{~cm}^{2}, \mathrm{SE}=4.37\right)$ being the smallest. However, there were no statistically significant differences among stream reaches with respect to percent deciduous trees $\left(F_{15,240}=0.97, P=0.903\right)$, mean temperature $\left(F_{15,240}=1.40, P=0.658\right), \mathrm{pH}\left(F_{15,240}=\right.$ $0.84, P=0.942)$ and relative humidity $\left(F_{15,240}=1.24, P=0.743\right)$ (Appendix 7).

\section{Habitat interactions}

The 4-way interaction in measured habitat parameters for year $\times$ season $\times$ study area $\times$ stream reach $\left(\chi^{2}{ }_{18,216}=1.54, P=0.408\right)$ was not statistically significant. The 3-way interactions in measured habitat parameters for year $\times$ season $\times$ study area $\left(\chi_{3,39}^{2}=0.76, P=\right.$ 
$0.604)$, year $\times$ season $\times$ stream reach $\left(\chi^{2}{ }_{15,195}=1.93, P=0.402\right)$, year $\times$ study area $\times$ stream reach $\left(\chi^{2}{ }_{15,195}=0.58, P=0.743\right)$, and season $\times$ study area $\times$ stream reach $\left(\chi^{2}{ }_{17,221}=0.79, P=\right.$ 0.549) were also not statisitically significant. Finally, the 2 -way interactions for year $\times$ season $\left(\chi_{1,14}^{2}=3.41, P=0.597\right)$, year $\times$ study area $\left(\chi_{3,42}^{2}=1.86, P=0.632\right)$, year $\times$ stream reach $\left(\chi^{2}{ }_{15,210}=1.31, P=0.721\right)$, season $\times$ study area $\left(\chi^{2} 3,42=1.53, P=0.707\right)$, season $\times$ stream reach $\left(\chi_{15,210}^{2}=0.87, P=0.823\right)$, and study area $\times$ stream reach $\left(\chi^{2}{ }_{45,288}=1.54, P=0.598\right)$ were not statistically significant.

\section{Good and poor habitat parameters}

The linear regression models that were used to compare the non-correlated measured habitat parameters to the mean northern dusky salamander densities of each stream reach were used to determine the relation, if any, between density and mean habitat parameter (Figure 4). More specifically, percent deciduous trees $\left(F_{1,30}=2.45, P=0.856\right)$, mean temperature $\left(F_{1,30}=\right.$ $3.98, P=0.702)$, herbaceous cover $\left(F_{1,30}=4.53, P=0.503\right), \mathrm{pH}\left(F_{1,30}=3.32, P=0.769\right)$, and relative humidity $\left(F_{1,30}=2.77, P=0.823\right)$ all suggested that there was no relation between mean habitat parameter and northern dusky salamander density. Tree canopy cover $\left(F_{1,30}=\right.$ 48.65, $P<0.001)$ and protective cover $\left(F_{1,30}=30.42, P<0.001\right)$ suggested a relation between the mean habitat value and northern dusky salamander density.

We then compared the non-correlated measured habitat parameters of the 7 good streams (LRSP1, LRSP3, RCSP1, RCSP2, RCSP3, RCSP4, SGL4) that averaged $\geq 10$ captured salamanders/visit to the 9 poor streams (LRSP2, LRSP4, MCCP1, MCCP2, MCCP3, MCCP4, SGL1, SGL2, SGL3) that averaged < 10 captured salamanders/visit. We discovered that the mean canopy cover for the good streams $(\overline{\mathrm{X}}=84 \% \mathrm{SE}=0.19)$ was $22 \%$ higher $\left(F_{1,30}\right.$ $=33.72, P<0.001)$ than the poor streams $(\overline{\mathrm{X}}=62 \%, \mathrm{SE}=1.32)$, mean protective cover for 
the good streams $(\overline{\mathrm{X}}=35 \%, \mathrm{SE}=0.44)$ was $9 \%$ higher $\left(F_{1,30}=20.43, P<0.001\right)$ than the poor streams $(\overline{\mathrm{X}}=26 \%, \mathrm{SE}=0.63)$, and mean stream size was $70 \%$ higher $\left(F_{1,30}=66.56, P<\right.$ 0.001 ) for good streams (good: $\bar{X}=2,146 \mathrm{~cm}^{2}, \mathrm{SE}=32.35$; poor: $\overline{\mathrm{X}}=1,266.60 \mathrm{~cm}^{2}, \mathrm{SE}=$ 81.99) (Figure 5). All other measured habitat parameters between the good stream and poor stream had similar values (herbaceous cover: good: $\overline{\mathrm{X}}=59 \%, \mathrm{SE}=0.39$, poor: $\overline{\mathrm{X}}=63 \%, \mathrm{SE}=$ $0.63, F_{1,30}=3.96, P=0.494 ; \mathrm{pH}:$ good: $\overline{\mathrm{x}}=6.20, \mathrm{SE}=0.00$, poor: $\overline{\mathrm{x}}=6.15, \mathrm{SE}=0.00, F_{1,30}$ $=1.84, P=0.893$; deciduous trees: good: $\overline{\mathrm{X}}=99 \%, \mathrm{SE}=0.08$, poor: $\overline{\mathrm{X}}=97 \%, \mathrm{SE}=0.37$, $F_{1,30}=1.01, P=0.935$; relative humidity: good: $\overline{\mathrm{x}}=68 \%, \mathrm{SE}=0.36$, poor: $\overline{\mathrm{x}}=64 \%, \mathrm{SE}=$ $0.78, F_{1,30}=3.36, P=0.597$; mean temperature: good: $\overline{\mathrm{x}}=14^{\circ} \mathrm{C}, \mathrm{SE}=0.16$, poor: $\overline{\mathrm{x}}=15^{\circ} \mathrm{C}$, $\left.\mathrm{SE}=0.25, F_{1,30}=2.42, P=0.734\right)($ Figure 5).

An odds ratio analysis showed that percent tree canopy cover was the most significant factor in determining the quality of a stream with respect to the northern dusky salamander such that for every $1 \%$ point decrease below the good stream mean tree canopy cover (84\%), there was a $13 \%$ increased chance that the stream would be classified as a poor stream. The second most important parameter was percent protective cover such that for every $1 \%$ point decrease below the good stream mean protective cover $(35 \%)$, there was a $1.8 \%$ chance that the stream would be classified as a poor stream. The last measured habitat parameter that had an impact on salamander density was stream size such that for every $1 \mathrm{~cm}^{2}$ of deviation (above or below) from the good mean stream size of $2,146 \mathrm{~cm}^{2}$, there was $0.1 \%$ chance that a stream being a poor stream. The small difference may not appear to be significant change, but there were large variances in stream size that ranged from as small as $200 \mathrm{~cm}^{2}$ to greater than $6,000 \mathrm{~cm}^{2}$ 


\section{Mark and recapture estimates versus repeated measure estimates}

A mark and recapture population estimate was used to estimate the northern dusky salamander density for each of the 16 stream reaches (Table 8). As previously described, only adult northern dusky salamanders were marked and there was no statistical difference in the mark and recapture density between study years $(2008: \bar{x}=0.19$ salamanders $/ \mathrm{m}, \mathrm{SE}=0.03$; 2009: $\overline{\mathrm{X}}=0.23$ salamanders $\left./ \mathrm{m}, \mathrm{SE}=0.04 ; F_{1,30}=0.68, P=0.412\right)$ and seasons (spring: $\overline{\mathrm{X}}=$ 0.24 salamanders $/ \mathrm{m}, \mathrm{SE}=0.03$; fall: $\overline{\mathrm{X}}=0.18$ salamanders $/ \mathrm{m}, \mathrm{SE}=0.03 ; F_{1,30}=1.96, P=$ 0.167). There also was no statistical difference $\left(F_{15,240}=2.45, P=0.153\right)$ in the number of recaptures among visits (visit $2: \overline{\mathrm{X}}=59.33 \%, \mathrm{SE}=0.33,150$ of 254 salamanders; visit 3: $\overline{\mathrm{X}}=$ $62.67 \%, \mathrm{SE}=1.20,129$ of 204 salamanders; visit $4: \overline{\mathrm{X}}=59.67 \%, \mathrm{SE}=3.18,145$ of 238 salamanders, visit $6: \bar{x}=66.00 \%, \mathrm{SE}=0.00,137$ of 220 salamanders; visit $7: \overline{\mathrm{X}}=67.00 \%, \mathrm{SE}$ $=0.00,132$ of 206 salamanders; visit $8: \overline{\mathrm{X}}=64.33 \%, \mathrm{SE}=0.33,124$ of 199 salamanders), nor was there any statistical difference $\left(F_{1,30}=2.54, P=0.153\right)$ between sampling seasons (spring: $\overline{\mathrm{X}}=61.00 \%, \mathrm{SE}=1.57$, fall: $\overline{\mathrm{X}}=63.67 \%, \mathrm{SE}=4.84$ ). Furthermore, there was no difference among the study areas $\left(F_{3,60}=62.34, P=0.579\right)$ in the percent of salamanders that were later recaptured at subsequent visits (LRSP: $\overline{\mathrm{X}}=65.78 \%, \mathrm{SE}=4.39$; $\mathrm{MCCP}: \overline{\mathrm{X}}=$ $57.63 \%, \mathrm{SE}=8.93 ; \mathrm{RCSP}: \overline{\mathrm{X}}=63.26 \%, \mathrm{SE}=7.12 ; \mathrm{SGL}: \overline{\mathrm{X}}=61.19, \mathrm{SE}=5.24)$. Although the percent of recaptured salamanders among study areas was similar, there were differences in density among study areas $\left(F_{1,30}=41.33, P<0.001\right)$ and stream reaches $\left(F_{1,30}=57.02, P<\right.$ 0.001). RCSP had the highest mark and recapture density estimate $(\overline{\mathrm{X}}=0.43$ salamanders $/ \mathrm{m}$, $\mathrm{SE}=0.04)$, while LRSP was half as large $(\overline{\mathrm{X}}=0.20$ salamanders $/ \mathrm{m}, \mathrm{SE}=0.03)$, and both $\operatorname{MCCP}(\overline{\mathrm{X}}=0.10$ salamanders $/ \mathrm{m}, \mathrm{SE}=0.02)$ and $\operatorname{SGL}(\overline{\mathrm{X}}=0.11$ salamanders $/ \mathrm{m}, \mathrm{SE}=0.03)$ were half as large as LRSP. Within LRSP, the mark and recapture northern dusky salamander 
density at LRSP1, LRSP2, and LRSP3 ( $\overline{\mathrm{X}}=0.25, \mathrm{SE}=0.03)$ was 13 times larger than LRSP4 $(\overline{\mathrm{X}}=0.02, \mathrm{SE}=0.01)$. A similar pattern was seen at SGL where SGL1, SGL2, SGL3 ( $\overline{\mathrm{X}}=$ 0.06 salamanders $/ \mathrm{m}, \mathrm{SE}=0.03)$ were one-fifth as large as SGL4 $(\overline{\mathrm{X}}=0.29$ salamanders $/ \mathrm{m}, \mathrm{SE}$ $=0.04)$. At RCSP, the salamander density ranged from a low at $\operatorname{RCSP} 4(\overline{\mathrm{x}}=0.30, \mathrm{SE}=0.02)$ to a high at $\operatorname{RCSP} 2(\overline{\mathrm{x}}=0.54, \mathrm{SE}=0.04)$. Similarly, at MCCP, $\operatorname{MCCP} 1(\overline{\mathrm{x}}=0.04, \mathrm{SE}=0.02)$ had the lowest density and MCCP4 had the highest $(\overline{\mathrm{X}}=0.19, \mathrm{SE}=0.03)$.

Although the mark and recapture data showed similar salamander density trends among years, seasons, study areas and stream reaches as the repeated measures salamander density; for every stream reach, the mark and recapture density estimates ranged from $0.01-$ 0.26 salamanders/m higher than the repeated measures density estimates. A scatter plot graph of the mark and recapture densities and the repeated measures densities indicated they were highly correlated with a $\mathrm{R}_{\text {adj }}^{2}$ value $>0.95$ (Figure 6). Since the repeated measures densities and mark and recapture densities were so highly correlated, and the $\mathrm{R}^{2}$ adj values for the mark and recapture density versus model estimates (Figure 7) were, in general, lower than $R_{\text {adj }}^{2}$ values for the repeated measures versus model estimates (Figure 8), the repeated measures densities were used for the remaining analyses.

\section{A priori relative abundance models}

Comparison of the 6 a priori models indicated that Model $5\left(\mathrm{AIC}_{\mathrm{c}}=209.88, \mathrm{w}_{5}=\right.$ 0.921) was the best model, while the next best model (Model 6: $\left.\mathrm{AIC}_{\mathrm{c}}=215.79, \mathrm{w}_{6}=0.048\right)$ and all other models carried little weight (Table 9). Additionally, scatter plots of the estimated northern dusky density versus the determined density from repeated measures indicate that Model 5 had the highest correlation (Figure 8) and included 3 measured parameters (tree canopy cover, protective cover, and stream size). However, Model 5 had a 
tendency to underestimate the northern dusky density for many of the stream reaches. For example, 11 of the 16 original streams were under-estimated and several (LRSP4, MCCP1, SGL1, SGL2, and SGL3) all had percent errors that were > 100\%. The mean percent error for each study area varied $(\mathrm{LRSP}=310 \%, \mathrm{MCCP}=153 \%, \mathrm{RCSP}=72 \%$, and $\mathrm{SGL}=501 \%)$; however, in 3 of the 4 study areas, the large percent error was influenced by one stream in each study area having a large percent error. For example, LRSP had a percent error $=310 \%$, but this was influenced by LRSP4 having a 1,080\% error, while the other 3 stream reaches having a percent error $\leq 80 \%$. Similar results occurred in MCCP and SGL study areas. Only in RCSP did the percent error values remain consistent (45-87\%) where one stream appeared not to be more influential than the others. Furthermore, Model 5 appeared to have a larger percent error for stream reaches with a lower density (Figure 9a). This was apparent in several streams (LRSP1, LRSP4, MCCP1, SGL1, SGL2, and SGL3) all having a percent error of $\geq 133 \%$, while stream with higher densities (LRSP3, RCSP1, RCSP2, RCSP3, RCSP4, and SGL4) all had percent error values $\leq 87 \%$ (Table 10 ).

\section{Post-hoc relative abundance model}

Data analysis prompted the creation of a post-hoc model (model 7) that incorporated a slightly modified stream size parameter $\left(\mathrm{S}^{\prime}{ }_{\mathrm{wd}}\right)$ and the 2 most important non-correlated measured riparian habitat parameters (tree canopy cover and protective cover). This determined the absolute value difference between the mean stream size of the good streams $(\overline{\mathrm{X}}$ $\left.=2,146 \mathrm{~cm}^{2}\right)$ and the stream size of the $\mathrm{i}^{\text {th }}$ stream.

$$
S^{\prime}{ }_{w d}=\left|S_{w d}-2,146\right|
$$

This new stream size difference $\left(S^{\prime}{ }_{w d}\right)$ was then compared to the mean stream densities in a linear regression and new $\mathrm{R}_{\text {adj }}^{2}$ value $\left(\mathrm{R}_{\text {adj }}^{2}=0.0767\right)$ was obtained that was 64 times greater 
than that of the original stream size $\left(S_{w d}\right) R_{\text {adj }}^{2}$ value of 0.0012) (Figure 10). Then, a constant was added to the post-hoc model and expressed as:

$$
\mathrm{MV}=151.13+(0.00345) \mathrm{C}_{\mathrm{t}}+(0.000148) \mathrm{C}_{\mathrm{p}}-(0.0014) \mathrm{S}_{\mathrm{wd}}^{\prime}
$$

With these modifications, model $7\left(\mathrm{AIC}_{\mathrm{c}}=203.83\right)$ had a $\Delta \mathrm{AIC}_{\mathrm{c}}=6.05$ lower than the previous best model (model 5) and a 0.0652 higher $\mathrm{R}_{\text {adj }}^{2}$ of 0.5095 (Figure 11). When using the original 16 streams, model 7 was able to estimate the density (with a percent error of $\leq$ $75 \%$ of the estimated number of salamanders $/ \mathrm{m}$ ) $69 \%$ of the time as opposed to model 5 which estimated density $38 \%$ of the time (with a percent error of $\leq 75 \%$ of the estimated number of salamanders/m). Similarly, model 7 was able to estimate the density (with a percent error $\leq 50 \%$ of the estimated number of salamanders $/ \mathrm{m}$ ) $44 \%$ of the time as opposed to model 5 which estimated density $13 \%$ of the time (with a percent error $\leq 50 \%$ of the estimated number of salamanders/m) (Table 10). Thirteen of the 16 estimated densities from model 7 were closer to the repeated measures densities than model 5 (Table 10). However, in 2 (LRSP and MCCP) of the 4 study areas, the average study area percent error was higher for model 7 than model 5. In these study areas, though, the average percent error for model 7 appeared to be largely influence by a single stream reach. For example, in LRSP, LRSPS4 had a percent error of $1,680 \%$ while all other streams in LRSP had a percent error $\leq 84 \%$. Similarly, in MCCP, MCCP1 had a percent error of 917\%, while all other streams in MCCP had a percent error $\leq 27 \%$. Again like model 5, the percent error values in RCSP were the most consistent $($ Percent error $=55-64 \%)$. Similar but opposite to model 5, the post-hoc model had a tendency to have a larger percent error for stream reaches with a higher density (Figure 9b). 


\section{Verification of the post-hoc model}

The post-hoc model was verified at an independent study area (Cedar Creek County Park, Westmoreland County, Pennsylvania) during September 2011. The verification indicated that model 7 was able to estimate the salamander density at the independent study area (with a percent error of $\leq 75 \%$ of the estimated number of salamanders $/ \mathrm{m}$ ) $75 \%$ of the time and the salamander density at the independent study area (with a percent error of $\leq 50 \%$ of the estimated number of salamanders $/ \mathrm{m}$ ) $25 \%$ of the time (Table 10). When used to analyze the original 16 streams, model 7 was able to estimate the salamander density (with a percent error of $\leq 75 \%$ of the estimated number of salamanders $/ \mathrm{m}$ ) lower ( $69 \%$ of the time) than at the verification study area, but this may be due to the lower number of test streams at the verification study area. Similarly, this occurred at the $\leq 50 \%$ error level (original 16 streams $=44 \%$ of the time). Additionally, the percent error values at CCCP had a similar narrower range (36-103\%) as the streams in RCSP and a similar study area average percent error $($ RCSP: percent error $=60 \%$, CCCP: percent error $=65 \%)$. Finally, 2 of the stream density estimates (CCCP2 and CCCP4) from model 7 were lower than the estimates from model 5, while the other 2 (CCCP1 and CCCP3) were higher.

\section{Metapopulation analysis}

Analysis using RAMAS Metapop was limited because we did not determine population growth rates, standard deviation of the growth rate, or survival rates. We were able to input for analysis the location of each stream reach, initial population (we used salamander count data), average dispersal distance, and maximum dispersal distance. When these data were input and run through the simulation, all stream reaches in MCCP, RCSP and SGL were too far apart from each other to allow for movement among them. Our data 
supported these results such that no salamander that was first captured and VIE marked in 1 stream reach was later captured in a different stream. For LRSP, the RAMAS Metapop analysis indicated that LRSP2, LRSP3 and LRSP4 were all close enough to each other to allow the movement of salamanders from 1 stream to another; however, our data did not support this result because no salamander that was first captured and VIE marked in 1 stream was later captured in another stream.

\section{DISCUSSION}

\section{Critical habitat parameters}

Modeling species populations and determining how the population reacts to environmental changes is crucial to successful wildlife management plans and Mader (1984), Miller et al. (1997), and van Buskirk (2005) have all shown that stream-side or pond salamander abundance is inversely related to the quality of the surrounding habitat. Our study indicated that tree canopy cover was the most important riparian habitat characteristic such that a $1 \%$ point decrease in canopy cover from good streams mean $(84 \%)$ meant a $13 \%$ increased chance that the stream would be a poor stream and have $<10$ captures $/ 60 \mathrm{~m}$, as defined by the NAAMP. Others (Orser and Shure 1972, Beschta and Platts 1986 van Buskirk 2005 and Bank et al. 2006) have indicated that the amount of protective cover in the stream also negatively impacts salamander density and our study indicated it was the second most important parameter such that for every $1 \%$ point decrease from the good stream mean (35\%), there was a $1.8 \%$ increased chance that the stream would be categorized as a poor stream. Stream size is also an important factor in estimating salamander populations because if a stream is too small, it may be an intermittent stream that becomes too dry and unsuitable for stream-side salamander; a stream also may be too large and contain predatory fish that may 
feed on juvenile salamanders (USGS 2004). Our study determined the mean good stream size to be $2,146 \mathrm{~cm}^{2}$. We found that for every 1 unit $\left(\mathrm{cm}^{2}\right)$ increase or decrease in the stream size from the good stream mean, there was a $0.1 \%$ increased chance of the stream being categorized as a poor stream.

The odds ratio analysis confirmed the AIC analysis that the 3 most important habitat parameters to impact northern dusky salamander densities are canopy cover, protective cover and stream size, respectively. For example, LRSP4, MCCP1, SGL1, SGL2 and SGL3 all had low percent canopy cover and a low number of captures. Furthermore LRSP4, MCCP1, SGL2 and SGL3 all had relatively lower percent protective cover $(\overline{\mathrm{X}}=15 \%, 9 \%, 14 \%$ and $21 \%$ respectively) than the good stream mean $(\bar{x}=35 \%)$ and thus lower number of observations ( $n=8,76,55$, and 28) when compared to the good streams. Finally, LRSP2, MCCP2 and MCCP3 appeared to be too small in size, and SGL1 and SGL2 appeared to be too big in size to support higher amounts of salamanders. Thus, ideal northern dusky salamander habitat consists of primarily head-water streams with intact riparian zones, higher percent canopy cover, abundant rocky substrate and shallow water.

\section{Salamander abundance models}

All of our models had a format similar to the Habitat Suitability Indices (HSI) published by the USGS that is measuring certain aquatic and terrestrial parameters useful for impact assessment and habitat management. Currently, the USGS has 1 published HSI model for the red-spotted newt (Notophthalmus viridescens) (Healy 1981, 1983). Our Model 5, which included tree canopy cover, protective cover and stream reach, proved to be the best fit a priori model (Chamberlin 1965) because of its lowest $\mathrm{AIC}_{\mathrm{c}}$ value and highest Akaike weight, and higher $\mathrm{R}_{\text {adj }}^{2}$ value (Burnham and Anderson 2002). Models 6 and 3 also had 3 
measured parameters but percent herbaceous cover in model 6 showed no correlation to salamander density, likewise with $\mathrm{pH}$ in models 6 and 3. All other a priori models added parameters that penalized them when using $\mathrm{AIC}_{\mathrm{c}}$ (Burnham and Anderson 2002). Finally, the global models (models 1 and 2) were the poorest and appeared to be over-parameterized.

The post-hoc model (model 7) proved to be better at estimating salamander density than a priori model 5 because we adjusted the stream size to fit our mean of the good streams and we added a constant. The independent verification of the post-hoc model (model 7) showed that it was able to estimate (with a percent error of $\leq 75 \%$ of the estimated number of salamanders $/ \mathrm{m}$ ) the salamander density $75 \%$ of the time. Additionally, the post-hoc model was able to estimate the salamander density (with a percent error of $\leq 50 \%$ of the estimated number of salamanders $/ \mathrm{m}$ ) $25 \%$ of the time. Estimates determined by the post-hoc model were closer to the repeated measures salamander density 13 out of the 16 times than model 5 . In all, model 7 could be used to estimate the density of the northern dusky salamander and if an anthropogenic disturbance must occur (i.e., development, logging) in a certain area, this model could be a valuable conservation management tool to help determine the type, severity, size and timing of the disturbance.

\section{Habitat parameters and density estimates}

The 9 poor streams were classified as poor (USGS 2005) because each one had a difference in 1,2 , or all 3 crucial habitat factors (stream size, tree canopy cover and protective cover). For example, LRSP2 (which had only 80 observations) had a $4 \%$ lower tree canopy cover indicating it had a $52 \%(4 \times 13 \%)$ increased chance of being a poor stream from lack of tree canopy cover alone. Additionally, LRSP2 had a small stream size $\left(\overline{\mathrm{X}}=144 \mathrm{~cm}^{2}\right)$ when compared to the good stream reach stream size $\left(\overline{\mathrm{X}}=2,146 \mathrm{~cm}^{2}\right)$ which resulted in the stream 
reach having a $200 \%\left(2,002 \mathrm{~cm}^{2} \times 0.1 \%\right)$ increased chance of being a poor stream from stream size alone; however, LRSP2 had a 7\% higher mean protective cover which gave it a $13 \%(7 \times 1.8 \%)$ increased chance of being a good stream. When all 3 of these factors were combined, LRSP2 had a $239 \%$ increased chance of being classified as a poor stream. SGL3, which had only 29 observations, was low in all 3 important factors and had a $646 \%$ increased chance of being a poor stream. In all, we noticed that poor stream reaches with 1 poor factor (LRSP2, MCCP2, MCCP3, MCCP4, and SGL1) had lower number of captures $(\overline{\mathrm{X}}=61, \mathrm{SE}=$ 0.76), while poor stream reaches with at least 2 poor factors (LRSP4, MCCP1, SGL2 and SGL3) had the lowest number of captures $(\overline{\mathrm{X}}=24, \mathrm{SE}=0.66)$. Again indicating not only that ideal northern dusky salamander habitat consists of primarily head-water streams with intact riparian zones, higher percent canopy cover, abundant rocky substrate and shallow water, but also that salamanders are sensitive to their surroundings and can be used as an indicator species.

In many cases, when a road transects a stream, the stream is usually disrupted to a certain degree such that the amount of tree canopy and the amount of protective cover on either side of the road is reduced (Orser and Shure 1972, Mader 1984, Bescheta and Platts 1986, Miller et al. 1997). Furthermore, studies have indicated that these disruptions could have impacts a minimum of $35 \mathrm{~m}$ into the forested area from each side of the road (de Maynadier and Hunter 1995). As indicator species, salamander populations need to be incorporated into conservation management plans that involve protecting road side tree canopy cover and protective cover, especially where the roads transect a stream. Previous studies (Orser and Shure 1972, Mader 1984, Bescheta and Platts 1986, Miller et al. 1997, Grant et al. 2004, Bank et al. 2006) have indicated that disruption of a stream habitat when it 
is intersected by a road can lead to lower canopy cover, lower herbaceous cover, lower

protective cover, faster stream currents, higher turbidity and drier riparian zones that surround the transect. For example, in several locations on the SGL and LRSP, the type and amount of protective cover changed as a stream approached a road that intersected it such that the protective cover became larger and more boulder-like. These boulders were typically stacked atop of one another, thus leaving areas that were above the water line and therefore drier and warmer conditions which would be less suitable for the northern dusky salamander. As indicated by this study, a single factor may severely decrease the salamander density.

\section{Model limitations}

Orser and Shure (1972) reported that as water quality decreases so can the salamander population. We did measure $\mathrm{pH}$, but not any other water quality parameter such as specific conductance, dissolved oxygen, turbidity or any nutrient ion concentration (nitrates, sulfates, phosphates, etc.) because we focused on measuring the physical components of the salamander habitat. Furthermore, all of our measured $\mathrm{pH}$ values ranged from 6.1-6.3 which did not allow us to effectively determine its impact on salamander density. As part of our stream selection process, our 16 selected streams and 4 post-hoc streams were located in areas where the stream's headwaters flowed from undisturbed forested land which can imply that there was no excessive turbidity or nutrient pollution, but not confirmed.

Model 7 was able to estimate the density at MCCP2 (percent error $=14 \%)$; however, it underestimated the density (percent error $=64 \%$ ) at RCSP2. This may be due to the lower amount of protective cover (26\%) available at RCSP2. Overall, the model appears to overestimate streams with lower relative abundances and to under-estimate the stream reaches with higher relative abundance (i.e., LRSP1, RCSP1, RCSP2, and RCSP3). Plausible 
explanations for these inaccuracies may include 1) stream and riparian zone parameters that we did not measure such as: stream velocity, stream slope, water nutrient and mineral quality, specific type of tree canopy cover (i.e., oak trees versus maple trees), age of canopy cover (i.e., young stand versus old stand), and the amount of substrate embeddedness, or 2) that the relation between northern dusky salamander density and the habitat parameters may not be linear.

\section{Salamander sizes and densities}

We did not distinguish in our data between male and female northern dusky salamanders and expected our mean SVL $(\overline{\mathrm{X}}=50.68 \mathrm{~mm}, \mathrm{SE}=0.21)$ for adult salamanders to fall between the SVL reported by Hulse et al. (2001) for male $(\overline{\mathrm{X}}=51.2 \mathrm{~mm})$ and female $(\overline{\mathrm{X}}=$ $46.2 \mathrm{~mm}$ ) northern dusky salamanders in Pennsylvania. Additionally, our mean SVL was similar to the SVL reported by Grover $(2000)(\overline{\mathrm{X}}=51.1 \mathrm{~mm})$ in New York; however, our SVL was larger than the $23 \mathrm{~mm}$ SVL reported by Grant et al. (2004) in Virginia. This interpopulation variation in length is possible (Davic 1983) and may be due to elevation differences (Takahashi and Pauley 2010). Our mean ToL $(\overline{\mathrm{X}}=100.67 \mathrm{~mm}, \mathrm{SE}=0.40 \mathrm{~mm})$ was $6 \%$ longer than the mean $(94 \mathrm{~mm})$ reported by Hulse et al. (2001) and 59\% longer than the mean reported by Grant et al. (2004) of $41 \mathrm{~mm}$. Our mean mass $(\overline{\mathrm{X}}=14.15 \mathrm{~g}, \mathrm{SE}=0.05$ g) was $77 \%$ heavier than a reported mean mass $(\overline{\mathrm{X}}=3.19 \mathrm{~g})$ by Grover $(2000)$.

Our study showed that juvenile northern dusky salamanders had a mean ToL $(\overline{\mathbf{X}}=$ $36.62 \mathrm{~mm}, \mathrm{SE}=0.40 \mathrm{~mm})$ and a mean SVL $(\overline{\mathrm{X}}=18.17 \mathrm{~mm}, \mathrm{SE}=0.26 \mathrm{~mm})$ which was less than reported by Grant et al. (2004) $(\overline{\mathrm{X}}=44 \mathrm{~mm})$. Hulse et al. (2001) reported that juvenile northern dusky salamanders were $10-12.5 \mathrm{~mm}$ in ToL when they emerge from their eggs as early as August. We observed juvenile salamander lengths larger than this in September and 
October, but there have been no reports to show juvenile salamander growth rate in their first month after hatching. Our larger number of juvenile captures in the fall sampling period as opposed to the spring sampling period was because northern dusky salamander eggs hatch during the fall (August - October) and our fall sampling period occurred at this time.

The USGS (2004) and BeeBee and Rowe (2005) both report that there is a general decrease in amphibian populations, but Smith and Green (2005) report that species specific data are too few to make any class-wide generalizations. Our overall density (total number of salamanders captured / total stream length $(\mathrm{m})$ searched $=1$ salamander $/ 6.7 \mathrm{~m}$ ) was lower than that reported by Hall (1977; 1 salamander/0.8 m of stream) from Tioga County, PA.

However, our overall density (total number of salamanders captured $/ \mathrm{m}^{2}=1$ salamander $/ 26.9$ $\mathrm{m}^{2}$ stream reach area) was similar to that reported by Burton and Likens (1975; 1 salamander $/ 26.3 \mathrm{~m}^{2}$ of forest) in the Hubbard Brook Experimental Forest.

\section{Cover board use and numbers}

Grover (2000) reported that $51 \%$ of the observed northern dusky salamanders were discovered under wooden cover object while only $38 \%$ were discovered under rocks. Furthermore, red-backed salamanders were captured $29 \%$ of the time under cover boards in Québec, Canada (Moore and Wyman 2010). Although our study had 9\% of the individuals captured under a wooden cover board while the remaining $91 \%$ were captured under other items, primarily rocks, but also moss, logs and leaves, $25 \%$ of the cover boards were used. While other amphibian studies have experienced success using wooden cover boards (Moore and Wyman 2010, Grover 2000, Monti 1995, Feder 1983), we recommend their use on more terrestrial types of salamander species and not stream-side salamanders. One explanation to 
the low cover board use by the northern dusky salamanders may be due to the large amount of natural cover already present (Heyer et al. 2001).

The number of cover boards used in this study $(n=800)$ exceeds the number of cover boards used in prior studies by Marsh and Goicochea (2003; $n=169)$, Raimondo et al. (2003; $n=320)$ and Bailey et al. $(2004 ; n=100)$. With all the factors (material cost, production cost, placement, and checking time) needed to use cover boards as a tool to capture salamanders, along with the possibility of having a percentage of the cover boards lost or broken (up to $40 \%$ in our study), the overall effectiveness of attracting stream side salamanders was minimal. We believe our cover boards were not as successful in capturing salamanders as compared to other studies because there was ample rock protective cover in most of our stream reaches and our cover boards were placed outside the stream channel to prevent loss from flooding, but still within the average retreat site distance of $2 \mathrm{~m}$ (Ashton 1975, Heyer et al. 2001). It may to be more efficient to use a visual encounter survey when surveying stream-side salamanders.

\section{Are northern dusky populations metapopulations?}

We believe that northern dusky salamander populations do possess metapopulation characteristics with respect to streams because this study supports the 4 conditions reported by Hanski and Gilpin (1997). Hanski and Gilpin (1997) states 2 key premises behind the metapopulation approach and they are that populations are spatially structured into assemblages of local breeding populations and that migration among the local populations has some effect on local dynamics. In order to support these 2 main premises, Hanski and Gilpin (1997) suggest 4 conditions that must be met. 
Condition 1: The habitat supports a local breeding population. According to Grant et al. (2004), the presence of larval salamanders indicates that the population is reproducing and resident in the stream on an annual basis. This study recorded that juvenile salamanders were observed during $2008(n=133)$ and $2009(n=149)$ in all but 2 of the stream reaches (MCCP1 and SGL1). Two other stream reaches recorded a relatively low number of juvenile observations (SGL3, $n=3$ and LRSP2, $n=2$ ), while the remaining 12 stream reaches ranged from 10-52 juvenile northern dusky juvenile salamanders. Thus, because these streams had significant numbers of juvenile salamanders observed over 2 years, these 12 stream reaches are believed to support condition 1 .

Condition 2: No single population is large enough to ensure long-term survival. Bank et al. (2006) reported that historical assessment of northern dusky salamander populations and ranges indicate that during a comprehensive survey of stream habitats in the mid-1950s, all age classes were commonly found in streams with cobble substrates and adults and larvae were widely distributed throughout Acadia National Park, Maine. During 2000-2003, Bank et al. (2006) searched the habitat of the northern dusky salamander that historically supported the salamander and found only 2 adult salamanders in the lower reaches of 1 stream. Furthermore, no eggs or larvae were observed, indicating even large populations of northern dusky salamanders can be extirpated. Although the cause for the observed decline is unknown, Bank et al. (2006) identified multiple stressors including stocking of predatory fish, fungal pathogens, substrate embeddedness, and widespread pollution (i.e., from atmospheric pollutants). Our study suggests that northern dusky salamander density can be so low possibly due to poor habitat characteristics that less than 2 salamanders are captured per visit, as observed in LRSP4, MCCP1, SGL1 and SGL3 (Table 9). Furthermore, our study indicates 
that if several factors (tree canopy cover, protective cover and stream size) do not exist at ideal levels, then northern dusky salamander populations can be severely reduced. Finally, if these certain poor habitat conditions exist, then there may be the absence of juvenile salamanders as was the case with 2 of our stream reaches, thus, supporting condition 2.

Condition 3: Patches are not too isolated to prevent recolonization. In several studies (Barbour et al. 1969; Ashton 1975), northern dusky salamanders have been reported to migrate distances of $17 \mathrm{~m}$ and $20 \mathrm{~m}$. Furthermore, Berven and Grudzien (1990), Sjogren (1991), Conroy et al. (1995) and Vos and Chardon (1998) all use $1 \mathrm{~km}$ as the distance beyond which amphibian populations would be isolated from dispersal events. Likewise, Smith and Green (2005) report that $94 \%$ of the maximum dispersal distances for salamanders are less than $1 \mathrm{~km}$. Thus, indicating that most salamanders may not move far, but some individuals may complete long-distance movements (home range $=48.4 \mathrm{~m}^{2}$ ) as reported by Barbour et al. (1969) especially when the presence of water acts as a stressor. Numerous low order streams exist throughout each of the study areas which may allow for recolonization to occur. Furthermore, analysis of our data supported the idea that migration from 1 stream reach to another is possible (as analyzed by RAMAS) even though it was not observed. However, one must realize that if certain factors caused salamanders in a stream to become extirpated, that stream may remain devoid of northern dusky salamanders until the detrimental factors are removed. In all, supporting condition 3.

\section{Condition 4: Local dynamics are sufficiently asynchronous to make simultaneous} extinction of all local populations unlikely. Because of the topography of the 4 study areas, many small isolated watersheds are present. Thus, simultaneous extinction of all populations within each study area, due to a localized disturbance, is highly unlikely. This study suggests 
that certain streams can have certain riparian zone characteristics that may result in extremely low northern dusky salamander population estimates, while other streams within the same study area can sustain larger salamander populations, thus, supporting condition 4.

\section{MANAGEMENT IMPLICATIONS}

Salamander populations can be used as indices of stream quality (Orser and Shure 1972) because they are sensitive to degradation of water quality and riparian disruption (Orser and Shure 1972, Beschta and Platts 1986, Henle et al. 1996, Miller et al. 1997). Our results indicate if even 1 habitat parameter (tree canopy cover or protective cover) was not at an optimal level, there was a decrease in the northern dusky salamander relative abundance. Conservation management plans need to incorporate the protection of not only headwater riparian zones but also the surrounding buffer zone because the effects of anthropogenic disturbances reach as far as 50 or more meters into a neighboring ecosystem. Thus, planning of development and or disturbances, especially in parks and wildlife reserves, needs careful attention. Furthermore, the increase in logging and Marcellus natural gas drilling in Pennsylvania and the northeastern United States has meant the creation of more rural roads into areas that never had roads before. These rural roads may transect headwater streams and conservation plans need to incorporate the impact of such crossing. Typically, the stream habitat is usually disrupted to a certain degree such that the amount of tree canopy and the amount of protective cover on either side of the road is reduced. Additionally, installation of an appropriate culvert needs to be incorporated because they also impact stream quality, such as appropriate sized protective cover for nesting sites, protection from predators, and providing idea habitat. Our results indicated that the amount of protective cover $(20 \mathrm{~cm}$ in 
diameter) does impact salamander relative abundance and streams without the optimal amount have reduced numbers.

Because certain salamander species have a strong site fidelity and limited dispersal, small first-order streams may act as isolated populations (Barbour et al. 1969, Houck and Bellis 1972, Ashton 1975, Berven and Grudzien 1990, Sjogren 1991, Vos and Chardon 1998, Newman and Squire 2001, Conroy and Brook 2003, Smith and Green 2005). Our results indicate that the northern dusky salamander does have strong site fidelity and limited dispersal capability. Thus, the probability of recolonization of an extirpated stream depends on the proximity of other streams and the matrix that exists between them. Thus, any type of development that could compromise the quality of the stream habitat or the matrix could decrease and even extirpate a population of northern dusky salamanders. Conservation and management of a stream and its riparian zone is vital at all times, but protection appears to be extremely important during the spring because of the eggs embedded in the stream substrate and their susceptibility to harm. Likewise, stream and riparian zone protection during the fall is extremely important because there are a larger number of juvenile salamanders present in the streams and may be susceptible to harm because many semi-aquatic salamanders spend their juvenile lives submerged in streams until they mature. Finally, our salamander density model (model 7) could be used to estimate a stream's salamander density. It could be used for long-term studies to see if a particular stream is experiencing a decrease in salamander populations as generalized by others. Furthermore, this model could be used to evaluate a stream to determine if and where, type, severity, size and timing of any anthropogenic disturbance that must occur (i.e., development, logging, drilling, etc.) in a certain area. Also, 
this model could be used to as a valuable tool to predict the impact of a disruption to the riparian zone by estimating the salamander abundance before and after the disruption. 


\section{ACKNOWLEDGMENTS}

We thank the Pennsylvania Department of Conservation of Natural Resources (DCNR) (Raccoon Creek and Linn Run), Washington County Parks and Recreation (Mingo Creek County Park) and the Pennsylvania Game Commission (State Game Land 203) for allowing us access to these properties. We thank Dr. Kyle J. Hartman, Dr. J. Todd Petty and Dr. Petra Bohall Wood for comments on this manuscript. Finally, we thank all those who helped place the necessary cover boards and all those who helped collect habitat and salamander data over the past several years. 


\section{LITERATURE CITED}

Adair, S.M., L.D., J. Doyle, A. Edwards, S. Jacobson, R. Jemison, L. Lewis, W. Melgin, C. Napper, T. Ratcliff, and T. Warhol. 2002. Management and techniques for riparian restorations. United States Department of Agriculture, Forest Service, Rocky Mountain Research Center, Research Note: RMRS-CTR-102.

Ashton, R.E., Jr. 1975. A study of movement, home range, and winter behavior of Desmognathus fuscus. Journal of Herpetology 9:85-91.

Bailey, L.L., T. Simmons, and K.H. Pollock. 2004. Temporal and spatial variation in detection probability of Plethodon salamanders using robust capture-recapture design. Journal of Wildlife Management 68:1-13.

Bailey, L.L., J.E. Hines, J.D. Nichols, and D.I MacKenzie. 2007. Sampling design trade-offs in occupancy studies with imperfect detection; examples and software. Ecological Applications 17:281-290.

Bank, M.S., J.B. Crocker, S. Davis, D.K. Brotherton, R. Cook, J. Behler, and B. Connery. 2006. Population decline of northern dusky salamanders at Acadia National Park, Maine, USA. Biological Conservation 130:230-238.

Barbour, R.W., J.W. Hardin, J.P. Schafer, and M.J. Harvey. 1969. Home Range, movements, and activity of the dusky salamander, Desmognathus fuscus. Copeia 1969:293-297.

Becker, C.G., C.R. Fonseca, C.F.B. Haddad, and P.I. Prado. 2010. Habitat split as a cause of local population declines of amphibians with aquatic larvae. Conservation Biology 24:287-294.

BeeBee, T.J.C., and G. Rowe. 2005. Intraspecific competition disadvantages inbred Natterjack toad (Bufo calamit) genotypes over out bred ones in a shared pond environment. Journal of Animal Ecology 74:71-76.

Belisle, M. and C.C. St. Clair. 2001. Cumulative effects of barriers on the movements of forest birds. Conservation Ecology 5:9. [online] URL: http://www.consecol.org/vol5/iss2/art9.

Beschta, R.L., and W.S. Platts. 1986. Morphological features of small streams: significance and function. Water Resources Bulletin 22:369-379.

Berven, K.A. and T.A. Grudzien. 1990. Dispersal in the wood frog (Rana sylvatica): implications for genetic population structure. Evolution 44:2047-2056.

Bonin, J., and Y. Bachand. 1997. The use of artificial covers to survey terrestrial salamanders in Quebec. Herpetological Conservation 1:175-179. 
Boward, D.M., P.F. Kazyak, S.A. Stranko, M.K. Hurd, and T.P. Prochaska. 1999. From the mountains to the sea: the state of Maryland's freshwater streams. EPA 903-R-99-023. Maryland Department of Natural Resources, Monitoring and Non-tidal Assessment Division, Annapolis, MD.

Burton, T.M., and G.E. Likens. 1975. Salamander populations and biomass in the Hubbard Brook Experimental Forest, New Hampshire. Copeia 1975:541-546.

Burnham, K.P. and D.R. Anderson. 2002. Model selection and multimodel interference: a practical information-theoretic approach. Second edition. Springer-Verlag, New York, New York, USA.

Bury, R.P., and P.S. Corn. 1988. Responses of aquatic streamside amphibians to timber harvest: a review. In K.J. Raedeke (ed.), Streamside management: riparian wildlife and forestry interactions. Contribution No. 59, Institute of Forest Resources, University of Washington, Seattle, Washington, USA.

Chamberlin, T.C. 1965. (1890). The method of multiple working hypotheses. Science 148:754-759.

Chambers, D.L. 2008. Logging road effects on breeding site selection in Notophthalus viridescens (red-spotted newt) and three Ambystomatid salamanders in south-central Pennsylvania. Northeastern Naturalist 15:123-130.

Chapman, D.G., and W.S. Overton. 1966. Estimating and testing differences between population levels by the Schnabel estimation method. Journal of Wildlife Management 30:173-180 .

Conroy, M.J., Y. Cohen, F.C. James, Y.G. Matsinos, and B.A. Maurer. 1995. Parameter estimation, reliability, and model improvement for spatially explicit models of animal populations. Ecological Applications 5:17-19.

Corn, P.S., and R.P. Bury. 1989. Logging in western Oregon: responses of headwater habitats and stream amphibians. Forest Ecology and Management 29:39-57.

Cornell University. 2007. Visual Estimates of Percentage Cover. http://www.birds.cornell.edu/bfl/percentcover.pdf

Crawford, J.A., and R.P. Semlitsch. 2007. Estimation of Core Terrestrial Habitat for stream breeding salamanders and delineation of riparian buffers for protection of biodiversity. Conservation Biology 21:152-158.

Davic, R.D. 1983. Micrographic body size variation in Desmognathus fuscus fuscus salamanders from Western Pennsylvania. Copeia 1983:1101-1114. 
de Maynadier, P.G., and M.L. Hunter, Jr. 1995. The relationship between forest management and amphibian ecology: a review of the North American literature. Environmental Review 3:230-261.

Department of Conservation of Natural Resources. 2005. Pennsylvania State Parks. http://www.dcnr.state.pa.us/stateparks/parks/raccooncreek.aspx.

Feder, M.E. 1983. Integrating the ecology and physiology of plethodontid salamanders. Herpetologica 39:291-310.

Graham, C., J.E. Martinez-Levva, and L.C. Paredes. 2002. Use of fruiting trees by birds in continuous forest and riparian forest remnants in Los Tuxtlas, Veracruz, Mexico. Biotropica 34:589-597.

Grant, B.W., A.D. Tucker, and J.E. Lovich. 1992. The use of cover boards in estimating patterns of reptile and amphibian biodiversity, in Wildlife 2001 eds. McCullough D. R., and R. H. Barret. Elsevier Science Pub., London, England.

Grant, E., H. Cambell, R.E. Jung, and K.C. Rice. 2004. Stream salamander species richness and abundance in relation to environmental factors in Shenandoah National Park, Virginia. American Midland Naturalist. 153:348-356.

Gray, M.J., R.M. Kaminski, and G. Weerakkody. 1999a. Predicting seed yield of moist-soil plants. Journal of Wildlife Management 63:1261-268.

Gray, M.J., R.M. Kaminski, and G. Weerakkody. 1999b. A new method to predict seed yield of moist-soil plants. Journal of Wildlife Management 63:1269-1272.

Greenwald K.R., H.L. Gibbs, and T.H. Waite. 2009. Efficacy of land cover models in predicting isolation of marbled salamander populations in a fragmented landscape. Conservation Biology 23:1232-1241.

Grover, M.C., 2000. Determinants of salamander distributions along moisture gradients. Copeia. 2000:156-168.

Hairston, N.G. Sr., and R.H. Wiley. 1993. No decline in salamander (Amphibia: Caudata) populations: a twenty-year study in the southern Appalachians. Brimeyana 1.

Hall, R.J. 1977. A population analysis of two species of streamside salamanders, genus Desmognathus. Herpetologica 33:109-113.

Hanski, I., and M. Gilpin. 1997. Metapopulation biology: ecology, genetics, and evolution. Academic Press. New York, New York, USA.

Harris, L.D., 1984. The fragmented forest: Island biogeography theory and the preservation of biotic diversity. University of Chicago Press, Chicago, Illinois, USA. 
Healy, W.R. 1981. Field test of an HSI model for the red-spotted newt, Notophthalmus viridescens, for the Habitat Evaluation Procedures Group. U.S. Fish and Wildlife Service, Fort Collins, Colorado, USA.

Healy, W.R. 1983. Re-evaluation of the terrestrial component of the HSI model for the redspotted newt (Notophthalmus viridescens. U.S. Fish and Wildlife Service, Fort Collins, Colorado, USA.

Henle, K., P. Poschlod, C. Margules, and J. Settele. 1996. Species survival in relation to habitat quality, size and isolation: Summary conclusions and future directions. In $\mathrm{J}$. Settele, C. Margules, and P. Poschlod (eds) Species survival in fragmented landscapes. Kluwer Academic Publishers, Norwell, Massachusetts, USA.

Heyer, R., M. Donnelly, R. McDiarmid, L. Hayek, and M. Foster. 2001. Measuring and monitoring biological diversity: Standard methods for amphibians. Smithsonian Institution Press, Washington D.C., USA.

Homyack, J.A., C.A. Haas, and W.A. Hopkins. 2011. Energetics of surface-active terrestrial salamanders in experimentally harvested forest. Journal of Wildlife Management. 75:1267-1278.

Houck, M.A., and E.D. Bellis. 1972. Comparative tolerance to desiccation in Desmognathus $f$. fuscus and Desmognathus o. ochrophaeus. Journal of Herpetology 6:209-215.

Hulse, A.C., C.J. McCoy, and E.J. Censky. 2001. Amphibians and reptiles of Pennsylvania and the Northeast. Cornell University Press. Ithaca, New York, USA.

Jackson, S.D. 2003. Ecological considerations in the design of river and stream crossings, In C.L. Irwin, P. Garret, and K.P. McDermott (Eds.), 2003, Proceedings of the International Conference on Ecology and Transportation. Raleigh, North Carolina: Center for Transportation and the Environment, North Carolina State University.

Lawler, J.J., S.L. Shafer, B.A. Bancroft, and A.R. Blaustein. 2010. Projected climate impacts for the amphibians of the western hemisphere. Conservation Biology 24:38-50.

Mader, H.J. 1984. Animal habitat isolation by roads and agricultural fields. Biological Conservation 29:81-96.

Marsh, D.M. and M.A. Goicochea. 2003. Monitoring terrestrial salamanders: biases caused by intense sampling and choice of cover objects. Journal of Herpetology 37:460-466.

Mathis, A., R.G. Jaeger, and W.H. Keen. 1995. Aggression and territoriality by salamanders and a comparison with the territorial behavior of frogs, In W. Heatwole and B.K. Sullivan (Eds.), Amphibian Biology Surrey Beatty and Sons, Australia. 
Means, D.B., and J. Travis. 2007. Declines in ravine-inhabiting Dusky salamanders of the southeastern US coastal plain. Southeastern Naturalist 6:83-96.

Meier, A.J., S.P. Bratton, and D.C. Duff. 1996. Biodiversity in the herbaceous land and salamanders in Appalachian primary forests, In M.B. Davis (Ed.), Eastern old-forests. Island Press, Washington D. C., USA.

Middlekoop, M.J., T. Watts, and M. Schorr. 1999. Acid mine drainage and its effects on physiochemical conditions and salamander populations in a Cumberland Plateau stream. Journal of the Tennessee Academy of Sciences 73:36-42.

Miller, Jr., R.L., D.R. Dewalle, R.P. Brooks, and J.C. Finley. 1997. Long-term impacts of forest road crossings of wetlands in Pennsylvania. Northern Journal of Applied Forestry 14:109-116.

Monti, L. 1995. The red-back salamanders (Plethodon cinereus) population in a Maine oakpine forest. Master's thesis, University of Maine.

Moore, J.D., and R.L. Wyman. 2010. Eastern red-backed salamanders (Plethodon cinereus) in a highly acid forest soil. American Midland Naturalist 163:95-105.

National Oceanic and Atmospheric Administration, 2005. Division of Normals and Standard Deviations of Temperature, Precipitation, and Heating and Cooling degree Days. http://hurricane.ncdc.noaa.gov/climatenormals/clim85/CLIM85_PRCP02.pdf

Nauman, R.S., and D.H. Olson. 2008. Distribution and conservation of Plethodon salamanders on Federal lands in Siskiyou County, California. Northwestern Naturalist 89:1-9.

Newman, R.A., and T. Squire. 2001. Microsatelite variation and fine-scale population structure in the wood frog (Rana sylvatica). Molecular Ecology 10:1087-1110.

Price, S.J., K.K. Cecala, R.A. Browne, and M.E. Dorcas. 2011. Effects of urbanization on occupancy of stream salamanders. Conservation Biology 25:547-555.

Pennsylvania Spatial Data Access. 2005. The Pennsylvania Geospatial Data Clearinghouse. http://www.pasda.psu.edu.

Ohio EPA. 2001. Field evaluation manual for Ohio's primary headwater habitat streams. Ohio EPA Division of Surface Water, Columbus, Ohio, USA.

Orser, P.N., and D.J. Shure. 1972. Effect of Urbanization on the salamander Desmognathus fuscus fuscus. Ecology 53:1148-1154.

Overton, W.S. 1965. A modification of the Schnabel estimator to account for the removal of animals from the population. Journal of Wildlife Management 29:392-395. 
Raimondo, S., T.K. Pauley, and L. Butler. 2003. Potential impacts of Bacillus thuringiensis var. kurstaki on five salamander species in West Virginia. Northeastern Naturalist 10:25-38.

Roberts, S.A., G.B. Hall, and P.H. Calamai, 2000. Analyzing forest fragmentation using spatial autocorrelation, graphs and GIS. International Journal of Geographical Information Science 14:185-204.

Rocco, G.L., and R.P. Brooks. 2000. Abundance and distribution of a stream Plethodontid salamander assemblages in 14 ecologically dissimilar watershed in Pennsylvania central Appalachians. Final Report. Report No. 2000-4 . Penn State Cooperative Wetlands Center, Forest Resources Laboratory, Pennsylvania State University. Prepared for U. S. EPA, Region III.

Roth, N.E., T. Southerland, G. Mercurio, J.C. Challou, D.G. Heimbuch, J.C. Seibel, R. Klauda, P. Kazyak, D. Boward, S. Stranko, M. Hurd, and T. Prochaska. 1999. State of the Streams: Results of the 1995-1997 Maryland Biological Stream Survey. Report to Monitoring and Non-Tidal Assessment Division, Maryland Department of Natural Resources, Annapolis, MD.

SAS Institute. 2005. SASSTAT user's guide, version 9.0 and 9.1. SAS Institute, Cary, North Carolina, USA.

Saunders, D.A., R.H. Hobbs, and C.R. Margules, 1991. Biological consequences of ecosystem fragmentation: A review. Conservation Biology 5:18-32.

Sepulveda A.J., and W.H. Lowe. 2009. Local and landscape influences on the occupancy and density of Dicamptodon aterrimus, the Idaho giant salamander. Journal of Herpetology 43:469-484.

Sjogren, P. 1991. Extinction and isolation gradients in metapopulations: the case of the pool frog (Rana lessonae). Biological Journal of Linn. Society. 42:135-147.

Smith, M.A. and D.M Green. 2005, Dispersal and the metapopulation paradigm in amphibian ecology and conservation: are all amphibian populations metapopulations? Ecography 28:110-128.

Snodgrass, J.W., D.C. Forester, M. Lahti, and E. Lehman. 2007. Dusky salamander (Desmognathus fuscus) nest-site selection over multiple spatial scales. Herpetologica 63:441-449.

Southerland, M.T., R.E. Jung, J. Volstad, D. Baxter, G. Mercurio, and I.C. Chellman. Patuxent Wildlife Research Center. 2007. Streamside salamanders as indicators of stream quality in Maryland. http://www.pwrc.usgs.gov/. 
Takahashi, M.K., and T.K. Pauley. 2010. Resource allocation and life history traits of Plethodon cinereus at different elevations. American Midland Naturalist 163:87-94.

United States Department of Agriculture, Soil Conservation Service. 1982. Pennsylvania State University, College of Agriculture, and the Pennsylvania Department of Environmental Resources, State Conservation Commission. Soil Survey of Beaver and Lawrence Counties, Pennsylvania, USA.

. 1982b. Pennsylvania State University, College of Agriculture, and the Pennsylvania Department of Environmental Resources, State Conservation Commission. Soil Survey of Westmoreland County, Pennsylvania, USA.

. 1982c. Pennsylvania State University, College of Agriculture, and the Pennsylvania Department of Environmental Resources, State Conservation Commission. Soil Survey of Washington and Greene Counties, Pennsylvania, USA.

. 1982d. Pennsylvania State University, College of Agriculture, and the Pennsylvania Department of Environmental Resources, State Conservation Commission. Soil Survey of Allegheny County, Pennsylvania, USA.

United States Geological Survey. 2005. North American Amphibian Monitoring Program. Patuxent Wildlife Research Center., http://www.pwrc.usgs.gov/naamp/.

b. North American Amphibian Monitoring Program. 2004. http://www.mplpwrc.usgs.gov/amphibs.html.

van Buskirk, J. 2005. Local and landscape influence on amphibian occurrence and abundance. Ecology 86:1936-1947.

Vos, C.C., and J.P. Chardon. 1998. Effects of habitat fragmentation and road density on the distribution pattern of the moor frog (Rana arvalis). Journal of Applied Ecology 35:4456 .

Wang, CL., J. Strazanac, and L. Butler. 2000. Abundance, diversity, and activity of ants (Hymenoptera: Formicidae) in oak-dominated mixed Appalachian forests treated with microbial pesticides. Environmental Entomology 29:579-586.

Ward, R.L., J.T. Anderson, and J.T. Petty. 2008. The effects of roads crossings on stream and stream-side salamanders. Journal of Wildlife Management 72:760-771.

Welsh, H.H. 1990. Spatial associations among individuals in a population of slimy salamanders (Plethodon glutinosus). Herpetologica 36:271-275.

Welsh, H.H. and L.M. Ollivier. 1998. Stream amphibians as indicators of ecosystems stress: A case study from California's Redwoods. Ecological Applications 8:1118-1132. 
Table 1. Summary of symbols used in the a priori models used to predict northern dusky salamander density in southwestern Pennsylvania that included 4 primary study areas (Linn Run State Park, Mingo Creek County Park, Raccoon Creek State Park, and State Game Land 203). Spring sampling occurred in April and May (4 visits/year) and fall sampling occurred in September and October (4 visits/year) 2008-2009.

\begin{tabular}{|c|c|c|c|c|}
\hline Symbol & Term, unit & Variable & Species studied & Reference \\
\hline $\mathrm{T}_{\mathrm{a}}$ & Ambient air temperature, ${ }^{\circ} \mathrm{C}$ & Continuous & D. fuscus fuscus & $\begin{array}{l}\text { Grover (2000) } \\
\text { Southerland et al. (2007) }\end{array}$ \\
\hline $\mathrm{T}_{\mathrm{w}}$ & Water temperature, ${ }^{\circ} \mathrm{C}$ & Continuous & D. fuscus fuscus & $\begin{array}{l}\text { Grover (2000) } \\
\text { Southerland et al. (2007) }\end{array}$ \\
\hline $\mathrm{T}_{\mathrm{s}}$ & Soil or retreat temperature, ${ }^{\circ} \mathrm{C}$ & Continuous & D. fuscus fuscus & Grover (2000) \\
\hline $\mathrm{T}_{\mathrm{m}}$ & Mean temperature ${ }^{\mathrm{a}},{ }^{\mathrm{o}} \mathrm{C}$ & Continuous & N/A & N/A \\
\hline $\mathrm{T}_{\mathrm{ave}}$ & Average monthly temperature ${ }^{\mathrm{b}},{ }^{\mathrm{o}} \mathrm{C}$ & Continuous & N/A & NOAA \\
\hline $\mathrm{C}_{\mathrm{t}}$ & Tree canopy cover, $\%$ & Continuous & N. v. viridescens & Healy (1983) \\
\hline $\mathrm{C}_{\mathrm{h}}$ & Herbaceous cover, $\%$ & Continuous ${ }^{\mathrm{e}}$ & N. v. viridescens & Healy (1983) \\
\hline $\mathrm{D}$ & Deciduous trees, $\%$ & Continuous & N. v. viridescens & Healy (1983) \\
\hline $\mathrm{pH}$ & $\mathrm{pH}$ & Continuous & D. fuscus fuscus & Hulse et al. (2001) \\
\hline $\mathrm{H}_{\mathrm{r}}$ & Relative humidity & Continuous & D. fuscus fuscus & Grover $(2000)$ \\
\hline $\mathrm{C}_{\mathrm{p}}$ & Protective cover ${ }^{c}, \%$ & Continuous ${ }^{\mathrm{e}}$ & D. fuscus fuscus & Hulse et al. (2001) \\
\hline $\mathrm{D}_{1 / 4}$ & Stream depth $1 / 4$ across stream, cm & Continuous & N/A & N/A \\
\hline$D_{1 / 2}$ & Stream depth $1 / 2$ across stream, $\mathrm{cm}$ & Continuous & N/A & N/A \\
\hline $\mathrm{D}_{3 / 4}$ & Stream depth $3 / 4$ across stream, cm & Continuous & $\mathrm{N} / \mathrm{A}$ & N/A \\
\hline$S_{\mathrm{wd}}$ & Stream size ${ }^{\mathrm{d}}, \mathrm{cm}^{2}$ & Continuous & Plethonidae & Southerland et al. (2007) \\
\hline $\mathrm{P}$ & Presence of predatory fish ${ }^{\mathrm{e}}$ & Categorical $^{\mathrm{f}}$ & D. fuscus fuscus & Bank et al. (2006) \\
\hline
\end{tabular}

${ }^{\mathrm{a}}$ Mean temperature $=\left(\mathrm{T}_{\mathrm{a}}+\mathrm{T}_{\mathrm{w}}+\mathrm{T}_{\mathrm{s}}\right) / 3$.

${ }^{\mathrm{b}}$ Average spring temperature (April and May) and fall temperature (September and October) was determined from NOAA Region 3609 data.

${ }^{\mathrm{c}}$ Protective cover $=$ number of rocks $(20 \mathrm{~cm}$ diameter $)$ that covered the stream bed.

${ }^{\mathrm{d}}$ Stream size $=\mathrm{W}_{\mathrm{s}} *\left(\left(\mathrm{D}_{1 / 4}+\mathrm{D}_{1 / 2}+\mathrm{D}_{3 / 4}\right) / 3\right)$.

${ }^{\mathrm{e}}$ Factors determined by comparing the habitat to a visual estimate of percentage cover that was categorized in groups of 10 , from $0-100 \%$.

${ }^{\mathrm{f}} \mathrm{A}$ value of 1.00 was given when predatory fish were not present, and a value of 0.25 was be given if predatory fish were present. 
Table 2. Number of captured individual salamanders by species and stream reach in all 4 primary study areas (Linn Run State Park (LRSP), Mingo Creek County Park (MCCP), Raccoon Creek State Park (RCSP), and State Game Land 203 (SGL)) in southwestern Pennsylvania, 2008-2009.

\begin{tabular}{|c|c|c|c|c|c|c|c|c|c|}
\hline \multirow[b]{2}{*}{ Location } & \multicolumn{7}{|c|}{ Species } & \multirow[b]{2}{*}{ Total } & \multirow[b]{2}{*}{$\%$} \\
\hline & Spotted & $\begin{array}{l}\text { Norther } \\
\text { n dusky }\end{array}$ & Seal & $\begin{array}{c}\text { Northern } \\
\text { 2-lined }\end{array}$ & $\begin{array}{c}\text { Northern } \\
\text { spring }\end{array}$ & $\begin{array}{l}\text { Mud } \\
\text { puppy }\end{array}$ & $\begin{array}{c}\text { Red } \\
\text { backed }\end{array}$ & & \\
\hline LRSP1 & & 242 & & 3 & 20 & 24 & & 289 & 12.64 \\
\hline LRSP2 & & 76 & & 2 & & 2 & & 80 & 3.50 \\
\hline LRSP3 & & 213 & 18 & 13 & 2 & 13 & & 259 & 11.32 \\
\hline LRSP4 & & 5 & 2 & & 1 & & & 8 & 0.35 \\
\hline Subtotal & 0 & 536 & 20 & 18 & 23 & 39 & 0 & 636 & 27.81 \\
\hline MCCP1 & & 10 & & & & & & 10 & 0.44 \\
\hline МССР2 & & 71 & & & & 8 & & 79 & 3.45 \\
\hline МCCP3 & & 45 & & & 6 & 2 & & 53 & 2.32 \\
\hline МССР4 & & 73 & & & 1 & 2 & & 76 & 3.32 \\
\hline Subtotal ${ }^{a}$ & 0 & 199 & 0 & 0 & 7 & 12 & 0 & 218 & 9.53 \\
\hline RCSP1 & & 239 & 2 & 14 & 7 & 15 & & 277 & 12.11 \\
\hline RCSP2 & 1 & 371 & 2 & 23 & 16 & 17 & 4 & 434 & 18.98 \\
\hline RCSP3 & & 270 & 1 & 9 & 6 & 15 & & 301 & 13.16 \\
\hline RCSP4 & & 140 & & 4 & 5 & 7 & & 156 & 6.82 \\
\hline Subtotal & 1 & 1,020 & 5 & 50 & 34 & 54 & 4 & 1,168 & 51.07 \\
\hline SGL1 & & 15 & & & & 3 & & 18 & 0.79 \\
\hline SGL2 & & 51 & & & & 4 & & 55 & 2.40 \\
\hline SGL3 & & 23 & & & 1 & 4 & & 28 & 1.22 \\
\hline SGL4 & & 154 & & 2 & 6 & 2 & & 164 & 7.17 \\
\hline Subtotal & 0 & 243 & 0 & 2 & 7 & 13 & 0 & 265 & 11.59 \\
\hline Total & 1 & 1,998 & 25 & 70 & 71 & 118 & 4 & 2,287 & 100 \\
\hline Percent & 0.04 & 87.36 & 1.09 & 3.06 & 3.10 & 5.16 & 0.17 & & \\
\hline
\end{tabular}

${ }^{a}$ Number of salamanders captured at each study was different $\left(F_{3,60}=76.19, P<0.001\right)$. 
Table 3. Snout-vent length (SVL), total length (ToL) and mass for northern dusky salamanders from 4 primary study areas (Linn Run State Park, Mingo Creek County Park, Raccoon Creek State Park, and State Game Lands 203) by season and year in southwestern Pennsylvania, 2008-2009.

\begin{tabular}{|c|c|c|c|c|c|c|c|c|c|c|c|c|c|c|c|c|c|}
\hline \multirow[b]{2}{*}{ Year } & \multirow[b]{2}{*}{ Age } & \multicolumn{8}{|c|}{ Spring } & \multicolumn{8}{|c|}{ Fall } \\
\hline & & No. & $\%$ & $\mathrm{SVL}^{\mathrm{b}}$ & $\mathrm{SE}$ & $\mathrm{ToL}^{\mathrm{c}}$ & SE & Mass $^{\mathrm{d}}$ & SE & No. & $\%$ & $\mathrm{SVL}^{\mathrm{b}}$ & SE & $\mathrm{ToL}^{\mathrm{b}}$ & $\mathrm{SE}$ & Mass $^{b}$ & SE \\
\hline \multirow[t]{3}{*}{2008} & Adult & 468 & 20.46 & 49.04 & 0.44 & 97.57 & 0.80 & 13.64 & 0.12 & 353 & 15.44 & 52.04 & 0.39 & 105.13 & 0.79 & 14.71 & 0.10 \\
\hline & Juvenile & 47 & 2.06 & 17.23 & 0.66 & 33.72 & 0.97 & 6.70 & 0.15 & 86 & 3.76 & 19.73 & 0.49 & 38.12 & 0.55 & 7.29 & 0.08 \\
\hline & Non target ${ }^{\mathrm{a}}$ & 84 & 3.67 & $\mathrm{n} / \mathrm{a}$ & $\mathrm{n} / \mathrm{a}$ & $\mathrm{n} / \mathrm{a}$ & $\mathrm{n} / \mathrm{a}$ & $\mathrm{n} / \mathrm{a}$ & $\mathrm{n} / \mathrm{a}$ & 56 & 2.45 & $\mathrm{n} / \mathrm{a}$ & $\mathrm{n} / \mathrm{a}$ & $\mathrm{n} / \mathrm{a}$ & $\mathrm{n} / \mathrm{a}$ & $\mathrm{n} / \mathrm{a}$ & $\mathrm{n} / \mathrm{a}$ \\
\hline \multirow[t]{3}{*}{2009} & Adult & 510 & 22.30 & 49.70 & 0.42 & 97.53 & 0.77 & 13.91 & 0.09 & 385 & 16.83 & 52.68 & 0.36 & 104.41 & 0.74 & 14.56 & 0.06 \\
\hline & Juvenile & 54 & 2.36 & 17.24 & 0.57 & 35.07 & 0.99 & 6.49 & 0.12 & 95 & 4.15 & 17.79 & 0.42 & 37.61 & 0.73 & 7.12 & 0.09 \\
\hline & Non target & 88 & 3.85 & $\mathrm{n} / \mathrm{a}$ & $\mathrm{n} / \mathrm{a}$ & $\mathrm{n} / \mathrm{a}$ & $\mathrm{n} / \mathrm{a}$ & $\mathrm{n} / \mathrm{a}$ & $\mathrm{n} / \mathrm{a}$ & 61 & 2.67 & $\mathrm{n} / \mathrm{a}$ & $\mathrm{n} / \mathrm{a}$ & $\mathrm{n} / \mathrm{a}$ & $\mathrm{n} / \mathrm{a}$ & $\mathrm{n} / \mathrm{a}$ & $\mathrm{n} / \mathrm{a}$ \\
\hline \multirow[t]{3}{*}{ Total } & Adult & 978 & 42.76 & 49.38 & 0.30 & 97.55 & 0.56 & 13.78 & 0.08 & 738 & 3.23 & 52.37 & 0.27 & 104.75 & 0.54 & 14.63 & 0.06 \\
\hline & Juvenile $^{\mathrm{e}}$ & 101 & 4.42 & 17.24 & 0.43 & 34.45 & 0.70 & 6.59 & 0.10 & 181 & 7.91 & 18.71 & 0.33 & 37.85 & 0.46 & 7.20 & 0.06 \\
\hline & Non target & 172 & 7.52 & $\mathrm{n} / \mathrm{a}$ & $\mathrm{n} / \mathrm{a}$ & $\mathrm{n} / \mathrm{a}$ & $\mathrm{n} / \mathrm{a}$ & $\mathrm{n} / \mathrm{a}$ & $\mathrm{n} / \mathrm{a}$ & 117 & 5.12 & $\mathrm{n} / \mathrm{a}$ & $\mathrm{n} / \mathrm{a}$ & $\mathrm{n} / \mathrm{a}$ & $\mathrm{n} / \mathrm{a}$ & $\mathrm{n} / \mathrm{a}$ & $\mathrm{n} / \mathrm{a}$ \\
\hline
\end{tabular}

a Any species other than northern dusky salamanders; SVL, ToL and mass were not recorded for non-target species.

${ }^{\mathrm{b}}$ Snout to vent length, mm.

c Total length, mm.

d Mass, grams.

${ }^{\text {e }}$ Number of spring captures was $54 \%$ lower than number of fall captures $\left(F_{1,281}=0.79, P<0.001\right)$ 
Table 4. Spring and fall estimated northern dusky salamander densities from the 4 southwestern Pennsylvania primary study areas: Linn Run State Park (LRSP), Westmoreland County; Mingo Creek County Park (MCCP), Washington County; Raccoon Creek State Park (RCSP), Beaver County, and State

Game Lands 203 (SGL), Allegheny County that we used to evaluate 4 (1-4) stream reaches in each primary study area, 2008-2009.

\begin{tabular}{|c|c|c|c|c|c|c|c|c|c|c|c|c|c|c|c|c|}
\hline \multirow[b]{3}{*}{ Year } & \multicolumn{4}{|c|}{ LRSP } & \multicolumn{4}{|c|}{ МCCP } & \multicolumn{4}{|c|}{ RCSP } & \multicolumn{4}{|c|}{ SGL } \\
\hline & \multicolumn{2}{|c|}{ Spring } & \multicolumn{2}{|c|}{ Fall } & \multicolumn{2}{|c|}{ Spring } & \multicolumn{2}{|c|}{ Fall } & \multicolumn{2}{|c|}{ Spring } & \multicolumn{2}{|c|}{ Fall } & \multicolumn{2}{|c|}{ Spring } & \multicolumn{2}{|c|}{ Fall } \\
\hline & $\overline{\mathbf{x}}$ & SE & $\overline{\mathbf{x}}$ & SE & $\overline{\mathbf{x}}$ & SE & $\overline{\mathbf{x}}$ & SE & $\overline{\mathbf{x}}$ & SE & $\bar{x}$ & SE & $\bar{x}$ & SE & $\overline{\mathbf{x}}$ & SE \\
\hline 2008 & 0.13 & 0.04 & 0.12 & 0.04 & 0.06 & 0.05 & 0.03 & 0.03 & 0.24 & 0.04 & 0.26 & 0.05 & 0.08 & 0.05 & 0.04 & 0.04 \\
\hline 2009 & 0.15 & 0.04 & 0.13 & 0.05 & 0.07 & 0.05 & 0.03 & 0.03 & 0.27 & 0.05 & 0.29 & 0.05 & 0.09 & 0.04 & 0.05 & 0.04 \\
\hline Total & 0.14 & 0.04 & 0.13 & 0.04 & 0.07 & 0.05 & 0.03 & 0.03 & 0.26 & 0.04 & 0.27 & 0.05 & 0.08 & 0.05 & 0.05 & 0.04 \\
\hline
\end{tabular}


Table 5. Estimated northern dusky salamander density by using repeated measure visual encounter survey from the 4 southwestern Pennsylvania primary study areas: Linn Run State Park (LRSP), Westmoreland County; Mingo Creek County Park (MCCP),

Washington County; Raccoon Creek State Park (RCSP), Beaver County, and State Game Lands 203 (SGL), Allegheny County that we used to evaluate 4 (1-4) stream reaches in each primary study area, 2008-2009.

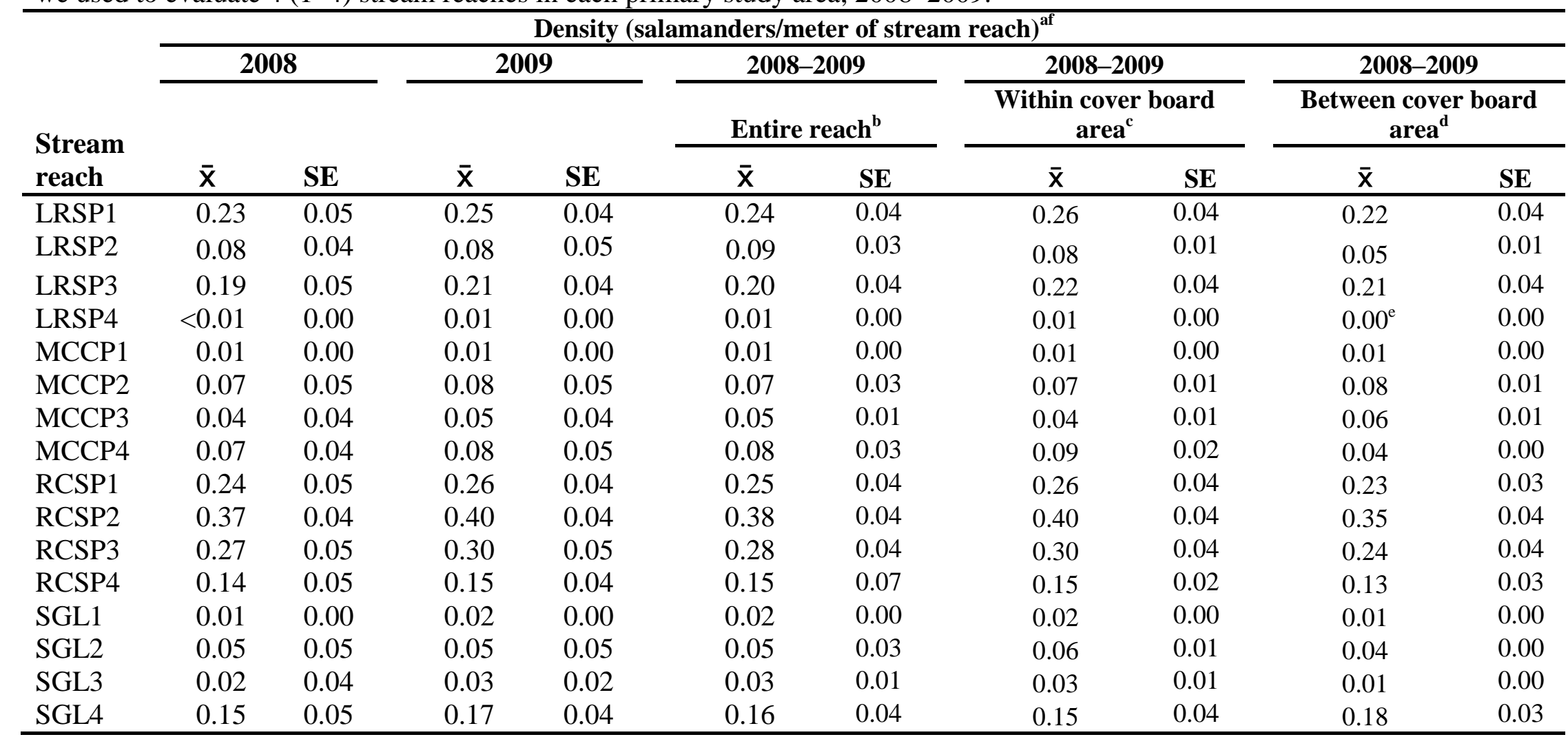

\footnotetext{
${ }^{\mathrm{a}}$ Density estimates were determined by the mean repeated measure of observations divided by the length of the stream reach.

${ }^{\mathrm{b}}$ Length $=60 \mathrm{~m}$ for each stream reach.

${ }^{\mathrm{c}}$ Length $=40 \mathrm{~m}$ for each stream reach.

${ }^{\mathrm{d}}$ Length $=20 \mathrm{~m}$ for each stream reach.

${ }^{\mathrm{e}}$ Estimated density $=0.00$ because no salamanders were observed.

${ }^{\mathrm{f}}$ No statistical difference in density between areas with cover boards and areas between cover boards $\left(F_{1,15}=4.97, P=0.402\right)$.
} 
Table 6. Northern dusky salamander capture data and total capture data by type of protective cover from all 4 primary study areas (Linn Run State Park, Mingo Creek County Park, Raccoon Creek State Park, and State Game Lands 203) by season and year in southwestern Pennsylvania, 2008-2009.

\begin{tabular}{|c|c|c|c|c|c|c|c|c|c|c|c|c|c|}
\hline \multirow[b]{3}{*}{ Year } & \multirow{3}{*}{$\begin{array}{l}\text { Type of } \\
\text { protective } \\
\text { cover }\end{array}$} & \multicolumn{4}{|c|}{ Spring $^{\mathrm{s}}$} & \multicolumn{4}{|c|}{ Fall $^{\text {b }}$} & \multicolumn{4}{|c|}{ Year Total } \\
\hline & & \multicolumn{2}{|c|}{ Northern dusky } & \multicolumn{2}{|c|}{ Total } & \multicolumn{2}{|c|}{ Northern dusky } & \multicolumn{2}{|c|}{ Total } & \multicolumn{2}{|c|}{ Northern dusky } & \multicolumn{2}{|c|}{ Total } \\
\hline & & No. & $\%^{\mathrm{e}}$ & No. & $\%^{\mathrm{c}}$ & No. & $\%^{c}$ & No. & $\%^{\mathrm{c}}$ & No. & $\%^{\mathrm{e}}$ & No. & $\%^{\mathrm{c}}$ \\
\hline \multirow[t]{5}{*}{2008} & Board & 46 & 2.30 & 51 & 2.23 & 38 & 1.40 & 47 & 2.06 & 84 & 4.20 & 98 & 4.29 \\
\hline & Leaves & 15 & 0.75 & 16 & 0.70 & 15 & 0.75 & 16 & 0.70 & 30 & 1.50 & 32 & 1.40 \\
\hline & $\log$ & 10 & 0.50 & 13 & 0.57 & 11 & 0.55 & 13 & 0.57 & 21 & 1.05 & 26 & 1.14 \\
\hline & Moss & 8 & 0.40 & 10 & 0.43 & 8 & 0.40 & 10 & 0.43 & 16 & 0.80 & 20 & 0.86 \\
\hline & Rock $^{\mathrm{d}}$ & 434 & 21.72 & 509 & 22.26 & 366 & 18.32 & 409 & 17.88 & 800 & 40.04 & 918 & 40.14 \\
\hline \multirow[t]{5}{*}{2009} & Board & 53 & 2.65 & 55 & 2.40 & 45 & 2.25 & 50 & 2.19 & 98 & 4.90 & 105 & 4.59 \\
\hline & Leaves & 12 & 0.60 & 13 & 0.57 & 18 & 0.90 & 20 & 0.87 & 30 & 1.50 & 33 & 1.44 \\
\hline & $\log$ & 9 & 0.45 & 13 & 0.57 & 13 & 0.65 & 15 & 0.66 & 22 & 1.10 & 28 & 1.23 \\
\hline & Moss & 9 & 0.45 & 11 & 0.48 & 8 & 0.40 & 10 & 0.43 & 17 & 0.85 & 21 & 0.91 \\
\hline & Rock $^{\mathrm{d}}$ & 480 & 24.02 & 560 & 24.49 & 395 & 19.77 & 446 & 19.50 & 875 & 43.79 & 1,006 & 43.99 \\
\hline \multirow[t]{5}{*}{ Total } & Board & 99 & 4.95 & 106 & 4.63 & 83 & 4.15 & 97 & 4.24 & 182 & 9.11 & 203 & 8.87 \\
\hline & Leaves & 27 & 1.35 & 29 & 1.27 & 33 & 1.65 & 36 & 1.57 & 60 & 3.00 & 65 & 2.84 \\
\hline & $\log$ & 19 & 0.95 & 26 & 1.14 & 24 & 1.20 & 28 & 1.22 & 43 & 2.15 & 54 & 2.36 \\
\hline & Moss & 17 & 0.85 & 21 & 0.92 & 16 & 0.80 & 20 & 0.87 & 33 & 1.65 & 41 & 1.79 \\
\hline & Rock $^{\mathrm{d}}$ & 914 & 45.75 & 1,069 & 46.74 & 761 & 38.09 & 855 & 37.39 & 1,675 & 83.83 & 1,924 & 84.13 \\
\hline
\end{tabular}

${ }^{\mathrm{a}}$ Sampling occurred in April and May.

b Sampling occurred in September and October.

${ }^{c}$ Percentage of total salamanders captured.

${ }^{\mathrm{d}}$ Rock size $=20 \mathrm{~cm}$ in diameter.

${ }^{\mathrm{e}}$ Percent of northern dusky captured 
Table 7. Cover board use data from the 4 southwestern Pennsylvania primary study areas: Linn Run State Park (LRSP), Westmoreland County; Mingo Creek County Park (MCCP), Washington County; Raccoon Creek State Park (RCSP), Beaver County, and State Game Lands 203 (SGL), Allegheny County that we used to evaluate 4 (1-4) stream reaches in each primary study area, 2008-2009.

\begin{tabular}{cccc}
\hline $\begin{array}{c}\text { Stream reach } \\
\text { or season }\end{array}$ & $\begin{array}{c}\text { No. of } \\
\text { captures }\end{array}$ & $\begin{array}{c}\text { No. captured } \\
\text { under cover } \\
\text { board }\end{array}$ & $\begin{array}{c}\text { Percent under } \\
\text { cover board }\end{array}$ \\
\hline LRSP1 & 242 & 24 & 9.92 \\
LRSP2 & 76 & 15 & 19.74 \\
LRSP3 & 213 & 17 & 8.98 \\
LRSP4 & 5 & 0 & 0.00 \\
& & 2 & 20.00 \\
MCCP1 & 10 & 3 & 4.22 \\
MCCP2 & 71 & 3 & 6.67 \\
MCCP3 & 45 & 7 & 9.59 \\
MCCP4 & 73 & 21 & 8.79 \\
& & 32 & 8.63 \\
RCSP1 & 239 & 18 & 6.67 \\
RCSP2 & 371 & 13 & 9.29 \\
RCSP3 & 270 & & \\
RCSP4 & 140 & 2 & 13.33 \\
& & 2 & 3.92 \\
SGL1 & 15 & 2 & 8.70 \\
SGL2 & 51 & 11 & 7.14 \\
SGL3 & 23 & & 8.52 \\
SGL4 & 154 & 92 & 8.71 \\
& & 80 & 8.61 \\
Spring & 1,079 & 172 & \\
Fall & 919 & & \\
Total & 1,998 & & \\
\hline
\end{tabular}


Table 8. Estimated northern dusky densities from a robust mark and recapture design from the 4 southwestern Pennsylvania primary study areas: Linn Run State Park (LRSP), Westmoreland County; Mingo Creek County Park (MCCP), Washington County; Raccoon Creek State Park (RCSP), Beaver County, and State Game Lands 203 (SGL), Allegheny County that we used to evaluate $4(1-4)$ stream reaches in each primary study area, 20082009.

\begin{tabular}{|c|c|c|c|c|c|c|}
\hline \multirow[b]{3}{*}{ Stream reach } & \multicolumn{6}{|c|}{ Density (salamanders/meter of stream reach) ${ }^{\mathrm{a}}$} \\
\hline & \multicolumn{2}{|c|}{2008} & \multicolumn{2}{|c|}{2009} & \multicolumn{2}{|c|}{ Entire reach $^{\mathrm{b}}$} \\
\hline & $\overline{\mathbf{x}}$ & SE & $\overline{\mathbf{x}}$ & SE & $\overline{\mathbf{x}}$ & SE \\
\hline LRSP1 & 0.32 & 0.42 & 0.33 & 0.83 & 0.32 & 0.63 \\
\hline LRSP2 & 0.15 & 0.44 & 0.15 & 0.47 & 0.15 & 0.46 \\
\hline LRSP3 & 0.25 & 0.56 & 0.34 & 0.64 & 0.29 & 0.60 \\
\hline LRSP4 & 0.03 & 0.18 & 0.01 & 0.16 & 0.02 & 0.17 \\
\hline MCCP1 & 0.05 & 0.15 & 0.03 & 0.15 & 0.04 & 0.15 \\
\hline MCCP2 & 0.10 & 0.23 & 0.16 & 0.26 & 0.13 & 0.24 \\
\hline MCCP3 & 0.07 & 0.19 & 0.06 & 0.19 & 0.06 & 0.19 \\
\hline MCCP4 & 0.15 & 0.24 & 0.21 & 0.25 & 0.18 & 0.25 \\
\hline RCSP1 & 0.37 & 0.99 & 0.39 & 1.07 & 0.38 & 1.03 \\
\hline RCSP2 & 0.50 & 1.23 & 0.56 & 1.21 & 0.53 & 1.22 \\
\hline RCSP3 & 0.39 & 0.81 & 0.63 & 0.83 & 0.51 & 0.82 \\
\hline RCSP4 & 0.25 & 0.75 & 0.34 & 0.59 & 0.30 & 0.67 \\
\hline SGL1 & 0.03 & 0.14 & 0.03 & 0.13 & 0.03 & 0.13 \\
\hline SGL2 & 0.09 & 0.11 & 0.04 & 0.12 & 0.07 & 0.11 \\
\hline SGL3 & 0.09 & 0.15 & 0.05 & 0.16 & 0.07 & 0.16 \\
\hline SGL4 & 0.23 & 0.51 & 0.34 & 0.63 & 0.29 & 0.57 \\
\hline
\end{tabular}

${ }^{\mathrm{a}}$ Length $=60 \mathrm{~m}$ for each stream reach.

b 2008 and 2009 data combined. 
Table 9. Ranking of 6 a priori models estimating northern dusky salamander density from 4 primary study areas (each with 4 stream reaches) in southwestern Pennsylvania, 2008-2009. Models were ranked using Akaike's Information Criterion adjusted for small sample size (AIC $\mathrm{C}_{\mathrm{c}}$ ).

\begin{tabular}{|c|c|c|c|c|c|c|c|}
\hline Model Structure $^{a}$ & Equation $y:^{\text {b }}$ & $\begin{array}{c}\text { Model } \\
\text { no. }\end{array}$ & $\mathbf{K}^{\mathbf{c}}$ & $\mathbf{A I C}_{\mathbf{c}}$ & $\Delta_{\mathbf{i}}^{\mathbf{d}}$ & $\mathbf{w}_{\mathbf{i}}^{\mathrm{e}}$ & $\begin{array}{c}\text { Adjusted } \\
\mathbf{R}^{2}\end{array}$ \\
\hline $\mathrm{y}=\mathrm{C}_{\mathrm{t}}+\mathrm{S}_{\mathrm{wd}}+\mathrm{C}_{\mathrm{p}}$ & $(0.00345) \mathrm{C}_{\mathrm{t}}+(0.00014) \mathrm{S}_{\mathrm{wd}}+(0.00148) \mathrm{C}_{\mathrm{p}}$ & 5 & 4 & 209.88 & 0.00 & 0.921 & 0.4443 \\
\hline$y=C_{t}+S_{w d}+C_{h}$ & $(0.00345) \mathrm{C}_{\mathrm{t}}+(0.00014) \mathrm{S}_{\mathrm{wd}}+(0.00019) \mathrm{C}_{\mathrm{h}}$ & 6 & 4 & 215.79 & 5.91 & 0.048 & 0.3797 \\
\hline $\mathrm{y}=\mathrm{C}_{\mathrm{t}}+\mathrm{C}_{\mathrm{h}}+\mathrm{pH}$ & $(0.00345) \mathrm{C}_{\mathrm{t}}+(0.00019) \mathrm{C}_{\mathrm{h}}+(0.00759) \mathrm{pH}$ & 3 & 4 & 217.09 & 7.21 & 0.025 & 0.3300 \\
\hline $\mathrm{y}=\mathrm{T}_{\mathrm{m}}+\mathrm{C}_{\mathrm{t}}+\mathrm{C}_{\mathrm{h}}+\mathrm{pH}$ & $(0.00457) \mathrm{T}_{\mathrm{m}}+(0.00345) \mathrm{C}_{\mathrm{t}}+(0.00019) \mathrm{C}_{\mathrm{h}}+(0.00759) \mathrm{pH}$ & 4 & 5 & 219.92 & 10.04 & 0.006 & 0.3141 \\
\hline $\begin{aligned} \mathrm{y}= & \mathrm{S}_{\mathrm{wd}}+\mathrm{T}_{\mathrm{m}}+\mathrm{C}_{\mathrm{h}}+\mathrm{pH}+ \\
& \mathrm{H}_{\mathrm{r}}+\mathrm{C}_{\mathrm{t}}+\mathrm{D}+\mathrm{C}_{\mathrm{p}}\end{aligned}$ & $\begin{array}{l}(0.00014) \mathrm{S}_{\mathrm{wd}}+(0.00457) \mathrm{T}_{\mathrm{m}}+(0.00019) \mathrm{C}_{\mathrm{h}}+(0.00759) \mathrm{pH} \\
+(0.00087) \mathrm{H}_{\mathrm{r}}+(0.00345) \mathrm{C}_{\mathrm{t}}+(0.0382) \mathrm{D}+(0.00148) \mathrm{C}_{\mathrm{p}}\end{array}$ & 1 & 9 & 285.35 & 75.47 & 0.000 & 0.1451 \\
\hline $\begin{aligned} \mathrm{y}= & 2 \mathrm{~S}_{\mathrm{wd}}+\mathrm{T}_{\mathrm{m}}+\mathrm{C}_{\mathrm{h}}+\mathrm{pH} \\
& +\mathrm{H}_{\mathrm{r}}+2 \mathrm{C}_{\mathrm{t}}+\mathrm{D}+\mathrm{C}_{\mathrm{p}}\end{aligned}$ & $\begin{array}{l}(0.00028) \mathrm{S}_{\mathrm{wd}}+(0.00457) \mathrm{T}_{\mathrm{m}}+(0.00019) \mathrm{C}_{\mathrm{h}}+(0.00759) \mathrm{pH} \\
+(0.00087) \mathrm{H}_{\mathrm{r}}+(0.00690) \mathrm{C}_{\mathrm{t}}+(0.0382) \mathrm{D}+(0.00148) \mathrm{C}_{\mathrm{p}}\end{array}$ & 2 & 9 & 321.33 & 111.45 & 0.000 & 0.1373 \\
\hline
\end{tabular}

${ }^{\mathrm{a}} \mathrm{y}=$ model value, $\mathrm{T}_{\mathrm{m}}=$ mean of water temperature, $\mathrm{C}_{\mathrm{t}}=\%$ tree canopy cover, $\mathrm{C}_{\mathrm{h}}=\%$ herbaceous cover, $\mathrm{C}_{\mathrm{p}}=$ percent protective cover, $\mathrm{S}_{\mathrm{wd}}=$ stream size, $\mathrm{H}_{\mathrm{r}}=$ relative humidity, $\mathrm{D}=$ percent deciduous trees.

${ }^{\mathrm{b}}$ Standard error values for each variable of the best fit model: $\mathrm{C}_{\mathrm{t}}=0.41, \mathrm{C}_{\mathrm{h}}=0.32, \mathrm{pH}=0.00$.

${ }^{\mathrm{c}}$ Number of estimable parameters.

${ }^{\mathrm{d}} \Delta_{\mathrm{i}}=\left|\mathrm{AIC}_{\mathrm{c} \text { lowest }}-\mathrm{AIC}_{\mathrm{ci}}\right|$ for the $\mathrm{i}^{\text {th }}$ model in comparison.

${ }^{\mathrm{e}} \mathrm{w}_{\mathrm{i}}=$ Akaike weights. 
Table 10. Estimated northern dusky salamander density using the best fit $\mathrm{AIC}_{\mathrm{c}}$ a priori model (Model 5) and a post-hoc model (Model 7) with data from the 4 southwestern Pennsylvania primary study areas: Linn Run State Park (LRSP), Westmoreland County; Mingo Creek County Park (MCCP), Washington County;

Raccoon Creek State Park (RCSP), Beaver County and State Game Lands 203 (SGL), Allegheny County that we used to evaluate 4 (1-4) stream reaches in each study area, 2008-2009. Cedar Creek County Park (CCCP) study area, Westmoreland County, was an independent secondary site where collected data (September 2011) was used in Model 5 and to verify the post-hoc model.

\begin{tabular}{|c|c|c|c|c|c|c|}
\hline \multirow[b]{2}{*}{ Stream reach } & \multirow[b]{2}{*}{$\begin{array}{c}\text { Total no. } \\
\text { of } \\
\text { captures }\end{array}$} & \multicolumn{5}{|c|}{ Density Estimator $^{\mathrm{g}}=151.13+(0.00345) \mathrm{C}_{\mathrm{t}}-(0.0014) \mathrm{S}_{\mathrm{wd}}^{\prime}+(0.000148) \mathrm{C}_{\mathrm{p}}$} \\
\hline & & $\begin{array}{c}\text { Estimated } \\
\text { no. of } \\
\text { captures }\end{array}$ & $\begin{array}{l}\text { Estimated no. } \\
\text { of captures } \\
\text { per visit }^{\mathrm{c}}\end{array}$ & $\begin{array}{c}\text { Total no. } \\
\text { of captures } \\
\text { per visit }\end{array}$ & $\begin{array}{l}\text { Difference in } \\
\text { no. of captures } \\
\text { per visit }^{\mathrm{d}}\end{array}$ & \% Error \\
\hline LRSP1 & 289 & 47 & 2.9 & 18.1 & -15.2 & $84^{\mathrm{f}}$ \\
\hline LRSP2 & 80 & 65 & 4 & 5 & -1 & $20^{\mathrm{e}}$ \\
\hline LRSP3 & 259 & 155 & 9.7 & 16.2 & -6.5 & $40^{\mathrm{e}}$ \\
\hline LRSP4 & 8 & 144 & 8.9 & 0.5 & 8.4 & $1680^{\mathrm{f}}$ \\
\hline \multicolumn{2}{|c|}{ Study area mean $\% E$} & & & & & $456^{f}$ \\
\hline MCCP1 & 10 & 99 & 6.1 & 0.6 & 5.5 & $917^{\mathrm{f}}$ \\
\hline МCCP2 & 79 & 68 & 4.2 & 4.9 & -0.7 & $14^{\mathrm{e}}$ \\
\hline MCCP3 & 52 & 68 & 4.2 & 3.3 & 0.9 & $27^{\mathrm{e}}$ \\
\hline MCCP4 & 76 & 84 & 5.2 & 4.8 & 0.4 & $8^{e}$ \\
\hline \multicolumn{2}{|c|}{ Study area mean $\% E$} & & & & & $242^{f}$ \\
\hline RCSP1 & 278 & 119 & 7.4 & 17.4 & -10 & $57^{\mathrm{f}}$ \\
\hline RCSP2 & 431 & 158 & 9.8 & 26.9 & -17.1 & $64^{e}$ \\
\hline RCSP3 & 304 & 110 & 6.8 & 19 & -12.2 & $64^{\mathrm{e}}$ \\
\hline RCSP4 & 157 & 71 & 4.4 & 9.8 & -5.4 & $55^{\mathrm{e}}$ \\
\hline \multicolumn{2}{|c|}{ Study area mean \% E } & & & & & $60^{e}$ \\
\hline SGL1 & 17 & 29 & 1.9 & 1.1 & -2.9 & $264^{\mathrm{e}}$ \\
\hline SGL2 & 55 & 76 & 4.7 & 3.4 & 1.3 & $38^{\mathrm{e}}$ \\
\hline SGL3 & 28 & 116 & 7.2 & 1.8 & 5.4 & $300^{f}$ \\
\hline SGL4 & 164 & 82 & 5.1 & 10.3 & -5.2 & $50^{\mathrm{e}}$ \\
\hline \multicolumn{2}{|c|}{ Study area mean \% E } & & & & & $163^{e}$ \\
\hline CCCP1 & 34 & 112 & 7 & 17 & -10 & $59^{f}$ \\
\hline $\mathrm{CCCP} 2$ & 48 & 152 & 9.5 & 24 & -14.5 & $60^{\mathrm{e}}$ \\
\hline CCCP3 & 6 & 98 & 6.1 & 3 & 3.1 & $103^{\mathrm{f}}$ \\
\hline $\mathrm{CCCP} 4$ & 27 & 140 & 8.7 & 13.5 & -4.8 & $36^{\mathrm{e}}$ \\
\hline \multicolumn{2}{|c|}{ Study area mean \% E } & & & & & $65^{f}$ \\
\hline
\end{tabular}

${ }^{\mathrm{a}}$ Estimated number of captures for 16 visits.

${ }^{\mathrm{b}}$ Actual number of captures for 16 visits for 4 the study areas (LRSP, MCCP, RCSP and SGL) and 2 visits for the independent site (CCCP).

${ }^{\mathrm{c}} \mathrm{A}$ visit to a stream reach that was $60 \mathrm{~m}$ in length.

${ }^{\mathrm{d}}$ A negative value indicated that the estimated density was less than the actual density.

${ }^{\mathrm{e}}$ The difference was smaller than Model 5.

${ }^{\mathrm{f}}$ The difference was larger than Model 5.

${ }^{\mathrm{g}}$ Where $\mathrm{S}_{\mathrm{wd}}^{\prime}=\left|\mathrm{S}_{\mathrm{wd}}-2,146\right|$ 
Table 10. Cont.

\begin{tabular}{|c|c|c|c|c|c|c|}
\hline \multirow[b]{2}{*}{ Stream reach } & \multirow[b]{2}{*}{$\begin{array}{l}\text { Total no. } \\
\text { of } \\
\text { captures }\end{array}$} & \multicolumn{5}{|c|}{ Model $5=(0.00345) C_{t}-(0.0014) S_{w d}+(0.000148) C_{p}$} \\
\hline & & $\begin{array}{c}\text { Estimated } \\
\text { no. of } \\
\text { captures }^{\text {a }} \\
\end{array}$ & $\begin{array}{c}\text { Estimated no. } \\
\text { of captures } \\
\text { per visit }^{\mathrm{c}} \\
\end{array}$ & $\begin{array}{c}\text { Total no. } \\
\text { of captures } \\
\text { per visit }\end{array}$ & $\begin{array}{c}\text { Difference in } \\
\text { no. of captures } \\
\text { per visit }^{\mathrm{d}}\end{array}$ & \% Error \\
\hline LRSP1 & 289 & 224 & 14 & 18.1 & -4.1 & 23 \\
\hline LRSP2 & 80 & 16 & 1 & 5 & -4 & 80 \\
\hline LRSP3 & 259 & 106 & 6.6 & 16.2 & -9.6 & 59 \\
\hline LRSP4 & 8 & 95 & 5.9 & 0.5 & 5.4 & 1080 \\
\hline \multicolumn{2}{|c|}{ Study area mean $\% E$} & & & & & 310 \\
\hline MCCP1 & 10 & 49 & 3.1 & 0.6 & 2.5 & 417 \\
\hline MCCP2 & 79 & 19 & 1.2 & 4.9 & -3.8 & 78 \\
\hline МCCP3 & 52 & 18 & 1.1 & 3.3 & -2.1 & 64 \\
\hline MCCP4 & 76 & 34 & 2.2 & 4.8 & -2.6 & 54 \\
\hline \multicolumn{2}{|c|}{ Study area mean $\% E$} & & & & & 153 \\
\hline RCSP1 & 278 & 153 & 9.5 & 17.4 & -7.8 & 45 \\
\hline RCSP2 & 431 & 109 & 6.8 & 26.9 & -20.1 & 75 \\
\hline RCSP3 & 304 & 61 & 3.8 & 19 & -15.2 & 80 \\
\hline RCSP4 & 157 & 22 & 1.3 & 9.8 & -8.5 & 87 \\
\hline \multicolumn{2}{|c|}{ Study area mean \% E } & & & & & 72 \\
\hline SGL1 & 17 & 290 & 18.1 & 1.1 & 17.1 & 1555 \\
\hline SGL2 & 55 & 184 & 11.5 & 3.4 & 8.1 & 238 \\
\hline SGL3 & 28 & 67 & 4.2 & 1.8 & 2.4 & 133 \\
\hline SGL4 & 164 & 33 & 2.1 & 10.3 & -8.2 & 80 \\
\hline \multicolumn{2}{|c|}{ Study area mean \% E } & & & & & 501 \\
\hline CCCP1 & 34 & 159 & 9.9 & 17 & -7.1 & 42 \\
\hline $\mathrm{CCCP} 2$ & 48 & 103 & 6.4 & 24 & -17.6 & 73 \\
\hline CCCP3 & 6 & 49 & 3 & 3 & 0 & 0 \\
\hline CCCP4 & 27 & 91 & 5.7 & 13.5 & -7.8 & 58 \\
\hline \multicolumn{2}{|c|}{ Study area mean $\% E$} & & & & & 43 \\
\hline
\end{tabular}


Figure 1. Map of southwestern Pennsylvania showing the location of the 4 counties (Allegheny, Beaver, Washington and Westmoreland) and the 5 study areas (4 primary areas: State Game Land 203, Raccoon Creek State Park, Mingo Creek County Park, and Linn Run State Park; 1 secondary: Cedar Creek County Park) where the study was conducted, 2008-2009.

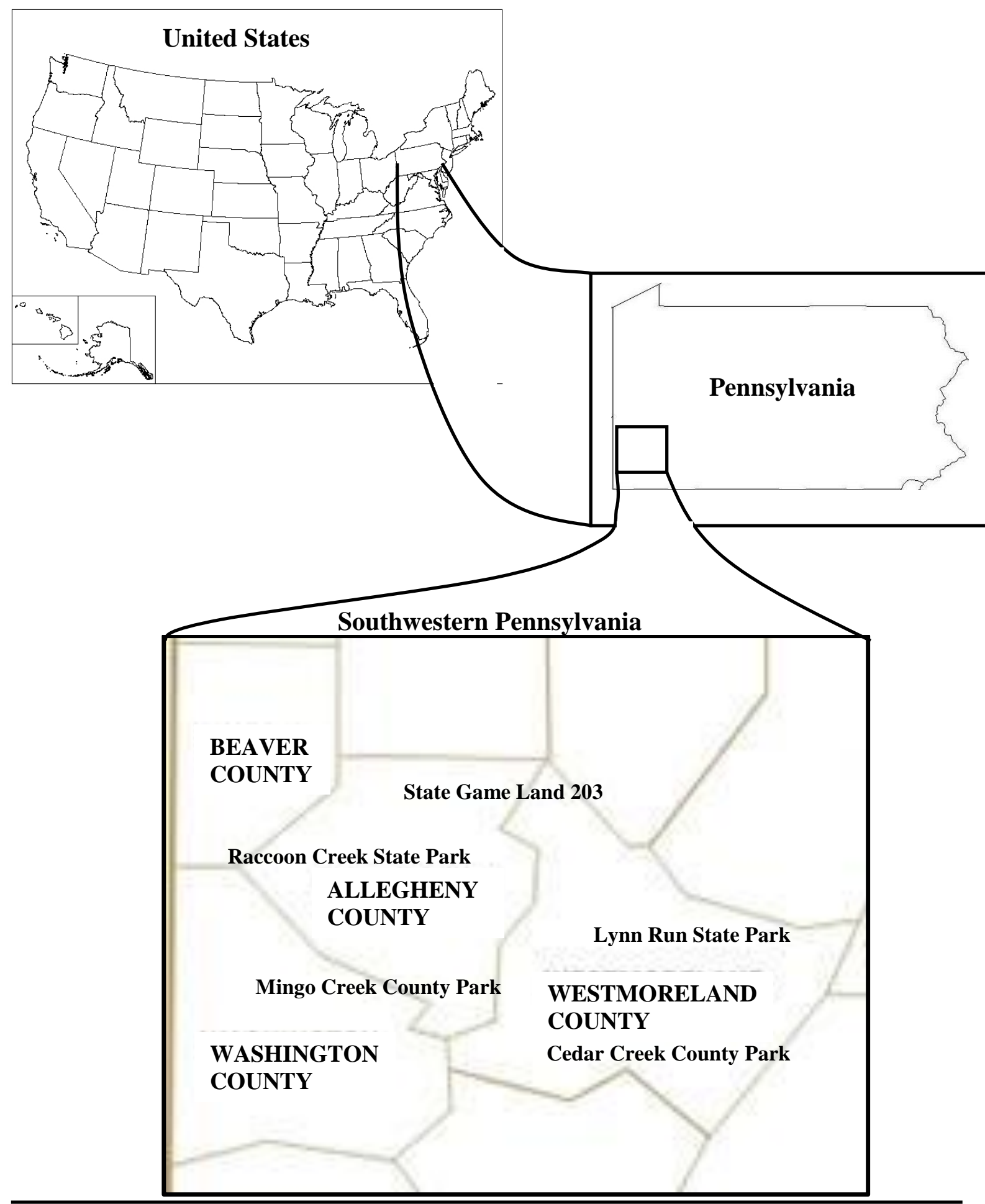


Figure 2. Conceptual diagram of cover boards placement (not drawn to scale) for stream side salamander study in southwestern Pennsylvania, 2008-2009. Sixteen streams in the 4 primary study areas with each stream having 5 groups of 10 boards ( 2 are shown here) with each group $5 \mathrm{~m}$ apart. Each group of cover boards consisted of 5 pairs of $30 \mathrm{~cm} \times 30 \mathrm{~cm} \times 5 \mathrm{~cm}$ cover boards with each pair being $2 \mathrm{~m}$ apart.

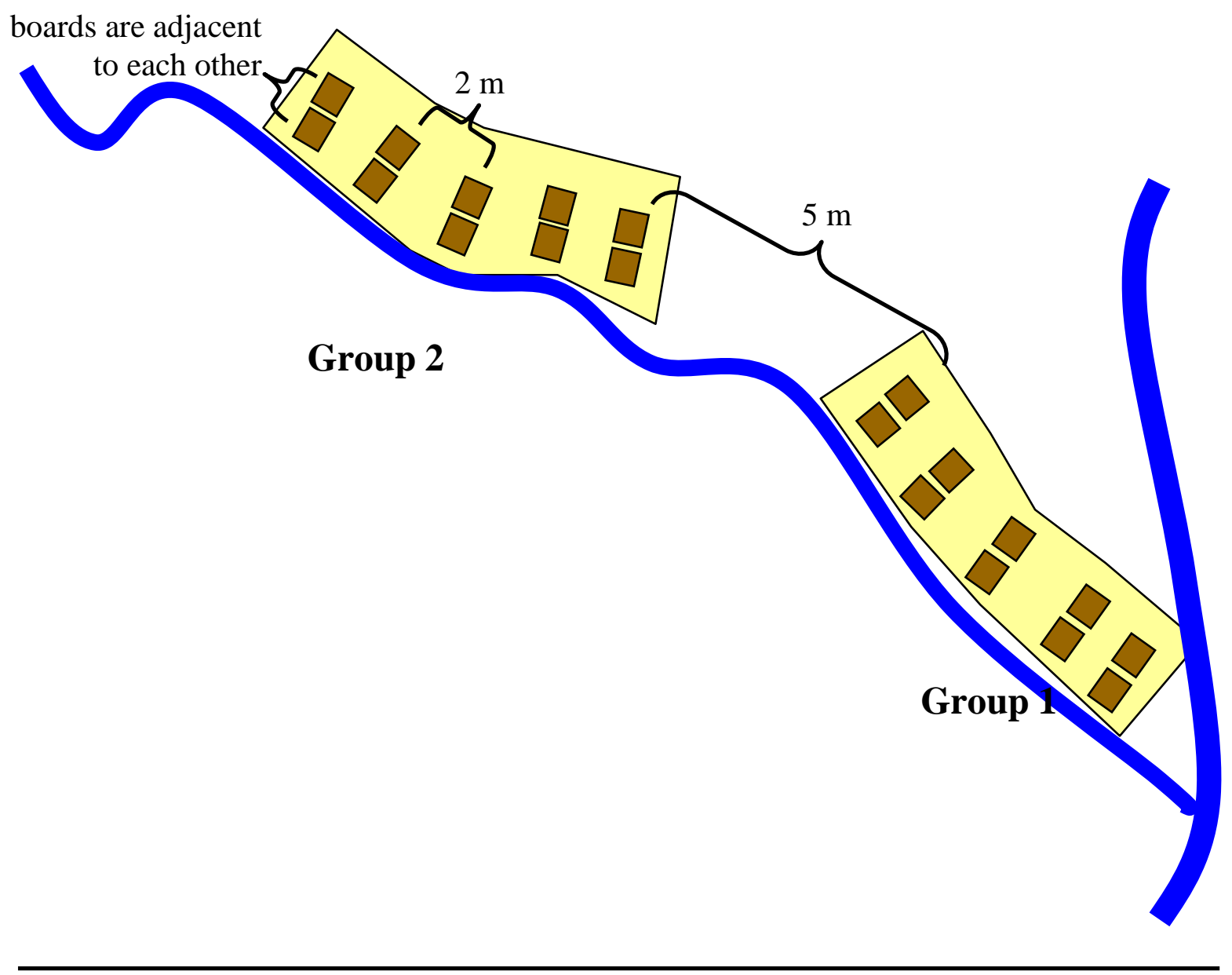


Figure 3. Scatter plot of the number of salamanders captured under a cover board versus mean protective cover by stream reach for the 16 streams in 4 primary study areas (Linn Run State Park (LRSP), Mingo Creek County Park (MCCP), Raccoon Creek State Park (RCSP), and State Game Land 203 (SGL)) in southwestern Pennsylvania, 2008-2009.

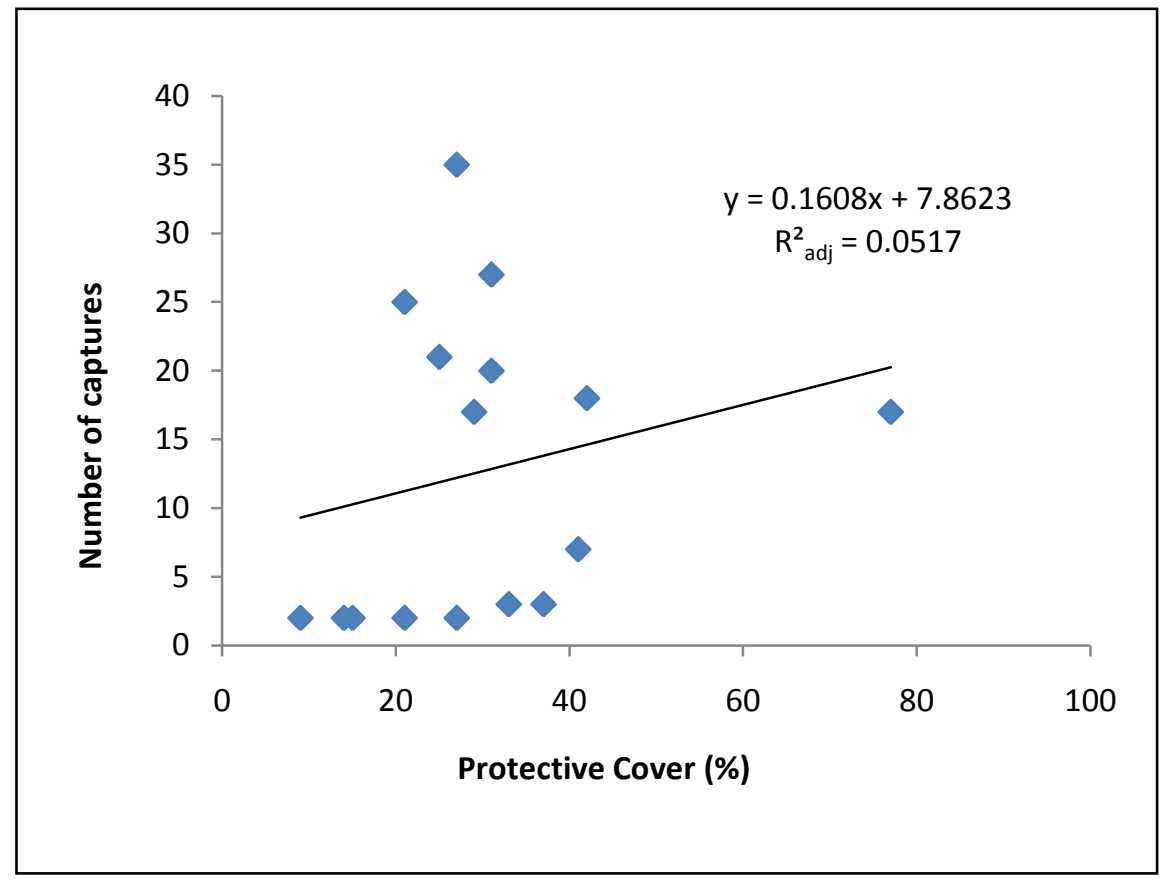


Figure 4. Scatter plots of the mean measured non-correlated habitat parameters (stream size, mean temperature, percent herbaceous cover, $\mathrm{pH}$, relative humidity, percent canopy cover, percent deciduous trees, and percent protective cover) versus estimated northern dusky salamander density (No. salamanders/m) from the 16 visit of the 16 stream reaches in the 4 study areas (Linn Run State Park, Mingo Creek County Park, Raccoon Creek State Park, and State Game Land 203) of southwestern Pennsylvania that were studied in 2008-2009.
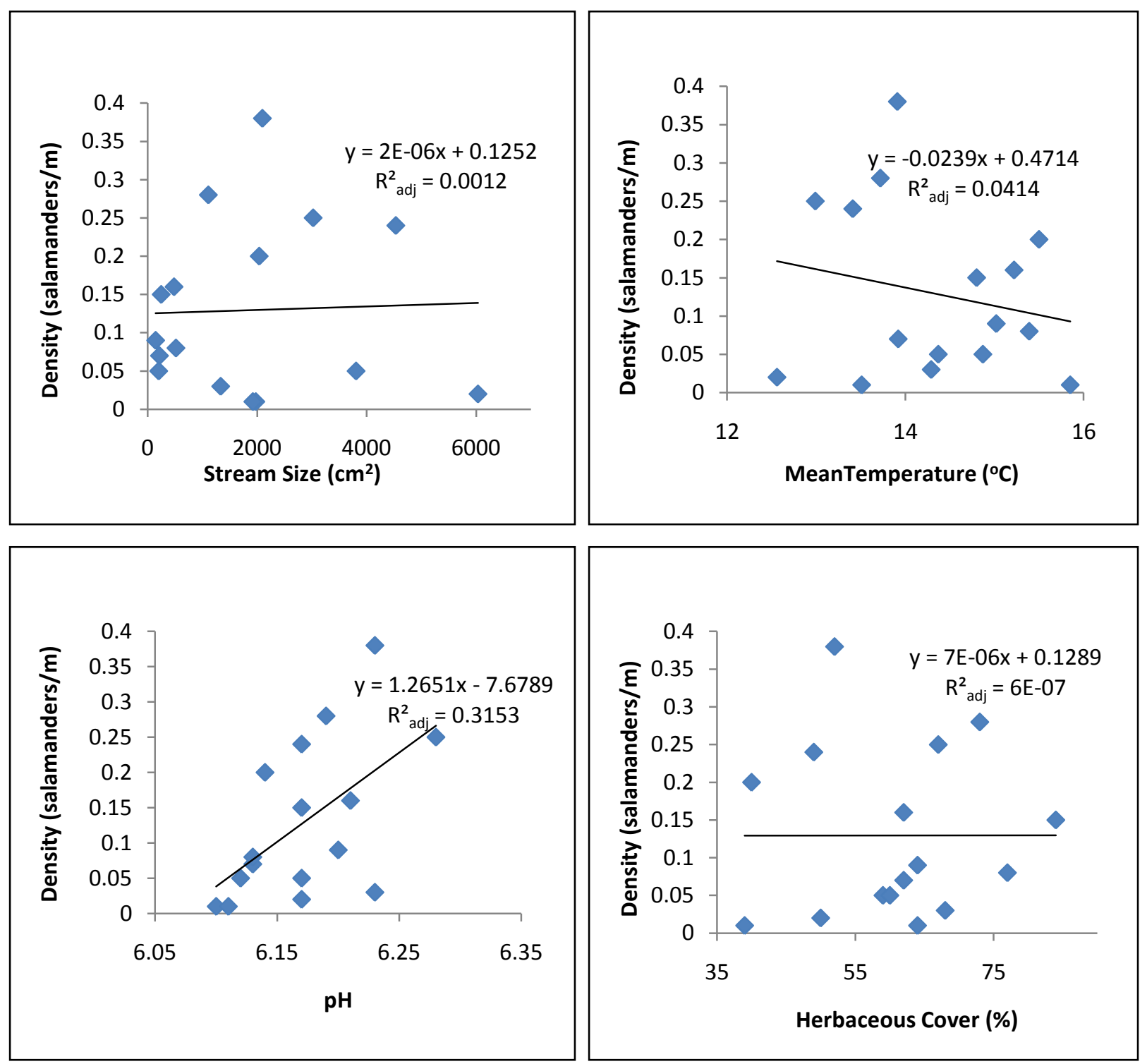
Figure 4. cont.
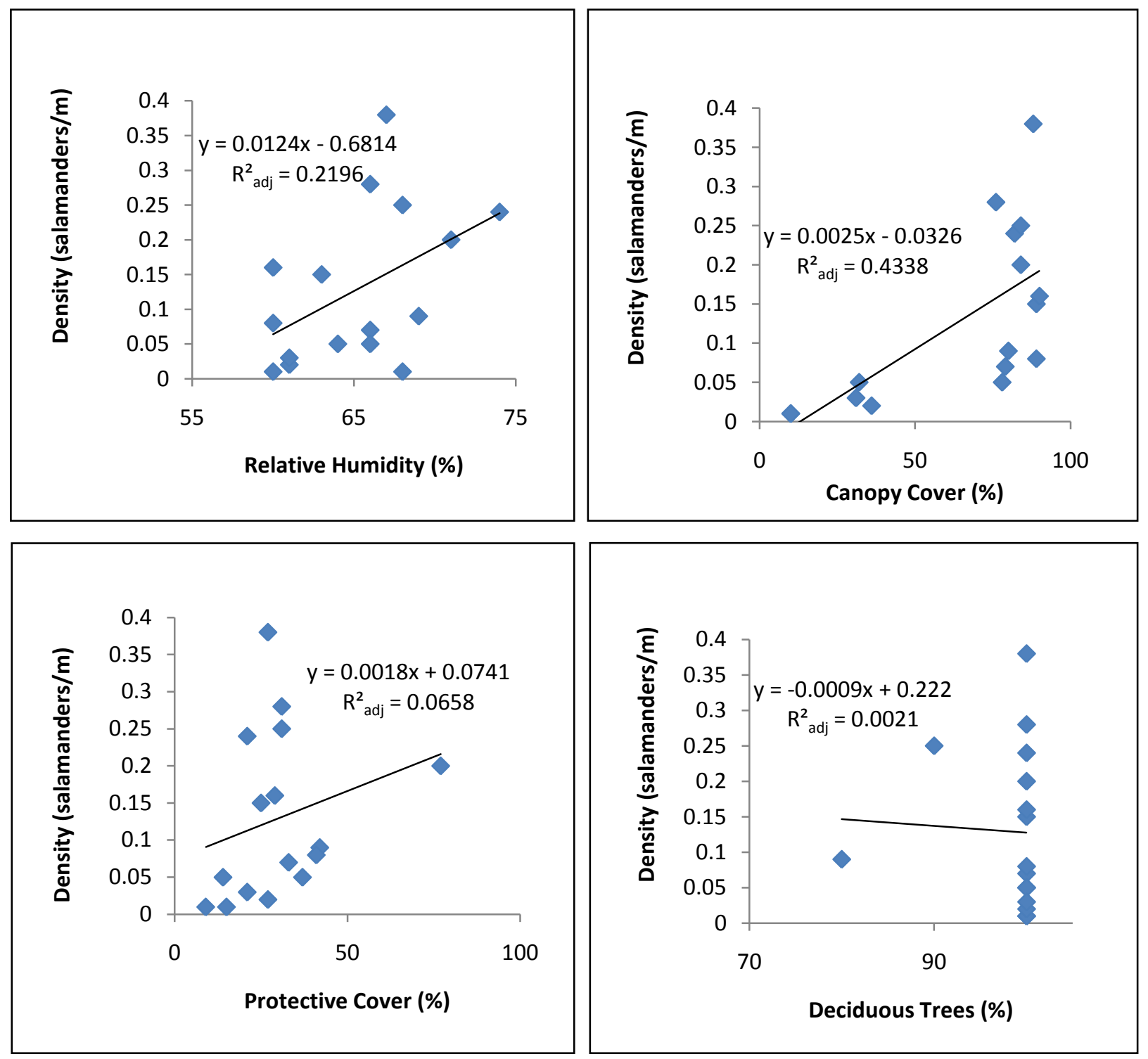
Figure 5. Bar graphs showing selected non-correlated measured habitat parameter (protective cover, canopy cover, stream size, and herbaceous cover) values sorted by stream reach and classification (Good or Poor) of the 16 streams in the 4 study areas (LRSP: Linn Run State Park, MCCP: Mingo Creek County Park, RCSP: Raccoon Creek State Park, and SGL: State Game Land 203) for this study in southwestern Pennsylvania, 2008-2009.
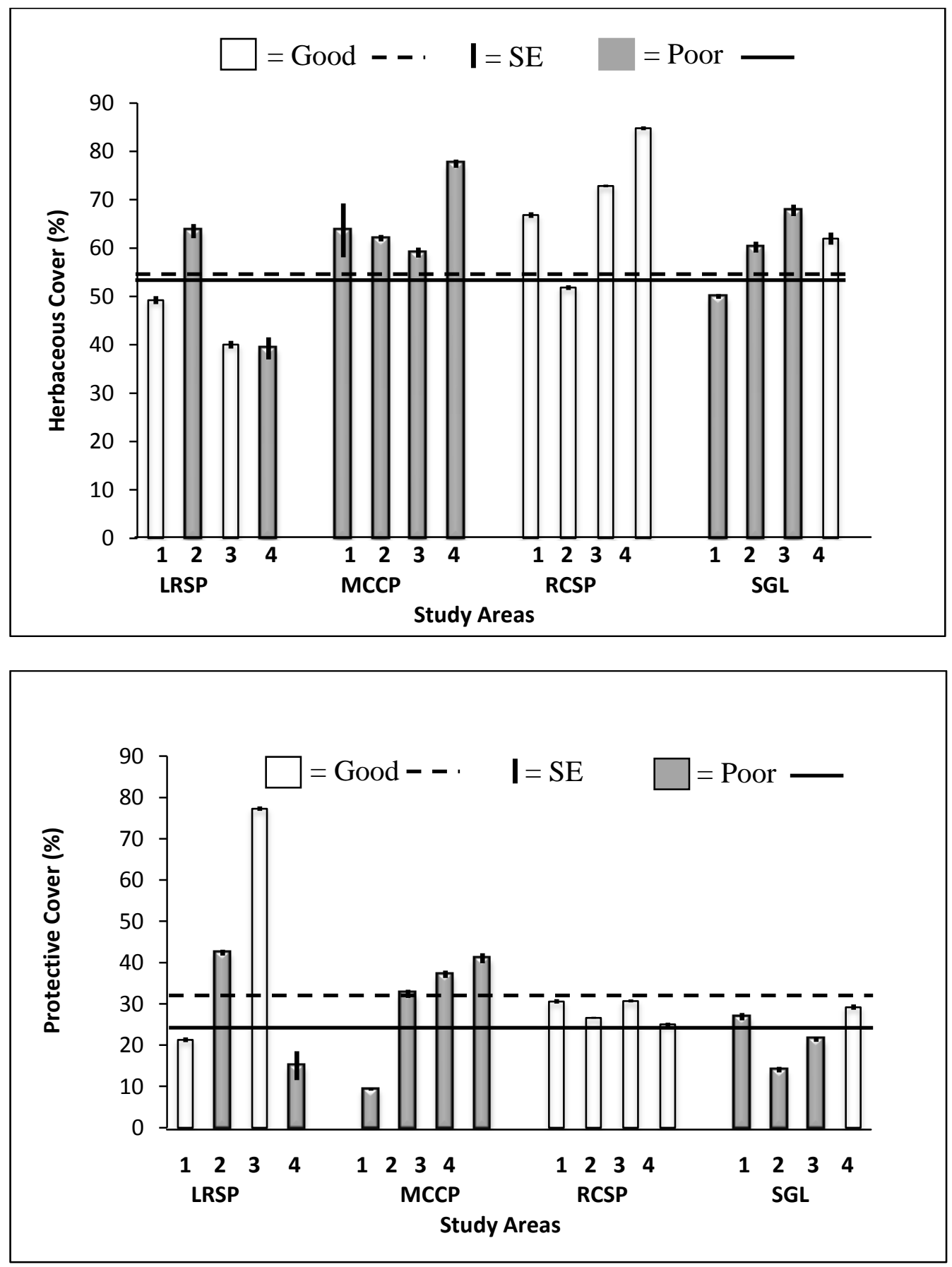
Figure 5. cont.
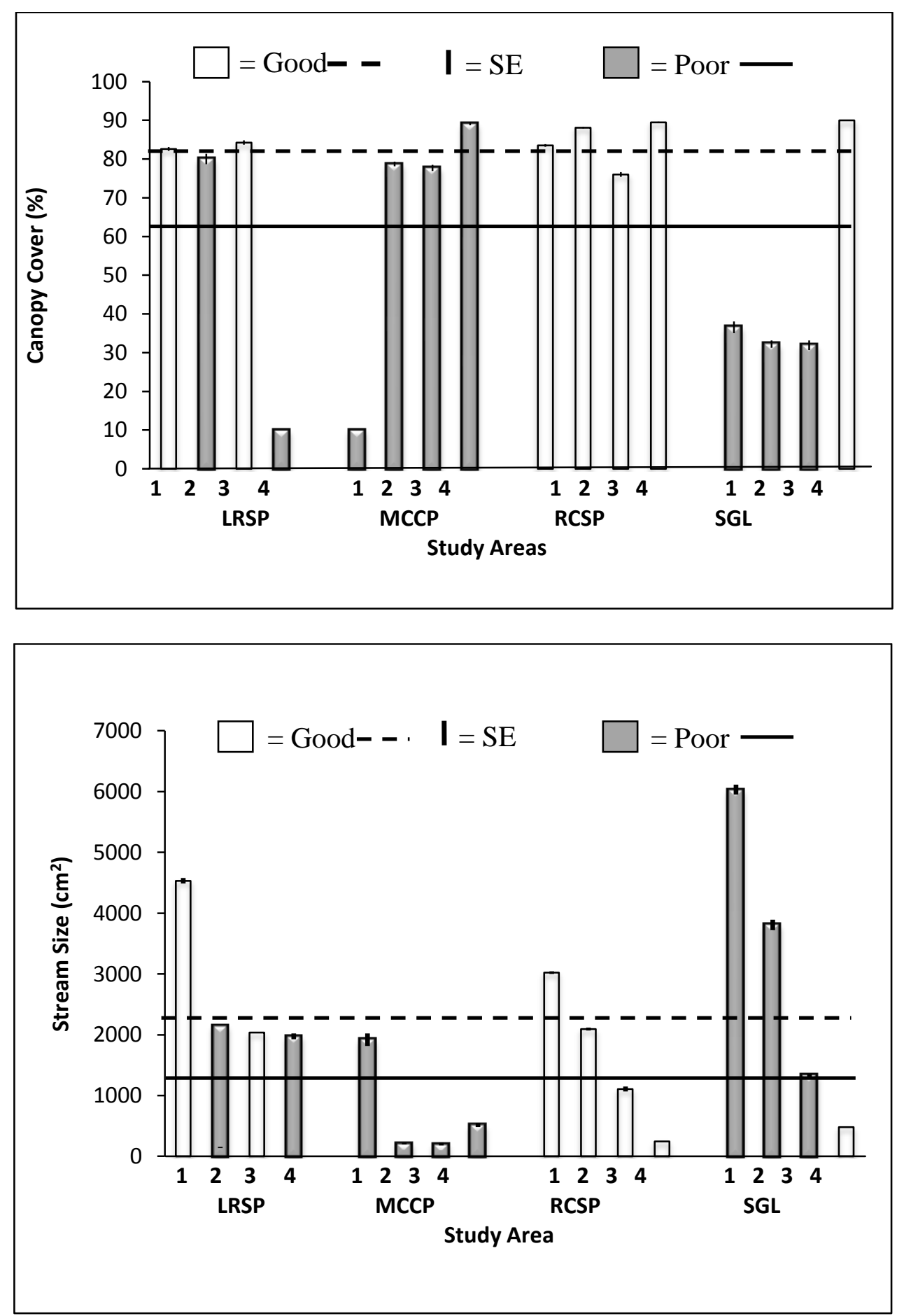
Figure 6. Scatter plot of the repeated measures density versus mark and recapture density for the 16 streams in 4 primary study areas (Linn Run State Park (LRSP), Mingo Creek County Park (MCCP), Raccoon Creek State Park (RCSP), and State Game Land 203 (SGL)) in southwestern Pennsylvania, 2008-2009.

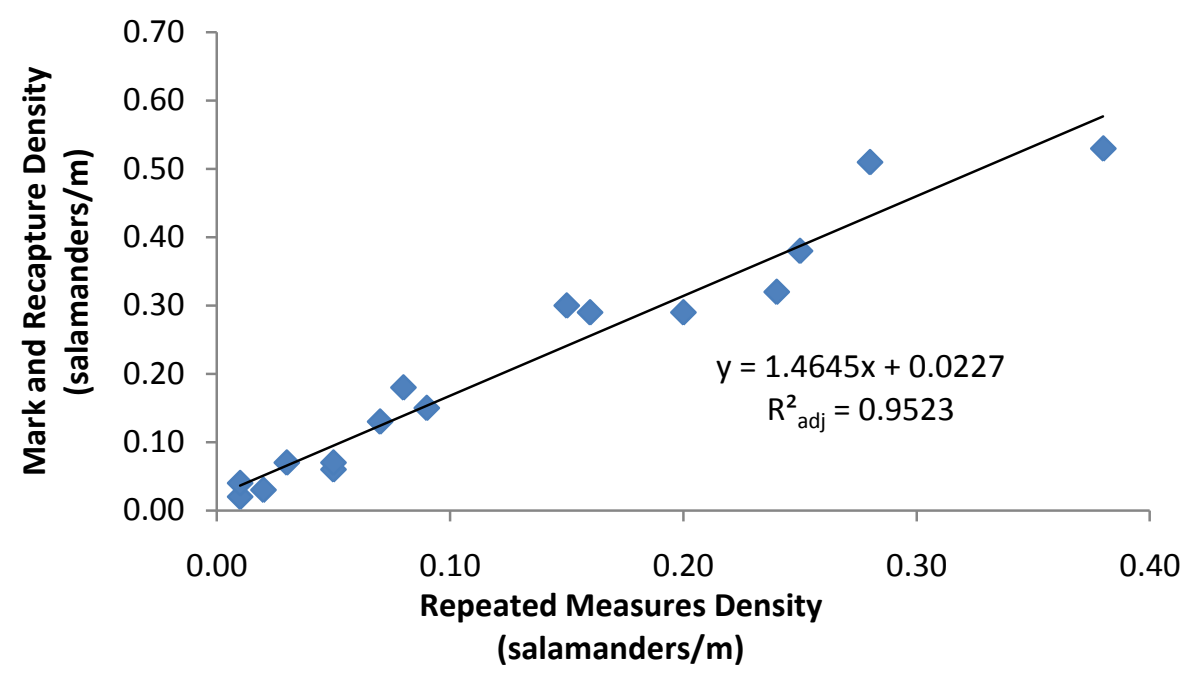


Figure 7. Scatter plots of the estimated northern dusky salamander density from the mark and recapture survey for each of the 6 a priori abundance models versus northern dusky salamander density (from repeated measures) from the 16 stream reaches of southwestern Pennsylvania that were studied in 20082009.
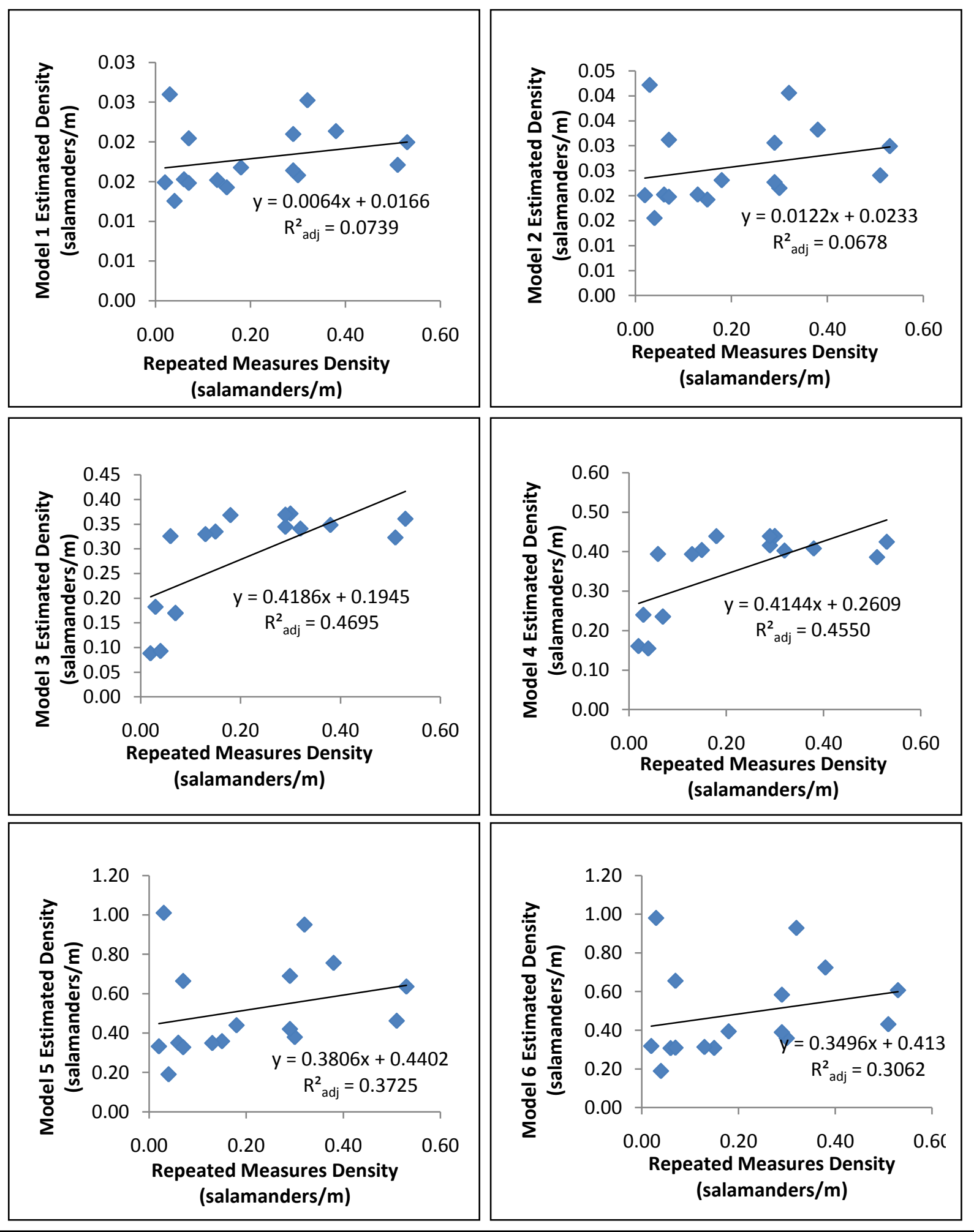
Figure 8. Scatter plots of the estimated northern dusky salamander density for each of the 6 a priori abundance models versus northern dusky salamander density (from repeated measures) for the 16 stream reaches of southwestern Pennsylvania that were studied in 2008-2009.
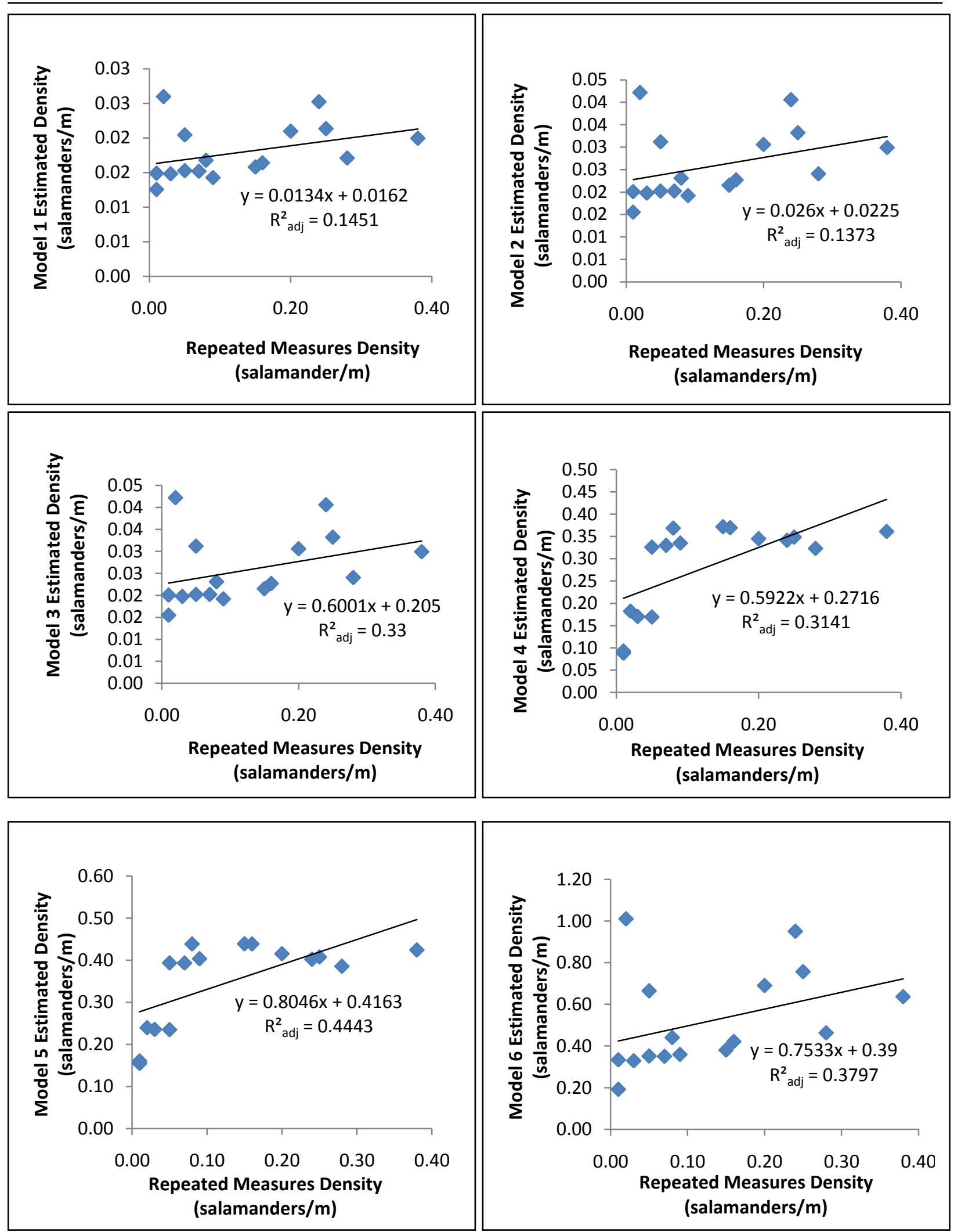
Figure 9. Scatter plots of the estimated northern dusky salamander density versus percent error for Model 5 (a) and the post-hoc model (b) for the 16 stream reaches of southwestern Pennsylvania that were studied in 2008-2009.

a)

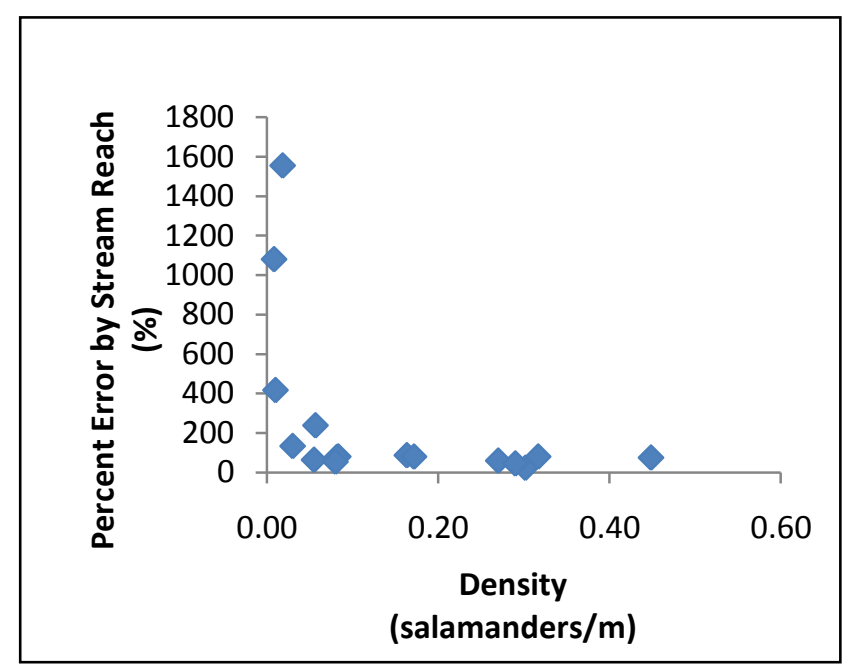

b)

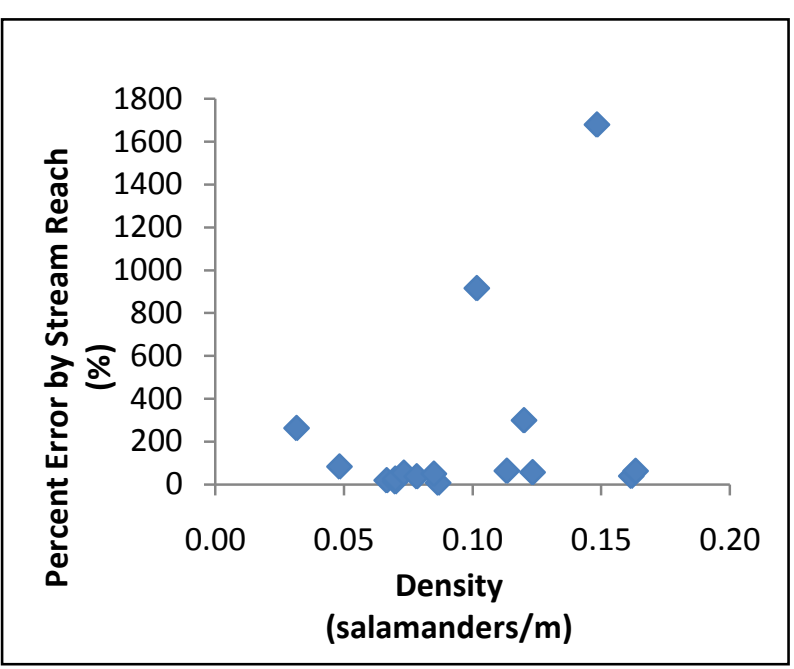


Figure 10. Scatter plot of the measured non-correlated habitat parameter stream size difference $\left(\mathrm{S}_{\mathrm{wd}}^{\prime}\right)$ versus estimated northern dusky salamander density (from repeated measures) from the 16 stream reaches of southwestern Pennsylvania that were studied in 2008-2009.

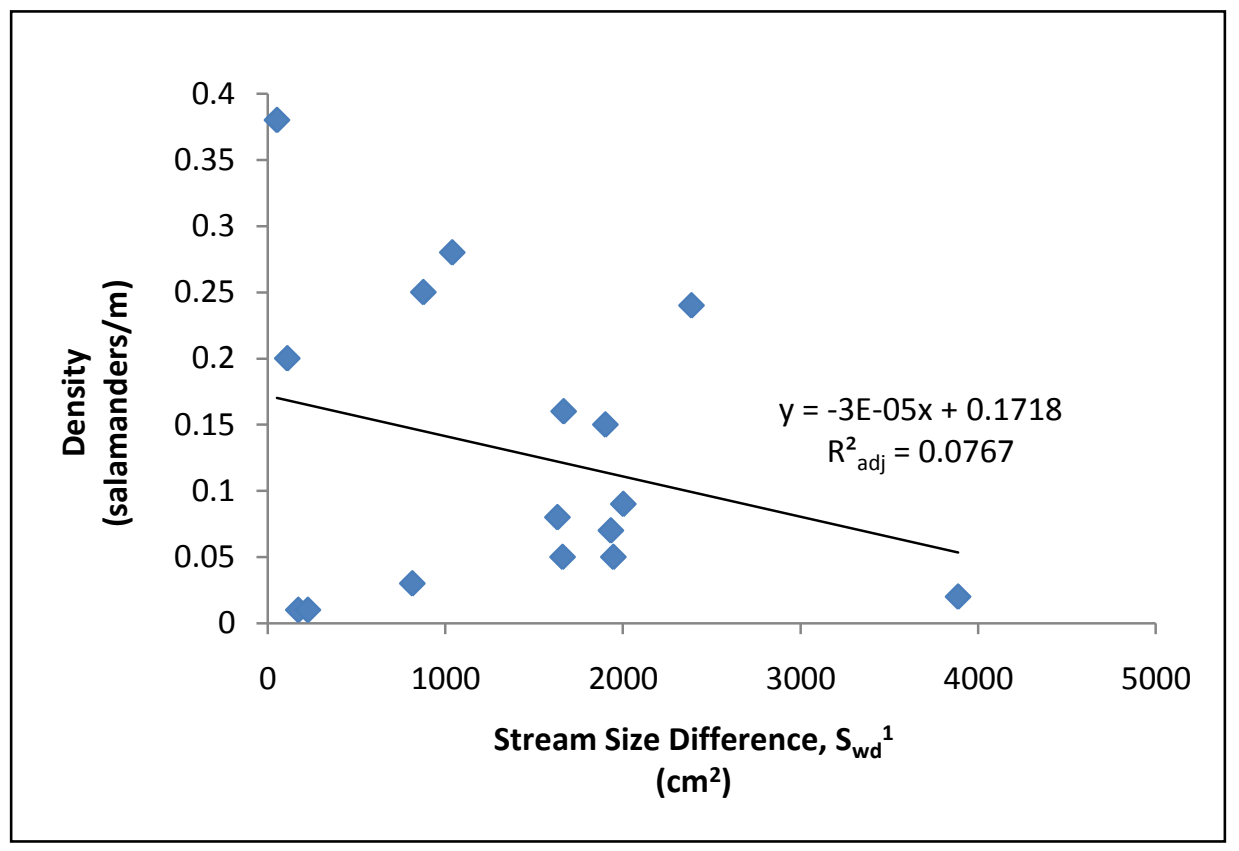


Figure 11. Scatter plot of the estimated northern dusky salamander density for post-hoc model 7 versus northern dusky salamander density (from repeated measures) from the 16 stream reaches of southwestern Pennsylvania that were studied in 2008-2009.

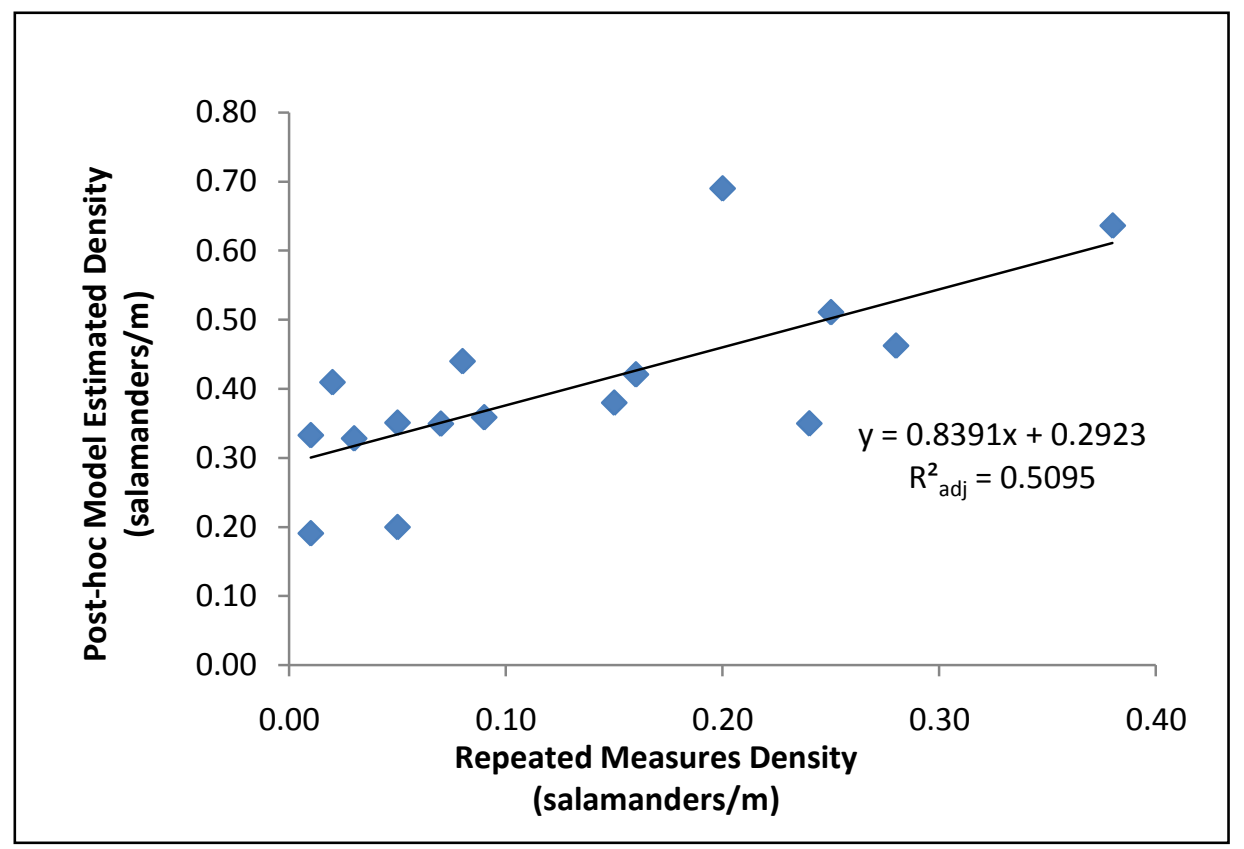


Appendix 1. Thirty year average of climatic conditions in southwestern Pennsylvania (Region 3609 of NOAA's Climate Divisions), 1971-2000 (NOAA 2005).

Average precipitation, in cm, from 1971-2000, for Pittsburgh, Pennsylvania.

Jan. Feb. Mar. Apr. May Jun. Jul. Aug. Sep. Oct. Nov. Dec. Ann.

$\begin{array}{lllllllllllll}6.7 & 6.0 & 8.0 & 7.7 & 9.7 & 10.5 & 10.1 & 8.6 & 8.2 & 5.7 & 7.7 & 7.3 & 96.1\end{array}$

Monthly average maximum temperatures, in degrees Celsius, from 1971-2000, for Pittsburgh, Pennsylvania.

Jan. Feb. Mar. Apr. May Jun. Jul. Aug. Sep. Oct. Nov. Dec. Ann.

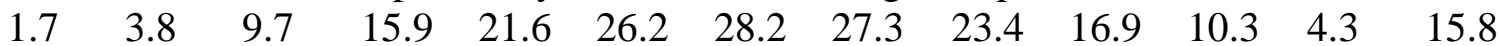

Monthly average minimum temperatures, in Degrees Celsius, from 1971-2000, for Pittsburgh, Pennsylvania.

Jan. Feb. Mar. Apr. May Jun. Jul. Aug. Sep. Oct. Nov. Dec. Ann.

$\begin{array}{lllllllllllll}-6.7 & -5.4 & -1.1 & 3.9 & 9.6 & 13.9 & 16.9 & 16.1 & 12.2 & 5.8 & 1.2 & -3.7 & 5.3\end{array}$

Monthly average temperatures, in Degrees Celsius, from 1971-2000, for Pittsburgh, Pennsylvania.

Jan. Feb. Mar. Apr. May Jun. Jul. Aug. Sep. Oct. Nov. Dec. Ann.

$\begin{array}{lllllllllllll}-2.5 & -0.8 & 4.3 & 9.4 & 15.6 & 20.2 & 22.6 & 21.7 & 17.8 & 11.4 & 5.7 & 0.3 & 10.5\end{array}$

Mean number of days with $0.03 \mathrm{~cm}$ of precipitation or more, 53 year mean, for Pittsburgh, Pennsylvania.

Jan. Feb. Mar. Apr. May Jun. Jul. Aug. Sep. Oct. Nov. Dec. Ann.

$\begin{array}{lllllllllllll}16 & 14 & 15 & 14 & 13 & 12 & 11 & 10 & 10 & 10 & 13 & 16 & 152\end{array}$

Average wind speed, in $\mathrm{Km} / \mathrm{Hr}$, for 53 years, for Pittsburgh, Pennsylvania.

Jan. Feb. Mar. Apr. May Jun. Jul. Aug. Sep. Oct. Nov. Dec. Ann.

$\begin{array}{lllllllllllll}16.7 & 16.6 & 16.9 & 16.4 & 14.0 & 12.9 & 11.7 & 10.9 & 11.9 & 13.4 & 15.4 & 16.3 & 14.5\end{array}$

Average percent of possible sunshine, for 49 years, for Pittsburgh, Pennsylvania.

\begin{tabular}{lllllllllllll}
\hline Jan. & Feb. & Mar. & Apr. & May & Jun. & Jul. & Aug. & Sep. & Oct. & Nov. & Dec. & Ann. \\
32 & 36 & 43 & 46 & 50 & 55 & 57 & 56 & 55 & 51 & 36 & 28 & 45
\end{tabular}

Average relative humidity morning (top) and afternoon (bottom), for 45 years, for Pittsburgh, Pennsylvania.

\begin{tabular}{lllllllllllll}
\hline Jan. & Feb. & Mar. & Apr. & May & Jun. & Jul. & Aug. & Sep. & Oct. & Nov. & Dec. & Ann. \\
77 & 76 & 76 & 74 & 78 & 80 & 83 & 86 & 87 & 83 & 79 & 78 & 80 \\
66 & 62 & 58 & 51 & 53 & 54 & 55 & 56 & 57 & 55 & 62 & 67 & 58 \\
\hline
\end{tabular}


Appendix 2. Identifying lateral eye stripe of the dusky salamander as used in this southwestern Pennsylvania study that included 4 primary study areas (Linn Run State Park, Mingo Creek County Park, Raccoon Creek State Park, and State Game Land 203) 2008-2009 (Hulse et al. 2001).

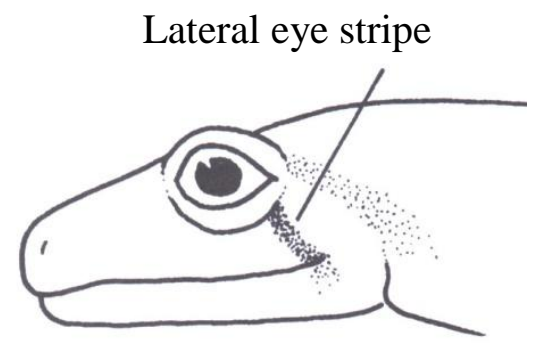

Appendix 3. Identifying wide dorsal stripe of the northern dusky salamander as used in this southwestern Pennsylvania study that included 4 primary study areas (Linn Run State Park, Mingo Creek County Park, Raccoon Creek State Park, and State Game Land 203) 2008-2009 (Hulse et al. 2001).

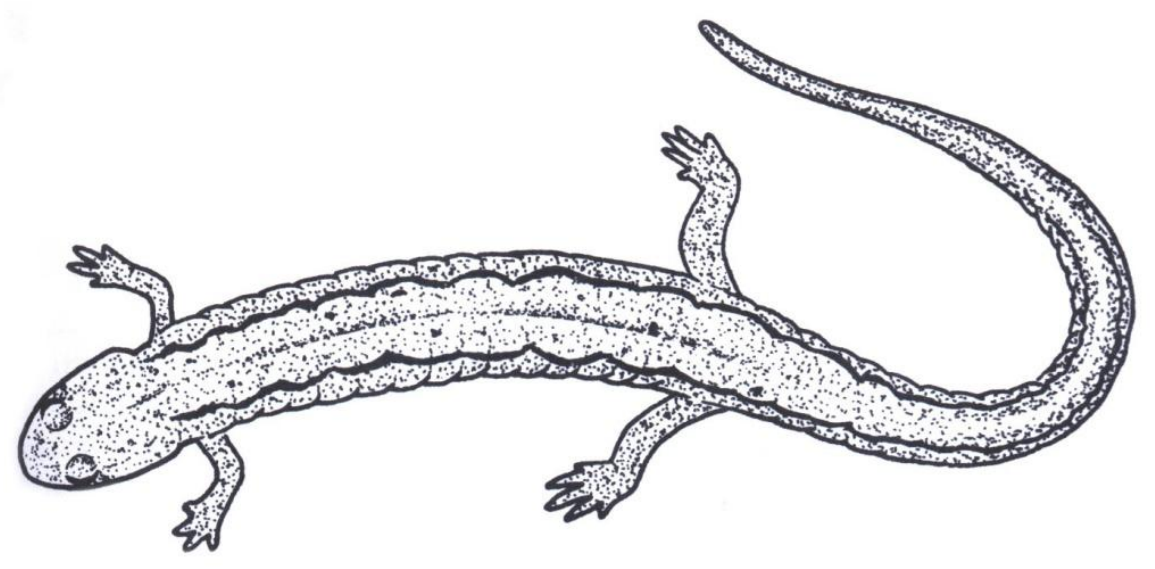


Appendix 4. Identifying keeled tail (on right) of the northern dusky salamander shown as used in this southwestern Pennsylvania study that included 4 primary study areas (Linn Run State Park, Mingo Creek County Park, Raccoon Creek State Park, and State Game Land 203) 20082009 (Hulse et al. 2001).
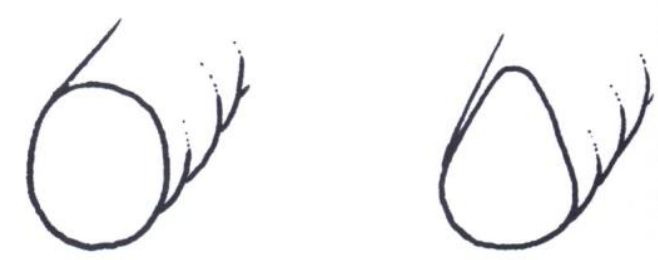
Appendix 5. Preferred habitat of the northern dusky salamander of the 4 primary study areas (Linn Run State Park, Mingo Creek County Park, Raccoon Creek State Park, and State Game Land 203) as determined by GIS data from Pennsylvania Spatial Data Access (PASDA).

\section{Pennsylvania Preferred Habitat and Rural Forests in Lynn Run State Park}

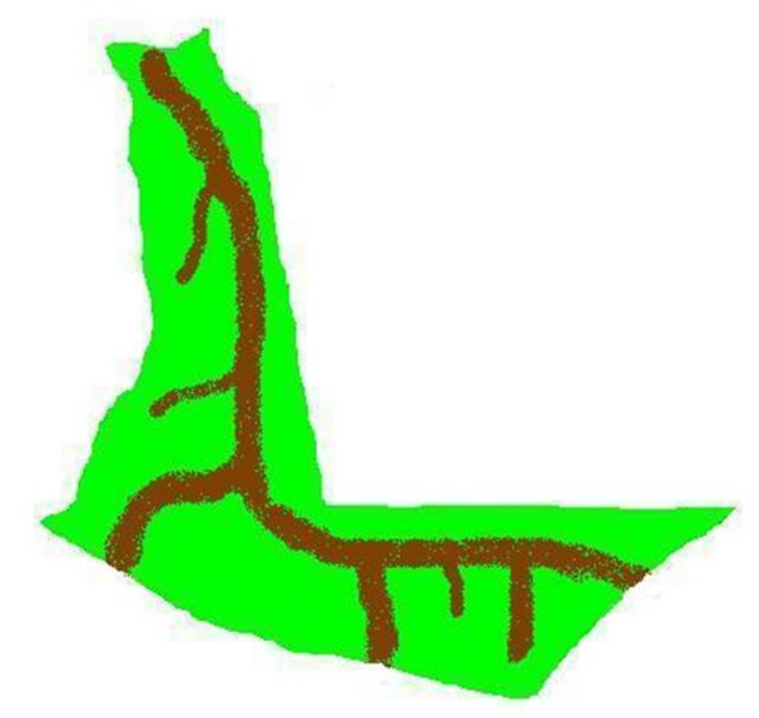

Rural forest and preferred habitat

Non habitat

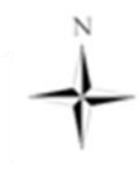


Appendix 5. cont.

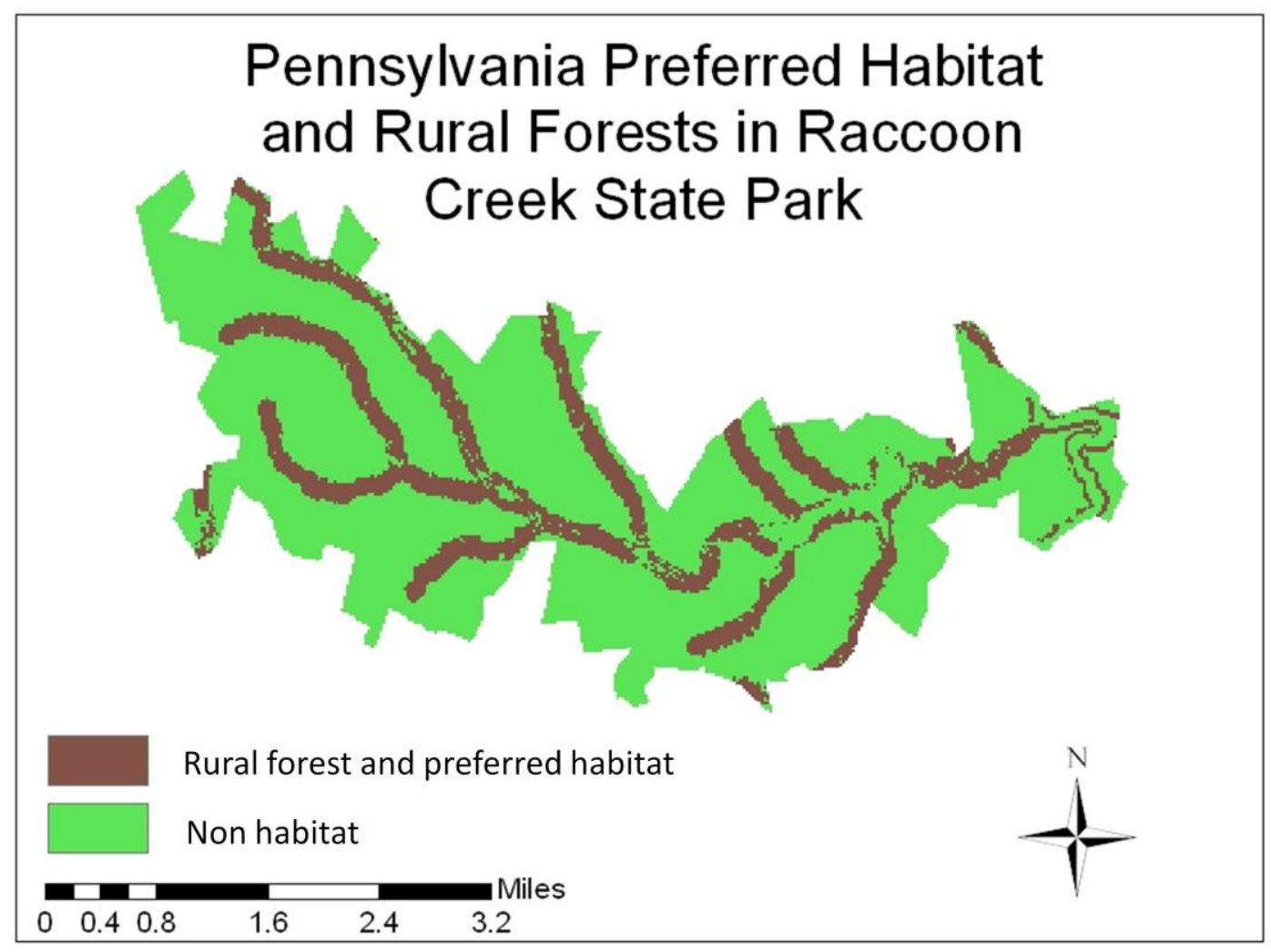


Appendix 5. cont.

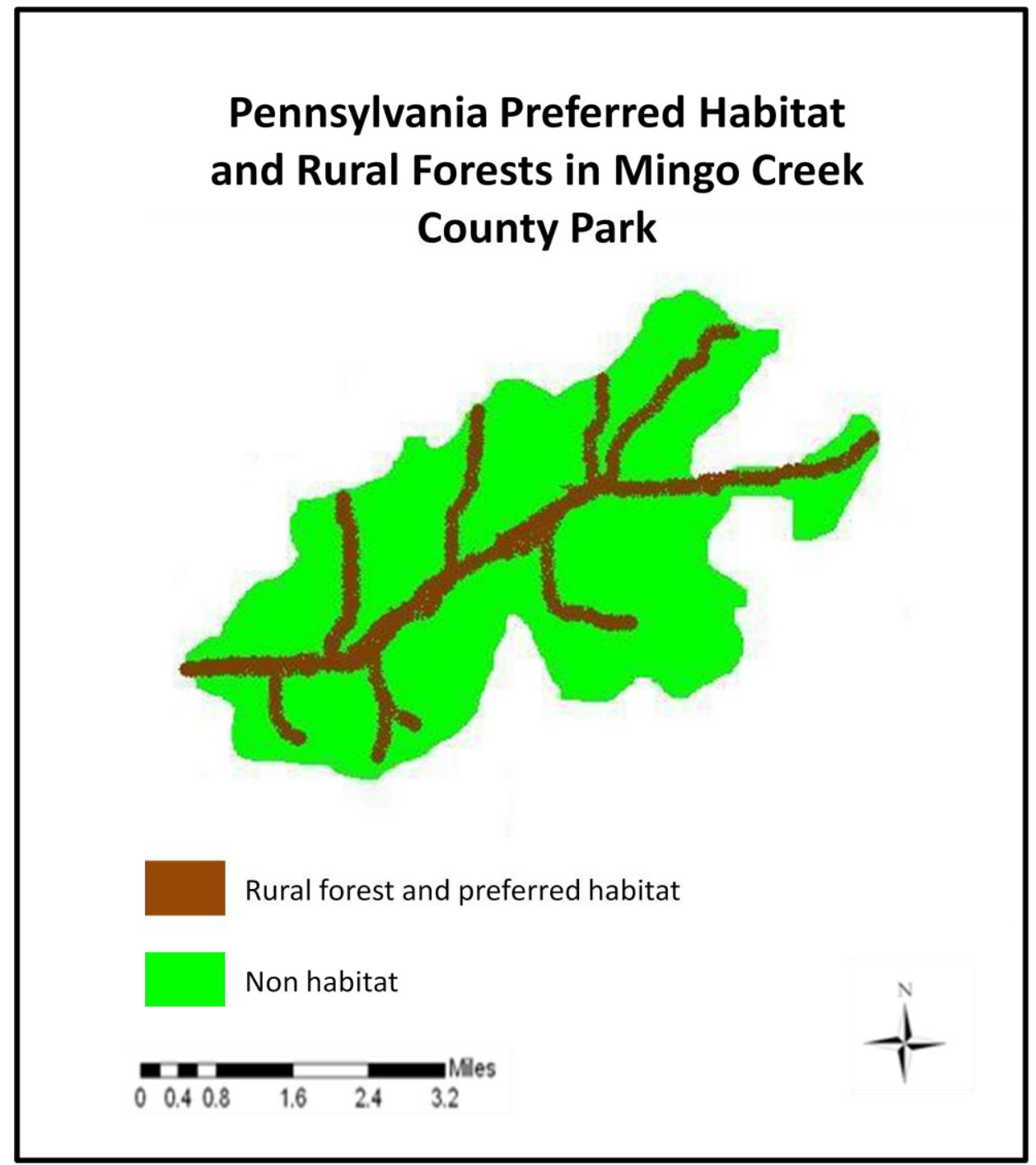


Appendix 5. cont.

\section{Pennsylvania Preferred Habitat and Rural Forests in State Game Land 203}

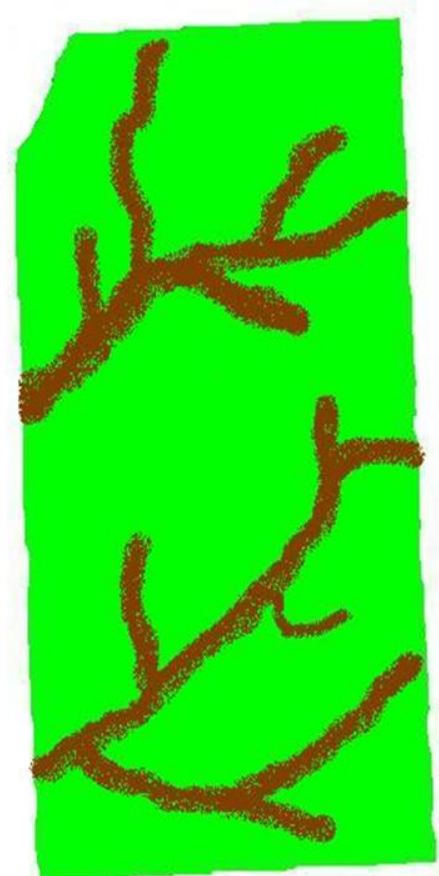

Rural forest and preferred habitat

Non habitat

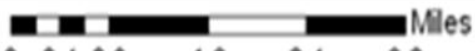

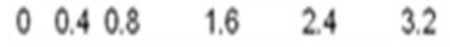

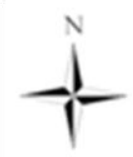


Appendix 6. Mean separated habitat data from the 4 southwestern Pennsylvania primary study areas: Linn Run State Park (LRSP),

Westmoreland County; Mingo Creek County Park (MCCP), Washington County; Raccoon Creek State Park (RCSP), Beaver County, and State Game Lands 203 (SGL), Allegheny County, 2008-2009.

\begin{tabular}{|c|c|c|c|c|c|c|c|c|c|c|c|c|}
\hline \multirow[b]{2}{*}{ Study Area } & \multicolumn{3}{|c|}{ Stream size $\left(\mathrm{cm}^{2}\right)^{\mathrm{a}}$} & \multicolumn{3}{|c|}{ Tree canopy cover $^{b}$} & \multicolumn{3}{|c|}{ Herbaceous cover $^{c}$} & \multicolumn{3}{|c|}{ Protective cover $^{d}$} \\
\hline & $\overline{\mathbf{x}}$ & SE & $\begin{array}{l}\text { Mean } \\
\text { group }\end{array}$ & $\overline{\mathbf{x}}$ & SE & $\begin{array}{l}\text { Mean } \\
\text { group }\end{array}$ & $\overline{\mathbf{x}}$ & SE & $\begin{array}{l}\text { Mean } \\
\text { group }\end{array}$ & $\overline{\mathbf{x}}$ & SE & $\begin{array}{l}\text { Mean } \\
\text { group }\end{array}$ \\
\hline LRSP & $2,889.56$ & 73.63 & A & 82.31 & 0.49 & A & 47.79 & 0.66 & B & 46.48 & 1.19 & $\mathrm{~A}$ \\
\hline MCCP & 362.59 & 22.21 & $\mathrm{C}$ & 78.89 & 1.22 & A & 67.09 & 0.83 & A & 35.35 & 0.80 & B \\
\hline RCSP & $1,803.25$ & 37.99 & B & 84.05 & 0.26 & A & 65.41 & 0.45 & A & 28.43 & 0.21 & $\mathrm{C}$ \\
\hline SGL & $1,599.84$ & 114.66 & B & 69.71 & 1.74 & B & 61.69 & 0.87 & A & 24.86 & 0.59 & $\mathrm{C}$ \\
\hline
\end{tabular}

${ }^{\mathrm{a}}$ Stream size $=\mathrm{W}_{\mathrm{s}} \times\left(\left(\mathrm{D}_{1 / 4}+\mathrm{D}_{1 / 2}+\mathrm{D}_{3 / 4}\right) / 3\right)$.

${ }^{\mathrm{b}}$ Percent tree canopy cover as determine by the mean of 4 densiometer readings.

${ }^{\mathrm{c}}$ Percent herbaceous cover $(<2 \mathrm{~m}$ tall $)$ as determined by ocular estimates.

${ }^{\mathrm{d}}$ Percent protective cover as a percentage of the stream reach by ocular estimates. 
Appendix 6. Cont.

\begin{tabular}{|c|c|c|c|c|c|c|c|c|c|c|c|c|}
\hline \multirow[b]{2}{*}{ Study Area } & \multicolumn{3}{|c|}{$\mathbf{p H}^{\mathrm{e}}$} & \multicolumn{3}{|c|}{ Mean temperature ${ }^{f}$} & \multicolumn{3}{|c|}{ Deciduous trees $^{\mathrm{g}}$} & \multicolumn{3}{|c|}{ Relative humidity $^{\text {h }}$} \\
\hline & $\overline{\mathbf{x}}$ & SE & $\begin{array}{l}\text { Mean } \\
\text { group }\end{array}$ & $\overline{\mathbf{x}}$ & SE & $\begin{array}{l}\text { Mean } \\
\text { group }\end{array}$ & $\overline{\mathbf{x}}$ & SE & $\begin{array}{l}\text { Mean } \\
\text { group }\end{array}$ & $\overline{\mathbf{x}}$ & SE & $\begin{array}{l}\text { Mean } \\
\text { group }\end{array}$ \\
\hline LRSP & 6.15 & 0.00 & $\mathrm{~A}$ & 14.95 & 0.25 & $\mathrm{~A}$ & 95.24 & 0.19 & $\mathrm{~A}$ & 68.23 & 1.89 & $\mathrm{~A}$ \\
\hline MCCP & 6.12 & 0.01 & A & 14.42 & 0.22 & A & 100.00 & 0.00 & A & 65.10 & 2.30 & A \\
\hline RCSP & 6.22 & 0.00 & A & 13.86 & 0.14 & A & 97.58 & 0.04 & A & 65.94 & 0.93 & A \\
\hline SGL & 6.20 & 0.01 & A & 14.11 & 0.17 & A & 100.00 & 0.00 & A & 61.39 & 2.41 & A \\
\hline
\end{tabular}

${ }^{\mathrm{e}}$ Measured by an electronic $\mathrm{pH}$ meter.

${ }^{\mathrm{f}}$ Mean temperature $=\left(\mathrm{T}_{\mathrm{a}}+\mathrm{T}_{\mathrm{w}}+\mathrm{T}_{\mathrm{s}}\right) / 3$.

${ }^{\mathrm{g}}$ Percent using a direct count (10 $\mathrm{m}$ wide $\times$ stream reach length).

${ }^{\mathrm{h}}$ Mean of three measurements of a wet and dry bulb sling psychrometer. 
Appendix 7. Measured mean habitat and salamander data by stream reach from the 4 southwestern Pennsylvania primary study areas: Linn Run State Park (LRSP), Westmoreland County; Mingo Creek County Park (MCCP), Washington County; Raccoon Creek State Park (RCSP), Beaver County and State Game Lands 203 (SGL), Allegheny County that we used to evaluate 4 (1-4) stream reaches in each study area, 2008-2009.

\begin{tabular}{|c|c|c|c|c|c|c|c|c|c|c|}
\hline \multirow[b]{2}{*}{ Variable, unit (symbol) } & \multicolumn{2}{|c|}{ LRSP1 } & \multicolumn{2}{|c|}{ LRSP2 } & \multicolumn{2}{|c|}{ LRSP3 } & \multicolumn{2}{|c|}{ LRSP4 } & \multicolumn{2}{|c|}{ MCCP1 } \\
\hline & $\overline{\mathbf{x}}$ & SE & $\overline{\mathbf{x}}$ & SE & $\overline{\mathbf{x}}$ & SE & $\overline{\mathbf{x}}$ & SE & $\overline{\mathbf{x}}$ & SE \\
\hline Air temperature, ${ }^{\circ} \mathrm{C}\left(\mathrm{T}_{\mathrm{a}}\right)$ & 13.81 & 0.33 & 17.13 & 0.71 & 18.71 & 0.34 & 18.50 & 1.61 & 11.82 & 0.73 \\
\hline Water temperature, ${ }^{\circ} \mathrm{C}$ & 13.31 & 0.13 & 13.91 & 0.24 & 13.59 & 0.13 & 14.03 & 0.47 & & \\
\hline$\left(\mathrm{T}_{\mathrm{w}}\right)$ & & & & & & & & & 13.93 & 0.38 \\
\hline Soil temperature, ${ }^{\circ} \mathrm{C}\left(\mathrm{T}_{\mathrm{s}}\right)$ & 13.09 & 0.13 & 14.03 & 0.26 & 14.18 & 0.12 & 15.00 & 0.56 & 14.48 & 0.24 \\
\hline Mean temperature ${ }^{\mathrm{a}},{ }^{\circ} \mathrm{C}$ & 13.41 & 0.13 & 15.02 & 0.28 & 15.50 & 0.12 & 15.85 & 0.46 & & \\
\hline$\left(\mathrm{T}_{\mathrm{m}}\right)$ & & & & & & & & & 13.51 & 0.31 \\
\hline Stream width, $\mathrm{cm}\left(\mathrm{W}_{\mathrm{S}}\right)$ & 374.10 & 1.56 & 140.70 & 1.93 & 373.10 & 0.34 & 181.10 & 6.55 & 110.18 & 9.12 \\
\hline Stream depth, cm $\left(\mathrm{D}_{1 / 4}\right)$ & 11.65 & 0.12 & 0.98 & 0.06 & 5.15 & 0.07 & 13.56 & 0.61 & 7.73 & 0.62 \\
\hline Stream depth, cm $\left(D_{1 / 2}\right)$ & 13.64 & 0.18 & 1.03 & 0.07 & 7.60 & 0.12 & 10.57 & 0.52 & 10.15 & 1.07 \\
\hline Stream depth, cm $\left(\mathrm{D}_{3 / 4}\right)$ & 10.80 & 0.17 & 0.97 & 0.05 & 3.64 & 0.11 & 8.88 & 0.48 & 6.83 & 0.67 \\
\hline Stream size ${ }^{\mathrm{b}}, \mathrm{cm}^{2}\left(S_{\mathrm{wd}}\right)$ & $4,532.21$ & 46.55 & 144.67 & 9.28 & $2,036.61$ & 11.13 & $1,974.91$ & 49.08 & $1,920.47$ & 102.75 \\
\hline Tree canopy cover, $\%\left(\mathrm{C}_{\mathrm{t}}\right)$ & 82.60 & 0.47 & 80.00 & 1.37 & 84.25 & 0.55 & 10.00 & 0.00 & 10.00 & 0.00 \\
\hline Herbaceous cover, $\%\left(\mathrm{C}_{\mathrm{h}}\right)$ & 49.22 & 0.81 & 63.50 & 1.48 & 40.04 & 0.80 & 39.25 & 2.30 & 63.64 & 5.57 \\
\hline Protective cover $^{\mathrm{c}}, \%\left(\mathrm{C}_{\mathrm{p}}\right)$ & 21.30 & 0.56 & 42.38 & 0.70 & 77.31 & 0.51 & 15.00 & 3.50 & 9.31 & 0.37 \\
\hline Deciduous trees, \% (D) & 100.00 & 0.00 & 80.94 & 0.77 & 100.00 & 0.00 & 100.00 & 0.00 & 100.00 & 0.00 \\
\hline Relative humidity, $\%\left(\mathrm{H}_{\mathrm{R}}\right)$ & 73.73 & 0.67 & 68.53 & 1.82 & 70.79 & 1.16 & 59.85 & 3.91 & 68.41 & 3.54 \\
\hline $\mathrm{pH}$ & 6.17 & 0.00 & 6.20 & 0.01 & 6.14 & 0.00 & 6.10 & 0.01 & 6.11 & 0.02 \\
\hline Snout to vent length, $\mathrm{mm}$ & 45.43 & 0.97 & 44.97 & 1.55 & 46.95 & 0.99 & 36.00 & 7.62 & & \\
\hline$(\mathrm{SVL})$ & & & & & & & & & 54.50 & 2.37 \\
\hline Total length, mm (ToL) & 89.60 & 1.85 & 89.33 & 3.16 & 92.48 & 1.85 & 74.00 & 14.83 & 107.40 & 3.60 \\
\hline Mass, $\mathrm{g}$ & 13.02 & 0.22 & 12.87 & 0.38 & 13.33 & 0.22 & 11.50 & 1.65 & 14.73 & 0.56 \\
\hline
\end{tabular}

${ }^{\mathrm{a}}$ Mean temperature $=\left(\mathrm{T}_{\mathrm{a}}+\mathrm{T}_{\mathrm{w}}+\mathrm{T}_{\mathrm{s}}\right) / 3$.

${ }^{\mathrm{b}}$ Stream size $=\mathrm{W}_{\mathrm{s}} \times\left(\mathrm{D}_{1 / 4}+\mathrm{D}_{1 / 2}+\mathrm{D}_{3 / 4}\right) / 3$.

${ }^{\mathrm{c}}$ Protective cover $=$ number of rocks (approximately $20 \mathrm{~cm}$ diameter) in the stream reach. 


\begin{tabular}{|c|c|c|c|c|c|c|c|c|c|c|c|}
\hline \multicolumn{2}{|c|}{ MCCP2 } & \multicolumn{2}{|c|}{ MCCP3 } & \multicolumn{2}{|c|}{ МССР4 } & \multicolumn{2}{|c|}{ RCSP1 } & \multicolumn{2}{|c|}{ RCSP2 } & \multicolumn{2}{|c|}{ RCSP3 } \\
\hline$\overline{\mathbf{x}}$ & SE & $\overline{\mathbf{x}}$ & SE & $\overline{\mathbf{x}}$ & SE & $\overline{\mathbf{x}}$ & SE & $\overline{\mathbf{x}}$ & SE & $\overline{\mathbf{x}}$ & SE \\
\hline 12.49 & 0.53 & 15.02 & 0.58 & 16.91 & 0.47 & 10.04 & 0.37 & 13.18 & 0.37 & 12.90 & 0.32 \\
\hline 14.37 & 0.16 & 14.57 & 0.20 & 14.38 & 0.16 & 14.67 & 0.07 & 13.94 & 0.04 & 13.93 & 0.07 \\
\hline 14.86 & 0.07 & 15.03 & 0.09 & 14.92 & 0.06 & 14.79 & 0.10 & 14.58 & 0.04 & 14.34 & 0.05 \\
\hline 13.92 & 0.19 & 14.87 & 0.20 & 15.39 & 0.18 & 12.99 & 0.12 & 13.91 & 0.12 & 13.72 & 0.13 \\
\hline 50.11 & 2.15 & 46.79 & 3.39 & 68.16 & 2.60 & 310.84 & 2.10 & 205.53 & 2.58 & 165.78 & 3.50 \\
\hline 3.83 & 0.27 & 3.10 & 0.28 & 6.52 & 0.32 & 7.10 & 0.18 & 11.50 & 0.14 & 5.74 & 0.07 \\
\hline 3.35 & 0.25 & 3.47 & 0.35 & 6.11 & 0.34 & 13.38 & 0.28 & 9.96 & 0.12 & 7.07 & 0.19 \\
\hline 3.44 & 0.22 & 3.30 & 0.29 & 7.32 & 0.42 & 8.69 & 0.25 & 9.41 & 0.11 & 5.52 & 0.15 \\
\hline 214.07 & 15.64 & 200.36 & 20.72 & 515.23 & 31.28 & $3,022.78$ & 22.49 & $2,094.11$ & 24.20 & $1,107.41$ & 41.14 \\
\hline 78.73 & 0.63 & 77.74 & 0.79 & 89.08 & 0.33 & 83.53 & 0.34 & 88.10 & 0.19 & 76.02 & 0.61 \\
\hline 62.03 & 0.68 & 59.07 & 1.05 & 77.43 & 0.86 & 66.83 & 0.58 & 51.84 & 0.48 & 72.84 & 0.29 \\
\hline 32.53 & 0.91 & 37.17 & 0.87 & 41.05 & 1.22 & 30.59 & 0.56 & 26.63 & 0.21 & 30.70 & 0.34 \\
\hline 100.00 & 0.00 & 100.00 & 0.00 & 100.00 & 0.00 & 90.38 & 0.08 & 99.95 & 0.03 & 100.00 & 0.00 \\
\hline 66.01 & 1.92 & 65.87 & 2.15 & 60.11 & 1.58 & 68.15 & 0.77 & 66.87 & 0.71 & 65.96 & 0.87 \\
\hline 6.13 & 0.01 & 6.12 & 0.01 & 6.13 & 0.01 & 6.28 & 0.00 & 6.23 & 0.00 & 6.19 & 0.00 \\
\hline 45.28 & 1.60 & 44.49 & 2.36 & 42.25 & 1.77 & 45.50 & 0.95 & 46.53 & 0.72 & 47.49 & 0.80 \\
\hline 91.08 & 3.22 & 87.76 & 4.57 & 83.66 & 3.39 & 90.66 & 1.86 & 92.26 & 1.41 & 94.86 & 1.57 \\
\hline 12.95 & 0.36 & 12.92 & 0.54 & 12.33 & 0.37 & 12.94 & 0.22 & 13.22 & 0.17 & 13.55 & 0.17 \\
\hline
\end{tabular}




\begin{tabular}{|c|c|c|c|c|c|c|c|c|c|}
\hline \multicolumn{2}{|c|}{ RCSP4 } & \multicolumn{2}{|c|}{ SGL1 } & \multicolumn{2}{|c|}{ SGL2 } & \multicolumn{2}{|c|}{ SGL3 } & \multicolumn{2}{|c|}{ SGL4 } \\
\hline$\overline{\mathbf{x}}$ & SE & $\overline{\mathbf{x}}$ & SE & $\overline{\mathbf{x}}$ & SE & $\overline{\mathbf{x}}$ & SE & $\overline{\mathbf{x}}$ & SE \\
\hline 15.98 & 0.52 & 9.17 & 0.88 & 13.44 & 0.58 & 14.08 & 0.73 & 17.29 & 0.43 \\
\hline 14.04 & 0.08 & 13.66 & 0.33 & 14.56 & 0.18 & 13.85 & 0.27 & 13.97 & 0.11 \\
\hline 14.35 & 0.08 & 14.79 & 0.13 & 15.11 & 0.08 & 14.97 & 0.20 & 14.44 & 0.03 \\
\hline 14.80 & 0.18 & 12.56 & 0.38 & 14.37 & 0.25 & 14.29 & 0.34 & 15.22 & 0.17 \\
\hline 63.59 & 0.81 & 383.48 & 5.89 & 265.69 & 5.61 & 161.03 & 5.01 & 76.45 & 0.66 \\
\hline 2.37 & 0.05 & 12.01 & 0.32 & 10.95 & 0.20 & 6.83 & 0.23 & 6.04 & 0.07 \\
\hline 5.63 & 0.10 & 16.99 & 0.21 & 14.82 & 0.26 & 6.70 & 0.46 & 5.51 & 0.13 \\
\hline 3.55 & 0.13 & 18.24 & 0.44 & 17.15 & 0.31 & 11.64 & 0.30 & 7.36 & 0.09 \\
\hline 245.70 & 5.02 & $6,033.57$ & 81.41 & $3,806.37$ & 86.19 & $1,332.72$ & 24.14 & 480.97 & 4.37 \\
\hline 89.48 & 0.18 & 36.55 & 1.51 & 32.22 & 0.94 & 31.94 & 1.25 & 90.00 & 0.00 \\
\hline 84.78 & 0.38 & 50.00 & 0.50 & 60.19 & 1.11 & 67.78 & 1.20 & 61.95 & 1.23 \\
\hline 25.06 & 0.40 & 26.90 & 0.87 & 14.07 & 0.67 & 21.39 & 0.58 & 29.20 & 0.64 \\
\hline 100.00 & 0.00 & 100.00 & 0.00 & 100.00 & 0.00 & 100.00 & 0.00 & 100.00 & 0.00 \\
\hline 62.78 & 1.35 & 60.58 & 3.48 & 64.06 & 2.36 & 60.86 & 2.55 & 60.05 & 1.24 \\
\hline 6.17 & 0.01 & 6.17 & 0.02 & 6.17 & 0.01 & 6.23 & 0.01 & 6.21 & 0.01 \\
\hline 48.31 & 0.96 & 49.93 & 2.77 & 43.02 & 2.28 & 42.08 & 2.09 & 45.46 & 1.06 \\
\hline 95.86 & 1.92 & 100.33 & 5.77 & 86.80 & 4.58 & 87.33 & 4.04 & 91.14 & 2.09 \\
\hline 13.64 & 0.23 & 13.71 & 0.67 & 12.50 & 0.52 & 12.05 & 0.52 & 12.90 & 0.23 \\
\hline
\end{tabular}

